Regional Economic Development Games of Competition and Cooperation

Carlie Geerdink 


\section{Regional Economic Development}

Games of Competition and Cooperation 


\section{PhD dissertation committee}

\section{Promotors:}

Prof.dr. A.E. Steenge

Prof.dr. N.S. Groenendijk

Members:

Prof.dr. N.P. Mol (University of Twente)

Prof.dr. M.A. Heldeweg (University of Twente)

Prof.dr. R. Boschma (University of Utrecht)

Prof.dr. G.J. Hospers (Radboud University)

Prof.dr. F. van Oort (University of Utrecht)

ISBN 978-90-8570-672-4

Printed by WPS

Copyright (C) 2010 by Carlie Geerdink

All rights reserved. No part of this publication may be reproduced, stored in a retrieval system or transmitted, in any form or by any means, without the written permission of the author. 


\title{
REGIONAL ECONOMIC DEVELOPMENT
}

\section{Games of Competition and Cooperation}

\author{
DISSERTATION \\ to obtain \\ the degree of doctor at the University of Twente, \\ on the authority of the rector magnificus, \\ prof. dr. H. Brinksma \\ on account of the decision of the graduation committee, \\ to be publicly defended \\ on Wednesday December 8, 2010 at 16:45
}

by

Gerhard Carel Geerdink

Born on April 2, 1954 in

Enschede, the Netherlands 
This dissertation has been approved by the promotors:

Prof.dr. A.E. Steenge

Prof.dr. N.S. Groenendijk 
"Cooperation, with a few obvious exceptions, occurs only in the shadow of conflict"

\section{Jack Hirshleifer}

THE DARK SIDE OF THE FORCE

WESTERN ECONOMIC ASSOCIATION INTERNATIONAL

1993 PRESIDENTIAL ADDRESS 



\section{Contents}

Preface xiii

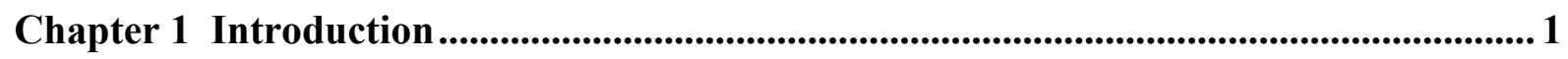

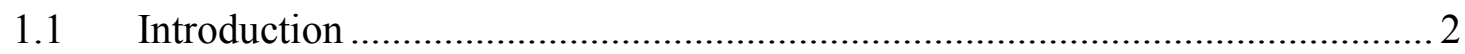

1.2 Concepts and Definitions ........................................................................ 4

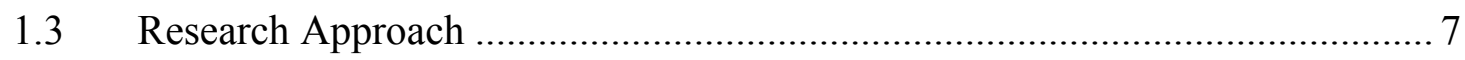

1.4 Research Objective and Questions ............................................................ 9

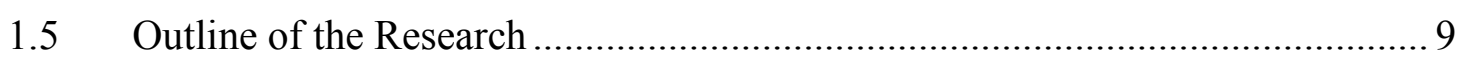

Chapter 2 Theoretical Ingredients................................................................................... 13

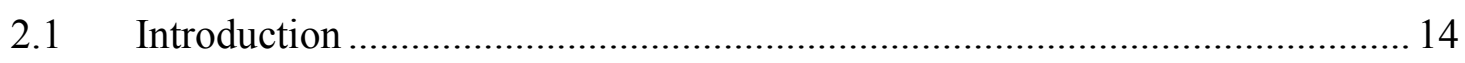

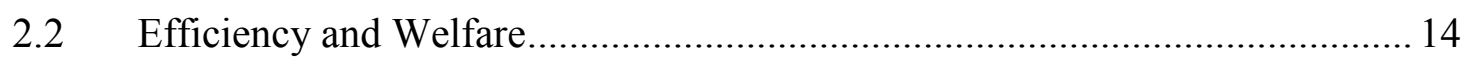

2.3 Regional Competition \& Comparative Advantage ...................................... 18

2.4 Economic Theory of Contest and Conflict.................................................... 20

2.5 Contribution of Firms to Regional Economic Development .......................... 24

2.5.1 Production Side: Firm Behaviour....................................................... 24

2.5.2 The Consumption Side: The Overlapping Generations Model ............ 27

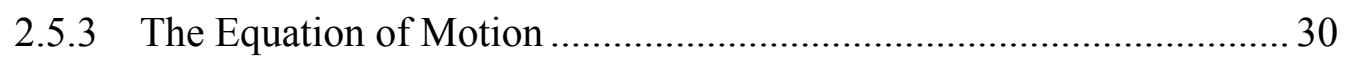

2.6 Externalities, Exogenous Growth and Endogenous Growth ............................ 31

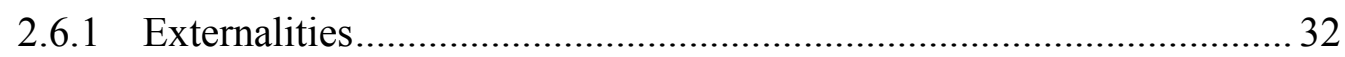

2.6.2 Exogenous Technological Progress ............................................... 32

2.6.3 Endogenous Technological Progress as Externality .......................... 35

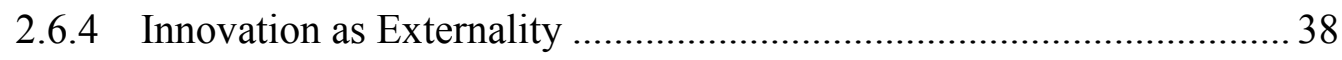

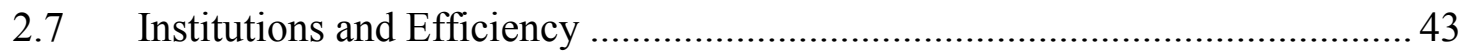

2.8 Conclusions: Review of Assumptions....................................................... 48

Chapter 3 Competition between Regions.....................................................................................5 51

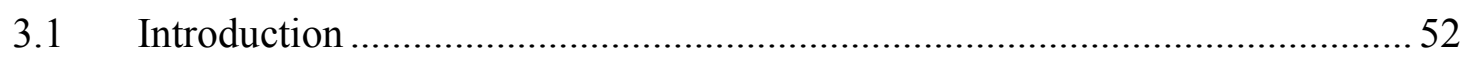

3.1.1 Firm Behaviour and the Decision where to Settle............................. 52

3.1.2 Full Liability and Limited Liability ............................................... 54

3.2 Regional Competition: The Full Liability Case .............................................. 56

3.2.1 Competition between Two Regions .................................................. 58

3.2.2 Efficiency Effects of Regional Competition .................................... 63 
3.2.3 Competition between $n$ Regions ..................................................... 64

3.2.4 Effect of Increasing Competition between Regions........................... 67

3.2.5 Financial Support for a Competing Region: An Extension.................. 68

3.3 Regional Competition: The Limited Liability Case ......................................... 71

3.3.1 Competition between Two Regions .............................................. 71

3.3.2 Competition between $n$ Regions .................................................. 77

3.4 Summary and Results of Regional Competition ......................................... 80

Chapter 4 Competing for Innovation, Internalizing Externalities? ................................. 83

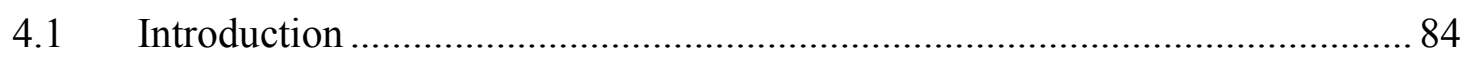

4.2 Firms, Innovation and Externalities: The Expanding Varieties Model............ 84

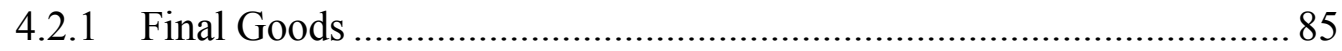

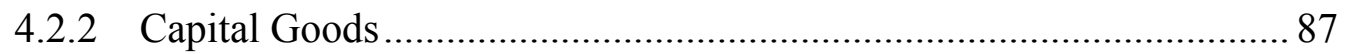

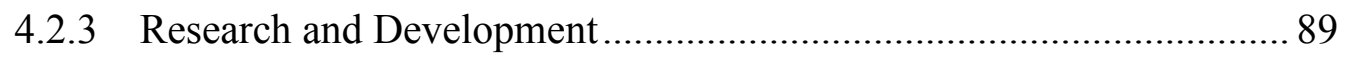

4.2.4 Contribution of the Innovative Firm to the Regional Economy........... 90

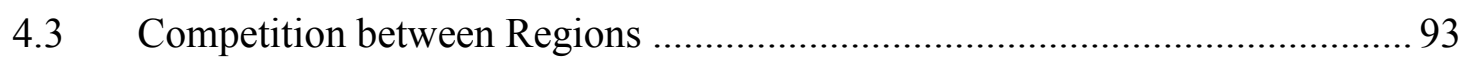

4.3.1 Effects of Competition on Efficiency............................................... 95

4.4 Innovations, Subsidies and Opportunistic Behaviour of the Innovative Firm .98

4.5 Summary of the Results and Conclusions..................................................... 103

Chapter 5 Economic Integration and Institutional Differences.................................... 107

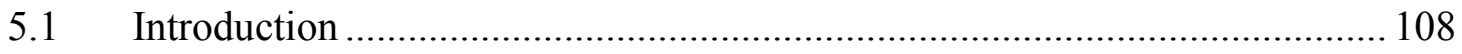

5.2 Institutional Arrangements and Income Distribution................................. 110

5.2.1 Institutions Determining Factor Remunerations ............................. 110

5.2.2 Institutions, Growth and Equilibrium......................................... 117

5.3 Economic Integration, from Autarchy to Mobility ................................... 121

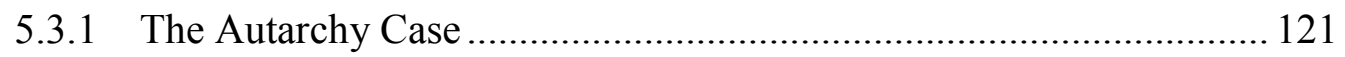

5.3.2 Integration: Opening the Capital Markets ..................................... 122

$5.4 \quad$ Economic Integration of Regions: Three Cases ........................................... 126

5.4.1 Case 1: Both Regions are in Equilibrium after Integration ................ 127

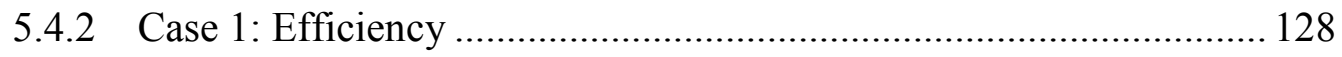

5.4.3 Case 2: Region 2 is on a Growth Path after Integration.................... 130

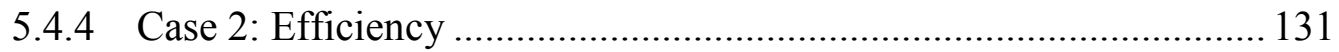

5.4.5 Case 3: Region 2 Ceases to Exist after Integration .......................... 134

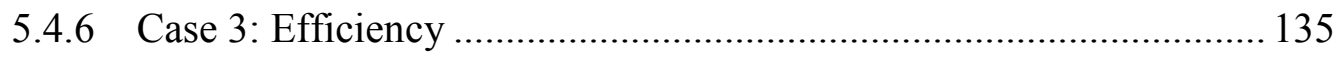

5.5 Summary and Comparison of Three Cases of Integration ............................ 137

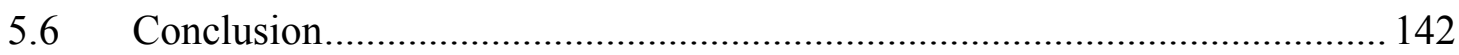




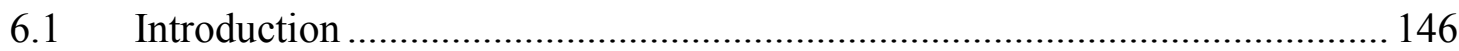

6.2 Public Capital and Externalities .................................................................. 147

6.2.1 Productivity of Public Capital .......................................................... 147

6.2.2 Firms and Externalities.................................................................. 149

6.2.3 Private and Public Capital Accumulation ........................................ 151

6.3 Productivity of Public Capital: the Autarchy Case ...................................... 155

6.4 Economic Integration: from Autarchy to Mobility ...................................... 158

6.4.1 The Arbitrage Process after Integration ............................................ 159

6.4.2 Private and Public Capital after Integration ..................................... 160

6.4.3 Aggregate (Private) Savings and Private Capital ............................. 161

6.4.4 Effects on Income and Growth......................................................... 164

6.5 Is Economic Integration Efficient? ……....................................................... 166

6.6 Summary of the Results and Conclusions .................................................... 168

Chapter 7 Coordination between Regions: An Application of the Coase Theorem .... 173

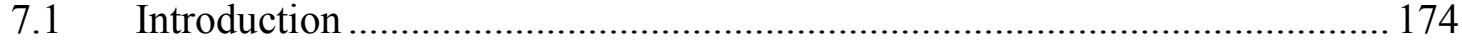

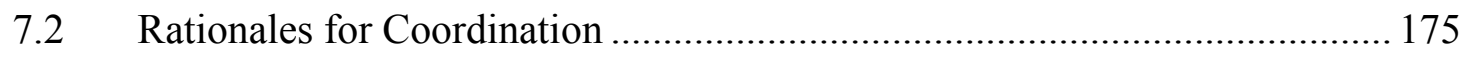

7.2.1 Can Competition be Avoided? ........................................................ 175

7.2.2 Can the Possible Benefits of Economic Integration be Reaped? ....... 178

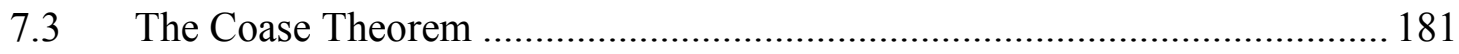

7.3.1 Agent A Owns the Property Rights............................................... 183

7.3.2 Agent B Owns the Property Rights .............................................. 184

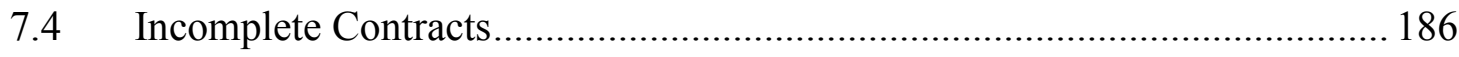

7.4.1 Agent A Owns the Property Rights.............................................. 187

7.4.2 Agent B Owns the Property Rights ............................................. 190

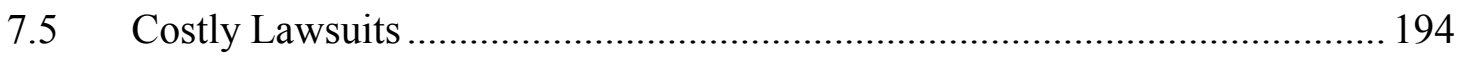

7.5.1 The Probability of Winning a Lawsuit ............................................ 194

7.5.2 Agent B Owns the Property Rights ................................................ 195

7.5.3 The Anglo-Saxon Civil Law System (AS)..................................... 196

7.5.4 The Roman Civil Law System ...................................................... 201

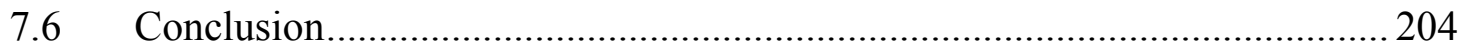

Chapter 8 Conclusions ................................................................................................................ 207

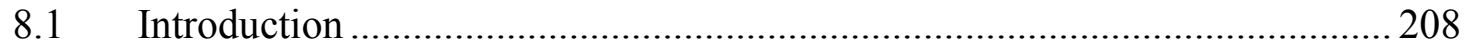

8.2 Competition between Regions: Does it Increase Efficiency? ....................... 208

8.3 Economic Integration and Different Institutions....................................... 210 
8.4 Solving the Coordination Problem: Applying the Coase Theorem................ 213

8.5 Avenues for Further Research ................................................................. 214

Appendix 1 The Contest Success Function .............................................................................. 217

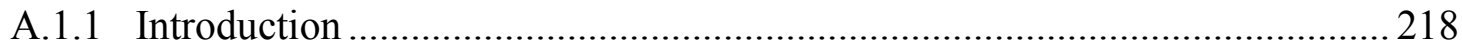

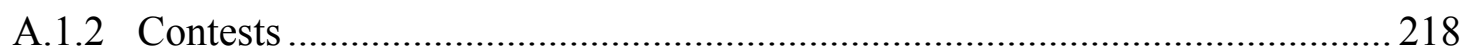

A.1.3 Contest Success Function....................................................................... 219

A.1.4 Types of Contest Success Functions ........................................................... 219

A.1.5 The Power Ratio Form or "Tullock" Contest Success Function.................... 220

A.1.6 The Logit or Difference Form of Contest Success Function ........................ 221

A.1.7 Axiom's of Contest Success Functions .......................................................... 222

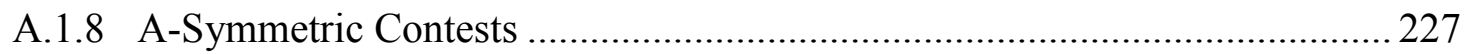

A.1.9 Expected Pay-off in Participating in Contests.............................................. 229

Appendix 2 Best Response Function, CSF, Full and Limited Liability ........................ 235

A.2.1 Regional Competition; the Full Liability Case .......................................... 236

A.2.2 Regional Competition; the Limited Liability Case ..................................... 237

A.2.3 Comparative Statics of the Limited Liability Case ..................................... 239

Appendix 3 Cobb-Douglas and Leontief Production Function...................................... 243

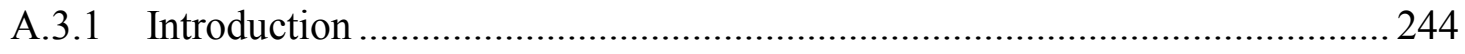

A.3.2 The Neo Classical Production Function...................................................... 244

A.3.3 Cobb-Douglas Production Function.......................................................... 248

A.3.4 Equilibrium Income and Capital Stock (Cobb-Douglas production function) ....

A.3.5 Leontief Production Function................................................................. 252

A.3.6 Equilibrium Income and Capital Stock (Leontief production function) ........ 254

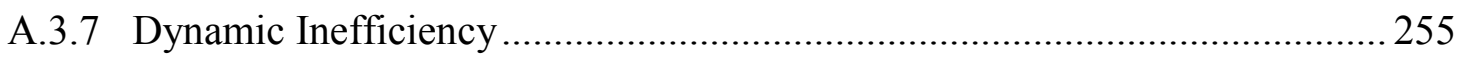

A.3.8 Cobb-Douglas Production Function Exogenous Technological Change and Externalities

A.3.9 Learning by Doing and Externalities, in the Context of Cobb-Douglas Production Function

A.3.10 Public Capital and Externalities, in the Context of a Cobb-Douglas Production Function

Appendix 4 The Dixit-Stiglitz Model of Monopolistic Competition 267

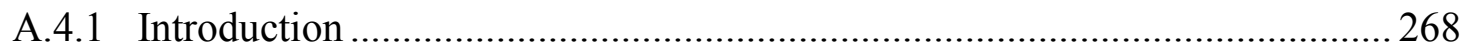

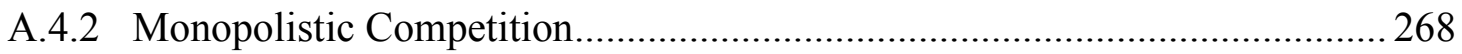

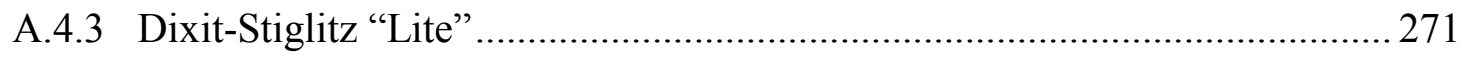

A.4.4 Consumer Behaviour; Utility Maximization................................................. 272

A.4.5 Demand for Different Types of Goods ........................................................ 276 
A.4.6 Firm Behaviour; Profit Maximization and Competition ................................ 277

A.4.7 The Large Number Assumption ............................................................... 281

Appendix 5 Romer's Model of Endogenous Technological Change................................ 285

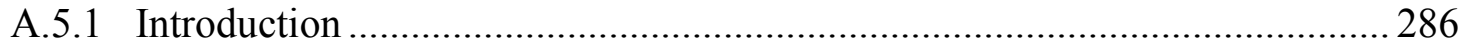

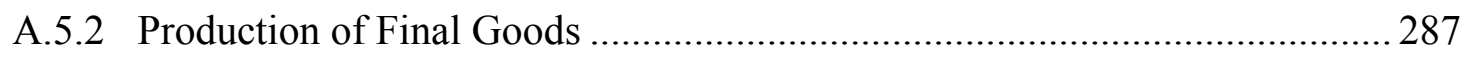

A.5.3 Final-Goods-Producing Firms; Profit Maximization .................................... 288

A.5.4 Capital-Goods-Producing Firms; Profit Maximization.................................. 289

A.5.5 Research and Development ....................................................................... 293

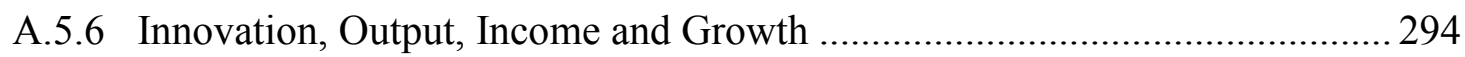

A.5.7 Economic Development; The Equation of Motion ...................................... 297

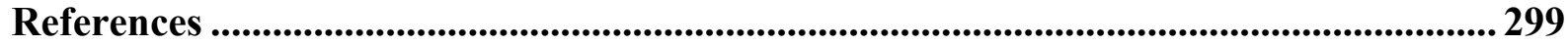

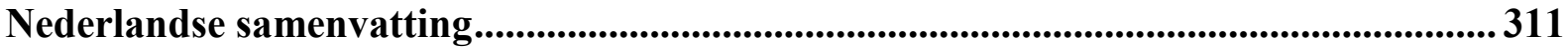

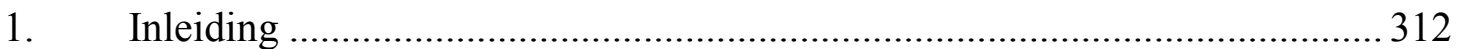

2. Concurrentie tussen regio's, verbetert het de efficiëntie? ............................ 313

3. Economische integratie van regio's met verschil in instituties ...................... 316

4. Analyse van de coördinatieproblemen, een toepassing van het 'Coase'

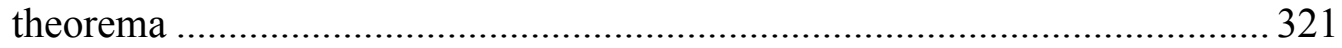

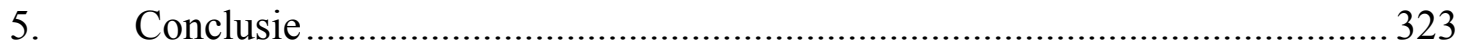

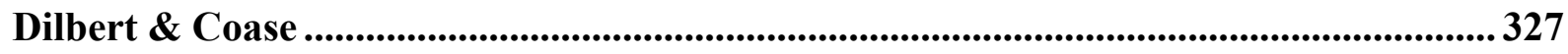





\section{Preface}


Writing a dissertation is not an easy task. You can compare it with running a (mental) marathon. If you tell people you are going to do this, everybody is enthusiastic and encourages you at the actual start. Then along the way, however, it gets rather quiet and lonely. You look at signs indicating how much distance there is still to cover and you hope not to miss any signs so that you will keep taking the right direction and reach the finish. The last kilometers, however there will be many people to encourage you until you actually cross the finish line.

The 'incentive' to write this dissertation resulted from contacts I had with Bert Steenge. These contacts resulted in a temporary stay at the University of Twente from 2002 and onwards. In many discussions that I had with Bert we wondered at cities and regions competing with each other, and whether there are benefits to such competition. This resulted in the idea to investigate this phenomenon.

At that time I also met Peter Stauvermann, who I consider to be my 'scientific brotherin-arms'. We shared the same room at the time, and during that period and also afterwards, we had many long discussions about economics and politics. Looking back, these discussions have provided me with much of the tools I have used in my dissertation.

The basis of this dissertation goes back to early 2004 when I had a long discussion with Peter Stauvermann at the occasion of his birthday party. Our discussion resulted in a first paper concerning regional competition and its welfare effect. Our collaboration, which was stimulated, supervised and critically surveyed by Bert Steenge, has resulted in a number of papers and publications.

The last part of the whole process, in which all the knowledge, ideas and analyzes had to be put into one coherent manuscript, has not been easy. During this phase I have had tremendous support of Nico Groenendijk who pointed me out how to restrict myself and focus on the essence of my research.

Dear Bert and Nico, this dissertation could not have been achieved without both your contributions. Your expertise is reflected in many parts of this dissertation. Dear Peter, you will find many aspects of our discussions and ideas also reflected in this dissertation. I am very grateful that I was able to cooperate and to collaborate with you. I hope that this will continue.

Of course this is not the whole story. I also owe many thanks to all my colleagues at the Department of Legal \& Economic Governance Studies (LEGS). Some names must be mentioned here. Ria, who always had an open ear for my many questions and has always supported me wherever she could. Gert-Jan, with whom I share the same academic interest (regions). Although our approaches differ often the outcomes of our analyses were similar. Martin, who has provided me with many day-to-day examples for my research. Thank you for being so alert. Leo: thank you for always having and lending me the right books whenever I 
needed them and discussing all kinds of economic difficulties. Maurits, with whom I discussed our mutual problems and interests.

Many thanks to Taeke and Wilbert, with whom I had long discussions during their stay in Twente and who have accompanied and supported me to the finish. Also, I want to thank my colleagues at Saxion / BSK. I left the beaten track and made a trail. As a result I did not always keep my appointments and promises, but I hope to improve my behavior.

Furthermore I want to thank the Zestor Arbeidsmarkt- en Opleidingsfonds HBO (PR012) and the Saxion University of Applied Science for the (financial) support to enable and finalize this research. Particular thanks in this respect go to Paul Bijleveld, Lector of Regional Development, and to Dick Sweitser, Director of the Department of Management and Law. Despite everything, both of you trusted me and gave me room to write and finalize my dissertation. I have always greatly appreciated your support. Jo-Ann, thanks for taking care of the layout and the cover design.

Finally, would all be possible without the support at home? No. I thank my parents, who always stimulated me to do the things I did. They were the ones who pointed out to me that knowledge you own cannot be appropriated, so investing in knowledge is a good thing. My two sons, Mart and Koen, who had a father who was there, but on the other hand was absent on many occasions. Both of you suffered from the negative externalities of writing a PhD. Last but surely not least, my loving wife Marja. Although we did not always agree, she always unconditionally supported me with $200 \%$ and more. Mart, Koen and Marja, what can one do to compensate for the many things we wanted to do but that were postponed or canceled because a dissertation had to be written and finalized? I hope to find some answer to that in the near future, but I think applying 'Coasian' bargaining will not be appropriate here. Regarding their contribution to this dissertation, what I can do at this point is to dedicate this thesis to them: to my parents, my sons Mart en Koen, and my loving wife Marja.

Twekkelo / Enschede, November 2010,

Carlie Geerdink. 



\section{Chapter 1}

Introduction 


\subsection{Introduction}

Within Europe, half a century of economic integration has resulted in the free movement of goods, services, persons and capital, coordination of economic policy, a common monetary policy, and - for a subset of EU member states - a common currency, the euro. The general idea underlying this integration is that the creation of a "level playing field" will increase competition between producers throughout the internal market, which will result in a more efficient allocation of resources. Although the emphasis of integration has always been on competition between firms, over the last decade, due to globalisation and under the umbrella of the Lisbon Agenda, regions are increasingly expected to compete as well, mainly to attract (innovative) firms to settle in their territory. Increasing competitiveness of EU member states and regions within these states has become the key policy objective within the EU ${ }^{1}$.

Due to economic integration, intra-EU trade (i.e. trade between EU member states) has indeed expanded considerably. Although factor mobility has also increased rapidly, it is especially capital that is footloose; labour mobility within the EU is still relatively poor as it is still restricted by cultural, linguistic and institutional differences ${ }^{2}$. Moreover, although economic disparities between EU member states have decreased somewhat, economic disparities between regions (in terms of per-capita income, for instance) have increased over the last 30 years $^{3}$.

Especially, in light of these phenomena (i.e. increased competition between regions for firms and increased economic disparities between regions) we will try to assess whether or not competition between regions for (innovative) firms, within a context of economic integration (characterized by high capital mobility), indeed enhance "efficiency". It is this problem that the present thesis addresses, with a special emphasis on the role of regional institutions.

Before proceeding, consider some real-life examples of the kind of problems that are of interest. In 2009, due to the financial and economic crisis, General Motors (GM) decided to restructure its European branches. GM has a number of different plants in different European countries, offering employment to tens of thousands of people. It had separate talks with different (national and regional) governments as well on the EU level. GM's aim was to gain financial support for their reorganization. A number of countries offered such financial support in order to safeguard employment (even though in most cases these governments were not sure how the reorganization would work out in employment terms). At the same

\footnotetext{
${ }^{1}$ European Union, 2000, Lisbon European Council, 23 and 24 March 2000, Presidency Conclusions.

2 European Union, Regional Policy / Why do we need Regional Policy., European Union., Regional Policy, Fifth interim report on economic and social cohesion.

${ }^{3}$ See for example; Martin, R.L., 2004. A study on the Factors of Regional Competitiveness,. Ch 4. Data Analyses, and Aalders,R.,2007. Convergentie en Divergentie tussen Europese Regio's, Economisch Statistische Berichten, pp. 747-750 and EUROSTAT http://epp.eurostat.ec.europa.eu/portal/page/portal/region_cities/regional_statistics/data/main_tables.
} 
time EU member states had agreed not to take individual action but rather at the EU level. Despite this, GM has received several financial grants from different countries ${ }^{4}$. The GM case clearly signals a certain duality in the behaviour of policy-makers. On the one hand they accept the idea of a level playing field and of EU involvement, while on the other hand they got involved in competition to safeguard jobs.

A similar duality in behaviour can also be witnessed on a smaller scale. If we look, for example, at the region of Twente ${ }^{5}$ in the Netherlands, a number of examples can be found. First, a couple of years ago, there was major competition between local authorities when a big brewery (Grolsch) wanted to move its factory to a different location within the region. Something similar happened when a hotel from a large chain wanted to settle in Twente. Although the local authorities in Twente cooperate (through the Twente regional authority, Regio Twente), and this cooperation includes the area of economic policy, the local authorities nevertheless started to compete.

Another striking example was the re-opening of the local airport, which used to be a military airport as well as a civilian one. When the military airport was closed, it was feared that the civilian airport would also have to close down. At first, the local authorities involved seemed to be convinced that it was in their interest to keep the airport open. The result was a joint effort aimed at lobbying the Dutch central government. After this first attempt, which was not successful, every local authority pursued its own success and there was no cooperation. The joint objective of keeping the airport open was abandoned. Apparently it turned out that there were conflicts of interest between the different local authorities, which could not be resolved.

Yet another example is the sale of commercial real estate plots. Until recently local authorities had their own policy governing the sale of such plots. Generating employment played an important role in their strategy of selling business plots. Recently the local authorities have agreed a common business plot sales policy. At this moment local authorities are coordinating their policy and they have agreed not to compete in this area. This cooperation was initially called into question by the Dutch Competition Authority (Nederlandse Mededingingsauthoriteit, NMa).

In this chapter we introduce the main elements of the research that gave rise to this thesis. We start by describing and explaining the most important concepts and definitions used (section 1.2). Section 1.3 deals with the research approach adopted here. Section 1.4 summarises the research objective and research questions. Section 1.5 outlines the structure of the thesis.

\footnotetext{
${ }^{4}$ See for example The Washington Post, 24-11-2009, and EU press release of 23-11-2009 MEMO/09/515.

${ }^{5}$ Twente is a region in the eastern part of the Netherlands, close to the German border. The University of Twente is situated in its largest city (Enschede).
} 


\subsection{Concepts and Definitions}

In this section we focus on a number of important concepts and definitions which are used in this research: region, regional competition, economic integration, competitiveness and efficiency. We first pay attention to the concept of region.

\section{Region}

According to Thisse and Behrens (2007, pp. 457-459), 'in its broadest sense the term region is used to describe a collection of places such that any two places belonging to the same region are, in one way or another, similar'. Further on they remark that 'thus, depending on the point of view selected by the analyst, the regional system, whence the shape and number of regions, may vary. Consequently, a given area cannot be considered as a region per se. Whether or not it is part of a regional system ultimately depends on the equivalence relation that is being used'

To define the concept of region for our research we adopt the diversified relational space concept introduced by Capello (2007). In this concept, space generates economic advantages through externalities. These externalities result in synergy at the local level. Capello (2007, p. 6) states:

'The concept of "diversified relational space" is interpreted as territory or in economic terms, as a system of localized (technological) externalities: a set of tangible and intangible factors which, because of proximity and reduced transaction costs, act upon the productivity and innovativeness of firms' and:

'The territory is conceived as a system of local governance which unites a community, a set of private actors and a set of local institutions.'.

The concept of diversified space abandons the notion that regional development mainly depends on the allocation of resources among regions. A region possesses characteristics which cause costs and prices of the production process to be lower than they are elsewhere. As such, the concept of space identifies "a territory" as a factor generating economic advantages and/or externalities for activities located in it. These factors can be exogenous or endogenous.

\section{Regional Competition}

Competition is a concept that is explained and applied in nearly every textbook on economics. Definitions of competition are relatively scarce, however; it is mostly associated with the private sector, market working, efficiency and welfare. Here we want to analyse the role of competition between regions and how it influences efficiency and in turn regional economic development. Therefore we need to describe the behaviour of "competing" regions. To define 
competition between regions we use the definition of Stigler (1957, pp. 1-17 and 1987, pp. 531-536), but adapt it to regional competition:

'Regional competition is a rivalry between regions, and it arises whenever two or more regions strive for something that all cannot obtain.

In this thesis, the "something that all cannot obtain" is the increase in economic activity in a particular region brought about by attracting firms.

\section{Economic Integration}

Economic integration and cooperation are terms used to describe more or less the same phenomenon. El-Agraa (2004, p. 1) gives the following definition:

'Economic integration (also referred to as regional integration) is concerned with the discriminatory removal of all trade impediments between at least two participating nations and with the establishment of certain elements of cooperation and coordination between them. The latter depends entirely on the actual form that integration takes.'

From this it follows that economic integration involves a certain objective (often the removal of trade barriers) and cooperation and/or coordination. Following Suranovic ${ }^{6}$ (1998, section 110-2) we shall use a definition of economic integration that focuses on these cooperative and coordinative aspects. By economic integration of two or more regions we mean:

'Any type of arrangement in which regions agree to coordinate their economic activities to achieve a certain objective.'

In our view of economic integration agents are explicitly interacting, ${ }^{7}$ which means all kinds of coordination problems can arise. In economic integration interaction is not taken for granted. For regions to integrate there has to be an economic incentive to integrate economic activities. It has to result in a kind of economic surplus, such as additional economic growth, income, production and employment. Besides that, all participating regions should benefit, otherwise integration will not occur.

\section{Competitiveness}

Competitiveness comes high up on the agenda of politicians and policy makers, at EU, national and regional levels. ${ }^{8}$ Every year the World Economic Forum (2009) publishes the

\footnotetext{
${ }^{6}$ The definition of, Suranovic, 2006, reads as follows: 'Any type of arrangement in which countries agree to coordinate their trade, fiscal, and/or monetary policies is referred to as economic integration. Obviously, there are many different degrees of integration'

${ }^{7}$ A definition of economic cooperation that could be applied is: 'Voluntary arrangement in which two or more entities engage in a mutually beneficial exchange instead of competing. Cooperation can occur where resources adequate for both parties exist or are created by their interaction', http://www.businessdictionary.com/-definition/cooperation.html

${ }^{8}$ Examples in this respect are: the European Union's Lisbon Agenda; European Union., 2000, Lisbon European Council, 23 and 24 March 2000, Presidency Conclusions.'http://www.europarl.europa.eu/summits/lis1, EU 2020_and.htm, Ministerie van
} 
Global Competitiveness Report, which ranks countries on the basis of their competitiveness. Increasing competitiveness seems to be the magic spell for stimulating regional economic development.

In a recent study of the EU, Martin (2004, pp. 2-4) investigated the competitiveness of several regions. Martin also looked at the 'definition' of, and the relation between, competitiveness and economic development. The definition of competitiveness applied by Martin is:

'The ability to produce goods and services which meet the test of international markets, while at the same time maintaining high sustainable levels of income or, more generally, the ability (of regions) to generate, while being exposed to external competition, relatively high income and employment level'.

There has been a lot of discussion in economic science about whether the competitiveness of countries (rather than firms) makes sense. One of the most prominent opponents of the view that countries can compete, Paul Krugman (1994, pp. 22-44) said '[R] eal economists don't talk about competitiveness, real businessmen and real politicians talk about it all the time.' According to Krugman, nations do not compete on the world product market as firms do. They do not have to make a profit to survive and cannot go bankrupt as firms can. Furthermore, an increase in the productivity in one nation increases its welfare, but as such that does not necessarily come at cost of welfare in other regions. On the contrary, other nations can benefit from this increase in productivity. It is not a zero-sum game, as in the case of firms, but a positive sum game. Although Krugman is right in pointing out the differences between competition between firms and competition between regions, we do believe that it is interesting (also for real economists) to discuss and analyse regional competition.

\section{Efficiency}

The notion of efficiency is associated with economic choices and solutions and plays an important role in economic science. According to Milgrom and Roberts (1997, p. 22);

'Economic choices are efficient if there is no available alternative that is universally preferred in term of the goals and preferences of the people involved.'

In economics it is commonly understood that a competitive market economy leads to an efficient allocation of goods and services. Dasgupta (2007, p. 82) gives the following description:

'By allocation we mean a complete specification of who produces what and who consumes what. We say that an allocation is feasible if given the economy's endowments of assets, it can be created in the economy. Now let there be a feasible allocation. We say that this feasible allocation is efficient if there is no alternative feasible allocation that all agents would choose.'

Economische Zaken, 2007. Pieken in de Delta; http://www.ez.nl/Onderwerpen/Meer_innovatie/Pieken_in_de_Delta, Innovatieplatvorm, 2010;http://www.innovatieplatform.nl/, Innovatieplatvorm Twente; http://www.twentse-innovatieroute.nl 
For a more detailed discussion we refer the reader to the second chapter.

\subsection{Research Approach}

In this research, where we focus on competition and economic integration, interactions between regions are important. Two kinds of interaction between regions play a central role in our research. First, regions can compete with each other, and secondly, regions can cooperate to integrate their economic activities. In both cases there has to be an economic incentive for regions and their governments to compete and/or integrate. The incentive to initiate competition or start integrating economic activities comes from the expected gains to the regions involved. These gains could be an increase in local income and local production, an increase in employment and so on.

Let us first turn to competition between regions. ${ }^{9}$ Regions have an incentive to attract firms because this increases the economic activities of the region, such as income, production and employment. Firms have an incentive to choose a location which returns maximum profit and/or minimum costs. Although a region cannot produce any output itself, it can influence the profits of a firm. A region can facilitate a firm with all kind of grants (subsidies, tax privileges, and so on) to influence the firm's profit. On the other hand, a firm can have a preference for a specific region because it possesses specific characteristics, like infrastructure. Other regions also have an interest in increasing their economic activity and as such also want to attract firms, which is how competition emerges between regions.

Economic integration between regions makes it possible to take advantage of economies of scale and scope. If regions are different they can specialize where they have a comparative advantage. Integration of their economic activities facilitates this process and reduces transaction costs. Besides that, economic integration could facilitate a more efficient allocation of scarce resources. This could in turn lead to an increase in efficiency, from which regions could benefit. This process can, however, also result in a reallocation of firms, income and production between regions. The distribution of benefits between regions remains unclear.

Our approach is to start from a general economic point of view point, incorporating spatial aspects. In the opening session of ERSA 2007 (European Regional Science Association), Thisse (2007, pp. 215-218), making this point, emphasized the importance of heterogeneity of economic agents in spatial economic models. Furthermore, he concluded his

\footnotetext{
${ }^{9}$ Throughout this thesis, when we refer to regions, we refer to the system of governance in line with our definition given in section 1.1.
} 
opening session with three important statements, two of which are especially relevant to this thesis ${ }^{10}$ :

1. General economists are paying more attention to spatial economics, spatial econometrics and regional science; and

2. Spatial economics and regional scientists should pay more attention to general economics and econometrics.

As noted above, we pay specific attention to differences between regions. This is the spatial aspect of this research. Furthermore to address endogeneity aspects we have regions responding to each other's actions. We make use of relevant general economic theories and models to find an answer to our research questions.

Economic activities always take place 'somewhere at some time'. The spatial dimension has not received much attention in general economics, since it has 'always' more or less been regarded as the explicit domain of regional economics. Capello, in her 'Regional Economics' (2007), provides a comprehensive review of this branch of economics. She notes that the most appropriate theories describing regional development and competitiveness are those which adopt the concept of relational and diversified space. These theories explicitly incorporate principles of agglomeration economies and spatial interactions and take into account the efficiency of the territorial organization of production. Besides tangible aspects (such as the availability of resources), intangible aspects like local governments, synergy stemming from local networks, and so on, also play a role in territorial competitiveness and the development process. One drawback of these models is that they are often insufficiently formalized, which renders an analytical treatment difficult, which may mean that only a qualitative treatment can be given. Capello (2007, p. 255) concludes with the following words:

'Still needed, therefore, is a convincing model which comprises the microterritorial, micro behavioural and intangible elements of the development process. Required for this purpose is definition of patterns, indicators, and analytical solutions to be incorporated into formalized models necessary more abstract and synthetic in terms of their explanatory variables.'

This observation fits very well with our suggested approach. Therefore, in our research we partly incorporate micro-territorial, micro-behavioural and specific intangible elements of the development process and we use for this purpose formalized models from general economics to find analytical solutions.

\footnotetext{
${ }^{10}$ The other statement of Thisse is that: new Economic Geographers should study more carefully 'old' economic geography.
} 


\subsection{Research Objective and Questions}

The foregoing sections have focused on the role of competition and economic integration in the regional development process. These sections permit us to conclude that there is both ambiguity in the actual behaviour of policy makers and in the possible outcomes, in terms of efficiency and economic development, of competition within the context of economic integration. This leads to the following research objective:

To analyze the consequences of regional competition and cooperation within the context of economic integration, for efficiency, with special emphasis on the interaction between regions with a different institutional structure.

To reach this objective the following research questions are addressed;

1 Which general economic concepts can be used to describe regional competition within the context of integration? (chapter 2)

2. What are the consequences of regional competition for efficiency? (chapter 3)

3. What are the consequences of regional competition for efficiency when firms are innovative and generate positive externalities? (chapter 4)

4. What are the consequences of regional integration for efficiency when regions differ in their institutional structure? (chapter 5)

5. What are the consequences of regional integration for efficiency when regions differ in their institutional structure and when the institutional structure generates externalities? (chapter 6)

6. Can the coordination problems resulting from competition and economic integration be solved? (chapter 7)

Traditionally, within regional economics topics like location theory and regional growth theory are distinguished. Research questions 3 and 4 can be seen as part of location theory, while questions 5 and 6 can be seen as part of regional growth theory. Question 7 results from the introduction of interaction between regions.

\subsection{Outline of the Research}

In chapter two we start by introducing a number of important economic concepts and theories that are used in this research. These are the theoretical ingredients which are used in the remaining chapters. 
In the third chapter we formalize competition between different regions. Regions can have certain favourable characteristics which make them attractive to certain firms. These characteristics give a region an advantage over other regions. On the other hand, regional governments can use other instruments, such as subsidies, to increase firms' profits or to induce firms to settle. There are no standard recipes for describing competition between regions within micro-economic theory. To formalize this kind of competition we make use of the economic theory of contest and/or conflict. We investigate different aspects of regional competition and look at efficiency and the welfare effects. We will ask whether this kind of competition generally does (or does not) increase efficiency and welfare, and as such does (or does not) contribute to regional economic development. Additionally we will look into the issue that, if one region starts competing, other regions will have to follow.

In the fourth chapter we extend the analysis of the third chapter. We take into account that regional governments favour not just any firm but especially innovative firms because such firms generate positive spillovers (externalities). To describe the process of innovation by firms we make use of endogenous growth theory (P. Romer, 1990). The incentive for firms to innovate is the profit they can make if their innovation is successful. At the regional level these innovations result in "positive externalities"11. Because these positive externalities are not taken into account by firms, in their decision to invest in innovation, the investment level is generally too low. In a region governments can encourage firms to invest in innovation. The last part of the chapter is devoted to possible opportunistic behaviour of firms when governments subsidise innovation to increase economic performance.

In the fifth chapter we focus on a more macro-economic view to analyse regional cooperation. Economic theory, especially international trade theory, emphasises that economic integration is beneficial to the development of regions. What is often forgotten, however, is that there are many differences in 'institutional structure', that is 'the rules of the game ${ }^{, 12}$, between regions. Authors like North (1991), Williamson (2000) and recently Acemoglu (2005), inter alia, have focused especially on the role of institutions in the process of development. Dasgupta (2007) even concludes that differences in institutions are the main cause of differences in economic development of regions. We first analyze the short-run consequences of these differences in institutional settings. We assume that income distribution is determined by various institutional arrangements and that factor proportions are relatively fixed. We therefore use a Harrod-Domar growth model to structure the institutional setting. We analyze the effect of economic integration of regions. As we shall see, this has a rather devastating effect on regions where the institutional setting supports the production factor labour, and will results in a coordination problem.

\footnotetext{
${ }^{11}$ Milgrom and Roberts (1992, p. 75) define externalities as: positive or negative effects that one economic agent's action have on another's welfare that ore not regulated by the system of prices.

${ }^{12}$ This term is often associated with North.
} 
In the sixth chapter we continue to focus on regional development and institutional setting. The difference from the fifth chapter is that we now permit institutions to have public good characteristics, which can result in positive externalities. To incorporate the institutional setting in the model we now make use of a neo-classical production function with labour, private and public capital as arguments. To compare different regions we assume that institutions differ in their efficiency: public capital in one region is more productive than in other (competing) regions. We then analyze the consequences of economic integration between the different regions. Integration leads to a reshuffling of economic activities between the integrating regions. We conclude that the less productive region is worse off after integration, while the more productive region is better off. There is thus no incentive for the less productive region either to cooperate or to integrate. The overall effect is positive, however.

Chapter seven deals with the coordination problems, due to externalities, which emerge from the previous chapters. We first look at whether the coordination problem we encountered in chapters 4 and 6 can be solved. With respect to chapter 4 we look at whether there are incentives not to compete and as such internalize the externalities involved. As far as chapter 6 is concerned, we investigate whether cooperation can be established between the integrating regions in order to internalize externalities Here we turn to concepts initially proposed by Ronald Coase (1960). We propose a Coasian bargaining solution where a region is rewarded for not competing and where the more productive regions compensate the other regions for cooperating. To analyse this we first look at the Coase theorem and analyze whether Coasian bargaining can solve the coordination problem. Important for successful Coasian bargaining are property rights and transaction costs. These are for the greater part anchored in the legal system, which is part of the institutional structure distinguishing two kinds of Legal systems, the Anglo-Saxon and the Roman Legal system We show that with respect to externalities, coordination problems can be solved, even though transaction cost are at stake. We conclude that in case of externalities, regional willingness to cooperate is highly dependent on the institutional setting and rules. As we shall see, in case of the Roman legal system there is no incentive for opportunistic behaviour, but in the Anglo Saxon legal system there certainly is.

In the last chapter, chapter eight, we summarize the main findings of the previous chapters, and, we outline some avenues for future research on this topic. Figure 1.1, provides an overview of the various chapters in key words. 
Figure 1.1 Overview of the Chapters in Key Words
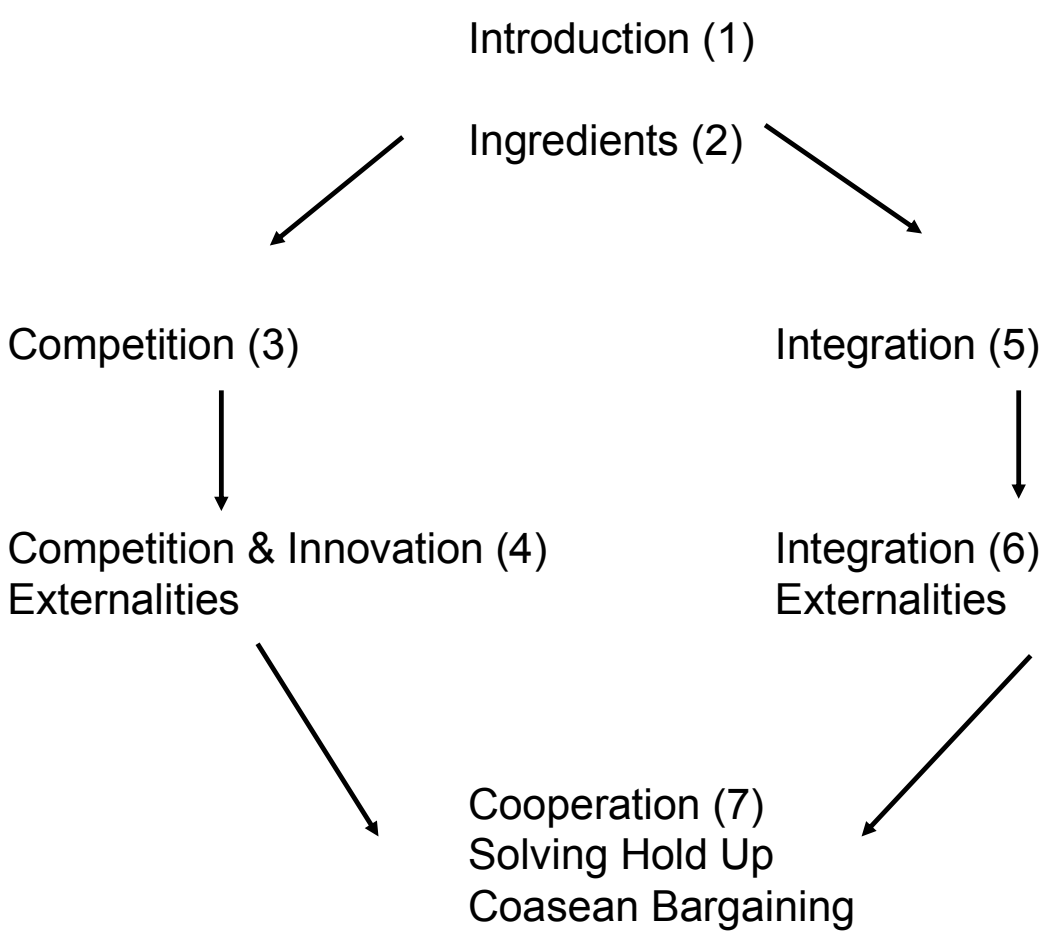

To facilitate the reader, we have included a more in depth treatment of the different economic theories used in this research in the appendixes of this thesis. 


\section{Chapter 2}

\section{Theoretical Ingredients}




\subsection{Introduction}

The purpose of this chapter is to review and explain the economic tools used in this research (and as such sub-question 1 is addressed). Many of the topics will be discussed in a rather general way, with a more detailed discussion reserved for the accompanying appendices as well as in subsequent chapters. We have opted for a general explanation of the main concepts and economic tools in this separate chapter to avoid distraction from the analyses in subsequent chapters.

We focus on welfare and efficiency first (section 2.2). These concepts are central to our research objective. Next in section 2.3, we take a closer look at regional competition for (the settling of) firms, relating competition to the concept of competitive advantage. Subsequently (section 2.4) we discuss the economic theory of contest and conflict which is used in this research to model competition between regions.

In section 2.5 we look at what a firm that settles in a particular region can contribute to the economic development of that region. What is it that regions are actually competing for? We discuss the assumptions used in this research regarding firm behaviour as well as the overlapping generation model that is used to model economic development over time. Subsequently, the focus moves on to externalities, exogenous and endogenous technological progress (section 2.6). Different assumptions regarding the type of regional economic growth require different assumptions about the market environment in which firms operate (perfect competition, monopolistic competition) and their production functions. Finally, in section 2.7, we discuss the role of institutions in economic development, in this case, the use of public goods as productive sources that contribute to economic development.

The chapter concludes with a survey of the main assumptions used in the subsequent chapters of the thesis (section 2.8).

\subsection{Efficiency and Welfare}

The yardstick used to investigate the effects of competition between regions is (allocative and productive) efficiency. Below we briefly reiterate the main elements of the concept of efficiency, with reference to the work of Milgrom and Roberts (1992, Ch 2 and 3); Viscusi, Vernon \& Harrington (2000) and Dasgupta (2007, Ch 4).

The goal of any economic organization, and of the economic system as a whole, is to satisfy the wants and the needs of individual human beings (Milgrom and Roberts p. 22). Economic organizations are created entities within and through which people interact to reach individual and collective goals (Milgrom and Roberts p. 19). In economics it is assumed that persons are primarily concerned with 'regular' economic goods and services. The economic 
system then is judged on how well it satisfies the economic needs of the population. It is assumed that people are equipped with measures of their welfare (called utility functions) and that their economic goal is to maximize their welfare. If they like situation A better than situation $\mathrm{B}$, i.e. if and only if situation $\mathrm{A}$ gives greater utility than situation $\mathrm{B}$, they are expected to choose situation A. Such choices have to be made due to individual budget constraints.

On the collective level, something similar applies. Due to scarcity, trade-offs have to be made. Increasing one person's utility may mean less utility for another. Efficient choices are choices for which there is no available alternative that is universally preferred in terms of the goals and preferences of the people involved. More precisely, if individuals are sometimes indifferent to some of the available options, then a choice is efficient if no other options are available which everyone in the relevant group likes at least as much and at least one person strictly prefers. Turning the definition around, a choice is inefficient when there is an alternative choice that would increase one person's utility without decreasing any other's. Note however that efficiency can never solve ethical questions and that the efficiency of a choice is always relative to some specific set of individuals whose interests are being taken into account and also to some specific set of available options (Milgrom and Roberts, p. 22). Efficiency can be defined and applied at many levels, depending on the kind of choices being considered. Our application is to compare alternative allocations of resources. An allocation of resources $\mathrm{X}$ is inefficient if there is some other available allocation $\mathrm{Y}$ that everyone concerned likes at least as well as $\mathrm{X}$ and that one person strictly prefers. If no other allocation exists that is unanimously preferred to $\mathrm{X}$, then the given allocation is efficient or Pareto optimal.

There are good reasons to expect that people will seek out and settle on efficient choices (Milgrom and Roberts, p. 24). If parties can bargain together effectively and can effectively implement and enforce any agreement they reach, they should be able to realize welfare gains. Inefficient choices will always be vulnerable to being overturned. Efficient choices will not be vulnerable because any change will be opposed by someone. Milgrom \& Roberts call this the efficiency principle; If people are able to bargain together effectively and can effectively implement and enforce their decisions, then the outcomes of economic activity will tend to be efficient (at least for the parties to the bargain).

A fundamental observation about the economic world is that people can produce more if they cooperate, specializing in their productive activities and then transacting with one another to acquire the actual goods and services they desire. When people are specialized producers who need to trade, their decisions and actions need to be coordinated to achieve the gains from cooperation, and people must be motivated to carry out their part of the cooperative activity 
A key problem in achieving effective coordination, however, is that the information needed to determine the best use of resources is not freely available to everyone. Efficient choices require information about individual tastes, technological opportunities and the availability of resources. In principle, two solutions are possible. Either dispersed information must be transmitted to a central planner, or else a more decentralized system must be developed that involves less information transmission and correspondingly leaves at least some of the calculations and decisions about economic activity to those actors where the relevant information resides. The essence of the first option is to make timely decisions while keeping the costs of communication and computation low. The challenge of the decentralization option is to ensure that decisions made separately yield a coherent, coordinated result.

Markets are one of the possible solutions to the problem of coordinating economic activities at a decentralized level and are often remarkably effective. A market system with private property not only provides the information needed to compute an efficient allocation of resources in an efficient way. It also channels self-interested behaviour into desired directions. The (archetypical) market system of perfect competition always results in an efficient allocation. No other system can solve the coordination problem more effectively than a system of competitive markets coordinated by prices. According to Milgrom and Roberts (1992, p. 62):

'if each productive unit knows the prices and its own production technology and maximizes its profit, at the prevailing prices, and each consumer knows the prices and his / her preferences and then maximizes utility given the prevailing prices, and income and the prices are such that supply equals demand for each good then the allocation of goods that results is efficient.'

They call this the fundamental theorem of welfare economics. If markets are perfectly competitive, an efficient solution will be the result. An important property of the resulting equilibrium is that prices equal marginal costs in all markets. In this ideal situation, no government intervention is needed to establish optimal welfare.

In the real economic world the assumptions of a fully competitive market are rarely met (Viscusi et al. (2000) p. 76). If the assumptions of perfect competition are relaxed, it becomes rather difficult to look at welfare consequences in a general equilibrium setting. In such a situation efficiency aspects can be considered just in the context of a single market, which means that interactions between markets are ignored.

Besides evaluating economic organizations in terms of efficiency, different policies can also be evaluated on the basis of efficiency, in which case it can become rather difficult to apply the Pareto criterion. In most cases some people will be hurt in one way or another. A generally accepted concept in micro-economics (introduced by Hicks and Kaldor) is the socalled compensation principle (Viscusi et al. (2000), p. 76; Church \& Ware (2000), p. 28), which looks at the surplus generated by an economic system or by a specific policy, as well as at the possible distribution of the surplus among the participating agents. A move from 
allocation or outcome $\mathrm{A}$ to $\mathrm{B}$ is a potential Pareto improvement if the winner could compensate the loser and still remain better off. So for the loser, allocation $\mathrm{B}+\mathrm{C}$ (compensation) equals $\mathrm{A}$ and for the winner B-C equals $\mathrm{A}^{\prime}$ where $\mathrm{A}^{\prime}>\mathrm{A}$. If the compensation is actually paid, it is an actual Pareto improvement (Church \& Ware (2000), pp. 28).

Assuming perfect competition in a particular market, equilibrium is where the supply of goods or services equals the demand for goods and services or where the supply curve intersects with the demand curve. This results in a unique market equilibrium price and quantity. At this equilibrium price producers will not change their supply nor will consumers change their demand, given that all other circumstances remain unchanged. All consumers buying on the market pay the same price, which means that there are consumers whose willingness to pay exceeds the price they actually pay. Referring to the demand for goods and services, there is also a demand for goods and services if the price $(p)$ exceeds the equilibrium price $\left(p^{e}\right)$, namely $p>p^{e}$, but the consumers actually pay the equilibrium price. If we add this up for all consumers it amounts to what is called the consumer surplus. This consumer surplus equals $\int_{0}^{q^{e}}\left[p\left(q^{d}\right)-p^{e}\right] d q=\int_{0}^{q^{e}} p\left(q^{d}\right) d q-p^{e} q^{e}=\mathrm{CS}$. In the figure below this is given by the triangle CS.

All producers also receive the same price when supplying and selling the goods on the market. For some producers this will exceed their production costs $\left(p<p^{e}\right)$, resulting in a profit. If all surpluses of these producers are aggregated the result is the producer surplus, which equals $\int_{0}^{q^{e}}\left[p^{e}-p\left(q^{s}\right)\right] d q=p^{e} q^{e}-\int_{0}^{q^{e}} p\left(q^{s}\right) d q=$ PS. This is the total revenue of all producers selling and producing their goods on the market, minus all these producers' costs, which is equal to total profits. This is given by the triangle PS in the figure below. The total surplus for the economy is the sum of the consumers' and producers' surplus, which equals $\int_{0}^{q^{e}}\left[p\left(q^{d}\right)-p\left(q^{s}\right)\right] d q$ or the addition of the triangle CS and PS in the figure below. 
Figure 2.1 Consumer and Producer Surplus

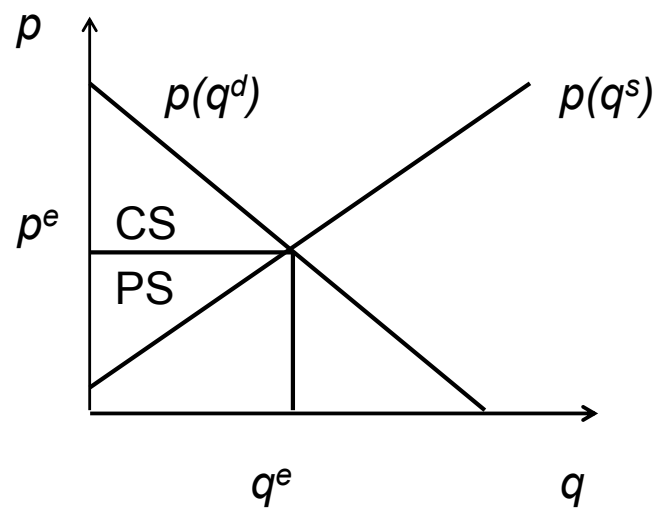

It is clear that any point deviating from equilibrium values of price and quantity leads to a lower surplus and thus lower welfare. The equilibrium outcome is thus efficient, i.e. Pareto optimal. Any other price-quantity combination will make producers and consumers worse off and no combination is available that makes a producer or consumer better off.

In the subsequent chapters, but predominantly in chapter 3, we use producer and consumer surpluses for our analysis of the welfare effects of competition.

\subsection{Regional Competition \& Comparative Advantage}

Our working definition as explained in the previous chapter reads as follows: A region is conceived of as a system of local governance which unites a community, a set of private actors and a set of local institutions (Capello, 2007, p. 6). In addition, following Stigler $\left(1987\right.$, p. 531), ${ }^{13}$ we have defined regional competition as a rivalry between regions, and it arises whenever two or more regions strive for something that all cannot obtain. The "something that all cannot obtain", for regions, is the increase in economic activity brought

\footnotetext{
${ }^{13}$ Stigler defines competition as the rivalry between individuals (or groups or nations), which arises whenever two or more parties strive for something that all cannot obtain. Further in the same contribution he notices that competition is a concept that is applicable to two cobblers a thousand ship-owners or two tribes. A more extensive review is given in Stigler, (1957), pp. 1-17). In this article Stigler describes how the term competition, in combination with the concept of a perfect market, has evolved in the economic literature.
} 
about by attracting new firms. We assume that in order to achieve their economic and political objectives, regions want to increase their gross product. ${ }^{14}$ Regions cannot increase the regional product themselves, but they can increase it by attracting new firms.

We assume that competing regions differ in such a way that a region as such either is 'more' or 'less' attractive to a particular firm ${ }^{15}$. Regions possess characteristics that cause the costs and prices of the production process differ from those in other regions. If a region is more attractive to a particular firm, we say that the region has a comparative advantage for the particular firm. This phenomenon has been recognized in economics for a long time. It is the basis for Ricardo's theory of comparative advantage and one of the basic elements of the theory of international trade. This theory states that economic regions should specialize in the production of goods where they have a comparative advantage. If all regions specialize and goods can be traded, then the overall welfare increases. All goods will be produced at minimum costs. Without the trading of goods between regions this specialization would not be possible. Comparative advantage refers to the ability of a region to produce a particular good at a lower opportunity $\operatorname{cost}^{16}$ than another region, which is the ability to produce a product most efficiently given all the other products that could be produced (Findlay, 1987, pp. 415-417).

Note that a region does not necessarily have a comparative advantage for all firms. A region can be more or less attractive, depending on the type of firm. Each region offers an initially given "economic" infrastructure resulting in a cost advantage to a firm. Supplementary to that, additional subsidy and firm-specific investments granted by a regional government can increase this cost advantage. By (firm) specific investments we mean investments by the region targeted to attract a firm, which can include specific cost-reducing subsidies; but we can also think of the economic infrastructure in general: streets, highways, airports, and harbours, business parks, a well-educated labour force, the availability of universities and research institutes, et cetera. All these tangible and intangible assets in a region can contribute to its comparative advantage and therefore to its competitiveness. Investments can differ in terms of the degree of asset-specificity. It is important to realize that specific investments made to attract a particular firm will be wasted if the firm decides to settle elsewhere. $^{17}$

\footnotetext{
${ }^{14}$ This assumption is made without loss of generality and only to simplify the analysis.

${ }^{15} \mathrm{We}$ abstract from cases that regions are equally attractive.

${ }^{16}$ The opportunity cost of a certain choice is defined as the value of the next best alternative choice available (Hendrikse (2003), p. 6).

17 An investment is said to be specific, i.e. there is 'asset specificity', when the investment has a higher value inside the specific relation than outside it. Asset specificity is a measure of non-redeployability. Such investments are sunk costs because part of them are sunk into the relation. Sunk costs are basically costs that are not recoverable elsewhere (Hendrikse (2003), pp. 207). Asset-specificity was first discussed by Williamson (1985). He pointed out that asset (relation) specific investments can increase welfare but also lead to opportunistic behaviour. Ex ante agreements between parties can lead to ex post renegotiations by one of the parties after the other has made specific investments. For example, an employer invests in
} 


\subsection{Economic Theory of Contest and Conflict}

To describe the competition game between regions we make use of economic theory of contest and conflict. The Contest Success Function (CSF), which is described in greater technical detail in appendix 1, is one of the key ingredients in the economic theory of contest and conflict which is linked to theories of rent seeking (Garfinkel \& Skaperdas (2007); Tullock (1980) and Konrad (2007)). These theories model conflict as a contest, i.e. a game in which participants expend resources in order to increase the probability of winning the conflict were it actually to take place. Or, put differently, a contest is a game ${ }^{18}$ in which players exert effort in order to win a certain prize. A contest can be characterized by the following elements. First there is a prize to be allocated among contestants; each contestant can make an effort. These efforts determine which contestant will receive which prize, where, in the simplest case, only one contestant gets a positive prize and all others contestants get zero. Actually, a conflict does not necessarily have to occur but exerting effort as such can also be used as a bargaining tool.

The function that maps effort and the various probabilities that a given contestant will win the prize is called the Contest Success Function (Skaperdas, 1996, p. 283; Konrad, 2007, p. 4). The role of the CSF resembles that of production functions and utility functions. In contrast to economic production (inputs are combined to produce useful output) the inputs or effort by agents are used in an adversarial way against other agents. The output can be seen in terms of losses and wins (instead of useful production). According to Konrad (2007, p. 1), competition in which goods or rents are allocated as a function of the various efforts expended by players in trying to win these goods or rents is a very common phenomenon. Some examples are marketing litigation, relative award schemes in internal labour markets, beauty contests, lobby activities, the R\&D contest (particularly relevant to our research), electoral competition in political markets, military conflicts, and sports. A description and review of a number of contest types and applications is provided in Konrad (2007, pp. 6-19). In our case the competition game is about the settlement of firms and the "prize" of winning the competition game is the settlement of the firm and the associated benefits for the region.

\section{Contest as a game: the Contest Success Function}

According to Konrad (2007, p. 6), contests are games that are defined by:

- $\quad$ A set of $n$ players, i.e. $n$ contestants are taking part in the game;

\footnotetext{
the "specific" education of an employee. After the employee has successfully finalized the training courses and has received his degree, he may go to the competitor because he is offered a higher salary.

${ }^{18}$ For a definition of a game and game theory we follow Dixit and Skeath (1999, p. 3): Game theory is the analysis of rational behaviour in interactive situations. When persons decide how to act in dealing with other people, there must be some cross effects of their actions. In game theory they are mutually aware of these cross effect and their actions are taken as a result of this awareness. A game is a description of these strategic interactions.
} 
- $\quad$ Pure strategy spaces described by a set of feasible pure strategies that are described as effort, $e_{i}$ for $i=1,2, \ldots, n$. Every contestant has a strategy of investing in effort in order to win the game;

A set of expected pay-off functions, $E\left(P O_{i}\right), i=1,2, \ldots, n$. This is the relation between the invested effort and the expected revenues / benefits of taking part in the contest. The effort invested influences the probability of winning the contest.

Rai and Sarin (2009, p. 3 ) note that a contest is modelled as a non-cooperative game between multiple agents. Agents make irreversible investments, which can be effort, money, or any other valuable resource depending on the context, to increase the probability that they will win the contest and obtain a private prize.

A widely used form of CSF is the additive form. Only this type of CSF satisfies the widely accepted axioms of choice theory (see appendix 1). Within this type of CSF we can distinguish between the ratio form CSF and the difference form CSF. In the ratio form CSF the probability of winning the contest is determined by the ratio of the effort invested by the contestants taking part in the contest game. For example, if the two contestants invest the same level of effort, their probability of winning the game equals $50 \%$. If one contestant invest twice as much as the other, the probabilities are $2 / 3$ and $1 / 3$. In the difference form CSF the probability of winning the contest is determined by the difference of effort by the contestants. If two contestants have invested the same effort the probability of winning the contest again equals $50 \%$ but in case contestant 1 invests twice as much as contestant 2 , their probabilities of winning equal, for example, $3 / 4$ and $1 / 4$, depending on the exact specification of the CSF.

\section{CSF and Expected Pay-Off}

The pay-off function relates the costs $C\left(e_{i}\right)$, of the contestants 'effort' to the expected gains $v\left(B_{i}\right)$, from winning the game. We assume that the cost function of effort can be written as $C\left(e_{i}\right)$. The costs of effort depend on the level of effort. In the simplest case this is a linear relation, so we have $C\left(e_{i}\right)=e_{i}$. Besides that we have to know the prize gained by winning the contest and the contestants' valuation of this prize. Assuming this equals $v_{i}(B){ }^{19}$, we can then formulate the expected pay-off for the contestants. In the simplest case the value of the prize is fixed and equal for all contestants. Then we have $v_{i}(B)=B$ for $i=1, \ldots, n$. Using the CSF in principle two different expected (net) pay off functions can be formulated. The first one we have labelled full liability. In this case, the net pay-off for the contestants equals:

\footnotetext{
${ }^{19}$ It exhibits the same characteristic as utility functions regarding to risk and uncertainty. In case $v_{i}(B)=B$ the player i is risk neutral.
} 


$$
E\left(P O_{i}\right)=\operatorname{Pr}_{i}\left(e_{i}, e_{-i}\right) v_{i}(B)-C\left(e_{i}\right) \text { for } i=1,2, \ldots, n
$$

The second one we have labelled limited liability. In this case, the net pay-off for the contestants equals:

$$
E\left(P O_{i}\right)=\operatorname{Pr}_{i}\left(e_{i}, e_{-i}\right)\left[v_{i}(B)-C\left(e_{i}\right)\right] \text { for } i=1,2, \ldots, n
$$

The difference between the two is that in case of full liability all players taking part of the game have to pay or to invest in effort where as in the second only the winner of the game has to pay or invest in effort. Later on in chapter 3 and in appendix 1we will go into more details. The expected pay-off depends on the expected gains minus the cost of effort. The expected gains depend on the probability of winning the game multiplied by its valuation. The probability of winning the game is determined by the invested effort of player $i, e_{i}$, and all competing agents, $e_{-i}$. These $e_{-i}$ are the effort levels of all competing agents, that is $e_{-i}=\sum_{j=1}^{n} e_{j}$ for $j \neq i$

Each contestant determines his effort level by maximizing the expected net gains from taking part in the contest. These net gains can be found by setting to zero the derivative of the expected net pay-off with respect to the effort level, thus:

$$
\frac{\partial E\left(P O_{i}\right)}{\partial e_{i}}=\frac{\partial \operatorname{Pr}_{i}\left(e_{i}, e_{-i}\right)}{\partial e_{i}} v_{i}(B)-\frac{\partial C\left(e_{i}\right)}{\partial e_{i}}=0 \text { for } i=1,2, . ., n
$$

and

$$
\frac{\partial E\left(P O_{i}\right)}{\partial e_{i}}=\frac{\partial \operatorname{Pr}_{i}\left(e_{i}, e_{-i}\right)}{\partial e_{i}}\left[v_{i}(B)-C\left(e_{i}\right)\right]-\operatorname{Pr}_{i}\left(e_{i}, e_{-i}\right) \frac{\partial C\left(e_{i}\right)}{\partial e_{i}}=0 \text { for } i=1,2, . ., n
$$

From this we find the optimal level of effort, that is $e_{i}=e_{i}^{*}$ for $i=1,2, \ldots, n$.

The graphs below illustrate the contest for two symmetric contestants. Note that this is only one representation of the contest; other types are possible. In the graph we have depicted the two reaction functions of the contestants. A contestant's reaction function illustrates how, for example, contestant 1 reacts to contestant 2, i.e. how much effort contestant 1 will invest if he knows his competitor's effort level. The two reaction functions of the players, $r f_{1}=r f_{1}\left(e_{1}, e_{2}\right)$ and $r f_{2}=r f_{2}\left(e_{1}, e_{2}\right)$ are depicted in the graphs. They can be derived from the first-order conditions above. The reaction functions, however, depend on the exact 
Figure 2.2 Contest Game (Full Liability)

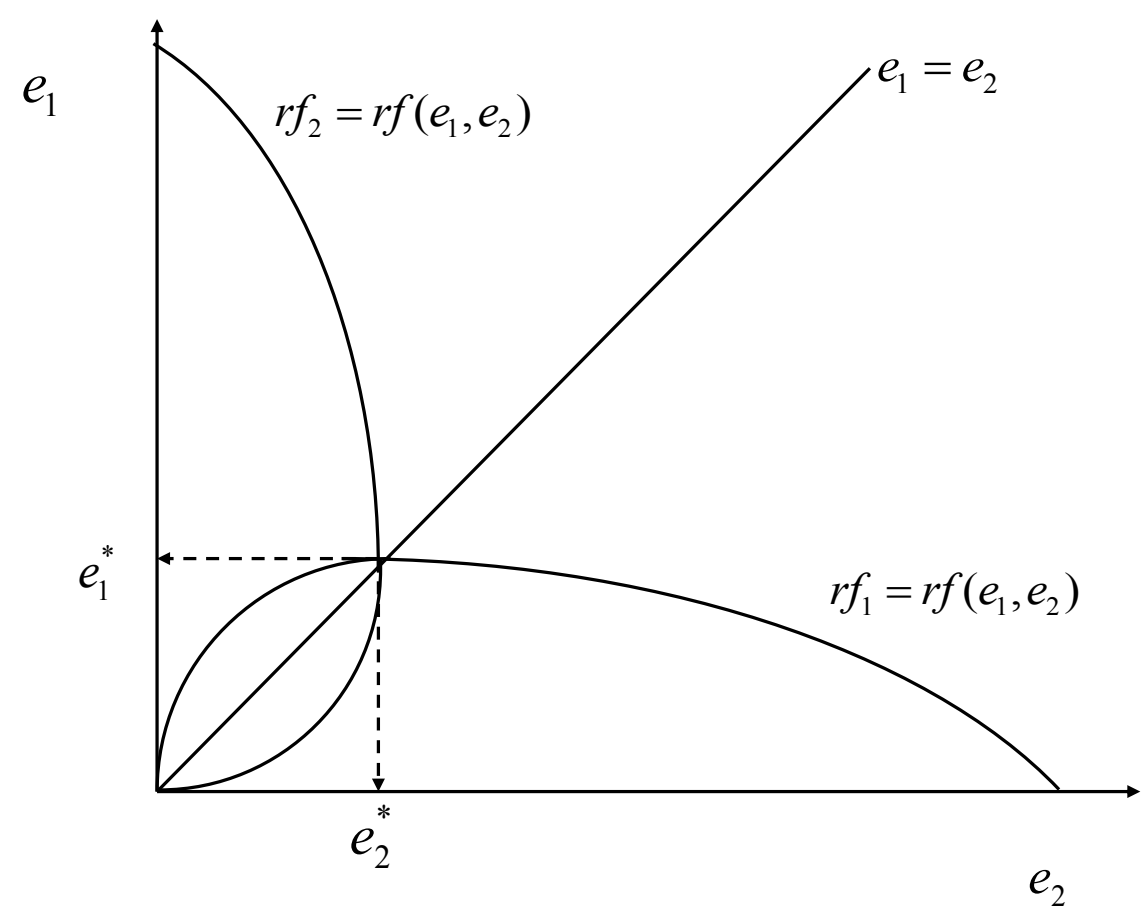

Figure 2.3 Contest Game (Limited Liability)

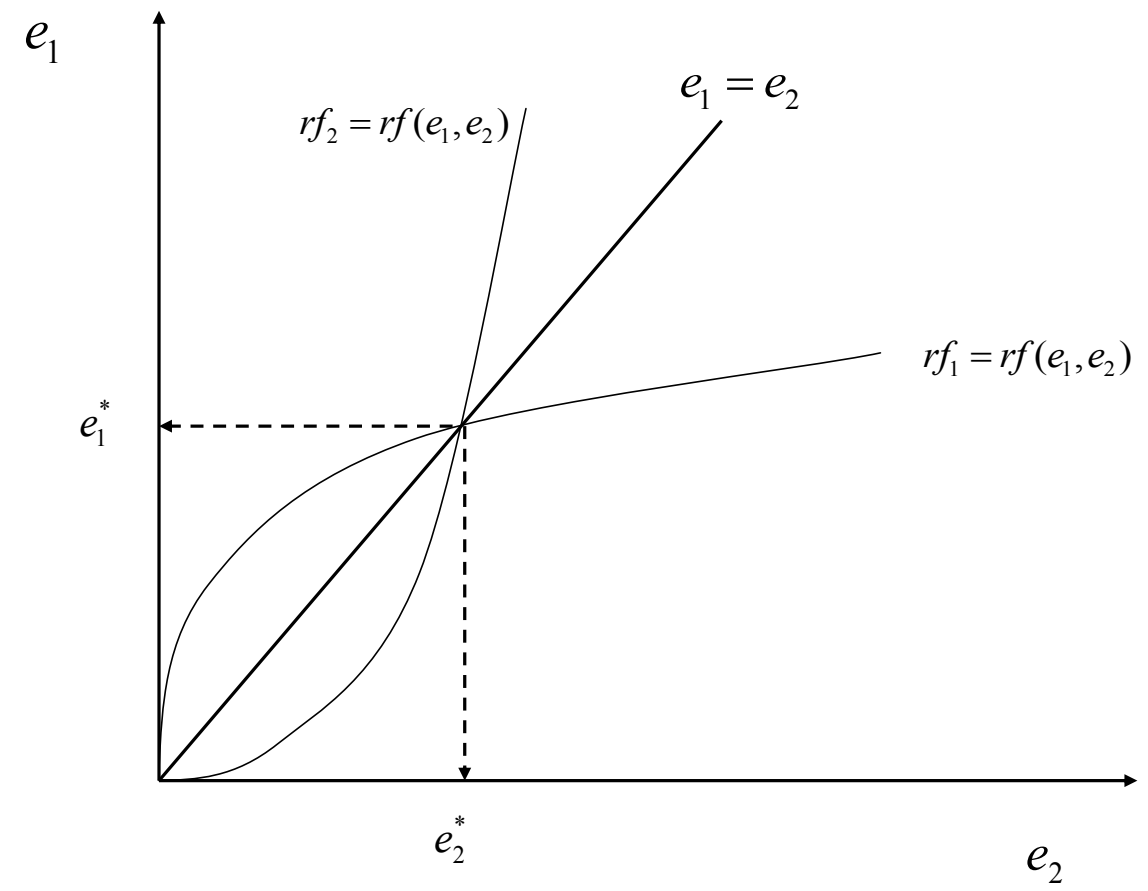


specification of the competition game, for example on the type of contest success function used.

Given the effort level of player 1, payer 2 chooses his the effort level that maximizes his expected net pay-off, that is the best reaction of player 1 .

An equilibrium occurs when the two contestants no longer change their investment in effort. This is where the reaction functions intersect. The equilibrium values of effort are the effort levels that maximize the expected benefits of the two contestants and equal $\left(e^{*}{ }_{1}, e^{*}{ }_{2}\right)$. In case the contestants have the same characteristics (are symmetric), the effort levels are also the same. Note that the investment level of contestant 1 first increases when contestant 2 increases its effort; it decreases after the optimal effort level, which also applies to contestant 2. This curvature of the reaction function guarantees that the equilibrium is a stable Nash equilibrium. Any deviation of effort levels from the optimum will result in a movement towards the equilibrium level of effort. For a more technical exposition we refer to appendix 1.

As explained above, the expected pay-off function is used in this research to formalize competition between regions to attract firms. Here the expected pay-off is the expected benefit to the region where the firm settles. This is the probability of the firm's settling multiplied by the benefits from the firm's settling $\left(v_{i}(B)=\Delta Y\right)$ minus the cost region $i$ invests $\left(e_{i}\right)$ in attracting firms. The probability that the firm settles in a specific $\left(\operatorname{Pr}_{i}\right)$ depends on the investments made by the region $\left(e_{i}\right)$ and its competitors $\left(e_{-i}\right)$. The purpose of competition is to win the prize, but what are the gains for regions when firms settle? In the next section we look more explicitly at the contribution of firms to regional economic development.

\subsection{Contribution of Firms to Regional Economic Development}

In this section we first discuss the production side of the regional economy (subsection 2.5.1), after which we deal with the consumption side (subsection 2.5.2). Subsection 2.5.3 combines both sides of the economy.

\subsubsection{Production Side: Firm Behaviour}

In this subsection we start by assuming perfect competition between firms that produce according to a neo-classical production function. The contribution of a firm settling in a specific region is the additional output generated by that firm. Due to the assumption of perfect competition, all $m$ competitive firms in the region are identical and thus we can use the production function of a firm $j$ to represent the production side of the regional economy: 


$$
Y_{j}=F\left(L_{j}, K_{j}\right) \text { or in intensive form } \frac{Y_{j}}{L_{j}}=y_{j}=f\left(k_{j}\right)
$$

Here the production of final goods, $Y_{j}$, depends on the inputs labour, $L_{j}$, and capital, $K_{j}$. The production function fulfils the standard neoclassical assumptions. ${ }^{20}$ It is important that the function is homogeneous of degree 1 in the inputs. If the inputs are increased by the same amount, output also increases by that amount. This is also called constant returns to scale. A result is that the production per unit of labour $\left(y_{j}=\frac{Y_{j}}{L_{j}}\right)$ depends on capital per unit of labour $\left(k_{j}=\frac{K_{j}}{L_{j}}\right)$. Furthermore, the marginal product of the separate inputs is positive but decreasing. For example, if the amount of capital is increased, the output is increased by a smaller amount.

It is assumed that firms try to maximize their profits. Profits, of course, are revenues minus costs. The revenues are the price of the final product multiplied by the firm's output. To simplify things we normalize the price of final output and products to 1 . The profit function of firm $j$ then equals:

$$
\pi_{j}=F\left(L_{j}, K_{j}\right)-w_{j} L_{j}-R_{j} K_{j} \text { or } \pi_{j}=L_{j} f\left(k_{j}\right)-L_{j} w_{j}-R_{j} K_{j}
$$

Here $\pi_{j}$ represent the firm's profit. The production costs consist of costs of labour and capital. Prices of labour and capital are fixed for the firm. The wage rate $w_{j}$ and the return on capital, $R_{j}$, that the firm faces, equals the economy-wide wage rate and return on capital. Thus the following holds: $w_{j}=w$ and $R_{j}=R^{21}$. The firm chooses labour and capital, given ${ }^{20} \frac{\partial F}{\partial K_{j}}>0, \frac{\partial^{2} F}{\partial K_{j}{ }^{2}}<0$ for all $K_{j}$ and $\frac{\partial F}{\partial L_{j}}>0, \frac{\partial^{2} F}{\partial L_{j}{ }^{2}}<0$ for all $L_{j}$ which means that the marginal products of capital and labour are positive but decreasing. Furthermore we have $\lim _{K_{j} \rightarrow \infty} \frac{\partial F}{\partial K_{j}}=0$ and $\lim _{L_{j} \rightarrow \infty} \frac{\partial F}{\partial L_{j}}=0$, which are called the Inada conditions. A further neoclassical assumption about the production function is that it is homogeneous of degree 1 . That is $F\left(\lambda L_{j}, \lambda K_{j}\right)=\lambda F\left(L_{j}, K_{j}\right)$, which states that if inputs are multiplied by the same factor $\lambda$ then output $F$ is also multiplied by that same factor

${ }^{21}$ Note that in case there is no depreciation, the return on capital equals the interest rate. If we have a depreciation rate of $\delta$ then return on capital equals interest rate plus depreciation rate, that is $R=r+\delta$. If capital is fully depreciated during the production process then evidently we have $R=1+r$. Below we have assumed that there is no depreciation of capital. 
their prices, in such way that profit is maximized. To find this we maximize the profit function with respect to labour and capital. Using the first-order approach we find ${ }^{22}$ :

$$
w_{j}=F_{L_{j}}\left(K_{j}, L_{j}\right) \text { and } R_{j}=F_{K_{j}}\left(K_{j}, L_{j}\right)
$$

and in intensive form ${ }^{23}$,

$$
w_{j}=f\left(k_{j}\right)-k_{j} f^{\prime}\left(k_{j}\right) \text { and } R_{j}=f^{\prime}\left(k_{j}\right)
$$

The firm will use inputs up to the point that the price equals their marginal product. If the marginal product exceeds that of the price of inputs, the firm can increase its profit, producing more by using more inputs. Note in this respect that the marginal product is decreasing. If the wage rate and the rate of return on capital are equal to their marginal product, than the firm's profit is zero. This can be shown by applying Euler's theorem. ${ }^{24}$ Tthe production function is homogeneous of degree 1 and so, equation (2.3) can be written as follows: $Y_{j}=F\left(L_{j}, K_{j}\right)_{=} L_{j} \frac{\partial F}{\partial L_{j}}+K_{j} \frac{\partial F}{\partial K_{j}}$. Substituting the wage rate and return on capital for marginal product of labour and capital leads to $Y_{j}=F\left(L_{j}, K_{j}\right)=w L_{j}+R K_{j}$. Finally, substituting this in the profit function we can see that the profit equals zero. ${ }^{25}$

Next we turn to the gains from attracting firms to a region. This is the output generated by the new firm. In a competitive environment firms are identical, that means the produce the same quantity of output where the make use of the same technology and use the

${ }^{22}$ Differentiating the profit function with respect to labour and capital we have $\frac{\partial \pi_{j}}{\partial L_{j}}=\frac{\partial F}{\partial L_{j}}-w_{j}=0$ and

$\frac{\partial \pi_{j}}{\partial K_{j}}=\frac{\partial F}{\partial K_{j}}-R_{j}=0$ Using $\frac{\partial F}{\partial L_{j}}=F_{L_{j}}\left(K_{j}, L_{j}\right)$ and $\frac{\partial F}{\partial K_{j}}=F_{K_{j}}\left(K_{j}, L_{j}\right)$ results in (2.5A)

${ }_{23} \frac{\partial \pi_{j}}{\partial L_{j}}=f\left(k_{j}\right)-L_{j} \frac{\partial f}{\partial k_{j}} \frac{\partial\left(\frac{K_{j}}{L_{j}}\right)}{\partial L_{j}}-w_{j}=0$ where $\frac{\partial f}{\partial k_{j}}=f^{\prime}\left(k_{j}\right)$ and $\frac{\partial\left(\frac{K_{j}}{L_{j}}\right)}{\partial L_{j}}=-\frac{K_{j}}{L_{j}{ }^{2}}$ thus $w_{j}=f\left(k_{j}\right)-k_{j} f^{\prime}\left(k_{j}\right)$ and $\frac{\partial \pi_{j}}{\partial K_{j}}=L \frac{\partial k}{\partial k_{j}} \frac{L_{j}}{L_{j}^{2}}-R_{j}=0$ thus $R_{j}=f^{\prime}\left(k_{j}\right)$.

${ }^{24}$ Euler's theorem states that if $f(x, y)$ is a homogeneous function of the degree $k$ then we have

$x \frac{\partial f}{\partial x}+y \frac{\partial f}{\partial y}=k f(x, y)$.

${ }^{25} \pi_{j}=Y_{j}-w L_{j}-R K_{j}$. Substituting for the wage rate and return on capital their marginal product results in: $\pi_{j}=Y_{j}-\frac{\partial F}{\partial L_{j}} L_{j}-\frac{\partial F}{\partial K_{j}} K_{j}=0$ 
same quantity of inputs. Thus assuming identical firms, the output of a new firm equals the output of the representative firm $j$. Previously, the region had $m$ firms; after settlement this will be $m+1$. The additional income of a region equals the output of the next firm $m+1$, but this is the same as for each of the $m$ firms already present in the region, which are represented by firm $j$, so:

$$
Y_{m+1}=\Delta Y=Y_{j}=w L_{j}+R K_{j}
$$

\subsubsection{The Consumption Side: The Overlapping Generations Model}

In this study, especially in chapters 5 and 6, we analyze the effects of economic integration, more specifically capital mobility across regional borders. This means we have to compare two periods: before and after integration. To do so we use a two-period overlapping generations model (OLG), in which consumers decide on their levels of consumption and savings. Savings are important for the future economic development. They contribute to the stock of capital and the production capacity and thus also to the development of an economy. To analyse the effect of economic integration we compare a period before integration (autarchy) with the period after integration. The two period type of OLG fits well in our approach considering these two different periods.

Following Romer's (2006, pp. 76-98) specification of the model, we have two generations, the young generation and the old one. We assume there is no population growth over time. The young generation works during the first period and earns a wage income. This wage income is used for consumption in the first and second period. Part of the wage income is thus saved for consumption in the second period. The young generation has to decide how much to consume in each period, based on its members' preferences. These preferences are set down in what is called lifetime utility functions. Below, the utility function is given of a representative young agent in period $t$ :

$$
U_{t}\left(c_{1, t}, c_{2, t+1}\right)=\left\{\begin{array}{l}
\frac{c_{1, t}^{1-\theta}}{1-\theta}+\frac{1}{(1+\rho)} \frac{c_{2, t+1}^{1-\theta}}{(1-\theta)} \text { for } \theta>0 \text { and } \theta \neq 1 \\
\ln c_{1, t}+\frac{1}{(1+\rho)} \ln c_{2, t+1} \text { for } \theta=1
\end{array}\right.
$$

Here $c_{1, t}, c_{2, t+1}$ is consumption in the current (first) period when the agent is young, and consumption in the next (second) period when the agent is old. The parameter $\rho$ is the subjective discount rate, or time preference, of the agent and the parameter $\theta$ is the 
consumption elasticity of marginal utility. With respect to the parameters it is assumed that $\theta>0, \rho>-1$. Future consumption (in the second period) is discounted at the rate of $\frac{1}{(1+\rho)}$

Consumption not only depends on time preference but also on the agent's available income. Labour income in the first period equals the units of labour supplied multiplied by the wage rate in the first period. In the second period income is made up of savings (from the first period) plus interest on savings, that is return on capital in the second period. If it is assumed that the young agent supplies one unit of labour when he is young then we have the following budget constraint; ${ }^{26}$

$$
w_{t}=c_{1, t}+s_{t}
$$

where $w_{t}$ represents labour income of the young agent. The variable $s_{t}$ stands for the young agent's savings. Net income equals current period consumption plus savings. Agents live for two periods, (current savings plus interest on savings next period, $r_{t+1}$ ), thus return on capital, $R_{t+1}$ is the second period's income, that is:

$$
c_{2, t+1}=R_{t+1} s_{t}
$$

where $R_{t+1}=\left(1+r_{t+1}\right)$ is return on capital which equals savings plus interest on savings Using the two results above, equations (2.8) and (2.9) result in the following inter-temporal budget constraint:

$$
w_{t}=c_{1, t}+\frac{1}{R_{t+1}} c_{2, t+1}
$$

This inter-temporal budget constraint describes how lifetime income is distributed over lifetime consumption, that is, consumption in the current and next period. Here $\frac{1}{R_{t+1}}$ is the discount factor of future consumption, which can also be seen as the relative price of future consumption. What we need to know next is the valuation of the agent of consumption in the

\footnotetext{
${ }^{26}$ Note that if government levies taxes on income we have; $w_{t}-i t_{t}=c_{1, t}+s_{t}$, Here $i t_{t}$ represents tax on income which we assume is proportional to wage income, that is, $i t_{t}=\tau w_{t}$. Here $\tau$ is the tax rate on wage income. This results in $(1-\tau) w_{t}=c_{1, t}+s_{t}(2.8 \mathrm{~A})$
} 
subsequent periods. We can find this relation using the log-linear utility function of equation (2.7). This results in what is called the 'Euler equation' of consumption:

$$
c_{1, t}=c_{2, t+1} \frac{(1+\rho)}{R_{t+1}}
$$

Any other combination of consumption goods as given in equation (2.11) will result in a lower utility. ${ }^{27}$ This is sometimes referred to as the efficiency condition of consumer behaviour. Next we can express current consumption in current period's savings, that is, $c_{1, t}=(1+\rho) s_{t}{ }^{28}$. Using this relation and substituting it in the budget constraint we can find the saving function, which equals:

$$
s_{t}=\hat{s} w_{t}
$$

where $\hat{s}=\frac{1}{(2+\rho)}$ is the marginal propensity to save. We can see that savings is a fixed proportion of (wage) income, i.e. the saving rate is constant. If only young agents save and supply labour, than total savings of the economy equals ${ }^{29}$ :

$$
S_{t}=\hat{s} L_{t} w_{t}
$$

where $L_{t} w_{t}$ is the wage share of total income. The young generation equals the labour force so actually we have $L_{t}=L_{y, t}$. Total population, $\hat{L}_{t}$, naturally equals young plus old generation, that is $\hat{L}_{t}=L_{y, t}+L_{o, t-1}$.

The consumers' decision on how to divide their income over their lifetime is important because this determines savings. The savings of the current period lead to the

\footnotetext{
${ }^{27}$ In this case the relative price equals the marginal rate of substitution between the current and next period's consumption. Optimality requires that the shape of the utility function equals that of the budget function. The shape of the log-linear utility function equals $\frac{d c_{2, t+1}}{d c_{1, t}}=-(1+\rho)\left\lfloor\frac{c_{2, t+1}}{c_{1, t}}\right\rfloor$ and that of the budget function equals $\frac{d c_{2, t+1}}{d c_{1, t}}=-\left(1+r_{t+1}\right)$, which results in equation (2.11).

${ }^{28}$ Substituting (2.9) in (2.11) we have $c_{1, t}=(1+\rho) s_{t}$ and substituting this in (2.8) gives $w_{t}=(2+\rho) s_{t}$.

${ }^{29}$ In case the government levies taxes on wage income we have $S_{t}=\hat{s}(1-\tau) w_{t}(2.12 \mathrm{~A})$ and $S_{t}=\hat{s}(1-\tau) L_{t} w_{t}$ $(2.13 \mathrm{~A})$.
} 
capital stock of the next period and thus to output in the next period. The last equation (2.13) is used to fill in the first part, the savings, of the so-called equation of motion, to which we now turn.

\subsubsection{The Equation of Motion}

We continue describing the regional economy where firm $j$ represents the production side of the economy. From subsection 2.5.1 it follows that the economy-wide regional production of goods can be expressed as follows:

$$
Y=F(L, K) \text { or in intensive form } \frac{Y}{L}=y=f(k)
$$

Here $Y$ equals total regional product, which equals the sum of the production of all firms in the region $\left(Y=\sum_{j=1}^{m} Y_{j}=m Y_{j}\right)$. Labour, $L=\sum_{j=1}^{m} L_{j}=m L_{j}$ and capital $K=\sum_{j=1}^{m} K_{j}=m K_{j}$ stand for the regional aggregate labour and capital stock. The variable $k=\frac{K}{L}$ is the capital-labour ratio, that is, capital per unit labour. The long-run profits of all firms are zero and factor prices of labour and capital equal their marginal product. Regional income is thus distributed between labour and capital income as follows:

$$
Y=w L+R K \text { and in intensive form } y=w+R k
$$

Due to the assumption of perfect competition, wage rates and the return on capital are equal across firms in the region.

If we look at the development of regional production over time, we have the dynamic versions of equations (2.14) and (2.15), viz.:

$$
Y_{t}=F\left(L_{t}, K_{t}\right), y_{t}=f\left(k_{t}\right) \text { and } Y_{t}=w_{t} L_{t}+R_{t} K_{t}, y_{t}=w_{t}+R_{t} k_{t}
$$

As noted before, we assume no population growth, so the labour force is constant $\left(L_{t}=L\right)$. As we have seen above, the development of regional output depends heavily on capital formation. What determines the regional capital stock? Output can be used for consumption and for increasing the capital stock, which means refraining from consumption, i.e. saving $\left(Y_{t}=C_{t}+S_{t}\right)$. These savings are investments and they are used to increase the capital stock. The next period's output can thus be increased with this increased capital stock. This last 
relation is sometimes called the equation of motion, i.e. the relation between current period's savings and next period's capital stock. If the capital stock is fully depreciated ${ }^{30}$ in every period we have the following equation of motion:

$$
S_{t}=K_{t+1}
$$

Here $S_{t}$ is the region's savings in period $t$ and $K_{t+1}$ is the region's capital stock in period $t+1$. The next period's capital stock (and thus output) depends on the current period's savings. The savings are determined by consumers. As explained in the previous section we use the two period OLG to describe the consumer behaviour, to see how savings are determined. Using the results from the previous section we find:

$$
S_{t}=\hat{s} L_{t} w_{t}=K_{t+1} \text { or } K_{t+1}=\hat{s} F_{L}\left(K_{t}\right)^{31}
$$

and

$$
s_{t}=\hat{s} w_{t}=k_{t+1} \text { or } k_{t+1}=\hat{s}\left[f\left(k_{t}\right)-k_{t} f^{\prime}\left(k_{t}\right)\right]
$$

Note that $F_{L}\left(L_{t}, K_{t}\right)$ and $f^{\prime}\left(k_{t}\right)$ are the partial derivatives. Next, using the wage income from equation (2.5) and equating $k_{t}=k_{t+1}=k^{*}$ we find the equilibrium level of capital stock and the equilibrium capital-labour ratio. ${ }^{32}$ This results in an equilibrium income, wage rate and return on capital, that is:

$$
y^{*}=f\left(k^{*}\right), w_{t}=w^{*} \text { and } R_{t}=R^{*}, y^{*}=w^{*} L+R^{*} K^{*} \text { and } Y^{*}=L y^{*}
$$

The regional economy is in equilibrium and no longer develops over time.

\subsection{Externalities, Exogenous Growth and Endogenous Growth}

As noted, firms can contribute to the economic development of regions through the additional output they generate. In addition, settlement of firms can have positive spill-over effects (or: externalities) on economic activity within the region and across regional borders.

\footnotetext{
${ }^{30}$ Capital is fully depreciated in one period so the savings are investments and are next periods capital stock.

${ }^{31}$ Here $F_{L}=\frac{\partial F}{\partial L}$.

${ }^{32}$ Note that this is a stable equilibrium because: $\frac{d k_{t+1}}{d k_{t}}=\hat{s}\left[f^{\prime}\left(k_{t}\right)-f^{\prime}\left(k_{t}\right)-k_{t} f^{\prime \prime}\left(k_{t}\right)\right]=k_{t} f^{\prime \prime}\left(k_{t}\right)$.
} 


\subsubsection{Externalities}

Milgrom and Robers (1997, p. 75) define externalities as the positive or negative effects that one agent's actions have on another agent's welfare that are not regulated by the system of prices. They affect people's consumption and firm's production behaviour, but if the associated costs and benefits are not taken into account (i.e. not internalized), their presence may result in inefficient levels of externality-bearing activities. Internalization does not occur because of missing markets. The externalities correspond to goods (or "bads") that individuals would want to buy or sell because they affect utility or production possibilities. These goods are not traded in competitive markets and no prices are attached to them so the market system fails to guide their allocation. These missing markets are a major source of market inefficiencies.

Generally, a distinction is made between technological externalities and pecuniary externalities; this was first done by Scitovsky (1954, pp. 144-146). Focusing on the production side, according to Antonelli (2007, p. 33) technological externalities are direct interdependencies among producers not mediated by the price mechanism. More precisely, technological externalities occur when unpaid production factors enter the users' production function. Pecuniary externalities are indirect interdependencies among producers mediated by the price mechanism. Interdependence occurs via the effect on the price system. It exerts an effect on the price of production factors and the price of products. Positive pecuniary externalities are found when the latter are below the equilibrium level and the former above. Pecuniary externalities effect the production function as well as the costs and the revenue function. Pecuniary externalities apply when the prices of both products and factors differ from equilibrium levels and reflect the effects of external forces.

\subsubsection{Exogenous Technological Progress}

In economics it is commonly observed that there is an overall increase in factor productivity over time. For a long time growth economists were not able to explain and model this overall increase (See for example Barro and Sala-i-Martin, 1997 and Acemoglu, 2009). In neo classical growth theory the assumption is made that technological progress leading to an overall productivity increase is exogenous. A productivity parameter is introduced in the production function to incorporate this technological progress. This parameter reflects the current state of technological knowledge. It is most often assumed that knowledge and technological progress change over time. In addition it is assumed that this also leads to an increase in labour productivity. If it is assumed that knowledge grows at $g \%$ and if it increases labour productivity, the following additional relations have to be added to the model. Technological progress takes the form of: 


$$
A_{t}=(1+g) A_{t-1}
$$

Here $A_{t}$ is the current state of technology, which increases at a fixed rate per time period. To express the fact that it increases the overall labour productivity we have the following additional relation between technology and labour productivity:

$$
E_{j, t}=L_{t} A_{t}
$$

Here the variable $E_{j, t}$ expresses the effective labour or the efficiency level of labour. It increases over time due to the technological development. The effective labour next to capital determines production, and so production will also increase in time. The state of technology is incorporated in this way. It will be clear that the state of technology and technological progress positively influences the firm's production process. Incorporating this in the production function leads to:

$$
Y_{j, t}=F\left(K_{j, t}, E_{j, t}\right)
$$

Here both capital and effective labour are arguments of the production function. The production function has the same properties with respect to capital and effective labour as the production function with no technological progress. Note that the factor inputs labour and capital are choice variables for firms. The state of technology is given for the firms, however. The marginal product of capital and effective labour is positive but decreasing. The production function is homogeneous of degree one. The marginal productivity of capital and effective labour equals those discussed in previous sections. The marginal productivity of labour increases and the labour productivity increases (with the exogenous rate of technological progress).

Profit maximization of the private sector with respect to capital and labour leads to the following two first-order conditions:

$$
\frac{\partial \pi_{j}}{\partial L_{j}}=\frac{\partial F}{\partial\left(A_{t} L_{j}\right)} \frac{\partial\left(A_{t} L_{j}\right)}{\partial L_{j}}-w_{t}=\frac{\partial F}{\partial\left(A L_{j}\right)} A_{t}-w_{t}=0 \text { and } \frac{\partial \pi_{j}}{\partial K_{j}}=\frac{\partial F}{\partial K_{j}}-R=0
$$

and in intensive form in units effective labour $\left(k_{j}=\frac{K_{j}}{E_{j}}=\frac{K_{j}}{A L_{j}}\right)$, 


$$
\begin{aligned}
& \frac{\partial \pi_{j}}{\partial L_{j}}=\frac{\partial \pi_{j}}{\partial\left(A_{t} L_{j}\right)} \frac{\partial\left(A_{t} L_{j}\right)}{\partial L_{j}}-w_{t}=A_{t}\left[f\left(k_{j}\right)-k_{j} f^{\prime}\left(k_{j}\right)\right]-w_{t}=0 \text { and } \\
& \frac{\partial \pi_{j}}{\partial K_{j}}=f^{\prime}\left(k_{j}\right)-R=0
\end{aligned}
$$

We note that return on capital in case of technological progress equals that of the economy with no technological progress. This differs for labour productivity, however. If we compare the situation with technological progress to that without it we see that the marginal product of labour increases with the rate of technological progress, as expressed in equation (2.19). This can be seen by comparing the two production functions.

Since technological progress grows at an exogenous rate this will also be the case for the wage rate, for the aggregate output and also for income. The production function is homogeneous of degree 1 and we have:

$$
Y_{t}=F\left(K_{t}, E_{t}\right) \text { or in intensive form }{ }^{33} y_{t}=A_{t} f\left(k_{t}\right)
$$

The output per unit labour or labour productivity will increase due to an exogenous increase in technological progress. As noted before, over time the capital-labour ratio will be in equilibrium thus, in equilibrium, $k_{t}=k_{t+1}=k^{*}$. To find the equilibrium we make use of the equation of motion as we did in the previous section, which results in the following:

$$
y_{t}=A_{t} f\left(k^{*}\right) \text { and } \quad Y_{t}=A_{t} L f\left(k^{*}\right)
$$

The regional production increases at a fixed exogenous rate of technical progress, whereas the inputs of labour and capital are at equilibrium level. Note that the wage rate and the marginal product of labour depend on the optimum capital-labour ratio $\left(k^{*}\right)$, and technical progress $\left(A_{t}\right)$. Return on capital and marginal product of capital depends on solely on the optimum capital-labour ratio. If, however, we look at the growth rate of the economy we see that $\frac{Y_{t+1}}{Y_{t}}=\frac{A_{t+1}}{A_{t}}$ which depends only on technological progress. After the economy has reached equilibrium, capital / output level $k^{*}$, output will grow at a constant rate ${ }^{34}$.

\footnotetext{
${ }^{33}$ Here $k_{t}=\frac{K_{t}}{A_{t} L}$ is the capital effective labour ratio thus $Y_{t}=A_{t} L f\left(k_{t}\right)$ and $\frac{Y_{t}}{L}=y_{t}=A_{t} f\left(k_{t}\right)$.

${ }^{34}$ From (2.19) we have $\frac{A_{t}}{A_{t-1}}=\frac{A_{t+1}}{A_{t}}=(1+g)$.
} 
In the same manner we can write down the income distribution. We now know the marginal productivities of labour and capital and because factor remunerations equal their marginal product we have:

$$
Y_{t}=R K+w_{t} L
$$

Due to exogenous technological progress, output will grow at a fixed rate. In the same way, the productivity of labour and thus wage rate and income will increase at that same rate.

\subsubsection{Endogenous Technological Progress as Externality}

In the previous subsection output was modelled as being exogenously influenced by technological progress. P. Romer $(1986,1987)$ proposed an entirely different approach, i.e. focussing on production externalities, generated through innovation. P. Romer (1986), also known as the founding father of endogenous growth theory (EGT), incorporated the role of externalities in a number of steps. First by taking the economy's average capital stock as an argument in the individual firm's production function. The average capital stock serves as an indicator for the available knowledge in the economy. This knowledge, generated by the economy as a whole, is accessible to all firms and there is no price label attached to it. It has public good characteristics. Nevertheless, a firm's private capital and labour are subject to diminishing marginal productivity. Because of the positive externalities, the marginal productivity may on aggregate exceed that of the private marginal productivity. Due to this externality, the overall productivity is increased and the economy reaches a stable growth path.

To incorporate knowledge, we have to adjust the neo-classical production function so that it includes average capital resulting from a positive production externality. The approach is similar to that is followed in the previous section. First, labour is expressed in effective labour or efficiency units. The average capital or overall capital-labour ratio is now endogenously determined through capital accumulation (assuming a fixed labour force):

$$
E_{j, t}=L_{j} \hat{k}_{t} \text { where } \hat{k}_{t}=\frac{K_{t}}{L}
$$

Exogenous technological progress is replaced by the average capital-labour ratio. The production function for the individual firm remains unchanged:

$$
Y_{j, t}=F\left(K_{j, t}, E_{j, t}\right)
$$


Here the inputs $K_{j}$ and $L_{j}$ are the firm's inputs, where $\hat{k}$ is the average aggregate capital stock, that is, $\sum_{j=1}^{m} \frac{K_{j}}{L_{j}}=\frac{m K_{j}}{m L_{j}}=\frac{K}{L}=\hat{k}$ per unit of labour, representing the economy's 'knowledge' stock. This average aggregate capital stock or overall capital intensity of the economy is determined by the aggregate economy. As with exogenous technological change, it is assumed this will lead to an overall increase in labour productivity. This means that for the individual firm, labour and capital are endogenous variables and the capital-labour ratio is exogenous. For the overall economy, the capital-labour ratio is endogenously determined.

Profit maximization by firms results in two first-order conditions. With respect to the return on capital this equals its marginal product, which is constant and remains the same as before. This is also the case for effective labour.

$$
\frac{\partial F}{\partial K_{j}}-R=0
$$

and

$$
\frac{\partial F}{\partial\left(\hat{k}_{t} L_{j}\right)} \frac{\partial\left(\hat{k}_{t} L_{j}\right)}{\partial L_{j}}-w_{t}=0 \text { and so } \frac{\partial F}{\partial\left(\hat{k}_{t} L_{j}\right)} \hat{k}_{t}-w_{t}=0
$$

The marginal product of labour is increasing due to an increase in the capital-labour ratio and so the wage rate will also increase.

The decision of firms with respect to the inputs labour and capital does not take account of the positive externality of the average capital stock. Although the capital stock for the firm is optimal (it maximizes the firms profit), this is not the case for the economy as a whole. Because there are positive externalities there are still benefits for the economy. Thus the social return on capital is in excess of the private return on capital. The social optimal is there where the social cost of capital (return on capital) equals the social benefits. If we take into account that the production function of the firm's inputs is homogeneous of degree one, this aggregate capital intensity generates positive externalities.

On aggregate, the production function, $Y_{t}=F\left(K_{t}, E_{t}\right)$ is no longer identical to that of the firm. Taking that into account, from equations (2.25) and (2.26) we find that $E_{t}=K_{t}{ }^{35}$. The aggregate production function exhibits constant returns to scale in its inputs. This results in the following aggregate production function $Y_{t}=K_{t} F(1)$, which can be written as ${ }^{36}$ :

${ }^{35} E_{t}=\sum_{j=1}^{n} E_{j, t}=\hat{k}_{t} \sum_{j=1}^{n} L_{j}=\frac{K_{t}}{L} L=K_{t}$.

${ }^{36}$ See for example Annichiarico \& Giammarioli (2004, pp. 12-14). 


$$
Y_{t}=A K_{t}
$$

and in intensive form:

$$
y_{t}=A k_{t} \text { where } A=F(1)>0
$$

Note that the firm's inputs of capital and labour exhibit positive but decreasing marginal product, but that on aggregate the production function exhibits constant return to scale in the factor capital. As said, this results in a difference between the private marginal product and the social (aggregate) marginal product. Therefore the social rate of return on capital exceeds that of the private rate of return: $A>R$.

Income from production is distributed over the factor inputs according to their (private) marginal product. Knowing the private rate of return on capital, which equals the private marginal product of capital, $A$ (see equation (2.28), labour income can be calculated residually. Thus total income consisting of labour and capital income which equals:

$$
Y_{t}=w_{t} L+R K_{t}=[A-R] K_{t}+R K_{t}=A K_{t}
$$

Frome the above equation, we see that the wage rate equals $w_{t}=\hat{k}_{t}[A-R],{ }^{37}$ which depends on the difference between the social return and the private return on capital.

It is easy to see how capital develops over time. We refer to the equation of motion (2.17) and we see the following development of capital over time (note that savings result from wage income). At the same time the growth rate can be calculated:

$$
K_{t+1}=\hat{s}(A-R) K_{t} \quad \frac{K_{t+1}}{K_{t}}=\hat{s}(A-R)=(1+g)
$$

where $g$ is the growth rate. We can see from equation (2.28) and (2.31), that the growth of capital stock also equals the growth of income ${ }^{38}$. The regional growth equals:

$$
\frac{Y_{t+1}}{Y_{t}}=\hat{s}(A-R)=(1+g)
$$

\footnotetext{
${ }^{37}$ From (2.31) we have $w_{t} L=[A-R] K_{t}$ and $w_{t}=[A-R] \frac{K_{t}}{L}$ where $\frac{K_{t}}{L}=\hat{k}_{t}$ the capital labour ratio.

${ }^{38}$ From (2.28) we have $\frac{Y_{t+1}}{Y_{t}}=\frac{A K_{t+1}}{A K}=\frac{K_{t+1}}{K_{t}}$.
} 
Comparing this to the previous section, we notice that capital stock and the capital-labour ratio are increasing over time and that the growth rate not only depends on the marginal product of labour and capital but also on the saving rate $\hat{s}$.Although the structure of the model with exogenous and endogenous technological change is identical, the outcome differs because technological change is now endogenously determined by capital formation.

\subsubsection{Innovation as Externality}

In the previous section we did not address how technological progress and thus growth is actually brought about. Within endogenous growth theory innovation plays an important part. Romer used Ethier's (1982) interpretation of the Dixit-Stiglitz (1977) model of monopolistic competition to formulate innovation as an intentional activity of entrepreneurs. Innovation leads to new varieties of intermediate capital goods, which increases productivity, which results in endogenous growth. Any new invention increases the stock of knowledge that can be used without limit to create new inventions. This increase in the stock of knowledge, in new varieties of intermediate capital goods, results in a constant growth of the economy. For our analysis this means that we see innovation as an intentional activity of firms, leading to positive externalities. If this reasoning holds, then it is possibly beneficial for regions not to attract just any firm but to attract especially innovative firms. It is therefore important to describe the behaviour of innovative firms to see how they can contribute to regional development.

Firms will invest in innovation if it benefits them. But in a perfect competition environment in the long run firms will make no profit and thus under perfect competition the result will be no innovation. This means we have to introduce another type of market, monopolistic competition, in which conditions are such that firms are willing to invest in innovation. The economy then consists of two types of markets in which two different types of firms are operating. First there are firms that produce final goods (operating under conditions of perfect competition) and secondly there are firms that produce intermediate and unique capital goods (operating under conditions of monopolistic competition), which are used for the production of final goods. For the production of final goods we have the following production function:

$$
Y_{j}=F\left(L_{j}, \sum_{i=1}^{N} K_{i, j}\right) \text { for } j=1, \ldots, m
$$

The inputs are again labour and capital. Here $N$ is the number of different types of capital goods and the capital stock is the total of $N$ different types of capital goods. 
All available different types of capital goods, which are given for the individual firm, can be used for the production of final goods. As in the previous case, the production function is homogeneous in labour and capital, consisting of all types of (intermediate) capital goods. Also the term intermediate goods is used because the different types of capital are intermediate inputs for the production of final goods. Whereas in the previous sections capital goods are homogeneous, they are now heterogeneous. The final goods sector is operating under perfect competitive conditions. The profit functions of the firms producing final goods look like the following:

$$
\pi_{j}=Y_{j}-w L_{j}-\sum_{i=1}^{N} p_{i j} K_{i j} \text { for } j=1, \ldots, m
$$

The profit of the firm producing final goods is equal to revenues minus costs. The costs are payments for production factor labour and for capital. For capital this is the used types of capital goods $\left(K_{i}\right)$ multiplied by its (market) price. The price of each different capital good $i$ equals $p_{i}$. The term $K_{i j}$ and $p_{i j}$ is the amount of capital goods $i$ of firm $j$ and the price firm $j$ pays for capital good $i$.

If firms maximize their profit factor, prices have to equal their marginal products. This applies to labour and all different kinds of (intermediate) capital goods. Taking the first derivative with respect to labour and all $N$ different types of capital goods, the result is:

$$
\frac{\partial Y_{j}}{\partial L_{j}}-w=0 \text { for } j=1, \ldots, m, \text { the number of firms in the region }
$$

and

$$
\begin{gathered}
\frac{\partial Y_{j}}{\partial K_{i j}}=p_{i j}=p_{i} \quad \text { for } i=1, \ldots, N, \text { the number of different types of capital and } \\
\text { for } i=1, \ldots, m, \text { the number of firms in the region }
\end{gathered}
$$

The marginal product of each different (intermediate) capital good equals its return on capital. This is the price firms producing final goods have to pay to purchase those (intermediate) capital goods. Firms producing different capital goods make use of final goods, transforming them in an innovative way into new capital goods. Making use of the available stock of knowledge, they invest in research and development and develop a unique, new "innovative" capital good.

Because of its uniqueness, the firm can charge a monopoly price that is a price in excess of the marginal costs. The firm charges a price above the marginal costs and makes a 
profit. This is the incentive to innovate and to produce new intermediate capital goods. The innovative firm $i$ has the following production function:

$$
K_{i}=\gamma Y_{i}
$$

For $K_{i}$ capital goods, the firm needs $\gamma Y_{i}$ final goods where $\gamma$ tells us how many final goods are needed for 1 capital good. Note that this production function is linear and exhibits constant returns to scale. For simplicity we set $\gamma=1$. Now we can formulate the profit function for a firm producing intermediate capital goods:

$$
\pi_{i}=p_{i} K_{i}-K_{i}
$$

In case the production function is twice differentiable than from equation (2.38) the relation between the variables $p_{i}$ and $K_{i}$ can be derived. In our case this results in the demand or inverse demand curve for capital goods. Using this we formulate the following inverse demand relation; $p_{i}=p_{i}\left(K_{i}\right)$, that is the price of capital goods depends on the amount of capital goods. Reformulating the profit function as $\pi_{i}=\left[p_{i}\left(K_{i}\right)-1\right] K_{i}$ we can derive the output level which maximizes the profit of the firm. Setting the first derivate with respect to output of capital goods $\left(K_{i}\right)$ equal to zero results in the following price relation; $p_{i}=\frac{1}{1-\frac{1}{\varepsilon_{d}}}$.

Here $\varepsilon_{d}$ is the price elasticity of demand of capital good $i$. Note that if the price exceeds that of the marginal costs, which equals 1 (for one new capital good one unit of final good at a price of one is used), then profits are $\left(p_{i}-1\right) K_{i}$. This profit is used to invest in research and development.

The market for intermediate capital goods is a market of monopolistic competition. This means that there are many firms (the competition part), all supplying a unique capital good (the monopolistic part). An important feature of this model is that firms are symmetric, which means that all different capital goods have the same price $\left(p_{i}=p\right.$ for $\left.i=1, \ldots, N\right)$ and the firms produce different capital goods in the same amount $\left(K_{i}=K\right.$ for $\left.i=1, \ldots, N\right)$. That is, for a given number of different capital goods, the economy's capital stock equals $\sum_{i=1}^{N_{t}} K_{i}=N_{t} K$. Because of the symmetry between firms producing capital goods, their output is the same, which at equilibrium equals $K$. Over time the capital stock only changes as a 
result of new types of capital goods, that is $\sum_{i=1}^{N_{t+1}} K_{i}=N_{t+1} K$. An other important feature is that firms will invest in innovation as long as it is profitable.

If we look at the aggregate economy we see that the number of different capital goods increases over time. This results in the following aggregate production function:

$$
Y_{t}=F\left(L, \sum_{i=1}^{N_{t}} K_{i}\right) \text { or } Y_{t}=N_{t} F(L, K)
$$

The capital stock of all types of capital goods is in equilibrium thus we can write the following AK type of production function:

$$
Y_{t}=\bar{A} N_{t}
$$

where $\bar{A}$ depends on the equilibrium values of the capital stock and labour, where the later one we have assumed to be fixed ${ }^{39}$.

Here we used the fact that the production function is homogeneous of degree one in labour and capital consisting of all different types of intermediate capital goods. Note that this equals the neo classical growth theory, where growth is determined by exogenous technological progress $\left(A_{t}\right)$ but here it is determined by endogenously developed new varieties of capital goods $\left(N_{t}\right)$. Capital stock per type is in equilibrium, but the number of types is increasing.

The positive externality is caused by the fact that the variety of intermediate capital goods is increasing over time $N_{t+1}=(1+g) N_{t}$, resulting from R\&D. For R\&D, however, resources in terms of output are necessary. This relation can be formulated as follows:

$$
\Delta N_{t}=\theta Z_{t}
$$

This states that resources invested in research and development $\left(Z_{t}\right)$ lead to new types of capital goods $\left(\Delta N_{t}\right)$. The parameter $\theta$ is an indicator of the efficiency of the research sector.

\footnotetext{
${ }^{39}$ In equilibrium Capital stock and Labour are fixed, so we can write. $F\left(K_{2} L\right)=\bar{A}$ In case of a Cobb-Douglas structure of the production function (2.39) we have $\bar{A}=\frac{K}{\alpha^{2}}$ and the equilibrium value of the capital stock equals $K=\alpha^{\frac{2}{1-\alpha}} L$, see chapter 3 and appendix 5.
} 
Note that there is a linear relation between new types of capital goods and resources devoted to research.

Looking at the resource constraint for the economy, we see that total output can be used for consumption or for capital formation; that is, all types of capital good to be used for the next period's production, and for resources for research:

$$
Y_{t}=C_{t}+N_{t+1} K+Z_{t}
$$

Current savings are thus used for research, developing new types of capital goods and producing new capital goods for the next period output. Total production minus consumption equals the economy's savings which can be derived from equation $(2.41)^{40}$ :

$$
S_{t}=N_{t+1} K+\frac{1}{\theta} \Delta N_{t}
$$

We used equation (2.40) to substitute for resources used to do research and development.

Using the savings function derived from the OLG model of consumption behaviour, we find the following equation:

$$
S_{t}=\hat{s} L w_{t}=\hat{s}(1-\alpha) \bar{A} N_{t}
$$

Here we have assumed that wage income is a fixed share of total income as is the case with Cobb-Douglas production functions. We then have the following equation of motion and growth rate $^{41}$ :

$$
N_{t+1}=\frac{\theta \hat{s}(1-\alpha) \bar{A}+1}{\theta K+1} N_{t} \text { and } \frac{N_{t+1}}{N_{t}}=\frac{\theta \hat{s}(1-\alpha) \bar{A}+1}{\theta \alpha^{2} \bar{A}+1}=(1+g)
$$

The only variable depending on time is $N$, the number of types of capital goods. Now the growth rate of types of capital goods and thus output can be calculated. The labour force is

\footnotetext{
${ }^{40}$ From (2.41) we derive $S_{t}=Y_{t}-C_{t}=N_{t+1} K+Z_{t}$. Substituting $Z_{t}=\Delta N_{t}$ results in (2.42).

${ }^{41} N_{t+1} K+\frac{1}{\theta} \Delta N_{t}=\hat{s}(1-\alpha) \bar{A} N_{t}$. Substituting $\Delta N_{t}=N_{t+1}-N_{t}$ and rearranging we find

$N_{t+1} K+\frac{1}{\theta} N_{t+1}=\hat{s}(1-\alpha) \bar{A} N_{t}+\frac{1}{\theta} N_{t}$. Next substituting $K=\alpha^{2} \bar{A}$ results in equation (2.44).
} 
assumed to be fixed and the output of capital good producing firms $(K)$ is also fixed in equilibrium.

It can also be seen that the private rate of return on capital lies below the social rate of return, that is:

$$
\frac{\partial Y}{\partial K_{i}}=p_{i}=\frac{\partial Y}{\partial K}=p>\frac{\partial Y}{\partial K}=1^{42}
$$

The optimum level of private intermediate capital goods is determined by the equality between marginal product and marginal costs. The last equals the price that firms producing final goods have to pay. For the aggregate economy the marginal costs of intermediate goods equals one, the price in terms of the inputs of final goods. A higher marginal product is associated with a lower quantity because the marginal product of capital decreases as capital increases. Thus, $\frac{\partial Y}{\partial K}>\frac{\partial Y}{\partial K^{\prime}}$ which implies $K^{\prime}<K$. Note too that we are also dealing with pecuniary externalities. The price of intermediate capital goods exceeds that of the marginal costs.

\subsection{Institutions and Efficiency}

From 1975 onwards the importance of institutions for economic performance has been stressed by a number of authors including Williamson $(1975,2000)$ and North (1990). Recently, the relation between economic growth and institutional setting was highlighted by Acemoglu, Johnson and Robinson (2005). Dasgupta (2007, p. 26) notes that the accumulation of productive capital assets is only a proximate cause of prosperity; the real cause is progressive institutions, which according to him (p. 90) are public goods. Romer (2006, p. 144) also argues that institutional differences can be an important sources of income differences. He notes that such differences in income stems largely from differences in what Hall and Jones (1999) call social infrastructure. By this they mean institutions and government policies that determine the economic environment that supports production activities and encourages capital accumulation, skills acquisition, invention and technology transfer. According to Hall and Jones 'such a social infrastructure gets the prices right so that, in the language of North and Thomas (1973,), individuals capture the social returns to their actions as private returns.' Social institutions that protect the output of individual productive

\footnotetext{
${ }^{42}$ On aggregate we have aggregate private marginal product which is below the overall economy-wide marginal producer, that is $N \frac{\partial Y}{\partial K}=N p>N \frac{\partial Y}{\partial K}=N$.
} 
units from diversion are an essential component of a social infrastructure favourable to high levels of output per worker; they also align private and social returns to activities.

In general, public capital has often been ignored in the literature, although it is increasingly coming to be recognized that public investments are important for the growth of an economy, see for example the findings of Aschauer (1989a, 1989b, 1990), and Easterly and Rebelo (1993). An investigation of the impact of public goods and publicly financed private goods on growth can be found in Barro and Sala-i-Martin (1992). A critical, up-todate survey and review of the role of public capital and public investments can be found in De Haan \& Romp (2007). The idea is that there is a strong positive link between the comparative advantage of a region, the availability and productivity of public capital and institutional setting in regions. Investing in institutional settings such as jurisdictional structure, public safety and so on can lead to more efficient use of resources and generate positive externalities.

Obstfeld and Rogoff (1996, p. 460) state that one obstacle to convergence by otherwise identical economies, even under perfect capital mobility, is government tax policy. Further on (p. 460) they note that differences in tax rate could more broadly be interpreted as incorporating variations in the strength of property rights across countries. In their opinion, such variations in the strength of property rights are not only the result of differences in tax rates, but more generally can be attributed to differences in the institutional settings of different regions. Due to the public good characteristics of institutions, government investment in "public capital" also can have an influence by means of influencing the institutional setting. Barro and Sala-i-Martin (1995, p. 159) state that activities that maintain property rights, such as police services, courts and national defence, can instead be viewed as affecting the probability that people will retain rights to their goods and thereby have an incentive to accumulate capital for production. These findings suggest that there is a positive relation between property rights and economic growth, and in a broader context, public capital, institutional structure and maintenance of property rights. Investing in public capital to improve the institutional setting that maintains property rights, could enhance economic growth and economic performance.

Another important contribution on the role played by institutions in economic development is the one by Accemoglu et al. (2005), who looked at a number of former European colonies. They distinguished two types of colonial regimes and their institutions. If there was a high mortality rate, Europeans did not settle and the institutions that were created did not pay much attention to the protection of private property. If the mortality rate was low and they wanted to settle, European institutions were copied and the protection of property rights was well anchored. After the period of colonization the former group of colonies did worse with respect to economic development (many countries in Africa) whereas the latter group did much better (for example New Zealand and Australia). 
How do we incorporate the importance of institutions in this research? First, the above leads us to suspect that wage rate and return on capital are not (solely) determined by their marginal productivity but by institutional arrangements. There has been a long debate in the literature about marginal productivity theory and its limitations. See, for example, Robinson (1934,1953/54), ${ }^{43}$ Sraffa (1960), Pasinetti (1977), or Labini (1995). Along with the fact that institutions change very slowly (see for example Williamson (2000)), a neo classical production function, where labour and capital are perfectly substitutable, is not always the most appropriate. This motivates us to use a Leontief production function instead of the neo classical one ${ }^{44}$ to describe the economic process, in which production, income and income distribution are not determined by technical characteristics of the production function but by the institutional structure. This is especially relevant to chapter 5 where we analyze the impact of institutional differences. Appendix 3 looks at the various production functions and their characteristics.

Secondly, assuming that institutions do matter, investing in institutions can be used by regions in the competition game for firms. Although it is generally accepted that public goods can contribute to production and income and increase efficiency, public goods are seldom explicitly modelled as a productive source, where Romer (2004), Obstfeld and Rogoff (1969), Barro and Sala-i-Martin (1992, 1995), are exceptions. They take public goods as an input in the production function, and investigate the consequences for economic development. The availability of public goods, which is given for the firms, generates externalities and so it is a source of production for which firm do not have to pay directly.

In this research we assume that public goods generate positive externalities but at a decreasing rate. We also assume that there is some kind of rivalry, i.e. the more the private sector makes use of it, the less effective it becomes. This is sometimes labelled the congestion effect. To take this into account we use the ratio of public and private capital stock. If an economy becomes more advanced, a higher level of public goods is needed, and thus a higher level of public capital stock (Barro and Sala-i-Martin, 1992). This can be incorporated as follows in the firm $j$ 's production function (assuming constant labour force):

$$
Y_{j, t}=F\left(K_{j}, \hat{k}_{t} L_{j}, \frac{P_{t}}{K_{t}}\right)
$$

\footnotetext{
${ }^{43}$ Robinson (1934) states "To some writers the theory of marginal productivity appeared as a grand moral principle which showed that what a social class gets is, under natural law, what it contributes to the general output of industry".

${ }^{44}$ In principle we also could use the neoclassical production function, as will be seen in the next chapter.
} 
Here the inputs $K_{j}$ and $L_{j}$ are the firm's inputs whereas $\frac{P}{K}$ is the ratio between public capital stock $P$ and the aggregate private capital stock $\sum_{j=1}^{m} K_{j}=K$. This ratio is determined by the overall economy but it is given for the individual firm. As before the economies capital labour ratio equals $\hat{k}=\frac{K}{L}$. Because labour in constant and capital changes over time, but is given for firm $j$ the ratio is indexed with $t$. The production function exhibits constant returns to scale and is homogeneous of degree 1 in private capital and labour. Furthermore, public goods as a source of production are represented by the public capital stock, generating positive externalities but at a decreasing rate. The marginal products of labour and capital are positive but decreasing, and the marginal product of public capital is also positive but decreasing. ${ }^{45}$ As before, if the firm maximizes its profit, the (private) marginal product of labour and capital equals the wage rate and the rate of return on capital:

$$
\frac{\partial F}{\partial\left(\hat{k}_{t} L_{j}\right)} \frac{\partial\left(\hat{k}_{t} L_{j}\right)}{\partial L_{j}}-w_{t}=0
$$

and

$$
\frac{\partial F}{\partial K_{j}}-R=0
$$

As before, we have assumed that firms operate in a perfect competitive market so the overall wage rate and return on capital equals the firm's wage rate and return on capital. The positive externality resulting from public goods can be expressed by the marginal product of public capital given the private capital stock, that is:

$$
\frac{\partial F}{\partial P}>0 \text { and } \frac{\partial^{2} F}{\partial P^{2}}<0
$$

If we look at the economy on aggregate then the capital-labour ratio of the individual firm equals the economy-wide capital-labour ratio $\left(\hat{k}_{t}=\frac{K_{t}}{L}=\frac{K_{j, t}}{L_{j}}\right)$. The aggregate production function reduces to:

${ }_{45} \frac{\partial F}{\partial K_{j}}>0, \frac{\partial^{2} F}{\partial K_{j}^{2}}<0$ for all $K_{j}$ and $\frac{\partial F}{\partial L_{j}}>0, \frac{\partial^{2} F}{\partial L_{j}^{2}}<0$ for all $L_{j}$ and $\frac{\partial F}{\partial P}>0, \frac{\partial^{2} F}{\partial P^{2}}<0$ which means that the marginal products of capital and labour and public goods are positive but decreasing. 


$$
Y_{t}=A K_{t} G\left(\frac{P_{t}}{K_{t}}\right)
$$

The ratio between public and private capital is constant in equilibrium, and the same approach as in section (2.1.6) can be used.

The aggregate production function is homogeneous of degree 1 and exhibits constant returns to scale in public and private capital. From the aggregate production function above we can derive the social return of private capital and the social rate of public capital. These are, respectively:

$$
\frac{\partial Y_{t}}{\partial K_{t}}=A \frac{\partial G}{\partial K_{t}}>0
$$

and

$$
\frac{\partial Y_{t}}{\partial P_{t}}=A \frac{\partial G}{\partial P_{t}}>0
$$

The optimal level of public capital can also be derived from the second equation. If the government is restricted to balancing its budget and if the current period's tax revenues result in the next period's public capital stock, the optimum level is where the marginal benefits equal the marginal costs; ${ }^{46}$ that is, $A \frac{\partial G}{\partial P_{t}}=\tau$ (see Barro \& Sala-i-Martin,1992, pp. 648-651).

Besides that, the ratio public capital private capital is fixed, so the aggregate production function can reduce to the production function of the previous section. Using the equation of motion for private and public capital we have:

$$
S_{t}=\hat{s}(1-\alpha)(1-\tau) Y_{t}=K_{t+1} \quad \text { private capital }
$$

and

$$
T_{t}=\tau(1-\alpha) Y_{t}=P_{t+1} \quad \text { public capital }
$$

The second equation is the balanced budget of the government, which we could also label the equation of motion of public capital. The ratio between public and private capital then reduces

\footnotetext{
${ }^{46}$ Note that in case of a balanced budget we have $P_{t}=\tau Y_{t}$. The marginal costs of $P_{t}$ are thus $\tau$ and the benefits are the marginal product of $P_{t}$.
} 
to $\frac{P_{t+1}}{K_{t+1}}=\frac{\tau}{\hat{s}(1-\tau)}=\frac{P_{t}}{K_{t}}$. Using this result and inserting this in the above production function, it reduces to:

$$
Y_{t}=\hat{A} K_{t} \text { with } \hat{A}=A G\left(\frac{\tau}{\hat{s}(1-\tau)}\right)
$$

As noted the results coincide with those derived in the previous section (2.1.6). Building on that section and using the equation of motion (2.17) we find the following equation of motion and growth rate of the regional economy with public capital:

$$
S_{t}=\hat{s}(1-\alpha)(1-\tau) \hat{A} K_{t}=K_{t+1}
$$

This in turn gives us the following growth factor of capital and income ${ }^{47}$ :

$$
\frac{K_{t+1}}{K_{t}}=\hat{s}(1-\alpha)(1-\tau) \hat{A}=\frac{Y_{t+1}}{Y_{t}}
$$

where the growth rate of capital equals the growth rate of income.

\subsection{Conclusions: Review of Assumptions}

To conclude this chapter we present a review of the assumptions that apply to the four subsequent chapters. The following general assumptions are used throughout the research. First of all regions differ in their comparative advantage and they interact. Besides that, there is free trade between regions (enabling technology transfers across regions) and there is freedom of (re-) location of firms across regions and there is low labour mobility across regions. Summarizing, the following assumptions are used in the specific chapters.

${ }^{47}$ From equation (2.52) we see that $\frac{K_{t+1}}{K_{t}}=\frac{Y_{t+1}}{Y_{t}}$. 


\section{Table 2.1 Review of Assumptions}

\begin{tabular}{|l|l|l|l|l|}
\hline & Ch 3 & Ch 4 & Ch 5 & Ch 6 \\
\hline Capital mobility & No (autarchy) & No (autarchy) & Yes & Yes \\
\hline Competition for; & Firms & $\begin{array}{l}\text { Innovative } \\
\text { Firms }\end{array}$ & Firms & Firms \\
\hline $\begin{array}{l}\text { Production } \\
\text { Function }\end{array}$ & $\begin{array}{l}\text { Neo-Classical } \\
\text { Cobb-Douglas }\end{array}$ & $\begin{array}{l}\text { Neo-Classical } \\
\text { Cobb-Douglas }\end{array}$ & $\begin{array}{l}\text { Keynesian } \\
\text { Leontief }\end{array}$ & $\begin{array}{l}\text { Neo-Classical } \\
\text { Cobb-Douglas }\end{array}$ \\
\hline Externalities & $\begin{array}{l}\text { Exogenous } \\
\text { Technical } \\
\text { progress }\end{array}$ & $\begin{array}{l}\text { Endogenous } \\
\text { Technical } \\
\text { progress }\end{array}$ & $\begin{array}{l}\text { Exogenous } \\
\text { Technical } \\
\text { progress }\end{array}$ & $\begin{array}{l}\text { Endogenous } \\
\text { Technical } \\
\text { progress } \\
\text { Public Private } \\
\text { Capital and } \\
\text { Learning by } \\
\text { Doing }\end{array}$ \\
\hline Institutions & $\begin{array}{l}\text { Given part of } \\
\text { comparative } \\
\text { advantage }\end{array}$ & $\begin{array}{l}\text { Given part of } \\
\text { comparative } \\
\text { advantage }\end{array}$ & $\begin{array}{l}\text { Determine } \\
\text { factor } \\
\text { remunerations }\end{array}$ & $\begin{array}{l}\text { Public Goods } \\
\text { with } \\
\text { externalities }\end{array}$ \\
\hline Liability & $\begin{array}{l}\text { Full / Limited } \\
\text { Liability }\end{array}$ & Full Liability & Full Liability & Full Liability \\
\hline No of Regions & $2, n$ & 2 & 2 & 2 \\
\hline
\end{tabular}





\section{Chapter 3}

Competition between Regions 


\subsection{Introduction}

This chapter starts by answering sub-question 2: 'What are the consequences of regional competition for efficiency?' The chapter is structured as follows. In section 3.1 we discuss firms' behaviour and their decisions to settle in a specific region. In order to attract firms, regions have to invest resources. We note that these public investments are sometimes made in advance, i.e. prior to a firm's decision to settle in the region. Sometimes these investments are made after the firm made its decision. The first case we call the full liability case, whereas we call the second one the limited liability case. In general, both kinds of investments are involved in regions' policies to attract firms.

We focus on the full liability case in section 3.2, first analyzing competition between two regions before extending the analysis to $n$ regions. Additionally (in sub-section 3.2.5), for the full liability case we analyze the effect of intergovernmental grants in support of less competitive regions.

Section 3.3 deals with the limited liability case, again for two regions initially and then for $n$ regions and section 3.4 summarizes the results of the analyses and offers conclusions.

\subsubsection{Firm Behaviour and the Decision where to Settle}

Before discussing how regions behave and compete, we have to determine what they actually compete for. What is the incentive? What is to be gained from competing? Obviously, from a public perspective, the gain is the firm's contribution to regional welfare and development, in terms of additional output, employment and income generated by the firm.

From the firm's perspective, profit is the most important factor in the decision to (re)locate. (Recall that, we assume that firms maximize profits and/or minimize costs.). If regions are identical then the firm can settle anywhere. The costs and profits are equal across all regions. Clearly this is seldom the case in reality. Regions differ in many ways, which can result in a firm having different costs and profit opportunities, which in turn leads to a region enjoying a comparative advantage. We use the parameter $\mu_{i}$ to express this comparative advantage, which is different for every region. In this and the next chapter comparative advantages are treated as exogenous to both the regions involved and to the firm that settles in a region. However, comparative advantages do influence the firm's decision on where to settle.

To see how the firm's decision on where to settle is influenced, we focus on the cost to the firm of a given level of output in different regions. The output of the representative firm is given by $Y_{j}$, the labour-input by $L_{j}$, the capital stock by $K_{j}$. This capital stock of firm $j$ in region $i$ consists of the private capital stock $K_{i, j}$, the specific investments of the regional 
government $e_{i}^{48}$, and the given comparative advantage of the region, $\mu_{i}$. This means that the privately financed part of capital stock of a new firm $j$ in region $i$, is given by $K_{i, j}=K_{j}-e_{i}-\mu_{i}$. Actually we should make use of $e_{i, j}$, which indicates the specific investment c.q. effort of region $i$ to attract firm $j$. We have assumed a fully competitive market, thus, all firms are identical and our analysis can be limited to one archetypical firm. This firm wants to minimize its production costs, where output, output prices as well as factor prices are given. The total cost to firm $j$, in region $i$, given its level of production, is given by:

$$
T C_{i, j}=R K_{i, j}+w L_{j}=R\left(K_{j}-e_{i}-\mu_{i}\right)+w L_{j}
$$

Here, $T C_{i, j}$ are the total costs of firm $j$ in region $i$, given a fixed output. The firm will choose the location where the total costs are lowest, given its fixed output. If a region does not support the firm with additional investments and subsidies $\left(e_{i}=0\right)$ then the firm will settle in the region with the highest comparative advantage, and this leads to a cost advantage. The firm will decide on region $i$ if $\mu_{i}>\mu_{\tau}$ for $\tau \neq i$ with $\mu_{\tau}$ being the comparative advantage of any other region except region $i$. From the efficiency point of view the firm's best choice then is to settle in region $i$ so production is done at minimum costs, that is $T C_{i, j}<T C_{\tau, j}$ which follows from the fact the region $i$ has a comparative advantage over region $\tau$, that is $\mu_{i}>\mu_{\tau}$.

If the regions compete by offering subsidies and investment, the decision on where to settle depends not only on the comparative advantage of the region but also on the specific investments offered by the region. The firm decides to settle in region $i$ if $e_{i}+\mu_{i}>e_{\tau}+\mu_{\tau}$, where $e_{\tau}$ are the firm-specific investments offered by the other competing regions. In other words, the firm will settle in region $i$ when, for a given output, it realizes the lowest cost and thus maximum profit. Note that even if a region has a lower comparative advantage it can attract firms by offering firm specific investments. Suppose that region $\tau$ offers a subsidy such that, $e_{\tau}+\mu_{\tau}>e_{i}+\mu_{i}$ and $\mu_{i}>\mu_{\tau}$ then the firm would settle in region $\tau$ because $T C_{\tau, j}<T C_{i, j}$. In this case production would not be done at minimum cost and this results in a welfare loss. From this it is easy to recognize that these kinds of policies can lead to distortions and inefficiencies. If a firm were to choose to settle in a region with a lower comparative advantage, it would not realize the least-cost combination, even though profits are maximized. Moreover, if regions apply these strategies (of competing by offering subsidies and investment) then specialization according the comparative advantage will not

\footnotetext{
${ }^{48}$ The symbol $e_{i}$ stands for effort level, the general term often used in this context.
} 
automatically occur. This process will also be distorted and potential efficiency gains due to specialization will probably not be (fully) utilized.

\subsubsection{Full Liability and Limited Liability ${ }^{49}$}

A region can offer a specific investment in order to attract firms. This firm-specific investment is sometimes referred to as "asset-specific" or "relation-specific" where we recall that an investment is said to be specific, i.e. there is asset specificity, when the investment has a higher value inside a specific relationship than outside it. Asset specificity is a measure of non-redeployability. Such investments are called sunk investments, therefore part of the costs are sunk into the relationship, i.e. cannot be recovered elsewhere (Hendrikse, 2003, p. 207). In case of specific investments, one of the trading agents will have to invest in order to increase efficiency or create an additional economic "surplus". In our case the region makes these kinds of investments to attract firms. These investments are of limited use if trading partners are changing. The investment used to attract a specific firm cannot be used to attract other firms; if the firm decides to settle elsewhere these investments are (partly) wasted.

An important problem is that these kinds of investments have high opportunity costs (i.e. a high value is foregone if the next best alternative is chosen). A high level of specific investment may lead to opportunistic behaviour. For example individuals are likely to be less than completely trustworthy in the sense that they may disguise preferences, distort them, deliberately confuse issues, et cetera, in order to gain advantage (Williamson, 1985, p. 47). The regional government involved will try to estimate the benefits of attracting a new firm, and compare them with the opportunity costs of the investments and subsidies. Although the opportunity costs of the specific investments are known, this is not the case with the benefits. A priori it is not certain that the firm will indeed settle in the region and the benefits are therefore uncertain. To express uncertainty about benefits we use the term 'expected pay-off', which can be defined as the weighted average of all the possible values of the pay-offs, using the probability as weights (Dixit, and Skeath, 1999, p. 169).

Let us recall that the contribution of the firm to the regional income and product can be described by the production function of a representative firm $j$ :

$$
Y_{j}=F\left(L_{j}, K_{j}\right)
$$

\footnotetext{
${ }^{49}$ Skaperdas and Gan (1996) use these terms to analyze the effect of risk behaviour of contestants on their level of effort. Our focus differs in that we use full liability for irreversible investments whatever the outcome of the contest is, and limited liability for reversible investments depending on the outcome of the contest.
} 
The production function fulfils the standard neoclassical assumptions. The output of the firm is given by $Y_{j}$, whereas the labour-input is denoted by $L_{j}$ and the capital-input by $K_{j}$. The output of the additional firm equals the increase of regional production and income:

$$
Y_{j}=\Delta Y=w L_{j}+R K_{j}
$$

Additional income consists of the labour employed by firm $j$ multiplied by the wage rate $(w)$ plus return on capital $(R)$ multiplied by the amount of capital used by firm $j .{ }^{50}$ Note that the same would apply if the firm were a monopolist. This also generates additional production, income and employment.

As was noted in the introduction, we distinguish two situations. In the first case is not certain whether a firm will indeed settle after the region has made its specific investments and the second case when specific investments have to be made after the firm has decided to settle in the region. We therefore analyze two different kinds of competition games. The first deals with the case where regions make firm-specific investments without knowing whether or not the firm will settle in the region. This means that all competing regions pay for the investments but only one region will win and receive the additional regional product. In the introduction to this chapter we labelled this kind of competition the full liability case. The pay-off of specific investment in case of full liability equals the expected gains minus the investment costs. The resulting expected net pay-off for region $i$ in case of full liability will amount to:

$$
E\left(P O_{i}\right)=\operatorname{Pr}_{i}\left(e_{i}, e_{-i}\right) \Delta Y-e_{i}
$$

Where $e_{-i}$ is the total effort level of all other competing regions, that is $e_{-i}=\sum_{j=1}^{n} e_{j}$, for $j \neq i$ $E$ is the operator expressing the mathematical expectation of a variable, $P O_{i}$, which is the net pay-off for region $i$, and $\operatorname{Pr}_{i}$ is the probability that a new firm will settle in region $i$, depending positively on the effort level of region $i\left(e_{i}\right)$ and negatively on the effort levels of all $n$ competing regions $\left(e_{i}+e_{-i}=\sum_{i=1}^{n} e_{i}\right)$. From equation (3.3) it is clear that the benefits, the

\footnotetext{
${ }^{50}$ Because of the assumption of perfect competition, the wage rate is the same for the regional economy and equals the marginal product of labour. The return on capital consists of interest plus depreciation. This is the same for the whole economy and equals the marginal product of capital. In case of a Cobb-Douglas production function this equals $w L_{j}=(1-\alpha) Y_{j}$ and $R K_{j}=\alpha Y_{j}$, where $(1-\alpha)$ is the income share of labour and $\alpha$ of capital.
} 
expected gain in terms of $\operatorname{Pr}_{i}\left(e_{i}, e_{-i}\right) \Delta Y$ are uncertain but not the costs (i.e. investment in terms of $e_{i}$ for the region). To determine the probability, $\operatorname{Pr}_{i}$, a Contest Success Function (CSF) is used, which was introduced in section 2.4. This CSF relates the probability of the new firm settling in a region to the specific investment of that region and to the specific investments of all competing regions. Interaction between regions is therefore incorporated by means of the CSF. The variable $e_{i}$ represents the opportunity costs of the specific investments of region $i$. These are sunk costs; that is, as soon as the region has invested they cannot be used, or only partly, to attract other firms.

In the second case, the limited liability case, the regions only offer a subsidy or specific investment to the courted firm after the location decision has been made. Of course, terms and conditions are subject to prior bargaining between the firm and the regional government. Only the winning region $i$ has to pay for the investments and subsidies if the firm decides to settle in region $i$. The expected pay-off in the limited liability case becomes:

$$
E\left(P O_{i}\right)=\operatorname{Pr}_{i}\left(e_{i}, e_{-i}\right)\left(\Delta Y-e_{i}\right)
$$

If the firm settles, then benefits accrue, but investments also have to be made. This is expressed in the second term of the equation above $\left(\Delta Y-e_{i}\right)$. The probability that the firm will settle depends on the relative effort, investments of the region, which is expressed in the first term of the equation. From the equation above it is clear that there are no costs if there are no benefits. In this way the equation differs from the full liability case, where playing the game is always costly and independent of the game's outcome. With limited liability, if the game is lost there are no costs associated with it, so playing the game is - in a sense costless. By looking at both kinds of competition separately we can highlight specific aspects of both kinds of competition. We start with the full liability case in the following section.

\subsection{Regional Competition: The Full Liability Case}

In this section we extend the previous one by incorporating the Contest Success Function. As was explained in chapter 2, the contest success sunction (CSF) shows how probabilities of winning vary with the different levels of effort exerted by agents potentially engaged in contest. The introduction of the CSF has two purposes. First, it specifies the probability that the firm will settle in the region and secondly it enables us to model interaction between regions. This is accomplished by relating the probability of the firm's settlement in the region to the investments of the respective region and that of competing regions. We also incorporate the effect of a region's comparative advantage. Given the same level of investments, the 
probability that the firm will settle in the region with a comparative advantage is greater than the probability it will settle in the other region(s).

We use the following probability function or contest success function, in ratio form, which is taken from Tullock (1980):

$$
\operatorname{Pr}_{i}\left(e_{i}, e_{-i}\right)=\frac{e_{i}+\mu_{i}}{\sum_{k=1}^{n}\left(e_{k}+\mu_{k}\right)} \text { for } i=1, \ldots, n
$$

If we rewrite the above equation in terms of $\widetilde{e}_{i}=e_{i}+\mu_{i}$, then we have the following:

$$
\operatorname{Pr}_{i}\left(\widetilde{e}_{i}, \widetilde{e}_{-i}\right)=\frac{\widetilde{e}_{i}}{\sum_{k=1}^{n} \widetilde{e}_{k}}=\frac{\widetilde{e}_{i}}{\widetilde{e}_{i}+\widetilde{e}_{-i}} \text { for } i=1, \ldots, n
$$

Where $\widetilde{e}_{-i}$ is the total effort level of all other competing regions, that is $\widetilde{e}_{-i}=\sum_{k=1}^{n} \widetilde{e}_{k}$, for $k \neq i$ In doing so the contest game can be written as a symmetric contest game, which simplifies the analyses. If there are $n$ competing regions, then $\mu_{i}$ is the comparative advantage of the competing region, with $i=1, \ldots, n$. Equations (3.5A) and (3.5B) show that the probability of a firm's settlement in a region depends on the relative effort. Put differently, the probability of a firm's settlement in region $i$ depends on the comparative advantage plus the effort level, that is $\left(e_{i}+u_{i}\right)$, offered to the firm compared with the comparative advantage plus the effort levels, that is $\sum_{k=1}^{n}\left(e_{k}+\mu_{k}\right)$, of all competing regions. In this setting, the term $\widetilde{e}_{i}=e_{i}+\mu_{i}$ is sometimes also known as the effective investment or effective effort level (Rai and Sarin, 2009, pp. 141-142). These effective effort levels determine the winning probabilities, or the ratio of winning probabilities of any two agents is thus equal to the ratio of their effective investments. Now we can determine the expected pay-off of the competition game of region $i$. Using equation (3.3) in combination with (3.5A) the expected pay off for region $i$ is as follows:

$$
E\left(P O_{i}\right)=\frac{e_{i}+\mu_{i}}{\sum_{k=1}^{n}\left(e_{k}+\mu_{k}\right)} \Delta Y-e_{i} \text { for } i=1, \ldots, n
$$


From equation (3.6) we can infer the support the regional government is willing to offer to the firm. If we assume that regional government wants to increase the regional output by attracting firms, it maximizes the expected pay-off with respect to the firm-specific investments. To see how this works we start with two competing regions (section 3.2.1) and subsequently extend the analysis to $n$ competing regions (section 3.2.3).

\subsubsection{Competition between Two Regions}

We start by describing the competition game between $t w o$ regions, 1 and 2 . If regions do not compete, that is, their effort levels equal zero $\left(e_{1}=e_{2}=0\right)$, then the firm will decide on the region with highest profits or lowest costs, that is, the region with the highest comparative advantage. In our case the firm will decide on region 1 because $\mu_{1}>\mu_{2}$ and therefore costs to the firm are lowest. To take this aspect into account we have to specify the CFS of (3.6). For

two competing regions this results in: $\operatorname{Pr}_{1}\left(e_{1}+\mu_{1}, e_{2}+\mu_{2}\right)=\frac{e_{1}+\mu_{1}}{\left(e_{1}+\mu_{1}\right)+\left(e_{2}+\mu_{2}\right)}>0$ for $e_{1}, e_{2}>0$. In case there is no competition the firm will settle in region 1 , which has the highest comparative advantage and lowest costs, thus for $e_{2}=e_{1}=0$ we have: $\operatorname{Pr}_{1}\left(e_{1}+\mu_{1}, e_{2}+\mu_{2}\right)=$ $\frac{e_{1}+\mu_{1}}{\left(e_{1}+\mu_{1}\right)+\left(e_{2}+\mu_{2}\right)}=1$. The firm settles in the region with a comparative advantage and it maximizes its profits.

The competition game starts when a region invests in efforts to attract the courted firm. The other competing region applies the same strategy to attract the firm, so the regions are uncertain where the new firm will settle. Each competing region knows the other's pay-off function, which leads to the following maximization problem of the two competing regions:

$$
\max _{e_{1}}\left\lfloor\frac{e_{1}+\mu_{1}}{\left(e_{1}+\mu_{1}\right)+\left(e_{2}+\mu_{2}\right)} \Delta Y-e_{1}\right\rfloor
$$

and

$$
\max _{e_{2}}\left\lfloor\frac{e_{2}+\mu_{2}}{\left(e_{1}+\mu_{1}\right)+\left(e_{2}+\mu_{2}\right)} \Delta Y-e_{2}\right\rfloor
$$

Note that the regions differ in their comparative advantage. For simplicity we assume region 1 has a comparative advantage, i.e., $\mu_{1}>\mu_{2}$.If we take the first derivative with respect to $e_{1}, e_{2}$ and apply the first-order conditions we get the following result ${ }^{51}$ :

\footnotetext{
${ }^{51}$ See appendix 2.
} 


$$
e_{1}+\mu_{1}=-e_{2}-\mu_{2}+\sqrt{\Delta Y\left(e_{2}+\mu_{2}\right)}
$$

and

$$
e_{2}+\mu_{2}=-e_{1}-\mu_{1}+\sqrt{\Delta Y\left(e_{1}+\mu_{1}\right)}
$$

The second term on the right always exceeds that of the first term, because we only consider positive levels of effort (see below equations (3.8)). Equations (3.9) are the best response functions of regions 1 and 2. The equations tell the regions what their best response is, in terms of effort level given the optimal effort level of the competing region. Region 1's best response $\left(e_{1}\right)$ depends on the gains from attracting firms, $\Delta Y$, the effort level, $e_{2}$, of the competing region and on the comparative advantage $\left(\mu_{1}\right)$ and that of the competing region 2 $\left(\mu_{2}\right)$.Using the two best response functions of the two regions we can determine the equilibrium effort levels of the regions 1 and $2^{52}$ :

$$
e_{1}^{*}=\frac{\Delta Y}{4}-\mu_{1} \geq 0
$$

and

$$
e_{2}^{*}=\frac{\Delta Y}{4}-\mu_{2}>0
$$

Equations (3.8) represent the equilibrium effort level of region 1 and 2. This effort level leads to the maximum expected pay-off of attracting a firm. Any other level of effort will lead to a lower expected pay-off. At these levels, $e_{1}{ }^{*}, e_{2}{ }^{*}$ neither of the two players will change its effort levels because every change (greater or lesser effort) will lead to a lower expected pay-off ${ }^{53}$. Note that from equations (3.9) we have $e_{1}^{*}+\mu_{1}=\frac{\Delta Y}{4}=e_{2}{ }^{*}+\mu_{2}$; that is, the effective investment thus effort levels plus comparative advantage are the same for the two regions but the investments in effort differ $\left(e_{2}^{*}>e_{1}^{*}\right)$ due to a difference in comparative advantage $\left(\mu_{1}>\mu_{2}\right)$. The optimal effort levels, $e_{1}^{*}$ and $e_{2}^{*}$, depend on the gains of attracting a firm $(\Delta Y)$, and the comparative advantage of the region $\left(\mu_{1}, \mu_{2}\right)$. A region will only invest if the expected pay-off of attracting the firm increases. The easiest way to see the consequences of a

\footnotetext{
${ }^{52}$ From equations (3.7) we can see that $\left(e_{1}+\mu_{1}\right)=\left(e_{2}+\mu_{2}\right)$. Substituting in one of the equations results in

$2\left(e_{1}+\mu_{1}\right)=\sqrt{\Delta Y\left(e_{1}+\mu_{1}\right)}$ and squaring gives $4\left(e_{1}+\mu_{1}\right)^{2}=\Delta Y\left(e_{1}+\mu_{1}\right)$ thus we have $\left(e_{1}+\mu_{1}\right)=\frac{\Delta Y}{4}$.

${ }^{53}$ We have assumed that the effort level of the competitor is positive; that is, it will facilitate the firm one way or another, for which resources are used. In principle this could also be negative, for example when firms bribe the regions to be allowed to settle.
} 
difference in comparative advantage is to assume region 2 has no comparative advantage. If $\mu_{2}=0$ we have $e_{1}^{*}+\mu_{1}=e_{2}{ }^{*}$ and the comparative advantage of region 1 is compensated by the effort level of region 2 .

What are the consequences of this kind of competition between regions? Using equations (3.4A) the probability that each region will win the contest after competition becomes ${ }^{54}$ :

$$
\operatorname{Pr}_{1}^{*}=\operatorname{Pr}_{2}^{*}=\operatorname{Pr}^{*}=\frac{1}{2}
$$

Here Pr is short for probability. This means that the comparative advantage of region 1 is counterbalanced by the investments made by region 2. Before competition, the firm would have chosen region 1 because of its comparative advantage, and the cost advantage to the firm of settling in this region. After competition the firm is indifferent between region 1 and 2. By introducing competition the probability of winning the competition is the same for both regions, although region 1 has a comparative advantage with regard to the given infrastructure. Both regions have a 50\% probability of attracting the firm. The effort level of the competitor, in our case region 2 , has to be positive otherwise there is no competition.. This need not be the case for region 1: due to its comparative advantage the effort level can still equal 0 . Thus we have $\frac{\Delta Y}{4} \geq \mu_{1}>\mu_{2}$. The net pay-off of region 1 is always higher than the net pay-off of region 2. The level of investment of region 2 exceeds that of region 1, due to the comparative advantage of region 1 , that is $e_{2}{ }^{*}>e_{1}{ }^{*}$. The probability of attracting the firm is the same for the two regions, namely $\frac{1}{2}, 55$ and it is uncertain where the firm will settle. From the firm's viewpoint it makes no difference where it settles, since profits are the same in the two regions. From the perspective of efficiency, however, it does make a difference because settling in region 2 does not result in a least-cost combination.

$$
\begin{aligned}
& { }^{54} \text { In equilibrium we have }\left(e_{1}+\mu_{1}\right)=\left(e_{2}+\mu_{2}\right) \text { and thus: } \operatorname{Pr}_{1}=\frac{e_{1}+\mu_{1}}{\left(e_{1}+\mu_{1}\right)+\left(e_{2}+\mu_{2}\right)}=\frac{1}{2}=\text { and } \\
& \operatorname{Pr}_{2}=\frac{e_{2}+\mu_{2}}{\left(e_{1}+\mu_{1}\right)+\left(e_{2}+\mu_{2}\right)}=\frac{1}{2} . \\
& { }^{55} \text { Equation (2.13) for region } 1 \text { becomes } E\left(P O_{1}\right)=\frac{e_{1}+\mu_{1}}{\left(e_{1}+\mu_{1}\right)+\left(e_{2}+\mu_{2}\right)} \Delta Y-e_{1}=\frac{1}{2} \Delta Y-e_{1} \text { and for } \\
& \text { region } 2 \text { we have } E\left(P O_{2}\right)=\frac{e_{2}+\mu_{2}}{\left(e_{1}+\mu_{1}\right)+\left(e_{2}+\mu_{2}\right)} \Delta Y-e_{2}=\frac{1}{2} \Delta Y-e_{2} .
\end{aligned}
$$


To illustrate the above we use the following figure to depict the best response curves. We have assumed that region 1 has a comparative advantage over region 2 . The equilibrium values of level of investment of the two regions are given by the intersection of the two best response curves.

Figure 3.1 Best Response Functions (Full Liability) $\quad \mu_{1}>0, \mu_{2}=0$

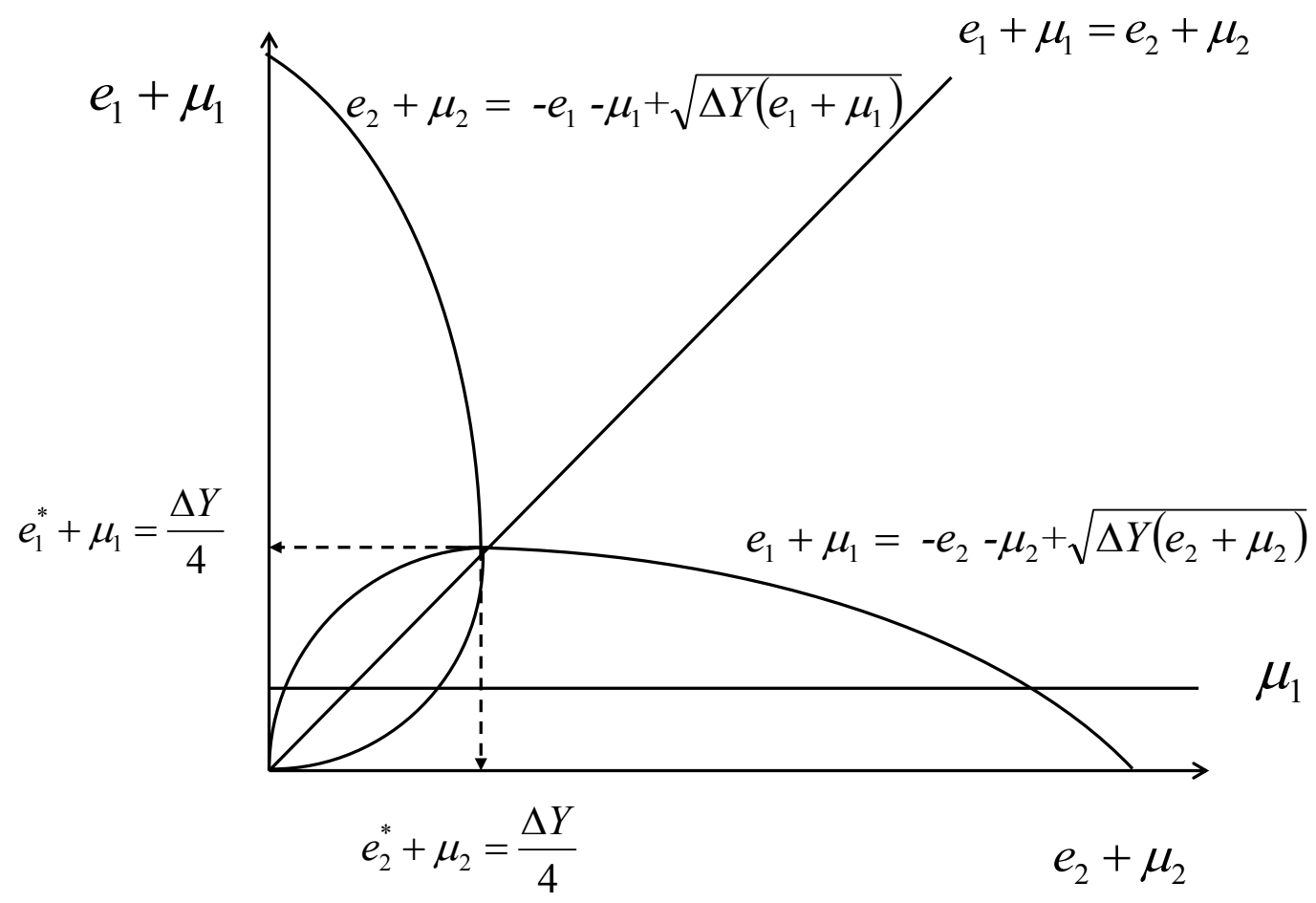

Having described the competition game we come to the following conclusion:

Introducing competition between regions will not lead to an increase of overall efficiency but it will decrease overall efficiency.

First, due to competition it is possible that a firm will not settle in the region with the comparative advantage and so a least-cost combination will not be attained. This is caused by the fact that the cost disadvantage of the firm can be compensated by specific investment so that the firm's profits are the same wherever it decides to settle. Without competition this would not have been possible. The firm would have chosen the region with a cost advantage. Second, parts of the specific investments made by regions are wasted. One region wins the game and there is always at least one region that loses the game and its investment. Only the firm increases its profits. We therefore arrive at the following proposition: 


\section{Lemma 3.1:}

If $\frac{\Delta Y}{4}>\mu_{1}>\mu_{2}$, then $e_{1}^{*}<e_{2}^{*}$ and $\operatorname{Pr}_{1}=\operatorname{Pr}_{2}=\operatorname{Pr}=\frac{1}{2}$.

\section{Proposition 3.1:}

If two regions invest in efforts to compete, the firm becomes indifferent to where it settles because the costs are the same regardless of the region chosen.

\section{Proof:}

The revenues are the same for the firm wherever it settles. Inserting equilibrium values $e_{1}^{*}$ and $e_{2}^{*}(3.8)$ in the cost function (3.1) of the firm for region 1 and 2 we find:

$T C_{1}=R K_{1}+w L_{1}=R\left[K_{1}-\left(e^{*}{ }_{1}+\mu_{1}\right)\right]+w L_{1}$ and $T C_{2}=R K_{2}+w L_{2}=R\left[K_{2}-\left(e^{*}{ }_{2}+\mu_{2}\right)\right]+w L_{2}$. Because $e_{1}^{*}+\mu_{1}=e_{2}^{*}+\mu_{2}$, we have $T C_{1}=T C_{2}$.

For the new firm the costs and thus profits are the same in both regions. For the regions, however, the expected pay-off from the firm's settlement differs. This results from the fact that the disadvantaged region started the competition game by making firm-specific investments and region 1 anticipated this. The expected pay-off for both region 1 and 2 can be found by inserting the equilibrium values of specific investments, (3.8), in the expected payoff from equation (3.2). This leads to the following expected pay-off:

$$
E\left(P O_{1}^{*}\right)=\frac{1}{4} \Delta Y+\mu_{1}>E\left(P O_{2}^{*}\right)=\frac{1}{4} \Delta Y+\mu_{2}
$$

These are the expected gains from the competition game of the two regions. $E\left(P O^{*}\right)$ stands for expected pay-off to the region resulting from competition ( $E$ again is the mathematical symbol for expectation). The term $P O^{*}$ stands for the pay-off to the competing regions with the equilibrium effort level $\left(e^{*}\right)$ of the two competing regions. Region 1 has a comparative advantage over region 2 and the expected pay-off to region 1 exceeds that to region 2 , that is $E\left(P O_{1}^{*}\right)>E\left(P O_{2}^{*}\right)$ because $\mu_{1}>\mu_{2}$. Note that the expected pay-off to region 1 is less than the pay-off in case of no competition. The expected pay-off to region 2 in case of competition exceeds that of no competition, because $E\left(\mathrm{PO}_{2}^{*}\right)>E\left(\mathrm{PO}_{2}\right)=0^{56}$. This is the incentive for region 2 to start the competition game. What is the overall effect of competition? The overall effect is given by the gains to the firm when it settles, which equals $\Delta Y$ minus the effort of

\footnotetext{
${ }^{56}$ In case of no competition the firm will settle in region 1 and thus the expected pay-off of region 2 is zero, that is $E\left(\mathrm{PO}_{2}\right)=0$.
} 
the two regions, which equals $e_{1}^{*}+e^{*}{ }_{2}=\frac{\Delta Y}{2}-\mu_{1}-u_{2}$. The overall effect of competition between the two regions is that both regions invest in effort but the firm settles in one of the regions. Therefore the investment in effort by one of the regions is more or less wasted. The result is that the total pay-off to the two regions is $\left(\Delta Y-\left(e_{1}^{*}+e^{*}{ }_{2}\right)\right)$ compared to $\Delta Y$ when regions do not compete. Now we can look at the overall effects of competition between two regions.

\subsubsection{Efficiency Effects of Regional Competition}

For the overall effects of competition we have to compare the effect on efficiency for the two regions when they compete with no competition between the two regions. We therefore look at the increase of consumer surplus ( $\triangle C S$ ) and producer surplus $(\triangle P S)$ in both situations. The producer surplus increases thanks to the additional profits of the new firm, that is, $\Delta P S_{1}=e_{1}^{*}=\frac{\Delta Y}{4}-\mu_{1}$ if the firm settles in region 1 or $\Delta P S_{2}=e_{2}^{*}=\frac{\Delta Y}{4}-\mu_{2}$ if it settles in region 2. Assuming that specific investments made by the regions are financed by lump-sum taxes (leaving relative prices and consumer decisions unchanged), the consumer surplus is reduced by the effort level, that is ${ }^{57}, \Delta C S=-\left(e_{1}^{*}+e^{*}{ }_{2}\right)=-\left\lfloor\frac{\Delta Y}{2}-\mu_{1}-\mu_{2}\right\rfloor$. The total effect on efficiency depends on where the firm finally settles. If the firm settles respectively in region 1 or 2 this amounts to:

$$
\Delta P S_{1}+\Delta C S=-\frac{\Delta Y}{4}+\mu_{2}<0
$$

or

$$
\Delta P S_{2}+\Delta C S=-\frac{\Delta Y}{4}+\mu_{1}<0
$$

No matter where the firm finally settles, competition has a negative effect on efficiency, as can be seen from equations (3.12). This leads us to formulate the following proposition:

\section{Proposition 3.2:}

Competition between two regions to attract a firm will lead to a decrease in efficiency.

\footnotetext{
${ }^{57}$ For the two regions we have $\Delta C S_{1}=-e_{1}^{*}$ and $\Delta C S_{2}=-e_{2}^{*}$ and $\Delta C S=\Delta C S_{1}+\Delta C S_{2}$.
} 


\section{Proof:}

The probability that the firm will settle in region 1 or 2 is $50 \%$ if the regions compete. Thus one of the equations (3.12) will hold and thus there is always a loss in efficiency when regions compete.

In the next section we analyze competition between more than two regions. In general it is assumed in economics that the more firms that compete, the more the efficiency is increased. We want to investigate whether this also holds for competition between more regions.

\subsubsection{Competition between $n$ Regions}

In real life generally there are more than two regions competing to attract firms to enhance their regional development. In this section we investigate the general case with $n(n>2)$ competing regions. The condition $n \geq 2$ makes sense. We can only speak of competition if two ore more parties are involved.

Similar to the previous section, in this section we assume that regions differ in their comparative advantage: $\mu_{i}>\mu_{i+1}$ for $i=1, \ldots, n-1$. In the same way as in the previous section we can formulate the expected pay-off of region $i$ in case it has to compete with the other ( $n$ 1) competitors to attract a firm. We recall equation (3.2):

$$
E\left(P O_{i}\right)=\left(\frac{e_{i}+\mu_{i}}{\sum_{k}^{n}\left(e_{k}+\mu_{k}\right)}\right) \Delta Y-e_{i} \text { for } i=1, \ldots, n
$$

Now each of the $n$ competing regions has to maximize its expected net pay-off. We therefore have the following maximization problem of $n$ competing different regions:

$$
\max _{e_{i}}\left\lfloor\left\lfloor\frac{e_{i}+\mu_{i}}{\sum_{k}^{n}\left(e_{k}+\mu_{k}\right)}\right) \Delta Y-e_{i}\right\rfloor \text { for } i=1, \ldots, n
$$

This maximization problem results in $n$ first-order conditions. Combining these $n$ first-order conditions and solving for $e_{i}$ we find the equilibrium effort level for region $i$. The derivation of the optimal effort level can be found in appendix 2. The optimal effort level equals: 


$$
e_{i}^{*}=\frac{(n-1)}{n^{2}} \Delta Y-\mu_{i} \geq 0 \text { for } i=1, \ldots, n
$$

Negative optimal effort levels by regions make no sense, so $e_{i}^{*} \geq 0$ for $i=1, . ., n$. The term $\frac{(n-1)}{n^{2}}$ expresses the competition between regions because $n$ is the number of competing regions. Thus if the number of regions in competition with each other increases, we interpret this as an increase in competition. From (3.14) we notice that an increase in competition (n) has a negative effect on the optimal effort level $e_{i}^{*}{ }^{58}$ The effect of the number of competing regions in the denominator exceeds the effect of the number of regions in the numerator. This term decreases as the number of competing regions increases. The more competitors, the lower the probability of wining and the lower the expected gains, so therefore the lower is the effort level of an individual region. When the number of competitors $(n)$ increases, the optimal effort level $\left(e_{i}^{*}\right)$ decreases. Now it is possible to discover the consequences of an increase in competition, i.e. an increase of the number of competing regions. We can see that the effort level decreases if the number of competitors $(n)$ increases (see equation (3.14)). Formally we can see this by taking the derivative of $e_{i}^{*}$ with respect to $n^{59}$. This results in:

$$
\frac{\partial e_{i}^{*}}{\partial n}=\frac{(2-n)}{n^{3}} \Delta Y
$$

Using the above equation we can also see that the optimal effort level reaches its maximum at $n=2$. This means that if just two regions compete, the firm will receive maximum financial support in terms of effort level of the regions. Because competition starts with $n=2$ the second derivative is negative, ${ }^{60}$ and it is a maximum. We can conclude that an increase in competition will lead to a decrease of the specific investments offered by the competing

$$
\begin{aligned}
& { }^{58} \text { The term } \frac{(n-1)}{n^{2}} \text { decreases as } n \text { increases because the denominator is growing faster than the numerator, or in other } \\
& \text { words, } \lim _{n \rightarrow \infty} \frac{(n-1)}{n^{2}}=\lim _{n \rightarrow \infty}\left(\frac{1}{n}-\frac{1}{n^{2}}\right)=0 . \\
& { }_{59} \frac{\partial e_{i}^{*}}{\partial n}=\frac{\left(n^{2}-2 n^{2}+2 n\right)}{n^{4}} \Delta Y=\frac{n(2-n)}{n^{4}} \Delta Y . \\
& { }_{6} \frac{\partial^{2} e_{i}^{*}}{\partial n^{2}}=\frac{-n^{3}-3 n^{2}(2-n)}{n^{6}}=\frac{-n^{3}-6 n^{2}+3 n^{3}}{n^{6}}=\frac{2(n-3)}{n^{4}} \text { For } n=2 \text { we have } \frac{\partial^{2} e_{i}^{*}}{\partial n^{2}}<0 \text { which means } \\
& \text { it is a maximum. }
\end{aligned}
$$


regions because the sign of $\frac{\partial e_{i}^{*}}{\partial n}$ is negative for $n>2$. If the firm is aware of this, it will invite just two regions to play the competition game. This guarantees the firm a maximum specific investments. From equation (3.14) we can clearly see that the effective effort levels plus comparative advantage of all regions is the same. That is:

$$
e_{i}^{*}+\mu_{i}=e_{i+1}^{*}+\mu_{i+1} \text { for } i=1, \ldots, n-1
$$

From the above it is easy to see what the consequences are if $n$ different regions compete for a firm. First of all, using (3.16) and (3.4) we can calculate the equilibrium probability that a firm will settle in one of the $n$ competing regions. They are the same for all competing regions, namely:

$$
\operatorname{Pr}_{i}^{*}=\frac{e_{i}^{*}+\mu_{i}}{\sum_{k=1}^{n}\left(e_{k}^{*}+\mu_{k}\right)} \text { for } i=1, \ldots, n
$$

The effective effort level (effort level plus comparative advantage) is the same for all regions. We can easily calculate the probability that the firm will settle in one of the $n$ regions. Using equation (3.16) and substituting $n\left(e_{i}{ }^{*}+\mu_{i}\right)=\sum_{k=1}^{n}\left(e_{k}{ }^{*}+\mu_{k}\right)$ in equation (3.4) gives us the probability that the firm will settle in one of the $n$ competing regions:

$$
\operatorname{Pr}_{1}^{*}=\ldots=\operatorname{Pr}_{i}^{*}=\ldots . \operatorname{Pr}_{n}^{*}=\operatorname{Pr}^{*}=\frac{e_{i}^{*}+\mu_{i}}{n\left(e_{i}^{*}+\mu_{i}\right)}=\frac{1}{n}
$$

If the competition increases, by which we mean that more regions are competing ( $n$ increases) to attract a firm, the probability that the firm will settle in any given region decreases. The firm will not settle automatically in the region with the greatest comparative advantage where it had a cost advantage compared to the other regions. As in the two competing regions case, regions can compensate for their comparative disadvantage with investment in effort. Therefore we find:

\section{Lemma 3.2:}

If $\frac{(n-1) \Delta Y}{n^{2}} \geq \mu_{i} \geq \mu_{i+1}$ then $e_{i}^{*}<e_{i+1}^{*}$ and $\operatorname{Pr}^{*}{ }_{i}=\operatorname{Pr}^{*}{ }_{i+1}=\operatorname{Pr}^{*}=\frac{1}{n}$. for $i=1, \ldots, n-1$. 


\section{Proposition 3.3:}

If more than two different regions compete by investing in effort, the firm becomes indifferent where to settle because the costs to the firm are the same in all competing regions.

\section{Proof:}

From equation (3.16) we know that the effective effort level plus comparative advantage is the same for all competing regions, that is $e^{*}{ }_{i}+\mu_{i}=e^{*}{ }_{i+1}+\mu_{i+1}$, then $T C_{i}=T C_{i+1}=T C^{*}$ for $i=1, \ldots, n-1$. The total cost to the firm is the same regardless of the region it settles in.

\subsubsection{Effect of Increasing Competition between Regions}

Generally it is assumed that increasing competition will have a positive effect on efficiency. If we interpret an increase in competition as an increase in the number of competing regions, will this also lead to an increase in efficiency? If we look at equation (3.14) we can conclude that an increase in the number of competing regions leads to a lower effort level. On the other hand the number of competing regions will increase. To discover what the total effect is on efficiency we again look at the change in the producer surplus and the consumer surplus (of all competing regions).

All financial support in terms of investments in effort leads to a decrease in consumer surplus, assuming this investment is financed by lump sum taxes. For all $n$ regions taken together the total decrease of consumer's surplus equals:

$$
\Delta C S=\sum_{k=1}^{n} \Delta C S_{k}=-\sum_{k=1}^{n} e_{k}^{*}=-\left\lfloor\frac{n(n-1) \Delta Y}{n^{2}}-\sum_{k=1}^{n} \mu_{k}\right\rfloor
$$

If we look at the producer surplus we see that it increases, due to the additional profit of the firm resulting from investment in effort by the competing regions. If the firm settles in region $i$, the producer surplus thus increases by:

$$
\Delta P S_{i}=e_{i}^{*}=\frac{(n-1) \Delta Y}{n^{2}}-\mu_{i}
$$

It is easy to see that this leads to an overall decrease of efficiency if we look at the change of producer plus consumer surpluses: ${ }^{61}$

\footnotetext{
${ }^{61}$ Change in welfare equals change in consumer surplus plus change in producer surplus, which equals

$\Delta P S_{i}+\Delta C S=e_{i}^{*}-\sum_{k=1}^{n} e_{k}^{*}=-\sum_{k=1}^{n} e_{k}^{*}<0$ for $k \neq i$ because $e^{*}{ }_{k}>0$
} 


$$
\Delta P S_{i}+\Delta C S=-\left\lfloor\frac{(n-1)^{2}}{n^{2}} \Delta Y-\sum_{k=1}^{n} \mu_{k}\right\rfloor<0 \text { for } k \neq i
$$

The above result holds regardless of which region the firm eventually chooses. The overall effect of competition is always negative if efficiency is considered. The more (number of) regions that compete, the higher the welfare loss.

\section{Proposition 3.4:}

Competition between more than two different regions is never efficient. The inefficiency increases if the number of competing regions increases.

\section{Proof:}

From equation (3.20) we see that efficiency decreases because total of consumer surplus and producer surplus decreases if regions compete. The derivative from equation (3.20) with respect to $n$ equals $\frac{2(n-1)}{n^{3}}$ and is positive for $n>2$. Furthermore by assumption we have $\frac{(n-1)^{2}}{n^{2}} \Delta Y>\sum_{k=1}^{n} \mu_{k}$ for $k \neq i$, thus inefficiency is increasing $\left(\Delta P S_{i}+\Delta C S\right.$ is decreasing $)$ if $n$ is increasing. ${ }^{62}$

This increase in inefficiency is caused by the effect that (n-1) investments in effort leads to a decrease in efficiency. Note that if $n$ becomes large the optimal effort level decreases but this is outweighed by the number of competing regions and their total amount of investment in effort.

\subsubsection{Financial Support for a Competing Region: An Extension}

In the EU there are great differences in the economic performance of regions. As noted in the introduction, in order to stimulate less developed regions, EU regional policy has become a major instrument. The question is what impact financial support for competing regions has on the competition game.

To analyze this we modify the model. We assume that region 1 is the less competitive, less developed region that receives financial support. Moreover, we assume that part of its effort to attract economic activity is reimbursed, by structural funds for example: $S_{1}=(1-\lambda) e_{1}$ where $0 \leq \lambda \leq 1$, where $\lambda$ is the regions own contribution, the share it has to

\footnotetext{
${ }^{62}$ The derivative of (3.20) with respect to $n$ equals $\frac{2(n-1)}{n^{3}}>0$ for $n>2$.
} 
pay it self and $S_{1}$ is the financial support for region 1 . The costs of taking part in the competition game are reduced to $\lambda e_{1}$ and the expected gains remain unchanged. The expected net pay-off in case of financial support amounts to:

$$
E\left(P O_{1}\right)=\frac{e_{1}+\mu_{1}}{e_{1}+\mu_{1}+e_{2}+\mu_{2}} \Delta Y-\lambda e_{1}
$$

Following the same approach as before, the following two best response functions are calculated. ${ }^{63}$ For region 1 this results in:

$$
e_{1}=-e_{2}-\mu_{1}-\mu_{2}+\sqrt{\frac{\left(e_{2}+\mu_{2}\right) \Delta Y}{\lambda}}
$$

where for region 2 we have:

$$
e_{2}=-e_{1}-\mu_{1}-\mu_{2}+\sqrt{\left(e_{1}+\mu_{1}\right) \Delta Y}
$$

For the competing region 2 nothing changes if the other region is financially supported, as can be seen if we compare equation (3.7) with equation (3.E3). As we can see, the more financial support a region receives (the lower $\lambda$ ) the higher the investment in effort of region 1 to win the game. This is expressed in term of $\left(\sqrt{\frac{\left(e_{2}+\mu_{2}\right) \Delta Y}{\lambda}}\right)$ of equation (3.E2). In other words, region 1 increases its effort level because it is financially supported. From the first-order condition and the best response functions above we can derive the relation between the two effort levels, which is $e_{2}+\mu_{2}=\lambda\left(e_{1}+\mu_{1}\right)$. Using this and substituting it in the first-order conditions, the following optimal effort levels for the two regions are found: ${ }^{64}$

\footnotetext{
${ }^{63}$ We simplify the analyses by letting $e_{1}+\mu_{1}=\widetilde{e}_{1}$ and $e_{2}+\mu_{2}=\widetilde{e}_{2}$. It that is identical to a symmetric game. This results in the 2 FOC's. $\frac{\widetilde{e}_{2} \Delta Y}{\left(\widetilde{e}_{1}+\widetilde{e}_{2}\right)^{2}}=\lambda$ and $\frac{\widetilde{e}_{1} \Delta Y}{\left(\widetilde{e}_{1}+\widetilde{e}_{2}\right)^{2}}=1$ which leads to the following best response functions; $\left(\widetilde{e}_{1}+\widetilde{e}_{2}\right)^{2}=\frac{\widetilde{e}_{2} \Delta Y}{\lambda}$ which can be written as $\widetilde{e}_{1}=-\widetilde{e}_{2}+\sqrt{\frac{\widetilde{e}_{2} \Delta Y}{\lambda}}$ and $\left(\widetilde{e}_{1}+\widetilde{e}_{2}\right)^{2}=\widetilde{e}_{1} \Delta Y$ thus $\widetilde{e}_{2}=-\widetilde{e}_{1}+\sqrt{\widetilde{e}_{1} \Delta Y}$. Next substituting for $\widetilde{e}_{1}$ and $\widetilde{e}_{2}$ leads to the best response functions.

${ }^{64}$ Substituting for $\widetilde{e}_{2}=\lambda \widetilde{e}_{1}$ in $\frac{\widetilde{e}_{1} \Delta Y}{\left(\widetilde{e}_{1}+\widetilde{e}_{2}\right)^{2}}=1$ results in $\frac{\widetilde{e}_{1} \Delta Y}{\left[(1+\lambda) \widetilde{e}_{1}\right]^{2}}=1$ resulting in $\widetilde{e}_{1} \Delta Y=(1+\lambda)^{2} \widetilde{e}_{1}^{2}$ so $\widetilde{e}_{1}=\frac{\Delta Y}{(1+\lambda)^{2}}$ and $\widetilde{e}_{2}=\lambda \frac{\Delta Y}{(1+\lambda)^{2}}$. Substituting for $\widetilde{e}_{1}$ and $\widetilde{e}_{2}$ leads to the optimum equilibrium effort levels.
} 


$$
e^{\prime^{*}}=\frac{1}{(1+\lambda)^{2}} \Delta Y-\mu_{1}
$$

and

$$
e^{\prime^{*}}=\frac{\lambda}{(1+\lambda)^{2}} \Delta Y-\mu_{2}
$$

We used $e^{\prime}$ to indicate that the effort levels deviates from the results in the previous sections From the above results we can see that the optimal effort levels of the two regions has changed. If we compare the above results with the outcomes of section 3.2.1, equation (3.8) we see that $e^{*^{*}}{ }_{1}>e^{*}{ }_{1}$ because $\frac{1}{4}<\frac{1}{(1+\lambda)^{2}}<1$. Note that $0<\lambda<1$. The same kind of conclusion can be drawn for region 2 , namely $e^{\prime^{*}}{ }_{2}<e^{*}{ }_{2}$ because $0<\frac{\lambda}{(1+\lambda)^{2}}<\frac{1}{4}$. If we look at the effective effort level we see that $e^{\prime^{*}}{ }_{1}+\mu_{1}=\frac{1}{(1+\lambda)^{2}} \Delta Y>\frac{\lambda}{(1+\lambda)^{2}} \Delta Y=e^{\prime^{*}}{ }_{2}+\mu_{2}$. The probability of winning the game depends on the relative effort (see equation (3.4.)), and region 1's probability to attract the firm exceeds that of region 2 . We see that offering financial support to a region reduces competition, that is, it reduces the effort level of competing regions and increases the probability of attracting the firm. Finally, we can see when region 2 will abort competition. This is the case when $\frac{\lambda}{(1+\lambda)^{2}} \Delta Y-\mu_{2}=0$, then the effort level is reduced to zero. It can easily be seen that in case region 1 is fully supported, that is $\lambda=0$, region 2 will stop competing. However, region 1 need not fully be supported. Region 2 will stop its competition even if $\frac{\lambda}{(1+\lambda)^{2}} \Delta Y=\mu_{2}$. As long as region 2 has a comparative advantage, $\mu_{2}>0$ and the price of winning the game is positive, $\Delta Y>0$, there is some $0<\lambda<1$ which fulfils the above equality. This will also maximize the probability that firms will settle in region 1 , even without full compensation.

From the above it is clear that regional policy to financially support the less competitive region can be effective. It increases the probability that the less competitive region will attract firms, but not $100 \%$ (see equation (3.4)). This is despite the fact that the region does not receive full reimbursement for its investments in effort. The region itself should also contribute to the effort level, otherwise this can lead to additional inefficiencies. We have not analysed whether such a policy leads to inefficiencies in this research. 


\subsection{Regional Competition: The Limited Liability Case}

In this section we deal with the case in which specific investments are made by the region involved only if the firm has decided to settle in that region. Other regions, which lose the competition, do not actually have to make investments. The contest is now a competition with limited liability. The idea of the model goes back to Skaperdas and Gan (1995a, 1995b). We note that there are no efficiency losses. Only the winning region is committed to invest.

Because the structure of the competition game between the regions has changed, the expected net pay-off of attracting a firm also changes. Using equations (3.3) and (3.2) we can formulate the expected net pay-off for regional competition with limited liability ${ }^{65}$ : Using the contest success function of section 3.2 equations (3.4A) or (3.4B) this results in;

$$
E\left(P O_{i}\right)=\frac{e_{i}+\mu_{i}}{\sum_{k=1}^{n}\left(e_{k}+\mu_{k}\right)}\left[\Delta Y-e_{i}\right] \text { for } i=1, \ldots, n
$$

or

$$
E\left(P O_{i}\right)=\frac{\widetilde{e}_{i}}{\sum_{k=1}^{n}\left(\widetilde{e}_{k}\right)}\left[\Delta Y+\mu_{i}-\widetilde{e}_{i}\right] \text { for } i=1, \ldots, n
$$

If we compare this with the expected pay-off in the full liability case (see equation (3.8)) we see (the second term in square brackets) that the probability of winning the game still depends on the effort levels of the competing region (the first term in equation (3.21)). What makes it different is that there are no costs without benefits (the second term in square brackets of equation (3.21)). As in the previous section, we start by describing the game for two regions, competing for a firm.

\subsubsection{Competition between Two Regions}

Each region knows that the other will invest in an effort to attract the firm and each knows the other's pay-off function. The regions determine their level of effort, which maximizes expected net payoff. The maximization problem of the respective regions is:

$$
\max _{e_{1}}\left\lfloor\frac{e_{1}+\mu_{1}}{e_{1}+\mu_{1}+e_{2}+\mu_{2}}\left(\Delta Y-e_{1}\right)\right\rfloor
$$

and

\footnotetext{
${ }^{65}$ In line with section 3.2 we can use the same contest success functions.
} 


$$
\max _{e_{2}}\left\lfloor\frac{e_{2}+\mu_{2}}{e_{1}+\mu_{1}+e_{2}+\mu_{2}}\left(\Delta Y-e_{2}\right)\right\rfloor
$$

The two first-order conditions (see appendix 2) from equation (3.22) are given below:

$$
\frac{\left(e_{2}+\mu_{2}\right)\left(\Delta Y-e_{1}\right)-\left(e_{1}+\mu_{1}\right)\left(e_{1}+\mu_{1}+e_{2}+\mu_{2}\right)}{\left(e_{1}+\mu_{1}+e_{2}+\mu_{2}\right)^{2}}=0
$$

and

$$
\frac{\left(e_{1}+\mu_{1}\right)\left(\Delta Y-e_{2}\right)-\left(e_{2}+\mu_{2}\right)\left(e_{1}+\mu_{1}+e_{2}+\mu_{2}\right)}{\left(e_{1}+\mu_{1}+e_{2}+\mu_{2}\right)^{2}}=0
$$

It is difficult to calculate analytically the optimal level of specific investments because both first-order conditions are implicit functions in $e_{1}$ and $e_{2}$. The same problem arises if we want to derive the best response function analytically. Note that $e_{1}+\mu_{1}=e_{2}+\mu_{2}$ is a solution which implies that $e_{1}=e_{2}$ and $\mu_{1}=\mu_{2}$. However, we want to investigate the competition where regions differ; that is, $\mu_{1} \neq \mu_{2}$. To simplify matters in order to find an analytical solution we start by analyzing two regions with the same comparative advantage: $\mu_{1}=\mu_{2}=\mu$. The new firm has an interest in the two regions. They have a comparative advantage compared to all other regions. If regions are identical (symmetric game) then the effort levels should also be the same. This implies we have $e_{1}{ }^{*}=e_{2}{ }^{*}=e^{*}$ as a solution. Combining this with the comparative advantage, which is the same for the two regions, we have $e_{1}^{*}+\mu_{1}=e_{2}^{*}+\mu_{2}=e^{*}+\mu$. Using these simplifications the best response functions as well the optimal specific investments can be calculated using equations (3.23). This results in the following best response function (see appendix 2):

$$
e_{1}=-e_{2}-2 \mu+\sqrt{\left(e_{2}+\mu\right)\left(\Delta Y+e_{2}+2 \mu\right)}
$$

and

$$
e_{2}=-e_{1}-2 \mu+\sqrt{\left(e_{1}+\mu\right)\left(\Delta Y+e_{1}+2 \mu\right)}
$$

The optimal effort level of the two competing regions can be found by simultaneously solving the two best response function given by equations (3.24). The same results can be derived by 
using the fact that the two regions are identical (symmetric) and therefore $e_{1}+\mu_{1}=e_{2}+\mu_{2}=e+\mu$. In both cases this results in the optimal effort level given below: ${ }^{66}$

$$
e_{1}^{*}=e_{2}^{*}=e^{*}=\frac{\Delta Y-2 \mu}{3} \geq 0
$$

We rule out negative amounts of effort and thus the following restriction holds: $e^{*}>0$. This means we have $\mu<\frac{1}{2} \Delta Y$. The optimal effort level exceeds that of the full liability case.

Given the restriction on the effort level, we see that $\frac{\Delta Y}{3}-\frac{2 \mu}{3}>\frac{\Delta Y}{4}-\mu \geq 0$.

We illustrate the above by a graph where we have depicted the best response curves and the equilibrium values off effort levels.

Figure 3.2 Best Response Curve (Limited Liability) $\mu_{1}=\mu_{2}$

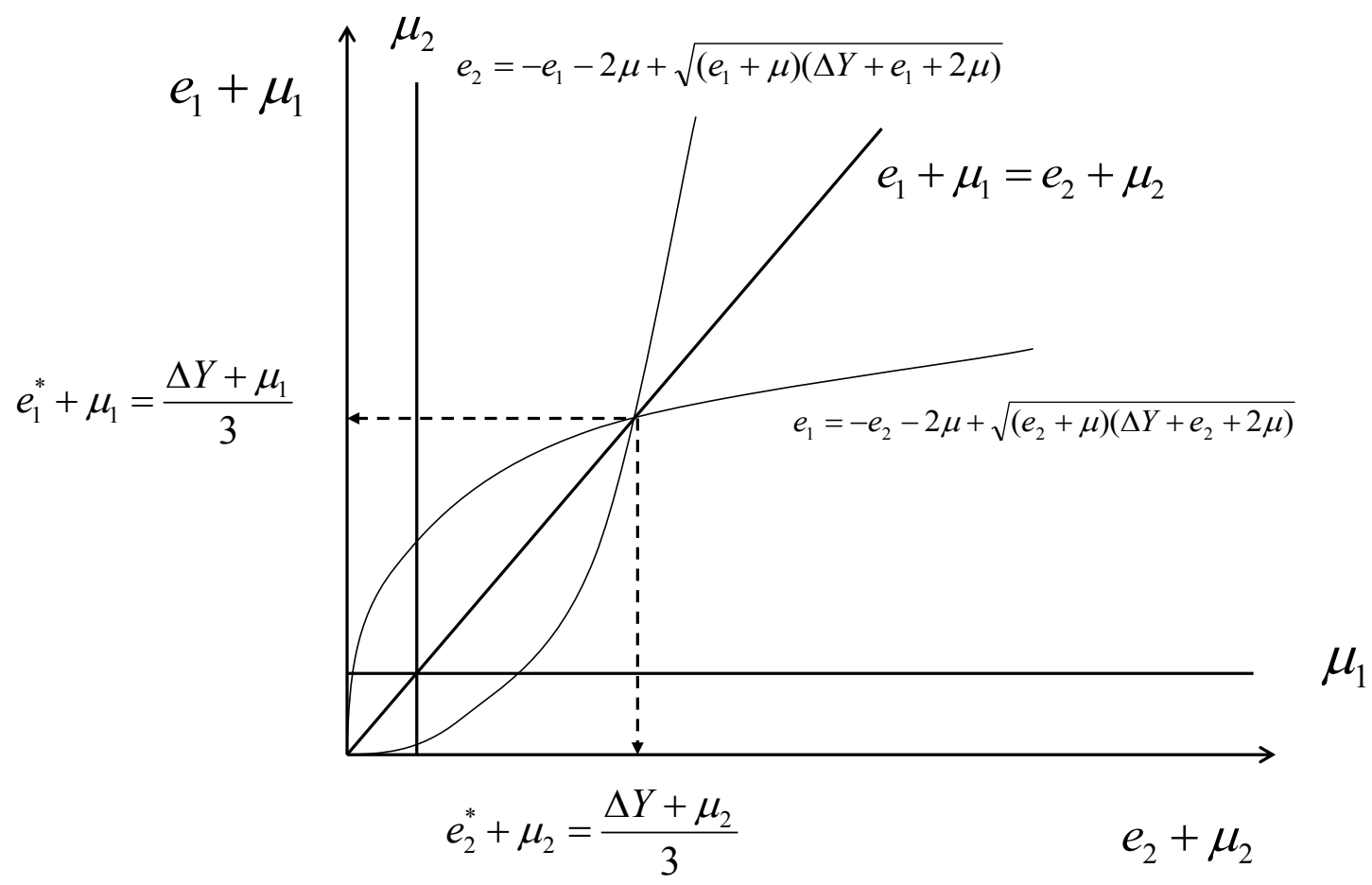

\footnotetext{
${ }^{66}$ From (3.24) we can see that; $\left(e_{2}+\mu\right)\left(\Delta Y+e_{2}+2 \mu\right)=\left(e_{1}+\mu\right)\left(\Delta Y+e_{1}+2 \mu\right)$. This will hold if $e_{1}=e_{2}=e$. Next rearranging and squaring both sides of equation 3.24, we derive $4(e+\mu)^{2}=(e+u)(\Delta Y+e+2 \mu)$ which equals $(4 e+4 \mu)=(\Delta Y+e+2 \mu)$ and this finally results in $3 e=\Delta Y-2 \mu$
} 
If the two regions are identical then their probability of winning the game is also the same, namely $\operatorname{Pr}_{1}=\operatorname{Pr}_{1}=\frac{1}{2}$. This is what was already expected. The same result can also be found by using equation (3.4A), the contest success function.

It is not surprising that the new firm is indifferent when choosing a region in which to settle. As soon as we know the probability of winning the competition game the expected payoff for region 1 and 2 is given by:

$$
E\left(P O_{1}\right)=E\left(P O_{2}\right)=\frac{\Delta Y+\mu}{3}
$$

It is clear that the expected pay off is reduced compared with no competition. Before competition the probability is the same for both regions and the expected pay-off is $E\left(P O_{i}\right)=\frac{1}{2} \Delta Y$ which exceeds the expected net pay-off in case of competition (see equation (3.27)) because $e^{*}{ }_{i}>0$ and thus $\mu_{i}<\frac{1}{2} \Delta Y$. Not participating in the competition game is no option as was the case with full liability. If the region will not invest in effort, its probability of attracting the firm will decline and so will the expected pay-off. This can easily be verified by inserting an effort level of $e_{1}=0$ in equation (3.21). Note too that this kind of competition does not lead to a decrease in welfare as is the case with full liability. In the limited liability situation, the firm's profit increases and thus the producer surplus increases. The consumer surplus reduces assuming the investments are financed by lump sum taxes. There is a redistribution of welfare from consumers to producers of $-\Delta C S=\frac{\Delta Y-2 \mu}{3}=\Delta P S$. In addition, the firm produces at the lowest cost level. Regions do not differ in comparative advantage, so there are no efficiency losses.

Next we have to analyze the case where regions differ in comparative advantage, that is, where $\mu_{1}>\mu_{2}$. If there were no competition, the firm $j$ would settle in the region with the highest comparative advantage (because $T C_{1, j}<T C_{2, j}$ ). If, however, the two different regions start competing, does this change the firm's decision? To analyze this we take the initial equilibrium point $\mu_{1}=\mu_{2}$ as a starting point and then marginally increase in $\mu_{1}$. First we consider the effect of the change in comparative advantage on the effort levels. The starting point is characterized by $e_{1}^{*}=e^{*}{ }_{2}=e^{*}$. Applying the implicit function theorem (see appendix A2) we get the following results using equations (3.24): 


$$
\left.\frac{d e_{1}}{d \mu_{1}}\right|_{\substack{\mu_{1}=\mu_{2}=\mu \\ e_{1}=e_{2}=e^{*}}}=\frac{e^{*}\left(e^{*}+\mu-\Delta Y\right)-\Delta Y^{2}-3 \Delta Y \mu-\mu^{2}}{(\Delta Y+\mu)\left(3 \mu+2 e^{*}+\Delta Y\right)}<0
$$

This tells us that if the comparative advantage of region 1 increases, then region 1 's effort level will decrease. Finally, inserting the optimal effort level $e^{*}=\frac{\Delta Y-2 \mu}{3}$ in equation (3.28) gives:

$$
\left.\frac{d e_{1}}{d \mu_{1}}\right|_{\substack{\mu_{1}=\mu_{2}=\mu \\ e_{1}=e_{2}=e^{*}}}=-\frac{11}{15}<0
$$

In case the comparative advantage of a region increases this leads to a decrease in effort level. The change of the equilibrium value of $e_{2}$ at the same point as above can also be calculated:

$$
\left.\frac{d e_{2}}{d \mu_{1}}\right|_{\substack{\mu_{1}=\mu_{2}=\mu \\ e_{1}=e_{2}=e^{*}}}=\frac{\left(e^{*}+\mu\right)^{2}}{(\Delta Y+\mu)\left(3 \mu+2 e^{*}+\Delta Y\right)}>0
$$

An increase in the comparative advantage of region 1 leads to an increase in the effort level of region 2. Again we insert the optimal effort level, $e^{*}=\frac{\Delta Y-2 \mu}{3}$, into equation (3.30), which gives us the following result:

$$
\left.\frac{d e_{2}}{d \mu_{1}}\right|_{\substack{\mu_{1}=\mu_{2}=\mu \\ e_{1}=e_{2}=e^{*}}}=\frac{1}{15}>0
$$

The effort level of region 2 is higher than that of region 1, if the comparative advantage of region 1 exceeds that of region 2 . These findings correspond with the results from the previous section, the full liability case. A comparative disadvantage can be partly counterbalanced by a higher level of effort. To discover the total effect of a change in comparative advantage we calculate the increase of the effective effort level; that is, the effort level due to a marginal increase of the comparative advantage of region 1 . We thus consider the change in attractiveness consisting of comparative advantage and effort from a change in comparative advantage. For region 1 this is: 


$$
\left.\frac{d\left(e_{1}+\mu_{1}\right)}{d \mu_{1}}\right|_{\substack{\mu_{1}=\mu_{2}=\mu \\ e_{1}=e_{2}=e^{*}}}=\left.\frac{d e_{1}}{d \mu_{1}}\right|_{\substack{\mu_{1}=\mu_{2}=\mu \\ e_{1}=e_{2}=e^{*}}}+\frac{d \mu_{1}}{d \mu_{1}}=-\frac{11}{15}+1=\frac{4}{15}>0
$$

and for region 2 :

$$
\left.\frac{d\left(e_{2}+\mu_{2}\right)}{d \mu_{2}}\right|_{\substack{\mu 1=\mu_{2}=\mu \\ e_{1}=e_{2}=e^{*}}}=\left.\frac{d e_{2}}{d \mu_{1}}\right|_{\substack{\mu_{1}=\mu_{2}=\mu \\ e_{1}=e_{2}=e^{*}}}=\frac{1}{15}>0
$$

Obviously, the effort level of region 1 decreases and the effort level of region 2 increases if the comparative advantage of region 1 increases marginally. The overall comparative advantage resulting from competition that is the comparative advantage including the effort level, of region 1 exceeds that of region 2 . We started from the equilibrium situation where effort levels and comparative advantage are the same, $e_{1}{ }^{*}+\mu_{1}=e_{2}{ }^{*}+\mu_{2}=e^{*}+\mu$, and changed $\mu_{1}$ marginally, which resulted in $\frac{d\left(e_{1}+\mu_{1}\right)}{d \mu_{1}}>\frac{d\left(e_{2}+\mu_{2}\right)}{d \mu_{1}}$. We find $e_{1}+\mu_{1}>e_{2}+\mu_{2}$ which, taking the CSF into account, implies that $\operatorname{Pr}_{1}>\operatorname{Pr}_{2}$. From this we can conclude that for the case of limited liability the region with a comparative disadvantage can partly compensate this with investments in effort. If region 1 has a comparative advantage over region 2 , there is an incentive for region 2 to invest in effort to attract a firm. By doing so it increases the probability that the firm will settle from zero to $\operatorname{Pr}_{2}>0$. Region 1 knows this and will also invest in effort to attract the firm. Otherwise the probability that the firm will settle reduces. Competition between two different regions leads to a positive level of effort of the two regions. Therefore the probability that a firm will settle in the region with a comparative advantage decreases and it increases for the region with a comparative disadvantage. The probability for the region with the comparative advantage still exceeds that of the other region, however.

\section{Lemma 3.3:}

If $\frac{\Delta Y}{2} \geq u_{1} \geq u_{2}$ then $e_{1}^{*}<e_{2}^{*}$ and $\operatorname{Pr}_{1}>\frac{1}{2}>\operatorname{Pr}_{2}$

\section{Proposition 3.5:}

Competition between two different regions results in a positive effort level of the two regions. The effort level of the region with the comparative advantage is below that of the competing region but the probability that the firm will settle in the region with the comparative advantage exceeds that of the competing region. 
The region with the greatest comparative advantage has the greatest probability of winning the competition. If a region's comparative advantage exceeds that of the competing region $\left(\mu_{1}>\mu_{2}\right)$, the effort level of the competing region can only partly compensate for this comparative disadvantage.

In case there is no competition the firm will settle in the region with the comparative advantage. This leads to a least-cost combination for the firm. If competition is allowed, this is still the case. The firm will choose the region with the lowest costs to maximize profit. Because $e_{1}+\mu_{1}>e_{2}+\mu_{2}$, the total costs of region 2 will exceed those of region 1; that is, $T C_{j, 1}<T C_{j, 2}$ There is, however, a decrease in consumer surplus and an increases in producer surplus, which offset each other. Introducing competition only leads to redistribution and not to an increase or decrease in efficiency.

\section{Proposition 3.6:}

Competition between two different firms leads to a positive effort level but has no influence on efficiency. It only leads to redistribution from consumer to producer surplus.

\section{Proof:}

Inserting $e_{1}+\mu_{1}>e_{2}+\mu_{2}$ in the cost function of the new firm in region 1 and 2 we find;

$$
\begin{aligned}
& T C_{1}=R K_{1}+w L_{1}=R\left(K_{1}-e_{1}-u_{1}\right)+w L_{1} \text { and } \\
& T C_{2}=R K_{2}+w L_{2}=R\left(K_{2}-e_{2}-u_{2}\right)+w L_{2}
\end{aligned}
$$

This results in $T C_{1}<T C_{2}$ and the profits of the new firm in region 1 exceeds those of region 2 , so the firm will choose region 1.

\subsubsection{Competition between $n$ Regions}

In this section we look at competition between more than two regions. Competition becomes more intense as the number of regions involved in the competition game increases. We extend the analysis to $n(n>2)$ regions, competing to attract a new firm. If we use the same approach as we applied before, then the maximization problem of the competing regions becomes:

$$
\max _{e_{i}}\left\lfloor\frac{e_{i}+\mu_{i}}{\sum_{k=1}^{n}\left(e_{k}+\mu_{k}\right)}\left(\Delta Y-e_{i}\right)\right\rfloor \text { for } i=1, \ldots, n
$$


The term $\frac{e_{i}+\mu_{i}}{\sum^{n}\left(e_{k}+\mu_{k}\right)}$ is the probability that region $i$ will win the competition game

$$
\sum_{k=1}^{n}\left(e_{k}+\mu_{k}\right)
$$

depending on effective effort level of region $i$ and the competing regions. To find the optimum effort level we maximize the above pay-off function for all $(n)$ competing regions. This gives us the following equilibrium result for the effort level (see appendix 2): to find an explicit solution we assume all the regions are identical, which results in:

$$
e_{i}^{*}=e^{*}=\frac{(n-1) \Delta Y-n \mu}{2 n-1} \text { for } i=1, \ldots, n
$$

Again, an effort level only makes sense if it is positive, so we assume that the restriction $e_{i}>0$ holds which means that $\frac{(n-1) \Delta Y}{n}>\mu$.

If the regions are identical, it follows directly that the effective effort level and effort levels of all regions are the same. It also means that they all have an equal probability of attracting the new firm. This can be verified by inserting (3.35) in (3.1) which results in:

$$
p_{i}^{*}=p^{*}=\frac{1}{n} \text { for } i=1, \ldots, n
$$

We can now also see what the consequences are of increased competition, in terms of an increase in the number of competing regions. From equation (3.36) we can see that if the number of competing regions increases the probability of winning the game decreases. We also analyze how the optimal effort level will change, if the number of competing regions changes. Taking the first derivative ${ }^{67}$ of the optimal effort level (3.35) with respect to the number of regions $(n)$ results in:

$$
\frac{\partial e^{*}}{\partial n}=\frac{(\Delta Y+\mu)}{(2 n-1)^{2}}>0
$$

${ }_{67} \frac{\partial e^{*}}{\partial n}=\frac{(\Delta Y-\mu)(2 n-1)-2[(n-1) \Delta Y-n \mu]}{(2 n-1)^{2}}$ The numerator is always positive, thus the sign is determined by the denominator. This can be simplified to:

$$
(\Delta Y-\mu)(2 n-1)-2[(n-1) \Delta Y-n \mu]=2 n \Delta Y-\Delta Y-2 n \mu+\mu-2 n \Delta Y+2 \Delta Y+2 n \mu=\Delta Y+\mu \text { and }
$$
because this is always positive we find $\frac{\partial e^{*}}{\partial n}=\frac{(\Delta Y+\mu)}{(2 n-1)^{2}}>0$. 
This is positive, so if the number of competing regions increases the optimal effort level of each region will rise. At the same time an increase in the number of competing regions will decrease the probability that a region will attract the firm. That means that the expected payoff of the regions decreases with the number of competing regions. The firm's profit increases with the number of competitors, because the effort level of the wining region increases if the numbers of competing regions increases, see equation (3.37). If there are $n$ competing regions, the expected pay-off to region $i$ is give by:

$$
E\left(P O_{i}\right)=\frac{1}{(2 n-1)}(\Delta Y+\mu)
$$

From the above equation it is easy to see that the expected pay-off decreases as the number of competing regions increases, the reason being that the effort level increases whereas the probability of attracting the firm decreases, which lowers the expected payoff. There will, however, always be an incentive for regions to compete because the expected pay-off of competition is always positive. The overall pay-off in this case is identical to the pay-off of the winning region: $\Delta Y-e_{i}^{*}$. Inserting the optimal level of effort delivers:

$$
P O=\frac{n}{2 n-1}(\Delta Y+\mu)
$$

Obviously, the overall pay-off decreases with an increasing numbers of competitors, because the investment in effort increases with an increasing number of competing regions.

In the same way as in the case of two competing regions we can now look at the case where regions differ in their comparative advantage. To highlight the consequences of competition between more than two different regions, we compare the region having a comparative advantage with all other competing regions, that is $\mu_{i}>\mu_{i+1}$ for $i=1, \ldots, 1-n$. Furthermore, we make use of the results of the previous section, namely that we have $e_{i}+\mu_{i}>e_{i+1}+\mu_{i+1}$ for $i=1, \ldots, n-1$. In case of identical regions, the probability of attracting the firm equals $1 / n$ but this changes if regions differ. The probability that a region with a comparative advantage will attract the new firm exceeds that of the other competing regions. Note that this depends on the effective effort level. We therefore have: ${ }^{68}$

${ }^{68} \operatorname{Pr}_{1}=\frac{e_{1}+\mu_{1}}{\sum_{k=1}^{n}\left(e_{k}+\mu_{k}\right)}>\operatorname{Pr}_{2}=\frac{e_{2}+\mu_{2}}{\sum_{k=1}^{n}\left(e_{k}+\mu_{k}\right)}>\ldots \operatorname{Pr}_{n}=\frac{e_{n}+\mu_{n}}{\sum_{=1}^{n}\left(e_{k}+\mu_{k}\right)}$ in case

$e_{1}+\mu_{1}>e_{2}+\mu_{2}>\ldots . .>e_{n}+\mu_{n}$ 


$$
\operatorname{Pr}_{1}>\operatorname{Pr}_{2}>\ldots . \operatorname{Pr}_{n}
$$

Making use of the results of the previous section it should be clear that the level of effort for region 1 decreases if it has a comparative advantage, while at the same time it increases for the other competing regions. The result is that the expected pay-off to region 1 increases if it has a comparative advantage, whereas the expected pay-off to the other competing regions decreases. As long as the expected pay-offs are positive, which is the case, there will be an incentive to compete, whereas without competition the firm will settle in the region with the comparative advantage. This is also the case when regions compete. The firm will choose the region where it maximizes its profits. This will be region $i$ when it has a comparative advantage $\left(e_{i}+\mu_{i}>e_{\tau}+\mu_{\tau}\right)$ for $\tau \neq i$. This process of competition, on the other hand, will result in a redistribution of welfare from consumers to producers, but it has no a negative impact on efficiency. This is because the firm still settles in the region, resulting in the leastcost combination.

\subsection{Summary and Results of Regional Competition}

In this section we have compared the results from section 3.3 and 3.4 and tried to compare the consequences of competition. The results are summarized in table 3.1 below.

\section{Table 3.1 Results Regional Competition}

\begin{tabular}{|l|l|l|l|}
\hline & $\begin{array}{l}\text { Competition with Full } \\
\text { Liability between } n \\
\text { Regions }\end{array}$ & $\begin{array}{l}\text { Competition with } \\
\text { Limited Liability } \\
\text { between } n \text { Regions }\end{array}$ & No Competition \\
\hline $\begin{array}{l}\text { Specific Investments \& } \\
\text { Advanarative }\end{array}$ & $e^{*}{ }_{i}+\mu_{i}=e^{*}+\mu$ & $e^{*}{ }_{i}+\mu_{i}>e^{*}{ }_{i^{\prime}}+\mu_{i^{\prime}}$ & $\mu_{i}>\mu_{i^{\prime}}$ \\
\hline $\begin{array}{c}\text { Total Costs Firm } \\
T C^{*}\end{array}$ & $T C_{i}=T C_{i^{\prime}}$ & $T C_{i}<T C_{i^{\prime}}$ & $T C_{i}<T C_{i^{\prime}}$ \\
\hline $\begin{array}{l}\text { Producers Surplus } \\
\Delta P S_{i}=e_{i}^{*}\end{array}$ & $\frac{(n-1) \Delta Y}{n^{2}}-\mu_{i}$ & $\frac{(n-1) \Delta Y-n \mu}{2 n-1}$ & 0 \\
\hline $\begin{array}{l}\text { Consumers Surplus } \\
-\Delta C S=\sum e_{k}^{*}\end{array}$ & $\frac{n(n-1) \Delta Y}{n^{2}}-\sum_{k=1}^{n} \mu_{k}$ & $\frac{(n-1) \Delta Y-n \mu}{2 n-1}$ & 0 \\
\hline Efficiency Effect & $\Delta P S_{i}+\Delta C S<0$ & $\Delta P S_{i}=-\Delta C S_{i}$ & 0 \\
\hline
\end{tabular}


Here $e_{i}$ is the effort level of region $i$ to attract a firm, and $u_{i}$ is region $i$ 's comparative advantage over other regions. Changes in producer surplus ( $\triangle P S)$ and consumer surplus $(\triangle C S)$ are used to capture the efficiency effects. The number of competing regions is indicated by $n$; increasing of $\mathrm{n}$ is supposed to stand for increasing competition.

For the two types of competition and the reference case of no competition the level of investment can be found in the first row. The second row shows the firm's costs. The third and the fourth rows indicate the welfare effects in terms of change in producer and consumer surplus, whereas the last row indicates the total change in welfare.

Comparing the results, we can conclude that competition between regions, as we have modelled it, does not increase efficiency. At best it does not increase inefficiency. In case of full liability, efficiency is decreased, but in case of limited liability, consumer surplus plus producer surplus remain the same. Both types of competition result in a redistribution of welfare. Competition decreases the consumer surplus but increases the producer surplus.

Obviously, an efficient outcome could be reached without investing in efforts by regions to attract firms. The problem is that if any region invests in an effort to attract a firm, all other competing regions must also offer investments to the courted firm to retain a chance of winning the competition. 



\section{Chapter 4}

Competing for Innovation, Internalizing Externalities? 


\subsection{Introduction}

In the previous chapter we analysed the situation in which regions compete to generally attract firms, concluding that competition as such will not enhance efficiency. A possible additional argument in favour of regional competition, however is the fact that, when innovative firms settle in a region, positive externalities are generated for the region. In this chapter we analyze whether it makes sense for regions to compete specifically for such new, high-tech, innovative industries. As in the previous chapter the regions are different, i.e., one region has a comparative advantage over the other. This means that in case there is no competition the firm has a preference to settle in the region with the comparative advantage. This changes after the competition game starts; both region have an equal probability that the firm will settle. We here restrict the analysis to two regions $(n=2)$, and to the case of full liability. We do this because, as was made clear in the previous chapter, this case involves possible competition-induced efficiency losses, whereas total welfare remains the same in the limited liability case. However, as in the previous chapter, when considering the limited liability case we look at the situation in which an innovative firm has settled in a region and regional government supports that firm. Such support may be desirable due to the fact that the firm itself does not take account of the externalities resulting from its innovative practices. Can the externalities stemming from innovation be fully internalized or not?

In this chapter we investigate sub-question 3 . The chapter is structured as follows. In section 4.2 we first discuss the contribution of innovative firms to regional development and the way it is modelled here. In section 4.3 we analyze competition for innovative firms between two regions. In section 4.4 we deal with the issue of subsidizing innovation to internalize externalities. Section 4.5 contains a summary and conclusions.

\subsection{Firms, Innovation and Externalities: The Expanding Varieties Model}

In the previous chapter the contribution of a firm to regional economic development consisted only of the firm's additional income and production. If, however, a firm's settling results in positive spill over's to the rest of the regional economy, such positive externalities have to be taken into account. We do this by using a simplified version of the expanding varieties model of endogenous growth, first introduced by P. Romer (1990).

According to this model, on the production side of the economy there are two types of firms: firms that produce final goods and firms that produce intermediate capital goods. Final goods can be used for consumption, the production of intermediate capital goods and as inputs to research and development. Firms use labour and capital goods as inputs for the production of final goods. The different capital goods are assumed to be complementary and the number of 
different capital goods employed to produce final goods is seen as an indicator of technological complexity and degree of specialization. Because the different capital goods are fully consumed during the production of final goods, they are also called intermediate goods. By introducing new types of capital goods the overall production and so also productivity is increasing (the positive externality of innovation).

Final goods are produced under perfect competition but firms that produce capital goods are monopolists because all capital goods are assumed to be different and unique. Monopolists can charge a price for their products which lies above the marginal costs and this results in a profit for the monopolist. To produce a unique capital good, the firms needs to invest in research and development, which is eventually financed by the profits the firm makes when it becomes a monopolist. Every innovation results in a new capital good, which increases overall production and income. We take a more detailed look at the two types of goods below.

\subsubsection{Final Goods}

We first look at the production of final goods in the economy. As stated, firms that produce final goods are assumed to operate under perfect competition; there is no long-run profit, and all firms are identical. In this case the aggregate production of final goods can be represented by a firm's production function of final goods. A Dixit-Stiglitz ${ }^{69}$ type production function is therefore used to formalize the production process of firm $\eta$, producing final goods in the following way:

$$
Y_{\eta}=L_{\eta}{ }^{1-\alpha} \sum_{j=1}^{N} K_{j}^{\alpha},
$$

Here firm $\eta$ 's production of final goods is $Y_{\eta}, L_{\eta}$ and $K_{\eta, j}$ for $j=1, \ldots, N$ are the inputs of labour and all types of (intermediate) capital goods used by firm $\eta$ for the production of final goods, with $0<\alpha<1$. Because this sector faces perfect competition, the firm's production function of final goods also represents the economy's overall production function of the final good sector. Thus, deleting $\eta$, for the economy-wide production of final goods we have:

\footnotetext{
${ }^{69}$ The model of P. Romer (1990) is based on the Dixit Stiglitz model of monopolistic competition. In 1979 Dixit and Stiglitz published their seminal article "Monopolistic competition and optimal product variety". In this article they described the market for monopolistic competition. According to Neary (2002, p. 3). "their prime concern, was to describe the social optimality of monopolistic competition. Would the market of monopolistic competition produce too many varieties? Would the industry operate with excess capacity that means at prices above the minimum of the average costs?' The driving force of the Dixit-Stiglitz model is that more varieties increase consumers' utility.
} 


$$
Y=L^{1-\alpha} \sum_{j=1}^{N} K_{j}^{\alpha}
$$

Here the total regional production of final goods here is denoted by $Y$, while $L$ stands for the amount of labour employed by all firms producing final goods and $K_{j}$ with $j=1, \ldots, N$ the different types op capital goods available ${ }^{70}$. Whereas the number of different capital goods is given for the individual firm, for the aggregate economy it is endogenously determined as will be explained in the next sections. With respect to labour we assume that it is fixed to avoid for example complications of scale and scope. To simplify, if we equate the price for final goods to one, the following profit function of the final good sector results:

$$
\Pi=Y-w L-\sum_{j=1}^{N} p_{j} K_{j} \geqq 0 \text { for } j=1, \ldots, N
$$

where $\Pi$ stands for total profit of the final goods sector. It equals, total revenue, $Y$.minus total costs, consisting of cost of the inputs labour and capital.. The wage rate is denoted by $w$ and $p_{j}$ is the price of a capital good of type $j$. We assume that the labour market, like the final goods market, is fully competitive. If we maximize profit with respect to labour we find the economywide demand for labour and the wage rate, which equals the marginal product of labour. In the same way we can derive the demand for and price of all different types of capitals goods ${ }^{71}$.

$$
w=(1-\alpha) L^{\alpha-1} \sum_{j=1}^{N} K_{j}^{\alpha}
$$

and

$$
p_{j}=\alpha L^{1-\alpha} K_{j}^{\alpha-1} \text { for } j=1, \ldots, N
$$

\footnotetext{
${ }^{70}$ Because over time new capital goods are developed, the number of types increases over time.

${ }^{71}$ Setting the first derivative with respect to labour and capital equal to 0 results in:$$
\frac{\partial \Pi}{\partial L}=\frac{\partial Y}{\partial L}-w=0 \text { and } \frac{\partial Y}{\partial L}=(1-\alpha) L^{\alpha-1} \sum_{j=1}^{N} K_{j}^{\alpha} \text { so } w=(1-\alpha) L^{\alpha-1} \sum_{j=1}^{N} K_{j}^{\alpha} \text { and }
$$$$
\frac{\partial \Pi}{\partial K_{j}}=\frac{\partial Y}{\partial K_{j}}-p_{j}=0 \text { and } \frac{\partial Y}{\partial K_{j}}=\alpha L^{1-\alpha} K_{j}^{\alpha-1} \text { so } p_{j}=\alpha L^{1-\alpha} K_{j}^{\alpha-1}
$$ 
By inverting the above equations the demand for labour and for the $N$ different types of capital goods can be derived. It can be seen that the demand for the different capital goods depends negatively on their price. $^{72}$

\subsubsection{Capital Goods}

Now we know the demand for all types of capital goods we can describe behaviour of the firm producing the capital good. For capital-good-producing firms the incentive for investing in $R \& D$ is the prospect of a possible profit. If $R \& D$ is successful, this results in a blueprint. Using final goods in combination with the blueprint leads to the manufacture of a unique capital good. Because there are many firms producing capital goods and each of them producing a unique capital good, the market structure is monopolistic competition, with many suppliers of unique capital goods.

Firms producing a capital goods use innovation to transform one final good into one capital good. Thus the production function of new types of capital goods is linear in final goods and so we have the following linear cost function: $T C_{j}=K_{j}$ with marginal cost equal to one. The firm chooses output and price to maximize its profit. The profit consists of revenues minus cost, where the revenues are the price multiplied by quantity $\left(p_{j} K_{j}\right)$ and the cost of inputs equals $K_{j}$. Firms face the following profit function:

$$
\pi_{j}=p_{j} K_{j}-K_{j} \text { for } j=1, \ldots, N
$$

The optimal price and quantity can be found by maximizing the profit function with respect to the price $\left(p_{j}\right)$ and output $\left(K_{j}\right)$, which results in $^{73}$ :

${ }^{72}$ Rewriting equation (4.3) results in $K_{j}=\frac{\alpha^{\frac{1}{(1-\alpha)}} L}{p_{j}^{\frac{1}{(1-\alpha)}}}$ for $j=1, \ldots, N$, relating the demand for $N$ different capital goods to their price.

${ }^{73}$ Inserting the price equation (4.3) in equation (4.4) results in: $\pi_{j}=\alpha L^{1-\alpha} K_{j}^{\alpha-1} K_{j}-K_{j}=\alpha L^{1-\alpha} K_{j}^{\alpha} K_{j}-K_{j}$. Differentiating the profit function with respect to capital, this turn in: $\alpha^{2} L^{1-\alpha}=K_{j}^{1-\alpha}$ or $\left[\alpha^{2} L^{1-\alpha}\right]^{-1}=K_{j}^{\alpha-1}$. Next, substituting this in the price equation from (4.3) gives the price of capital goods, $p_{j}=\alpha L^{1-\alpha}\left[\alpha^{2} L^{1-\alpha}\right]^{-1}$ which reduces to $p_{j}=\frac{1}{\alpha}$ in equation (4.6). 


$$
K_{j}=K=\alpha^{2 /(1-\alpha)} L \text { for } j=1, \ldots, N
$$

and

$$
p_{j}=p=\frac{1}{\alpha} \text { for } j=1, \ldots, N
$$

As can be seen from the above equations, all firms charge the same price and produce the same quantity of capital goods. The figure below shows the demand for capital goods resulting from the final good sector and the supply from the capital goods sector at the equilibrium level. Profit maximization is where marginal revenue, ${ }^{74} M R=\alpha^{2} L^{1-\alpha} K_{j}{ }^{\alpha-1}$, meets marginal costs, which equal one: $M C=1$ (note that total costs of production equals $T C_{j}=K_{j}$ ). This is the equilibrium resulting in equilibrium quantity and price. If we look at figure 4.1 it is also easy to see what the consequences are for the economy if capital-good-producing firms charge a price, $p=\frac{1}{\alpha}$, above marginal costs. The quantity of capital goods produced and used for the production of final goods is lower than it is in case the price equals the marginal cost. The resulting income is therefore also lower, and this thus leads to an efficiency loss.

\section{Figure 4.1 Demand for and Supply of Capital Goods for all $N$ Capital goods}

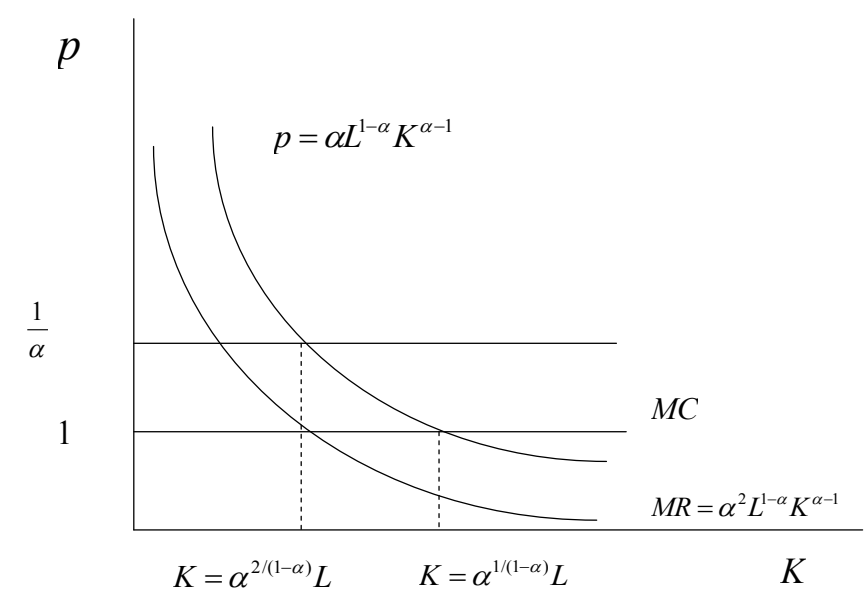

\footnotetext{
${ }^{74}$ Total revenue equals $T R=p_{j} * K_{j}=\alpha L^{1-\alpha} K_{j}{ }^{\alpha-1} * K_{j}=\alpha L^{1-\alpha} K_{j}{ }^{\alpha}$ and $M R=\frac{d T R}{d K_{j}}=\alpha^{2} L^{1-\alpha} K_{j}{ }^{\alpha-1}$
} resulting in quantity and price of capital goods. 


\subsubsection{Research and Development}

What is the contribution of $R \& D$ ? $R \& D$ allows firms to produce new capital goods, which can be sold at a profit. It also increases existing knowledge. This increase in knowledge again allows new capital goods to be developed.

What is crucial is the fact that knowledge has the characteristics of a non-rival good, so knowledge is accessible to every firm. There are no costs to its use and it can be used unboundedly. This is not the case with capital goods. These depreciate when they are used and they exhibit decreasing returns to scale. Because capital goods are private goods the firm can establish a patent on them. In doing so the firm becomes a monopolist and can earn a profit. This possible profit is the incentive for a firm to invest in R\&D. If a new type of capital good can be patented, then the capital good delivers a profit to the monopolist..

Thanks to the characteristics of knowledge described above, we have the following linear type of "production function" of knowledge / new types of capital goods:

$$
\Delta N_{t}=\theta Z_{t} \text { or } \quad N_{t+1}=N_{t}+\theta Z_{t}
$$

Here $\Delta N_{t}$ is the output of $\mathrm{R} \& \mathrm{D}$, the increase in stock of knowledge, which can be used to produce new types of capital goods. $N_{t+1}, N_{t}$, represent the stock of knowledge in period $t$ and $t+1$, respectively. Expenditure, in terms of final goods, in innovation at time $t$ is denoted by $Z_{t}$. The parameter $\theta$ indicates how much expenditure and resources (in terms of final goods) is / are needed for successful innovation. It also is an indication of the productivity of the R\&D sector.

How much $R \& D$ are firms willing to engage in? The revenues of $R \& D$ are the discounted profits of a new type of capital good. In case of an one period lasting patent this equals $\frac{\pi}{R}$, where $R=(1+r)$ is the return on capital. ${ }^{75}$ The costs are the resources used, in term of final goods. Optimal $\mathrm{R} \& \mathrm{D}$ is where marginal revenue, i.e., $\frac{\theta \pi}{R}$, equals marginal cost, which equals $1 .^{76}$ Note, this means that knowledge is a positive externality for the economy as a whole, endogenously determined by profit-seeking firms.

\footnotetext{
${ }^{75}$ If the profits of a patent can be realized in the next period, than the discounted profits equals $\frac{\pi}{R}$.

${ }^{76}$ Revenue equals output times price of R\&D, that is $\Delta N_{t} \frac{\pi}{R}$. Substituting for $\Delta N_{t}$ gives $\theta Z_{t} \frac{\pi}{R}$. Costs in terms of

resources equals $Z_{t}$. Thus marginal costs are equal 1 and so $\frac{\theta \pi}{R}=1$ or $\theta \pi=R$.
} 
After the firm has decided how much to invest in innovation, which are fixed, total cost of a new type of capital good is known. The equilibrium of monopolistic competition can be seen by figure 4.2 below. In equilibrium firms make no profit. That means that average total costs $(A C)$ that is costs of production and investments in innovation equals the price $(p)$ of the capital good.

\section{Figure 4.2 Equilibrium Monopolistic Competition where} Price equals Average Costs

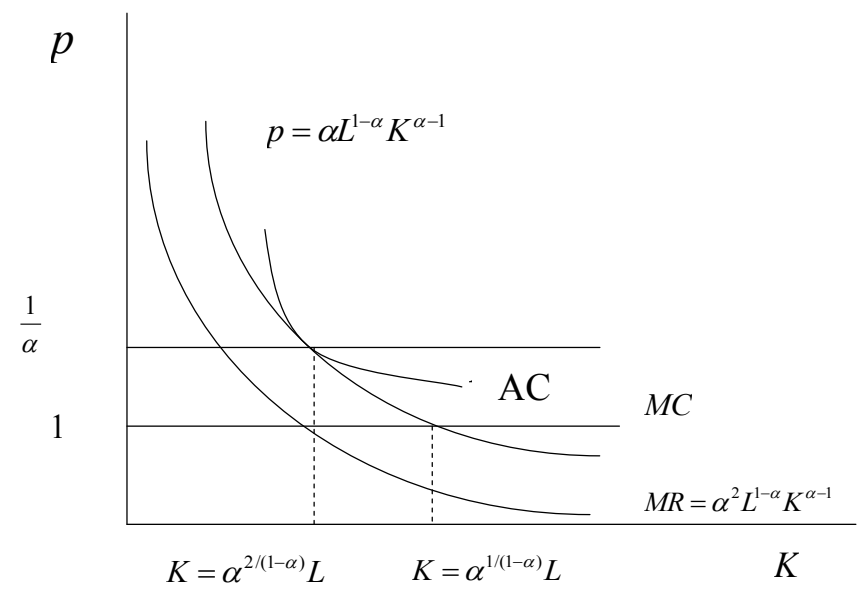

\subsubsection{Contribution of the Innovative Firm to the Regional Economy}

To see what the innovative firm contributes to the regional economy we make use of a footnote in Barro and Sala-i-Martin (1996). ${ }^{77}$ Romer's expanding product variety model of endogenous growth by innovation is summarized in the production function below.

$$
Y_{t}=L^{1-\alpha} \sum_{j=1}^{N_{t}} K_{j}^{\alpha}=N_{t} L^{(1-\alpha)} K^{\alpha}
$$

In equilibrium the amount of types of capital used is the same for all the types, that is $K_{j}=K_{i}=K$ and thus, $\sum_{j=1}^{N_{t}} K_{j}^{\alpha}=N_{t} K^{\alpha}$. This production function is similar to the production function used in the neo-classical growth theory. The difference, however, is that technical

\footnotetext{
${ }^{77}$ See Barro and Sala-i-Martin (1994, footnote 9 on page 219): "Since the factor prices equal the respective marginal product, the household's aggregate income, $w L+R \pi N$, can be shown to equal the economy's net product, $Y-N K$.
} 
progress, $N_{t}$, is endogenously determined by market-driven R\&D. From this it is easy to see that the development of production and income depends on the existing stock of technology, which depends on the R\&D effort. It is easy to see that production growth equals the growth of the number of different capital goods, or the variety of capital goods; that is, $\frac{Y_{t+1}}{Y_{t}}=\frac{N_{t+1}}{N_{t}}=1+g$.

Next we want to discover how these externalities influence the income distribution. To analyze the development of income resulting from innovation we use the following equation of income distribution:

$$
Y_{t}-N_{t} K=w_{t} L+R N_{t} \pi
$$

Net income $\left(Y_{t}-N_{t} K\right)$, that is gross income minus the inputs of capital goods, is paid as remuneration for labour $\left(w_{t} L\right)$ and capital $\left(R N_{t} \pi\right)$ according to the marginal product of those factors. We can see that the production function has a Cobb-Douglas structure (equation (4.9)). One of the properties of the Cobb-Douglas function is that factor incomes are fixed proportions of total income. Using this property we can find the share of wage and the capital income. The wage rate, which equals the marginal product of labour, is derived from equation (4.3). The income share of labour amounts to the wage rate multiplied by labour.

$$
L w_{t}=(1-\alpha) N_{t} L^{1-\alpha} K^{\alpha}
$$

Labour income increases because the wage rate increases (we assume there is no population growth, so the labour force is fixed). The wage rate increases because the labour productivity increases. $^{78}$

In addition to labour income we have capital income, which consists of income from asset holdings. We assume that total assets are evenly distributed among the older generation of the population, which invested in innovative firms when they were young. The total assets consist of all discounted profits of all capital-good-producing firms, each producing a unique capital good. This amounts to:

${ }^{78}$ Dividing total output by the labour force result in the production per unit labour. This equals $\frac{Y_{t}}{L}=y_{t}=N_{t} k^{\alpha}$ where $k=\frac{K}{L}$, the capital labour ratio is constant in equilibrium. 


$$
T A=\frac{\pi}{R} N_{t}
$$

where $T A$ are the total assets in the economy. Now we can easily determine income from asset holdings. This, of course, is the return on capital multiplied by the amount of assets in the economy. The capital income in the economy is the return on total asset and therefore equals:

$$
C I=R\left(\frac{\pi}{R} N_{t}\right)=N_{t} \pi=N_{t} \frac{1-\alpha}{\alpha} K
$$

Here $C I$ is the capital income. Capital income increases thanks to new varieties of capital goods. Profits, however, remain the same for all different types of capital goods. Wage income plus capital income equals net income. If we substitute the above result in $Y_{t}-N_{t} K=w_{t} L+N_{t} \pi$ we obtain the following expression:

$$
N_{t} L^{1-\alpha} K^{\alpha}-N_{t} K=(1-\alpha) N_{t} L^{1-\alpha} K^{\alpha}+N_{t} \frac{1-\alpha}{\alpha} K
$$

Dividing both side by $N_{t}$ and rearranging leads to the following equality: ${ }^{79}$

$$
K=\alpha^{2 /(1-\alpha)} L
$$

This, of course, is the optimal value of each type of capital good for profit-maximizing, innovative firms. We use the above result to determine the contribution of an innovative firm to regional activity.

Suppose a new firm settles in a region and produces a new capital good. As such, the stock of capital of the region increases. After settlement, on aggregate we have $N_{t+1}=N_{t}+1$ capital-good-producing firms. Using equation (4.14) and the fact that $\Delta N_{t}=1$ we can see the increase in production and income. The increase in net output of course equals $L^{1-\alpha} K^{\alpha}-K$. The increase in output leads to an increase in wage income of $(1-\alpha) L^{1-\alpha} K^{\alpha}$ and an increase in

\footnotetext{
${ }^{79}$ Using equation (4.10) and substitution equations (4.11) and (4.13) for labour and capital income we find $L^{1-\alpha} K^{\alpha}-K=(1-\alpha) L^{1-\alpha} K^{\alpha}+\frac{1-\alpha}{\alpha} K$. Next rearranging the results in $\alpha L^{1-\alpha} K^{\alpha}=K+\frac{1-\alpha}{\alpha} K$ which leads to $\alpha L^{1-\alpha} K^{\alpha}=\frac{1}{\alpha} K$ and $\alpha^{2} L^{1-\alpha}=K^{1-\alpha}$ which results in equation (4.5).
} 
capital income of $\frac{1-\alpha}{\alpha} K$. It is easy to see that the increase in wage income can be attributed to an increase in the wage rate, because labour is fixed. From equation (4.3) we know that in equilibrium the wage rate equals $w_{t}=(1-\alpha) N_{t} L^{-\alpha} K^{\alpha}$ and for $\Delta N_{t}=1 \mathrm{we}$ have $\Delta w_{t}=(1-\alpha) L^{-\alpha} K^{\alpha}$. In other words, an increase in wage income equals $\Delta w_{t} L$. For capital income this equals the profits of the new firm, $\pi=\frac{1-\alpha}{\alpha} K$. An innovative firm increases regional output by:

$$
\Delta Y_{t}=L^{1-\alpha} K^{\alpha}-K
$$

This leads to an increase in wage income, which results from an increase in the wage rate, due to an increase in productivity:

$$
\Delta w_{t} L=(1-\alpha) L^{1-\alpha} K^{\alpha}
$$

Capital income increases by the profit made by the innovative firm:

$$
\pi=\frac{(1-\alpha)}{\alpha} K
$$

The outcome is thus an increase in production, income and the competitiveness of the region compared to other regions. Note that obviously $\Delta Y_{t}=\Delta w_{t} L+\pi$. The average labour productivity increases from $\frac{Y_{t}}{L}=N_{t} k^{\alpha}$ to $\frac{Y_{t+1}}{L}=\left(N_{t}+1\right) k^{\alpha}$ because $N_{t+1}=N_{t}+1$.

\subsection{Competition between Regions}

Regarding the competition between regions, we discuss only the simplest case of a world consisting of two regions (1 and 2). This case offers sufficient complexity to discuss the mechanisms at stake. Both regions can be assumed to be identical in terms of the number of inhabitants and capital-good-producing firms. The government of each region has an interest in increasing its (regional) income. We shall also assume that workers are mobile and able to work in both regions, but always spend their (wage) income in the home region. What will happen now, if an innovative firm settles in a region to produce a new type of capital good? Let us say the firm settles in region one. If there is no economic integration, the results are clear. Only the 
region where the firm settles will have an increase in income - wage income as well as capital income. In case of labour mobility wage rates will converge and this will change the wage income of both regions.

To describe the competition, we use the same competition game as in the previous section, with the exception that none of the competing regions has a comparative advantage. After competition however the winning region will have a comparative advantage. Below we review the most important elements of the game. We assume that both regions make use of lump-sum taxes. As noted, there will be an increase in income for both regions no matter where the firm settles, due to the overall increase in wage rate and wage income. We assume that the expected gains are the same for both regions (i.e., $\Delta Y_{1}=\Delta Y_{2}=\Delta Y$ ). Intuitively this means that the invested effort levels of the two regions should also be the same. The players move sequentially, which means that this competition can be interpreted as a Stackelberg type of competition game. ${ }^{80}$ Using the two first-order conditions of equation, the following two best response functions can be derived: ${ }^{81}$

$$
e_{1}=-e_{2}+\sqrt{e_{2}(\Delta Y)} \text { and } e_{2}=-e_{1}+\sqrt{e_{1}(\Delta Y)}
$$

The optimal effort level derived from the equations above equals $e^{*}{ }_{1}=e^{*}{ }_{2}=e^{*}=\frac{1}{4} \Delta Y^{82}$. The equilibrium probability that region 1 and 2 will win the game is, for both regions:

\footnotetext{
${ }^{80}$ It can be shown that under the given assumptions a Cournot-Nash and a Stackelberg type of game are equivalent so we do not need to distinguish between the two.

${ }^{81}$ The expected pay-off s are $\mathrm{E}\left(P O_{1}\right)=\frac{e_{1}}{e_{1}+e_{2}} \Delta Y_{1}-e_{1}$ and $\mathrm{E}\left(P O_{2}\right)=\frac{e_{2}}{e_{1}+e_{2}} \Delta Y_{2}-e_{2}$. The first-order conditions are given by: $\frac{\partial \mathrm{E}\left(P O_{1}\right)}{\partial e_{1}}=\frac{e_{2}}{\left(e_{1}+e_{2}\right)^{2}} \Delta Y_{1}-1=0$ which equals $e_{2} \Delta Y_{1}=\left(e_{1}+e_{2}\right)^{2}$ resulting in $\left(e_{1}+e_{2}\right)=\sqrt{e_{2} \Delta Y}$. In the same manner we find $\frac{\partial \mathrm{E}\left(P O_{2}\right)}{\partial e_{2}}=\frac{e_{1}}{\left(e_{1}+e_{2}\right)^{2}} \Delta Y_{2}-1=0$ leading to $e_{1} \Delta Y_{2}=\left(e_{1}+e_{2}\right)^{2}$ resulting in $\left(e_{1}+e_{2}\right)=\sqrt{e_{1} \Delta Y}$

${ }^{82}$ If the optimum effort levels are the same that is $e_{1}=e_{2}=e$ the best response function results in $2 e=\sqrt{e(\Delta Y)}$, or $4 e^{2}=e \Delta Y$ The equilibrium effort level of both players equals $e^{*}=\frac{1}{4} \Delta Y$.
} 
$\operatorname{Pr}_{1}^{*}=\frac{e_{1}^{*}}{e^{*}{ }_{1}+e^{*}{ }_{2}}=\frac{1}{2}=, \frac{e_{2}^{*}}{e^{*}{ }_{1}+e^{*}{ }_{2}}=\operatorname{Pr}_{2}{ }^{*}$. The optimal effort level derived from the equations above equals $e_{1}^{*}=e_{2}^{*}=e^{*}=\frac{1}{4} \Delta Y^{83}$. We summarize the result in figure 4.3 , below.

\section{Figure 4.3 Best Response Functions}

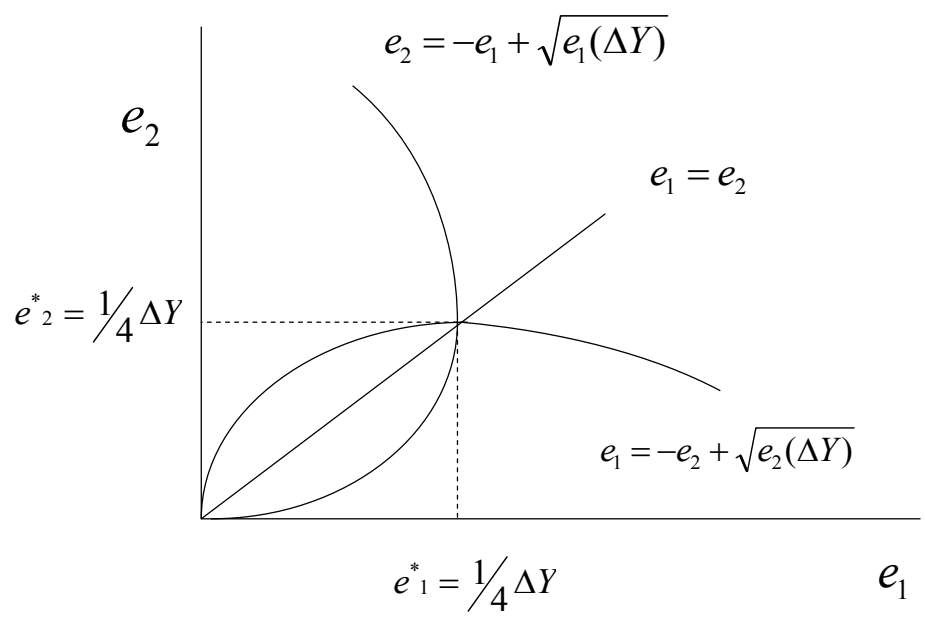

We now look at the effects of competition between two regions to attract an innovative firm.

\subsubsection{Effects of Competition on Efficiency}

To analyze the effect of competition on regional income we again assume that the world is made up of two identical regions. Labour, capital and firms are evenly distributed over the two regions. So, without loss of generality, we can assume that $L=L_{1}+L_{2}$, and $L_{1}=L_{2}$ thus $L_{1}=L_{2}=\frac{1}{2} L$ and $K_{1}+K_{2}=K$ and $K_{1}=K_{2}=\frac{1}{2} K$. This is of course not the case with the stock of knowledge or the number of varieties of capital goods. This is available to both regions, thus $N_{t}=N_{1, t}=N_{2, t}$. The following production functions apply to the two regions:

$$
Y_{1, t}=N_{t} L_{1}^{1-\alpha} K_{1}^{\alpha} \text { and } Y_{2, t}=N_{t} L_{2}^{1-\alpha} K_{2}^{\alpha}
$$

\footnotetext{
${ }^{83}$ If the optimum effort levels are the same that is $e_{1}=e_{2}=e$ the best response function results in $2 e=\sqrt{e(\Delta Y)}$, or $4 e^{2}=e \Delta Y$ The equilibrium effort level of both players equals $e^{*}=\frac{1}{4} \Delta Y$.
} 
Production of final goods is the same in the two regions, both using $N$ types of different capital goods. On aggregate we have of course $Y_{t}=N_{t} L^{1-\alpha} K^{\alpha}$, the sum of output and production in the two regions.

Let us look first at the overall increase of income and output associated with an additional firm settling in one of the two regions. Notice that in this case $\Delta N_{t}=1$ and thus on aggregate this equals $\Delta Y=\Delta Y_{1}+\Delta Y_{2}$. Both regions will benefit from the innovative firm, but the benefits will differ depending on whether the region wins or loses the competition game. If we look at the production side, the production of the new capital goods will take place in region 1 , the winning region. The production of final goods for both regions increases, as does the aggregate production, i.e.:

$$
\Delta Y=\Delta Y_{1}+\Delta Y_{2}=L^{1-\alpha} K^{\alpha}=L_{1}^{1-\alpha} K_{1}^{\alpha}+L_{2}^{1-\alpha} K_{2}^{\alpha}
$$

If a region wins the game the overall increase in income is an increase in wage income plus the capital income from the new capital-goods-producing firm. If region 1 wins the game, its increase in income equals $\Delta Y_{1}=\Delta w L_{1}+\pi$ (see equations (4.15), (4.16) and (4.17)). The presence of an innovative firm that produces a unique capital good will lead to an overall increase in productivity. This results in an overall wage increase for both regions. Output, production of capital goods, is realized in the "winning" region. ${ }^{84}$ Note that for the region that loses the game, the wage rate and income increase despite the fact that the firm settles and produces elsewhere. This is the positive externality resulting from an innovative firm, no matter where it settles. This results in an increase in wage income for region 2 equal to $\Delta Y_{2}=\Delta w L_{2}$. When regions compete they will not take account of these kinds of externalities (the overall wage increase). The benefits to a region winning the game are the additional wage income and capital income. Even the losing region benefits from the overall increase in wage rate.

From the previous section we know that in case of competition, both regions will invest $25 \%$ of the potential gains to attract the firm, i.e. $\frac{1}{4} \Delta Y_{1}=\frac{1}{4}\left[\Delta w L_{1}+\pi\right]$. In case of competition (denoted by (comp) in the following equations), the winning region will increase its income by:

$$
\Delta Y_{1}(\operatorname{comp})=\frac{3}{4} \Delta Y_{1}=\frac{3}{4}\left[\Delta w L_{1}+\pi\right]
$$

\footnotetext{
${ }^{84}$ Income equals $\Delta Y=\Delta Y_{1}+\Delta Y_{2}=\Delta w L_{1}+\Delta w L_{2}+\pi=\Delta w L+\pi$ and production and output equals $\Delta Y=L^{(1-\alpha)} K^{\alpha}=L_{1}^{(1-\alpha)} K_{1}^{\alpha}+L_{2}^{(1-\alpha)} K^{\alpha}{ }_{2}$
} 
The losing region has also invested in attracting the firm but there are no direct benefits. Taking this into account we find the following change in income for the losing region:

$$
\Delta Y_{2}(\text { comp })=\Delta w L_{2}-\frac{1}{4}\left[\Delta w L_{2}+\pi\right]=\frac{3}{4} \Delta w L_{2}-\frac{1}{4} \pi
$$

Although the region loses the competition game, it still benefits thanks to the fact that the settlement of the innovative firm in any region will increase the overall wage rate and thus also the wage rate in the losing region. Losing the competition then results in an income loss equal to $\frac{1}{4}\left[\Delta w L_{1}+\pi\right]$. The overall effect on the losing region is still positive because equation (4.22) is positive. ${ }^{85}$

\section{Proposition 4.1:}

Competition between regions for an innovative firm will decrease efficiency.

\section{Proof:}

If there is no competition the overall increase in income equals $\Delta Y=\Delta Y_{1}+\Delta Y_{2}=\Delta w L_{1}+\pi+\Delta w L_{2}=\Delta w L+\pi$, where $\Delta Y_{1}$ is the increase in production and income of the winning region and $\Delta Y_{2}$ is the increase in production and income in the losing region. In case of competition this increase amounts to:

$$
\Delta Y(\mathrm{com})=\Delta Y_{1}(\mathrm{comp})+\Delta Y_{2}(\mathrm{comp})=\frac{3}{4}\left[\Delta w L_{1}+\pi\right]+\left\lfloor\frac{3}{4} \Delta w L_{2}-\frac{1}{4} \pi\right\rfloor=\frac{3}{4} \Delta w L+\frac{1}{2} \pi . \quad \text { From }
$$

this we see that $\Delta Y>\Delta Y$ (comp).

Let us now compare a situation of competition with one of no competition. If there is no competition then, as we have said, the firm will settle in region 1. Comparing competition with no competition results in $\Delta Y_{1}(\mathrm{comp})=\frac{3}{4} \Delta Y_{1}<\Delta Y_{1}$. The reason for this is that region 1 now has made investments in effort to win the game, namely $\frac{1}{4} \Delta Y_{1}$. These, then, are the costs of the competition between the two regions. The benefits of the competition game to region 2 are the following: no competition results in an increase of income, $\Delta w L_{2}$, and an overall wage increase.

\footnotetext{
${ }^{85}$ Equation (4.22) is positive if $3 \Delta w L_{2}>\pi$. Inserting equation (4.16) and (4.17) and thus for an increase in wage income, i.e. $w L_{2}$ and profit we have $3 \alpha L^{1-\alpha} K^{\alpha}>K$, which reduces to $3 \alpha L^{1-\alpha}>K^{1-\alpha}$ and $(3 \alpha)^{1 /(1-\alpha)} L>K=\alpha^{2 /(1-\alpha)} L$. Finally canceling labour results in $(3 \alpha)^{1 /(1-\alpha)}>\alpha^{2 /(1-\alpha)}$ which will hold because $0<\alpha<1$.
} 
If region 2 wins the game the benefits are $\frac{3}{4}\left[\Delta w L_{2}+\pi\right]$. The region benefits if $\frac{3}{4}\left[\Delta w L_{2}+\pi\right]>\Delta w L_{2}{ }^{86}$. If it loses the game it still can benefit from an overall increase in the wage income. If the externalities are not taken into account in the decision process, competition is attractive to region 2 because $\frac{3}{4}\left[\Delta w L_{2}+\pi\right]>0$. This is the incentive for region 2 to start the competition game.

\section{Proposition 4.2:}

There is always an incentive for regions to compete for innovation if interregional externalities are not taken into account.

\section{Proof:}

The expected benefits of competition exceed that of no competition; that is, $\frac{3}{4}\left[\Delta w L_{2}+\pi\right]>0$.

So the overall picture that emerges is that this kind of competition is not beneficial to both regions. The expected increase in income with competition exceeds the expected increase in income without competition, for the two competing regions separately and on aggregate ${ }^{87}$.

\subsection{Innovations, Subsidies and Opportunistic Behaviour of the Innovative Firm}

In the previous section we described the competition for innovative firms between regions. An important incentive to compete is that innovations result in positive externalities. In their decision to compete, regions do not take account of positive spill over's due to innovation for competing regions, although this is the reason for attracting such firms. Once a firm has settled it is supposed to invest in innovation, which generates externalities. The firm's investments are expected to be below the social optimum, because the firm does not take externalities into account. If innovations generate positive externalities, government

$$
\begin{aligned}
& { }^{86} 3 \pi>\Delta w L_{2} \text { substituting result in } 3 K>\alpha L^{1-\alpha} K^{\alpha} \text { which leads to } K^{1-\alpha}>\frac{\alpha}{3} L^{1-\alpha} \text {.Simplifying this results } \\
& \text { in } K>\left(\frac{\alpha}{3}\right)^{1 /(1-\alpha)} L \text {. Next substitution the equilibrium value for } K(4.5) \text { we have } \alpha^{2 /(1-\alpha)}>\left(\frac{\alpha}{3}\right)^{1 /(1-\alpha)} \text { thus } \\
& \alpha^{2}>\left(\frac{\alpha}{3}\right) \text { that is } \alpha>\frac{1}{3} \text {. } \\
& { }^{87} \Delta Y_{1}>\Delta Y_{1}(\text { comp }) \text { and } \Delta Y_{2}>\Delta Y_{2}(\text { comp }) \text { so } \Delta Y=\Delta Y_{1}+\Delta Y_{2}>\Delta Y_{1}(\text { comp })+\Delta Y_{2}(\text { comp }) \text {. }
\end{aligned}
$$


intervention is necessary to internalize such externalities. With externalities, in terms of the model presented in the previous section, the price of capital goods is in excess of marginal cost. This implies that the level of capital stock is below the social optimum. This social optimum is reached when the profits of capital-goods-producing firms reduce to zero and the price of capital goods equals marginal costs, in our case unity. From the demand function for the final goods we can obtain the size of the optimal capital stock. Inserting price, which equals marginal costs (unity), in the price / demand function of (4.3), this results in $1=\alpha L^{1-\alpha} K_{j}^{\alpha-1}$ and an optimal capital stock of $K_{j}=K=\alpha^{1 /(1-\alpha)} L$.

The problem with setting the price equal to marginal costs is that it reduces the firm's profit to zero, leaving no incentive for the firm to invest in R\&D. To reach a perfect competition outcome the government could also give capital-good-producing firms a subsidy in the amount of $\frac{(1-\alpha)}{\alpha}$ for each capital good produced. The incentive to innovate is then artificially introduced. Let us look more carefully at the consequences of this kind of policy. Does it increase innovative investments and therefore generate more externalities? For instance, is it possible for a region to enhance regional welfare by offering a subsidy to a potential investor who wants to develop a new patent?

In this section we consider one region only, and we retain the assumptions of the previous sections. Our point of departure is that innovative firms do not know beforehand whether or not investment in innovation (resulting in the establishment of a new patent) will be successful and as such the investment is risky. What they do know is that the more they invest the greater their probability of success, but at a decreasing rate. Firms invest up to the point where the expected benefits equal the costs. Note that in case of externalities this is, of course, below the socially desirable level. Therefore the regional government can decide to support the firm financially. The regional government, however, is not able to observe the investment behaviour of the firm directly, as this information is confidential to the innovative firm. It can only observe the result ${ }^{88}$ (expressed by such indicators as the number of patents obtained by the firm).

Let us first turn to the innovative firm. A priori it is not clear to the firm whether the investments in innovation will be successful and result in a patent. We assume there is a relation between the level of investment (z) and the probability of having success, $\phi(z)$. We can describe the probability function of successful innovation as follows:

$$
\mu=\phi(z), \mu^{\prime}>0, \mu^{\prime \prime}<0 \text { and } \phi(0)=0
$$

\footnotetext{
${ }^{88}$ We adopt the approach off Gertler \& Rogoff (1990) and Aghion \& Howitt (2009) pp. 94-96.
} 
A greater amount of investment increases the probability of success and as such the expected profit, but at a decreasing rate. As in the previous sections, we distinguish two types of firms, i.e. firms operating under perfect competition, with zero profit, and innovative firms with a positive profit level, $\pi_{j}=\pi$, for $j=1, \ldots, N$. Let us assume that the firm could alternatively invest its money on the international capital market, where $r$ is the given world riskless interest rate and $R=1+r$ is return on capital. Obviously, in a world without any risk, the following condition must hold: $\mu^{\prime}(0) \pi_{j}>R=1+r$, because otherwise no investment in innovation will be made. It is now easy to obtain the expected profit of the innovative firm:

$$
E\left(\pi_{j}\right)=\mu\left(z_{j}\right) \pi_{j}+\left(1-\mu\left(z_{j}\right)\right) 0-z_{j}(R)
$$

The expected profits from investing in innovative activities equal the expected revenues of innovation minus the cost of $R \& D$. The first term in (4.23) represents the profit in case of success; the second represents the outcome if the innovation fails. The third term represents the opportunity costs, the return on riskless investments. Taking the first derivative with respect to expenditure on $\mathrm{R} \& \mathrm{D}$ results in the following expression:

$$
\mu^{\prime}\left(z_{j}\right) \pi_{j}=R
$$

This expression states that the marginal benefits of $R \& D$, that is, the incremental probability times the value of success due to $R \& D$, equals the marginal costs, that is, the opportunity cost of riskless outside investments. The firm will invest up to the point where (4.24) is satisfied. This means it will invest in $R \& D$ up to the point where the expected return equals the "riskless" rate of return outside the firm, which are the opportunity costs. For our analyses we use the following relation between investment in R\&D and the probability of successful innovation:

$$
\mu_{j}=\theta z_{j}^{\sigma}
$$

The parameter $\theta$ is an indicator of the productivity (see previous section) of R\&D and $\sigma$ is the elasticity, which lies between zero and one. The probability function satisfies the conditions that $\mu^{\prime}{ }_{j}=\sigma \theta z_{j}{ }^{\sigma-1}>0$ and $\mu^{\prime \prime}{ }_{j}=(\sigma-1) \sigma \theta z_{j}{ }^{\sigma-2}<0$ because $(\sigma-1)<0$. It is easy now to use this specific function to determine the investment in R\&D of the firm. Using the 
first-order condition, equation (4.24) gives the firm's profit in case the innovation is successful: ${ }^{89}$

$$
\sigma \theta z_{j}^{\sigma-1} \pi=R
$$

This leads to the optimal level of investment in R\&D of $z_{j}=z^{*}{ }_{j}$. This level of investment results in the greatest possible profit of the firm. Rearranging equation (4.26), the firm's investment in $\mathrm{R} \& \mathrm{D}$ amounts to:

$$
z_{j}^{*}=\left[\frac{\sigma \theta \pi}{R}\right]^{\frac{1}{1-\sigma}}
$$

The quantity of resources available for R\&D depends on the profit, productivity of R\&D and the world riskless return on capital. The social optimal level of R\&D associated with the optimal amount of capital and a corresponding profit ( $\bar{\pi}$ )for the firm, equals: ${ }^{90}$

$$
\bar{z}_{j}^{*}=\left[\frac{\sigma \theta \bar{\pi}}{R}\right]^{\frac{1}{1-\sigma}}
$$

Here $\bar{z}^{*}{ }_{j}$ is the social optimal level of R\&D. Evidently, the level of private investments of the firm is below the social optimal level of investments due to positive externalities, which are ignored by the firm in its decision making process. The amount of capital resulting from the firm's decision, and the optimal amount a central planner would chose to maximize income and production, differ by a factor $\alpha^{1 /(1-\alpha)}$. It can be verified from equations (4.27) and (4.28) that $\bar{z}^{*}{ }_{j}>z^{*}{ }_{j}{ }^{91}$, they differ by a factor $\alpha^{1 /(1-\alpha)}$.

\footnotetext{
${ }^{89}$ For the profit of the innovative firm we have substituted the optimal amount of capital, which is $\pi=\frac{1-\alpha}{\alpha} K=\frac{1-\alpha}{\alpha} \alpha^{\frac{2}{1-\alpha}} L$ this results in: $\sigma \theta z_{j}{ }^{\sigma-1} \frac{(1-\alpha)}{\alpha} \alpha^{\frac{2}{1-\alpha}} L=R$.

${ }^{90}$ Social optimal capital stock equals: $K=\alpha^{\frac{1}{(1-\alpha)}} L$. The corresponding firm profit equals: $\bar{\pi}=\frac{1-\alpha}{\alpha} \alpha^{\frac{1}{(1-\alpha)}} L$. Using (4.24) we have $\sigma \theta z_{j}^{\sigma-1} \frac{(1-\alpha)}{\alpha} \alpha^{\frac{1}{1-\alpha}} L=R$. Note that we have the following relation between the two profits: $\pi=\alpha^{1 /(1-\alpha)} \bar{\pi}$.

${ }^{91}$ We know that $z^{*}{ }_{j}=\alpha^{1 /(1-\alpha)} z^{*}{ }_{j}$ and because for $0<\alpha<1$ we have: $0<\alpha^{1 /(1-\alpha)}<1$.
} 
Assuming full information first, it is essential for the region to determine what the financial contribution should be. To do so, it first determines the socially optimal level of investment in R\&D exceeds the private level of investment $\left(\bar{z}^{*}{ }_{j}>z^{*}\right)$. Next, the region offers a subsidy to the firm in order to increase the amount it invests, up to the social desirable level of investment. The firm is financially supported to invest up to this level $\left(e_{j}=\bar{z}_{j}{ }_{j}-z^{*}{ }_{j}\right)$. In our example this would result in a subsidy, which amounts to:

$$
e_{j}=\left\lfloor\frac{1}{\alpha^{1 /(1-\alpha)}}-1\right\rfloor z^{*}
$$

In reality the size of an investment is confidential information to the firm and cannot be observed by the regional government. This means that any financial support can also be used by the firm for investments other than in R\&D when this is more profitable.

To see how we may proceed, let us take a look at the following expected profit function, assuming the firm will receive a subsidy of $e_{j}=\bar{z}_{j}^{*}-z^{*}{ }_{j}$, see equation (4.29). In case the investment is successful the firm earns a positive monopoly profit; otherwise it will earn no profit. This means that if the investment is not successful, the firm will not be able to refund the subsidies received. This results in the following adjusted profit function:

$$
E \pi_{j}=\mu\left(z_{j}+e_{j}\right) \pi_{j}-z_{j} R
$$

The optimal level of the firm's investment can be derived from the first-order condition:

$$
\mu^{\prime}\left(z_{j}+e_{j}\right) \pi_{j}=R
$$

Comparing (4.31) with (4.24) gives $\left(z_{j}+e_{j}\right)=z^{*}{ }_{j}$ because the term on the right-hand side is the same in both cases, and thus $z_{j}=z^{*}{ }_{j}-e_{j}$. This means that the level of investment without financial support through subsidy is the same as when the firm receives a subsidy. Applying the previous example we see that:

$$
z_{j}=z^{*}{ }_{j}-e_{j}=\left\lfloor 1-\frac{1}{\alpha^{1 /(1-\alpha)}}\right\rfloor z^{*}
$$

If we take the level of innovation financed by the firm in case the firm is financially supported and compare that with the case of no financial support, we conclude that the proportion of private investment in $\mathrm{R} \& \mathrm{D}$ decreases. Comparing equations we find that $z_{j}<z^{*}{ }_{j}$ because 
$\left\lfloor 1-\frac{1}{\alpha^{1 /(1-\alpha)}}\right\rfloor<1$ due to the fact that $0<\alpha<1$. The part of the investment in $\mathrm{R} \& \mathrm{D}$ that is financed by the firm decreases by the amount of subsidy it receives for innovation: it is more profitable to invest outside the firm because the return exceeds that of investing in R\&D.

In case the investments cannot be monitored, it is impossible to internalize these positive externalities by means of financial support to the innovative firms. We thus arrive at the following proposition.

\section{Proposition 4.3:}

In the case of asymmetric information between the firm and regions, financial support by the region will not increase investment in innovation and externalities will not be internalized.

\subsection{Summary of the Results and Conclusions}

In this chapter we first analyzed the contribution of innovation to economic development and efficiency. To highlight the effects we made use of the expanding products variety model of endogenous growth introduced by P. Romer. Innovation results in improved capital goods, which increase efficiency, production and income. We differentiated between the level of investment as a result of a firm's decision to invest in R\&D (not taking into account the externalities resulting from $R \& D$ ) and the level of investment resulting from a decision by a central planner (taking such externalities into account), as can be seen in tables 4.1A and 4.1B below. We next looked at the possible contribution of an innovative firm to a region in terms of production and income, in the case of competition between two regions to gain the settlement of an innovative firm. Assuming region 1 wins the game, table 4.2 summarizes the increases in income and production that result from the innovative firm's settlement in region 1. 
Table 4.1A Output, Production and Income

\begin{tabular}{|c|c|c|}
\hline $\begin{array}{l}\text { Output and Production } \\
\text { and Income }\end{array}$ & $\begin{array}{l}\text { Decentralized Firms } \\
\text { Decision }\end{array}$ & Centralized Decision \\
\hline$Y_{t}=L^{1-\alpha} \sum_{j=1}^{N_{t}} K_{j}^{\alpha}=N_{t} L^{(1-\alpha)} K^{\alpha}$ & $Y_{t}=L^{1-\alpha} \sum_{j=1}^{N_{t}} K_{j}^{\alpha}=N_{t} L^{(1-\alpha)} K^{\alpha}$ & $Y_{t}=L^{1-\alpha} \sum_{j=1}^{N_{t}} K_{j}^{\alpha}=N_{t} L^{(1-\alpha)} K^{\alpha}$ \\
\hline Capital stock: & $K=\alpha^{\frac{2}{(1-\alpha)}} L$ & $K=\alpha^{\frac{1}{(1-\alpha)}} L$ \\
\hline Output: & $Y_{t}=N_{t} \alpha^{\frac{2 \alpha}{(1-\alpha)}} L$ & $Y_{t}=N_{t} \alpha^{\frac{\alpha}{(1-\alpha)}} L$ \\
\hline $\begin{array}{c}\text { Innovation and R\&D: } \\
z^{*}{ }_{j}=\alpha^{1 /(1-\alpha)} z^{*}{ }_{j}\end{array}$ & $z_{j}^{*}=\left[\frac{\sigma \theta \pi}{R}\right]^{\frac{1}{1-\sigma}}$ & $\bar{z}_{j}^{*}=\left[\frac{\sigma \theta \bar{\pi}}{R}\right]^{\frac{1}{1-\sigma}}$ \\
\hline $\begin{array}{l}\text { Wage Income: } \\
(1-\alpha) N_{t} L^{1-\alpha} K^{\alpha}=(1-\alpha) Y_{t}\end{array}$ & $Y_{t}=(1-\alpha) N_{t} \alpha^{\frac{2 \alpha}{(1-\alpha)}} L$ & $Y_{t}=(1-\alpha) N_{t} \alpha^{\frac{\alpha}{(1-\alpha)}} L$ \\
\hline $\begin{array}{l}\text { Capital } \\
\text { Income: } r N_{t} \frac{\pi}{r}=N_{t} \frac{1-\alpha}{\alpha} K\end{array}$ & $N_{t} \frac{1-\alpha}{\alpha} \alpha^{\frac{2}{(1-\alpha)}} L$ & $N_{t} \frac{1-\alpha}{\alpha} \alpha^{\frac{1}{(1-\alpha)}} L$ \\
\hline
\end{tabular}

Table 4.1B Price of Capital Goods, Wage Rate, Profit and Return on Capital

\begin{tabular}{|c|c|c|}
\hline & $\begin{array}{l}\text { Decentralized Firm } \\
\text { Decision }\end{array}$ & Centralized Decision \\
\hline Price of Capital Goods: & $\frac{1}{\alpha}>M C=1$ & $1=M C$ \\
\hline $\begin{array}{l}\text { Wage Rate: } \\
w_{t}=(1-\alpha) N_{t} L^{-\alpha} K^{\alpha}\end{array}$ & $w_{t}=(1-\alpha) N_{t} \alpha^{\frac{2 \alpha}{(1-\alpha)}} L$ & $w_{t}=(1-\alpha) N_{t} \alpha^{\frac{\alpha}{(1-\alpha)}} L$ \\
\hline Profit: & $\pi=\frac{1-\alpha}{\alpha} \alpha^{\frac{2}{(1-\alpha)}} L$ & $\pi=\frac{1-\alpha}{\alpha} \alpha^{\frac{1}{(1-\alpha)} L}$ \\
\hline $\begin{array}{l}\text { Return on Capital: } \\
\quad R=\theta \pi\end{array}$ & $R=\theta \frac{1-\alpha}{\alpha} \alpha^{\frac{2}{(1-\alpha)}} L$ & $R=\theta \frac{1-\alpha}{\alpha} \alpha^{\frac{2}{(1-\alpha)}} L$ \\
\hline
\end{tabular}


Table 4.2

Benefits from Innovation and Innovative Firm

\begin{tabular}{|l|l|l|}
\hline & Winning Region 1 & Losing Region 2 \\
\hline $\begin{array}{l}\text { Increase in Income and } \\
\text { Production: } \\
\Delta Y=L^{(1-\alpha)} K^{\alpha}\end{array}$ & $\Delta Y_{1}=L_{1}{ }^{(1-\alpha)} K_{1}{ }^{\alpha}$ & $\Delta Y_{2}=L_{2}{ }^{(1-\alpha)} K_{2}{ }^{\alpha}$ \\
\hline $\begin{array}{l}\text { Increase in Wage Rate: } \\
\Delta w=(1-\alpha) L^{-\alpha} K^{\alpha}\end{array}$ & $\Delta w=(1-\alpha) \alpha^{\frac{2 \alpha}{(1-\alpha)}} L$ & $\Delta w=(1-\alpha) \alpha^{(1-\alpha)} L$ \\
\hline $\begin{array}{l}\text { Increase in Final Goods: } \\
L^{1-\alpha} K^{\alpha}-K\end{array}$ & $L_{1}{ }^{1-\alpha} K_{1}{ }^{\alpha}-K$ & $L_{2}{ }^{1-\alpha} K_{2}{ }^{\alpha}$ \\
\hline $\begin{array}{l}\text { Increase in Capital } \\
\text { Goods: }\end{array}$ & $K$ & 0 \\
\hline $\begin{array}{l}\text { Increase in Capital } \\
\text { Income / Profit: } \\
\pi\end{array}=\frac{1-\alpha}{\alpha} K=\pi$ & $R \frac{\pi}{R}=\frac{1-\alpha}{\alpha} K=\pi$ & 0 \\
\hline $\begin{array}{l}R \\
R\end{array}$ & $R$ & \\
\hline
\end{tabular}

Table 4.3

Effect of Competition on Regional Incomes

\begin{tabular}{|l|l|l|}
\hline & Winning Region 1 & Winning Region 2 \\
\hline $\begin{array}{l}\text { Optimal Effort Level: } \\
e_{1}+e_{2}=1 / 4 \Delta Y\end{array}$ & $\begin{array}{l}e_{1}=1 / 4 \Delta Y_{1}= \\
1 / 4\left(\Delta w L_{1}+\pi\right)\end{array}$ & $\begin{array}{l}e_{2}=1 / 4 \Delta Y_{2}= \\
1 / 4\left(\Delta w L_{2}+\pi\right)\end{array}$ \\
\hline $\begin{array}{l}\text { Increase in Wage } \\
\text { Income: }\end{array}$ & $3 / 4 \Delta w L_{1}$ & $3 / 4 \Delta w L_{2}$ \\
\hline $\begin{array}{l}\text { Increase in Capital } \\
\text { Income: }\end{array}$ & $\pi$ & 0 \\
\hline $\begin{array}{l}\text { Increase in Net } \\
\text { Income: }\end{array}$ & $\Delta Y_{1}=3 / 4\left(\Delta w L_{1}+\pi\right)$ & $\Delta Y_{2}=3 / 4 \Delta w L_{2}-1 / 4 \pi$ \\
\hline $\begin{array}{l}\text { Increase in Net Income } \\
\begin{array}{l}\text { According the } \\
\text { Competing Region: }\end{array}\end{array}$ & $3 / 4\left(\Delta w L_{1}+\pi\right)$ & $-1 / 4 \pi$ \\
\hline
\end{tabular}





\section{Chapter 5}

Economic Integration and Institutional Differences 


\subsection{Introduction}

In the previous two chapters we dealt with competition between autarchic regions. We concluded that it is very questionable whether competition will lead to improved efficiency and as such will contribute to an increase in welfare. In this chapter we consider the benefits of co-operation between regions. Economic cooperation between regions was defined in chapter 1 as any type of arrangement in which regions agree to coordinate their economic activities. Such coordination can take the form of economic integration in case the coordination is aimed at integrating product and/or factor markets. With integrated markets, factors of production will be used where they are most productive. In this chapter we focus on capital mobility and the integration of regions with different institutions. In this way we address research question 4 , What are the consequences of regional integration for efficiency when regions differ in their institutional structure.

There is a vast body of literature on international economics covering the topics economic cooperation and economic integration (see for example, Obstfeld and Rogoff,1996 and Krugmann and Obstfeld, 2002 ). Next to that some of the literature specifically focuses on European economic integration, (for example Baldwin and Wyplosz (2009) and Pelkmans (2001) but differences in institutional aspects are seldom taken into consideration when analyzing the effects of economic integration. Our approach takes into account differences in institutional settings, their effect on factor markets in a broad sense, and on regions that integrate. We follow more or less the work of Acemoglu, Johnson and Robinson (2005) ${ }^{92}$ emphasizing the role of different institutions on economic development. We especially focus on the effects of different institutions on the economic integration between regions,

In the economic literature on institutions it is noted that institutions change very slowly. If factor markets are greatly influenced by all kind of institutional arrangements, which are rather fixed and change very slowly, this has two important implications for our analyses. First, factor intensities, capital-output and labour-output ratios are determined by those institutional arrangements and not by their marginal productivity, as is assumed in the neoclassical approach. This points to using a Leontief production function rather than a neoclassical one (Hussein and Thirlwall (2000), pp. 427-435).

Secondly, rather than using the marginal productivity approach, we assume that factor remuneration is greatly influenced by the bargaining process of factor owners. To model this bargaining process we shall use elements from the economic theory of conflict and contest, as we did in the previous chapter, in combination with a Harrod-Domar growth model. In this growth model both capital and labour are taken to be proportional to output. This captures

\footnotetext{
${ }^{92}$ As a striking example they take the economic development of North- and South-Korea, where the former country is led by a centralized economy opposite to the latter, which is based on a market economy. They also refer to former colonies and their economic current development influenced by the types of colonial regimes previously.
} 
quite nicely the fact that factor proportions resulting from institutional arrangements change very slowly. Factor prices are no longer determined by production technology but instead by wage negotiations. The microeconomic foundation of this approach is given in Stauvermann (2005) and Geerdink \& Stauvermann (2006), who analyze a closed economy with an OLG structure and a Leontief production function.

In a closed economy the results of using a neoclassical production function are very similar to the results of using a Leontief production function, except for a few specific characteristics. ${ }^{93}$ However, the results differ considerably when one analyzes an open economy with capital mobility. Using a neoclassical production function, under specific conditions, Pareto improvements can be realized by opening the capital markets. See for example Rogoff and Obstfeld (1996) and Buiter (1981) ${ }^{94}$. In our model however, opening capital markets will not lead to an increase of efficiency because factor prices are determined by institutional settings and arrangements. The rate of return on capital, which is determined by the institutional setting, will influence the movement of capital in case of integration. Some individuals will be better off after opening the capital markets, but others will be harmed: at best it is a zero sum game. None of the regions concerned will benefit; at best, all regions will maintain the autarchy situation or lose. Additionally, it makes clear how important social standards, like labour laws and industrial laws, are in determining the factor prices.

The chapter is structured as follows. In section 2 we lay the foundation for the rest of the chapter. We deal with the production side of the economy and model the bargaining process between factor owners by means of a contest success function. This provides us with the microeconomic foundation of income distribution of the Leontief production function. Factor income and factor prices are determined and the equilibrium ${ }^{95}$ situations are described. Then, for the consumption side of the economy, we make use of the results of a two-period, overlapping generations model (OLG) with a log-linear utility function. This allows us to compare two periods, namely the period before integration (the autarchy case) and the period after integration. Section 3 starts with an analysis of the case of two autarchic regions. We then analyze the consequences of integration of the two regions, i.e. the transition from autarchy to an open economy with one capital market. Depending on the magnitude of capital movement from one region to another, different post-integration scenarios can be discerned. In section 4 we consider three different post-integration scenarios in more detail:

- Case 1: both regions are in equilibrium;

\footnotetext{
${ }^{93}$ For example the transition path to the steady state in the model of Stauvermann (2005) unemployment will always be present and in the steady-state, capital will always be over-accumulated.

${ }^{94}$ Buiter analyzes the integration of economies with a different time preference. He particularly analyzes the effect of openness on its welfare effects.

${ }^{95}$ By equilibrium we mean equilibrium in output and production but not necessary capital stock. Because a Leontief production function is used the capital stock can change without a change in the equilibrium level of output and production.
} 
- Case 2: region 2 is on a growth path;

- Case 3: region 2 ceases to exist.

In analyzing these three cases we distinguish between the short-run effects of this transition process and the long-run effects. Section 5 summarizes and section 6 concludes.

\subsection{Institutional Arrangements and Income Distribution}

In this section we model the economy of a representative region. We discuss factor remunerations first, in a static version, followed by consumption and savings decisions (section 5.2.1). In section 5.2.2 we turn the model into a dynamic version.

\subsubsection{Institutions Determining Factor Remunerations}

As was explained in the previous section, rather than assuming that capital and labour are perfect substitutes, as is done in neo-classical models, we assume a fixed capital-labour ratio. We do not assume perfect competition on the factor markets (capital and labour market) but instead we assume a bilateral monopoly. Because the techniques are fixed on the "short run" for the production function of firm $j$, representing the production side of the economy, we use a Leontief type of production function as in the Harrod-Domar model of economic growth. This production function is given by $Y=F(K, L)=\min \{A K, B L\}$ where $\mathrm{A}$ and $\mathrm{B}$ are the fixed coefficients, i.o. one unit of output requires $1 / A$ of capital and $1 / B$ of labour. If capital or labour falls short of the minimum requirement, it cannot be compensated by substituting the other input. As a result there will either be a surplus of capital or of labour. In the HarrodDomar model capital is the limiting factor, that is $A K<B L$ and $Y=A K$. Capital accumulation results in an increase in capital stock and as such to a growth in production and income. On the other hand, capital accumulation is the result of the economy's savings. This relation provides the dynamics of the model by means of the "equation of motion".

We use the modified production function, namely $Y_{j}=A \min \left[K_{j}, L_{j}\right]$. Here $Y_{j}$ represents the firm's output of final goods. $A$ is a constant productivity shift parameter, $K_{j}$ is the capital used, whereas $L_{j}$ is the labour employed. Aggregating over all $n$ firms, this results in the aggregate production:

$$
Y=A \min [K, L]
$$

$K$ represents the capital stock and $L$ represents the labour force in the region which are measured in efficiency units. We assume that the labour force is constant and therefore it can 
be normalized to one; $L=1$. Notice that as a result, variables can also be expressed as per capita variables.

Our assumption is that, in the short run $^{96}$, the distribution of income will be determined by the negotiations between labour and capital owners. These negotiations are highly institutionalized. Below we describe the bargaining process between wage earners and capital owners using a contest success function. The workers maximize the labour share of income, that is $w L$. If we normalize the labour force this reduces to maximizing $w$, i.e. the wage rate. The wage rates are the same for all firms and workers throughout the economy; the bargaining process between workers and capital owners is bilateral: two monopolists are bargaining. Given the institutional arrangements, both monopolists determine the effort level which gives them the largest share of income. This results in the following maximization problem for the wage earners:

$$
\underset{e_{L}}{\operatorname{Max}} w=\frac{G_{L}+e_{L}}{G_{C}+G_{L}+e_{C}+e_{L}} Y-e_{L}
$$

If we set $L=1$, the wage rate is also the wage income. The price of the contest is the share of income (given by equation (5.1)) to be received by workers and capital owners. The institutional arrangements, which are given by industrial and social laws (e.g. minimum wage), are represented by $G_{L}$ and $G_{C}$. If the institutional arrangements are in favour of the workers and capital owners, respectively, this could be seen as a specific fixed-type of investments of workers and capital owners. These arrangements have public good characteristics and are (at least partly) non- exclusive and non-rival. In part they determine the bargaining positions of the players. These variables are under the control of the government and are exogenous for capital owners and workers. The variables $e_{L}$ and $e_{C}$ represent the effort levels, stakes of the workers and the capital owners (e.g. times of strike and times of lock-out). The terms $G_{L}+e_{L}$ and $G_{C}+e_{C}$ are the as to say comparative advantage and 'effective' effort levels of wage earners and capital owners, respectively. We only take positive effort levels into consideration. The bargaining position of workers and capital owners depends on the institutional setting and the relative effort invested by workers and capital owners. If the institutional arrangements are in favour of workers $\left(G_{L}\right)$, then this strengthens the relative bargaining position of the workers $\left(\frac{G_{L}+e_{L}}{G_{C}+G_{L}+e_{C}+e_{L}}\right)$. If the institutional arrangements are in favour of capital owners $\left(G_{C}\right)$ this strengthens the relative

\footnotetext{
${ }^{96}$ By short run we mean the period in which there is no change in institutional structure.
} 
bargaining position of the capital owners $\left(\frac{G_{C}+e_{C}}{G_{C}+G_{L}+e_{C}+e_{L}}\right)$. For the capital owners the bargaining process can be written down in the same way as for the wage earners. Capital owners also want to maximize their share of income, namely $R K$, where $R$ is return on capital. This results in the following maximization problem:

$$
\underset{e_{c}}{\operatorname{Max}} R K=\frac{G_{C}+e_{C}}{G_{C}+G_{L}+e_{C}+e_{L}} Y-e_{C}
$$

Both parties, wage earners and capital owners, determine how much effort they will invest in gaining the largest share possible of total income, given the institutional arrangements. This optimum effort level can straight forward be found using the first-order conditions. We know that the outcome of a bilateral bargaining process will generally results in a reaction function. Using the two first-order conditions we find the following reaction functions of the wage earners and the capital owners ${ }^{97}$ :

$$
e_{L}=-e_{C}-G_{L}-G_{C}+\sqrt{\left(G_{C}+e_{C}\right) Y}
$$

and

$$
e_{C}=-e_{L}-G_{L}-G_{C}+\sqrt{\left(G_{L}+e_{L}\right) Y}
$$

As these two equations show, the optimum effort levels are interdependent, that is the effort level of capital owners influences that of the labourers and the other way around. The solution of these two equations leads to the following optimum effort levels for capital owners and wage earners: ${ }^{98}$

${ }^{97}$ The first-order conditions from (5.2) and (5.3) are respectively $\frac{\partial(w)}{\partial e_{L}}=\frac{\left(G_{C}+e_{C}\right)}{\left(G_{C}+G_{L}+e_{C}+e_{L}\right)^{2}} Y-1=0$ and $\frac{\partial(R K)}{\partial e_{C}}=\frac{\left(G_{L}+e_{L}\right)}{\left(G_{C}+G_{L}+e_{C}+e_{L}\right)^{2}} Y-1=0$.

${ }^{98}$ Inserting $\left(G_{L}+e_{L}\right)=\left(G_{C}+e_{C}\right)$ in the first order condition $\left(G_{C}+G_{L}+e_{C}+e_{L}\right)^{2}=\left(G_{C}+e_{C}\right) Y$ leading to $\left(2 G_{C}+2 e_{C}\right)^{2}=\left(G_{C}+e_{C}\right) Y=4\left(G_{C}+e_{C}\right)^{2}=\left(G_{C}+e_{C}\right) Y$. This results in the optimum $1 G_{C}+e_{C}=\frac{1}{4} Y$.

Because of symmetry we also have $G_{L}+e_{L}=\frac{1}{4} Y$ resulting in (5.5). Equating the two reaction functions from (5.4) gives the same result. 


$$
e_{L}^{*}=\frac{1}{4}\left(Y-4 G_{L}\right) \geq 0
$$

and

$$
e_{C}^{*}=\frac{1}{4}\left(Y-4 G_{C}\right) \geq 0
$$

Note that both effort levels depend negatively on institutional arrangements. In addition, higher effort levels lead to lower net income of capital owners and wage earners (see equation (5.2) and (5.3)). Economically the most efficient solution would be an effort level of both parties equal to zero. In that case no resources are wasted on strengthening their bargaining position. These resources can be used for either consumption or investments or both, which increases efficiency.

The institutional arrangements and settings can be seen as a kind of public good, see for example Dasgupta (2007, p. 90). Such institutional arrangements are at least partly non-rival and non-excludable. To make the analysis as simple as possible, we assume that the government invests sufficiently in institutional arrangements so that $\min \left[G_{L}, G_{C}\right]>1 / 4 Y$ holds. If this is the case then the overall government investments in institutional arrangements, $G$, are at the same time accessible for capital owners and wage earners. In case they are fully non-rival and non-excludable then, with respect to the institutional arrangements, we have $G=G_{C}+G_{L}<e_{C}+e_{L}$. Here we assume that the government can do this more efficiently than private parties. As emphasised in public finance the government can enforce all parties to contribute and so overcome the free rider problem of public goods. In other words, government investment in institutional settings generates positive externalities. Thus government investments can reduce or prevent private agents investing to increase their bargaining position, and so contribute for more efficiency and growth ${ }^{99}$.

If we assume that the government supplies an efficient institutional setting, then the outcome of the negotiations between factor owners depends only on the institutional arrangements in the region. If effort levels equal zero, see equation (5.2) and (5.3), than the income shares for capital and labour are ${ }^{100}$ :

\footnotetext{
${ }^{99}$ Gonzalez (2007, pp. 127-139) investigates more in general the role of property rights on growth. He investigates the interaction between conflict and growth, where resources can either be used to secure property right or for the production of economic goods. We however assume that there is a role for the government to secure property rights and those therefore private parties do not need to devote resources to secure property rights. We call this an efficient institutional setting. All private resources can be used for production of economic goods. All other constellation of the institutional setting would result in fewer resources for production and are thus not efficient.

${ }^{100}$ Note that there is no direct maximization of the factor owners, income distribution is given by the institutional setting.
} 


$$
\alpha=\frac{G_{C}}{G_{C}+G_{L}} \text { and }(1-\alpha)=\frac{G_{L}}{G_{C}+G_{L}}
$$

The income shares are fixed (i.e. $\alpha$ and $(1-\alpha)$ ) and depend only on the institutional arrangements represented by $G_{C}$ and $G_{L}$. Any investment in effort of the factor owners will lead to a lower income for both, wage earners and capital owners. This can be verified if we look at equations $\left((5.2)\right.$ and (5.3) and insert a positive level of effort $\left(e_{L}{ }^{*}=e_{C}{ }^{*}>0\right)$. This obviously does not need to be an efficient outcome in the economic sense. This will only be the case if income shares resulting from the bargaining process are equal to the marginal product which may not be very likely.

Taking the efficient ${ }^{101}$ institutional setting as our point of departure, we can determine the factor prices. This results in the income of wage earners and capital owners: $w=(1-\alpha) Y$ and $R K=\alpha Y \cdot{ }^{102}$ Using the Leontief type of production function (5.1) gives us in the wage rate and the return on capital, i.e.:

$$
w=(1-\alpha) A \min [K, 1] \text { and } R=\alpha \frac{A \min [K, 1]}{K}
$$

Here we divided the last expression by capital stock to obtain the return on capital. We also assume that the bargaining process is taking place between the boundaries set by the reservation wages and return on capital for wage earners and capital owners respectively. By reservation wage and return on capital we mean the wage rate and return on capital below which workers and capital owners are not willing to supply labour and capital. This implies that the following restriction has to be met:

$$
w \geq w_{\min } \text { and } R \geq R_{\min }
$$

The wage rate and return on capital corresponding to the reservation utility are, respectively, $w_{\min }$ and $R_{\min }$. If on of the limits is violated, one of the parties is not willing to co-operate and there will be no output and production by firms and thus on aggregate no output and income.

Using the Leontief production function given by equation (5.1) we first determine aggregate production in order to find the aggregate factor income. There are two possibilities,

\footnotetext{
101 This means that capital owners and wage earners do not need to invest effort in order to strengthen their bargaining position as to gain a larger share of income, thus $e_{L}=e_{C}=0$. Resources can thus be used by the private sectors for more productive use that increases income.

${ }^{102}$ We substituted $e_{L}=e_{C}=0$ in (5.2) and (5.3) in combination with (5.6).
} 
i.e. either capital, $K$ is the limiting factor or labour, $L=1$, is the limiting factor and therefore the production is given by:

$$
Y=\left\{\begin{array}{c}
A K, \text { if } K \leq 1 \\
A, \text { if } K>1
\end{array} .\right.
$$

The economy is in equilibrium in the case where $K>1$. In this case output depends on labour, which we have assumed to be constant and consequently output, is constant. It is on a growth path if $K \leq 1$ The capital stock will grow until $K>1$ and output until $Y=A$. Naturally this also applies to the factor prices below. Knowing the income, the corresponding factor prices of capital and labour are derived by substituting equation (5.8) in equation (5.7). This results in:

$$
R=\left\{\begin{array}{l}
\alpha A, \text { if } K \leq 1 \\
\frac{\alpha A}{K}, \text { if } K>1
\end{array}\right.
$$

and

$$
w=\left\{\begin{array}{c}
(1-\alpha) A K, \text { if } K \leq 1 \\
(1-\alpha) A \text { if } K>1
\end{array}\right.
$$

On the growth path $(K \leq 1)$, income and wage rates are increasing, whereas the return on capital is constant. In equilibrium $(K>1)$, the income and the wage rate are fixed and the return on capital decreases as the capital accumulation exceeds its optimal level. To illustrate the above results we include figures 5.1 and 5.2 below. 
Figure 5.1 Return on Capital and Capital Stock

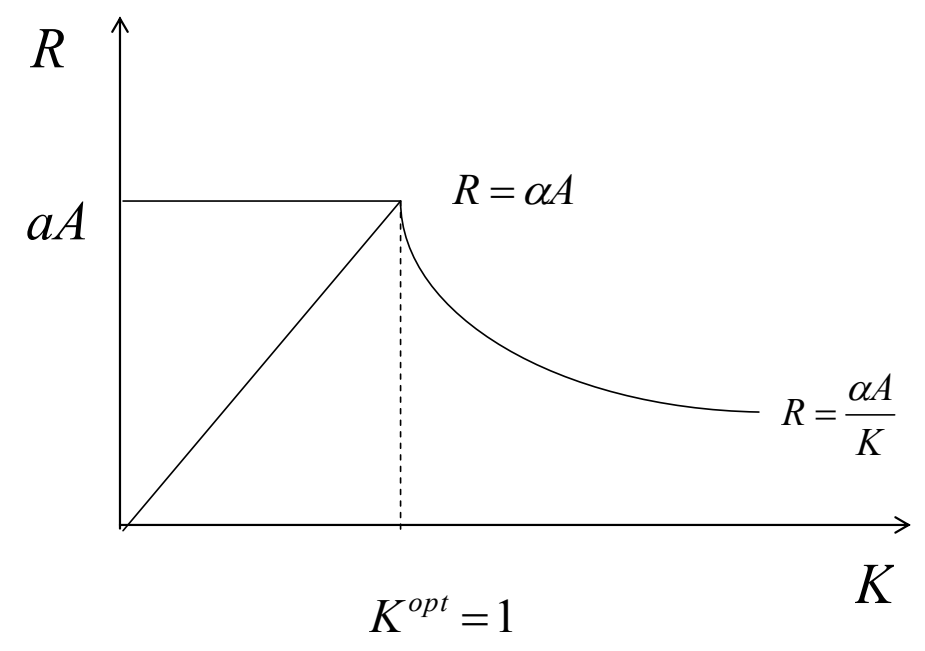

Figure 5.2 Income, Wage Rate and Capital Stock

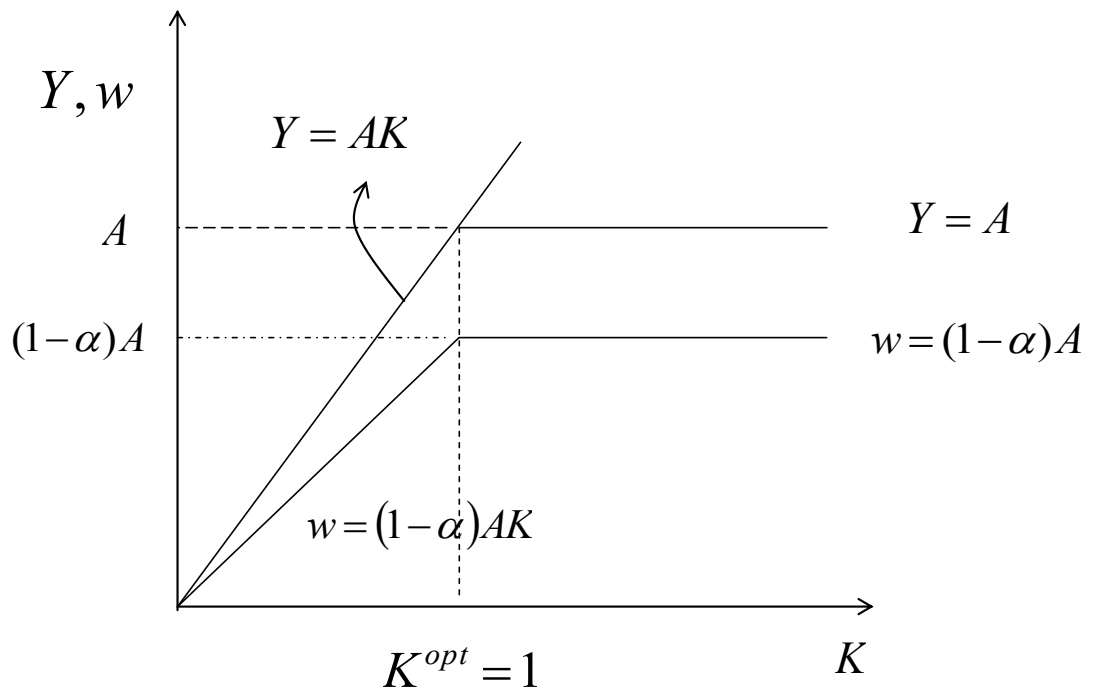


Here we can see the return on capital and the wage rate in both situations. The change from the growth path to equilibrium occurs where the optimal capital stock is achieved, i.e., $K^{o p t}=1$. We can distinguish two situations, namely the economy on a growth path $(K \leq 1)$ and in equilibrium ( $K>1$ ). In case $K<1$, capital is the limiting factor (see previous section) and otherwise labour is the limiting factor.

\subsubsection{Institutions, Growth and Equilibrium}

As we have seen above, the economy is either in equilibrium or on a growth path leading finally to equilibrium. This development is determined by the current period's savings and the next period's capital formation. This can be represented by introducing the dynamic version of the production function. We can make use of the production function of the previous chapter, namely equation (5.8), and add a time index to indicate that it depends on time:

$$
Y_{t}=\left\{\begin{array}{c}
A K_{t}, \text { if } K_{t} \leq 1 \\
A, \text { if } K_{t}>1
\end{array} .\right.
$$

The saving decisions are determined on the consumption side of the economy. Using a twoperiod overlapping generations model (OLG), we find the following aggregate saving function: $\left.S_{t}=s(1-\alpha) Y_{t}\right)^{103}$. Savings will also differ depending on the state of the economy, whether is it on a growth path or in equilibrium. Using equation (5.8') gives us:

$$
S_{t}=\left\{\begin{array}{c}
s(1-\alpha) A K_{t}, \text { if } K_{t} \leq 1 \\
s(1-\alpha) A, \text { if } K_{t}>1
\end{array}\right.
$$

\section{Equilibrium}

First we describe the steady-state equilibrium $\left(K_{t} \geq 1\right)$. In equilibrium the aggregate savings in period $t$ should match the capital stock in period $(t+1)$. The market clearing condition that must be fulfilled, that is, current savings, leads to next period's capital stock:

$$
K_{t+1}=S_{t}
$$

\footnotetext{
${ }^{103}$ To model a consumer's decision we made use of a two-period OLG model with log-linear utility function. This implies that the decision between current and next period consumption is independent of the interest rate, and thus the saving rate is independent of the interest rate and is constant. The first period generation works an receives a (wage) income, which is used for consumption and savings. These savings plus interest payments are use for the next period's consumption. A fixed part of the wage income is thus saved, i.e, $S=s(1-\alpha) Y$.
} 
This is the equation of motion we need, as noted before. In equilibrium, if $K_{t}=K_{t+1}=K>1$ and $Y_{t}=Y_{t+1}=A$, then the steady-state capital stock is given by:

$$
K=s(1-\alpha) Y=s(1-\alpha) A
$$

In equilibrium we have $K_{t}=K_{t+1}=K>1$, so we assume $s(1-\alpha) A>1$ holds. This equilibrium is globally stable. ${ }^{104}$. By globally stable we mean that if the economy deviates from the equilibrium position, it will eventually return to this position. Then the capital stock no longer does not change, nor do the other variables.

\section{Growth Path}

Next we look at the transition path or the growth path. The economy is on a transition path if $K_{t} \leq 1$. If this condition is fulfilled, a positive growth rate will be realized. Then we have the following equation for capital accumulation (see equation $(5.11),(5.12)$ and $\left(5.8^{\prime}\right)^{105}$ :

$$
K_{t+1}=s(1-\alpha) A K_{t}
$$

Using the previous equation we can alternatively write the equation for the growth rate:

$$
1+g=\frac{K_{t+1}}{K_{t}}=s(1-\alpha) A>1
$$

In this case the economy is on a growth path and capital stock changes at a rate of $g$ over time. This growth rate of capital stock is also the growth rate for income and consumption. ${ }^{106}$

\footnotetext{
${ }^{104}$ The growth of capital stock which equals $\frac{K_{t+1}}{K_{t}}=s(1-\alpha) \frac{Y_{t}}{K_{t}}$. In this case we have $Y_{t}=A$ and $K_{t}=K=s(1-\alpha) A$ and thus $\frac{K_{t+1}}{K_{t}}=1$.

${ }^{105}$ From equation (5.10) we have $K_{t+1}=S_{t}$ and from (5.8') we have $S_{t}=s(1-\alpha) A K_{t}$, because $K_{t} \leq 1$

and thus $\frac{K_{t+1}}{K_{t}}=s(1-\alpha) A$ and capital stock increases at a fixed rate.

$106 \frac{Y_{t+1}}{Y_{t}}=\frac{A K_{t+1}}{A K_{t}}=\frac{K_{t+1}}{K_{t}}=1+g$. Using the resource constraint $Y_{t+1}=C_{t+1}+K_{t+2}$ we find

$(1+g) Y_{t}=\left(1+g_{c}\right) C_{t}+(1+g) K_{t+1}$ which results in $1+g_{c}=1+g$, and thus $g_{c}=g$.
} 
Complementary to the growth in capital stock we can also easily derive the growth in income. Using equation (5.14), (5.15) and (5.8') the growth path of income equals: ${ }^{107}$

$$
Y_{t+1}=s(1-\alpha) A Y_{t} \text { and } \frac{Y_{t+1}}{Y_{t}}=s(1-\alpha) A
$$

The corresponding growth rate of income of course equals the growth rate of capital stock. As we have normalized population as equal to 1 these are also the per capita growth rates. We illustrate the above results in figures 5.3 and 5.4.

In figure 5.3 we see that the economy is on a growth path, $Y_{t}=A K_{t}$, until the capital stock reaches $K_{t}=1$. If the capital stock exceeds 1 then the economy is in equilibrium, that is $Y_{t}=Y^{*}=A$. We should note that unemployment is present on the transition path, because $K_{t}<L_{t}=1$. Consequently the unemployment rate is given by $\left(1-K_{t}\right) 100 \%$. In case $K_{t}>1$ then $Y_{t}=A L_{t}$ and thus there is full employment.

\section{Figure 5.3 Income, Output and Capital Stock}

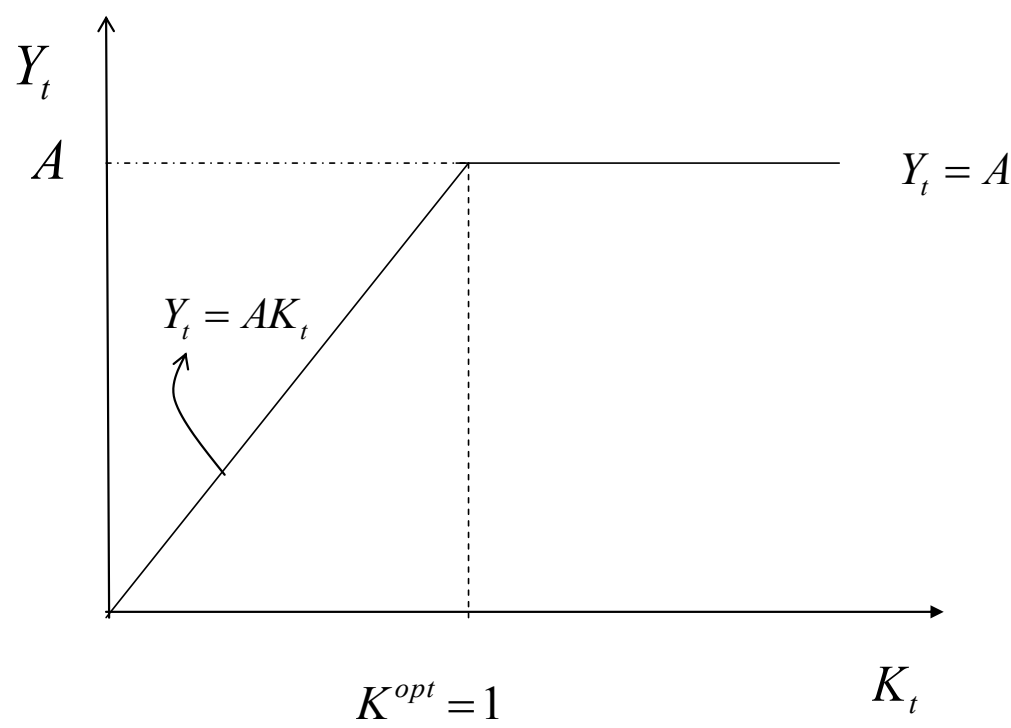

${ }^{107} Y_{t+1}=A K_{t+1}$ and $K_{t+1}=s(1-\alpha) A K_{t}=s(1-\alpha) Y_{t}$. 
Figure 5.4 Equilibrium Capital Stock

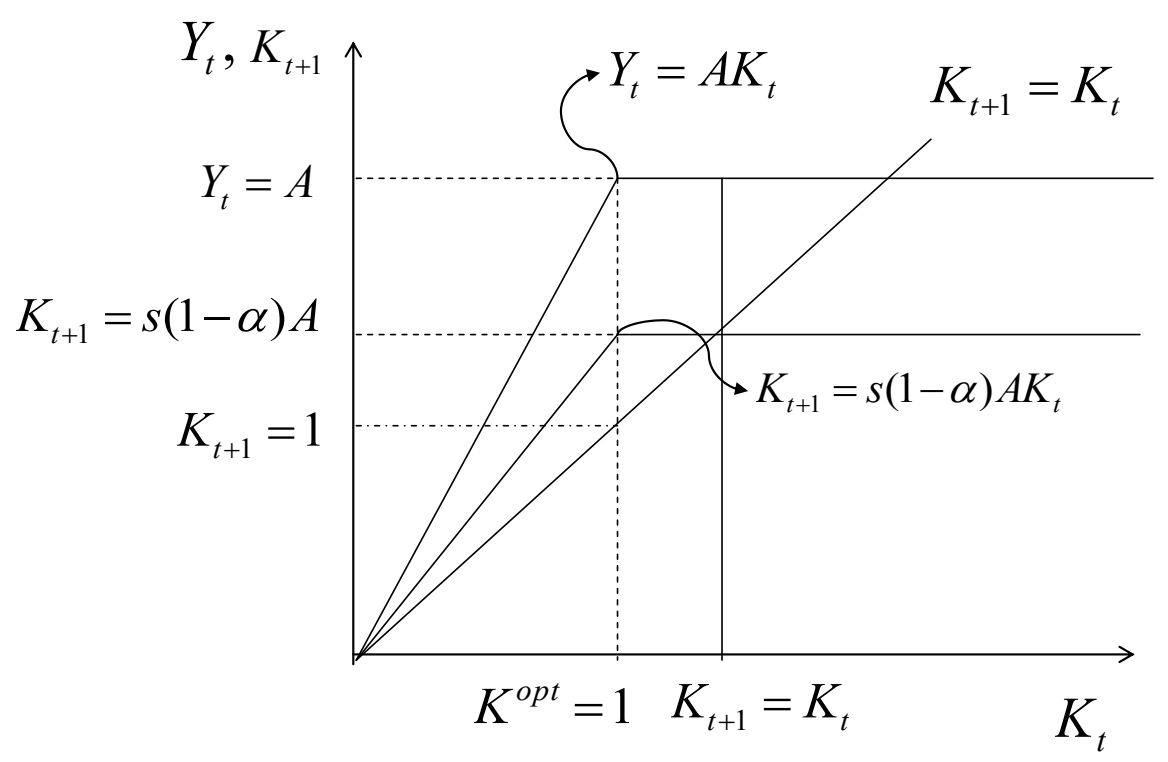

In figure 5.4 we can see that the economy is on a growth path up to the point that the capital stock equals $K_{t+1}=K_{t}=s(1-\alpha) A$. We can also see that this is beyond the optimal capital stock, $K_{t+1}=K_{t}=1$, which is needed for equilibrium and full employment. At this level of capital stock, output is in equilibrium. (see equation (5.8') where we have $Y_{t}=A$ for $K_{t} \geq 1$ ).

The equilibrium capital stock exceeds that of the optimal capital stock. From equation (5.13) we have $K=s(1-\alpha) A>1$. This implies that savings are in excess of what is needed for the optimal capital stock. In this situation consumption could be increased without harming future production and income, by saving less and consuming more. In equilibrium, consumption equals $C=Y-S=A-s(1-a) A$ which is smaller than $A-1$. This situation of excess capital is called dynamic inefficiency (see for example Romer, D. (2006) pp. 87-91)

We can conclude that the growth rate and capital accumulation depend on the savings rate $(s)$ as well as on the institutional setting $(\alpha,(1-\alpha))$. This institutional setting greatly influences the income distribution between wage earners and capital owners. As a result it determines aggregate savings in the economy. Therefore it also determines the growth path but not the equilibrium income. 


\subsection{Economic Integration, from Autarchy to Mobility}

Because institutions differ between regions we now focus on the consequence of such differences. Note that due to differences in institutional setting the economies of two regions can have a different development although the initial endowments are the same. Due to the difference, one region can be more (economically) efficient that the other.

If we assume that capital is mobile between the two regions after the capital market has been opened, we are able to analyze what will happen when regions integrate. We start by analyzing the reference case of two different regions in autarchy, after which we investigate the two regions after integration.

\subsubsection{The Autarchy Case}

Let us assume there are two regions, 1 and 2, and, due to differences in the institutional setting, the income shares of labour and capital income also differ, i.e. $\alpha_{1}>\alpha_{2}$ and $\left(1-\alpha_{1}\right)<\left(1-\alpha_{2}\right)$. This difference is due to different government investment in institutional setting, that is $G_{1, C} \neq G_{2, C}$ and $G_{1, L} \neq G_{2, L}$ which are investment in institutional structure of region 1 or region 2 , respectively.

Furthermore, we assume for example that $\frac{G_{1, C}}{\left(G_{1, C}+G_{1, L}\right)}=\alpha_{1}>\alpha_{2}=\frac{G_{2, C}}{\left(G_{2, C}+G_{2, L}\right)}$. The capital share of income in region 1 exceeds the capital share of income in region 2 and the labour share of income in region 2 exceeds that in region 1. Further, let us assume that both regions are in equilibrium $\left(Y_{1}=Y_{2}=A\right)$ before the capital market is opened and economic integration takes place. The autarchic equilibria for regions 1 and 2 are given by (see equations (5.8), (5.9) and (5.10)):

$$
\begin{aligned}
& Y_{1}=A \text { and } Y_{2}=A \\
& K_{1}=s\left(1-\alpha_{1}\right) A<K_{2}=s\left(1-\alpha_{2}\right) A \\
& R_{1}=\frac{\alpha_{1}}{s\left(1-\alpha_{1}\right)}>R_{2}=\frac{\alpha_{2}}{s\left(1-\alpha_{2}\right)} \\
& w_{1}=\left(1-\alpha_{1}\right) A<w_{2}=\left(1-\alpha_{2}\right) A
\end{aligned}
$$

Note that we did not use a time index because the variables are equilibrium values in the autarchy situation (period $t$ ). Income and output of the two regions are the same, namely A. 
The only difference is the distribution of income between the two regions. ${ }^{108}$ Differences in return on capital and the wage rate are the result of a different institutional setting in the two regions. Return on capital of region 1 exceeds that of region 2, whereas the wage rate in region 2 is higher that in region 1 . If we compare the capital stock of the two regions we see that the capital stock of region 2 exceeds that of region 1 see (5.17). Wage income and therefore savings in region 2 in autarchy exceed those in region 1 and thus we have $K_{2}>K_{1}>1^{109}$ (Note that the saving rate, $s$, is the same for both regions).

Savings determine capital accumulation and economic growth of the two regions. If both regions are in equilibrium the income of both regions is the same despite the differences in capital stock. Both regions are in a situation of over-accumulation of their capital stock. The over-accumulation of capital in region 2 exceeds that in region 1 . The over-accumulation of capital is caused by the fact that aggregated savings exceed the savings needed for the optimal capital stock $(K=1)$. The individual savings are not co-coordinated. We can illustrate these facts more clearly by looking at figure 5.5 .

Figure 5.5 looks like a stylized neoclassical growth model. However, there are some differences compared to the neoclassical model. First it should be mentioned that an overaccumulation of capital is present in both regions. In region 1 and 2 the steady state capital stock exceeds the optimal capital stock because $1<K_{1}=K_{1, t+1}=s\left(1-\alpha_{1}\right) A$ and $1<K_{2}=K_{2, t+1}=s\left(1-\alpha_{2}\right) A$. In addition, the capital stock in region 2 exceeds that of region 1 , as has been explained before. Both levels of income and output are the same, however.

\subsubsection{Integration: Opening the Capital Markets}

If economic integration is to be successful, both regions should benefit from it. In this section we look at whether this is the case for two regions with a different institutional setting, which open up their capital markets. If there is one capital market for the two regions, then as long as the return on capital of region 1 exceeds that of region 2, capital will flow from region 2 to region 1. This flow of capital will stop if the return on capital balances between the two regions. For the economies described above this is the case if, after the capital market has opened, the following (non-arbitrage) condition is fulfilled:

\footnotetext{
${ }^{108}$ Total income for region 1 equals $A=L_{1, y} w_{1}+R_{1} K_{1}$ while for region 2 we have $A=L_{1, y} w_{2}+R_{2} K_{2}$. Here $L_{1, y}$, $L_{2, y}$ is the labour force, the young generation, of region 1 respectively region 2 and $L_{2, y}$. Furthermore we have set $L_{1, y}=L_{2, y}=1$

${ }^{109}$ The optimal capital stock would be equal to one, because if it is bigger the wage rate will be not increased and the interest factor is lower than in equilibrium where the capital stocks equal one. See Geerdink \& Stauvermann (2006) for a proof.
} 
Figure 5.5 Equilibrium Capital Stock for two Different Regions

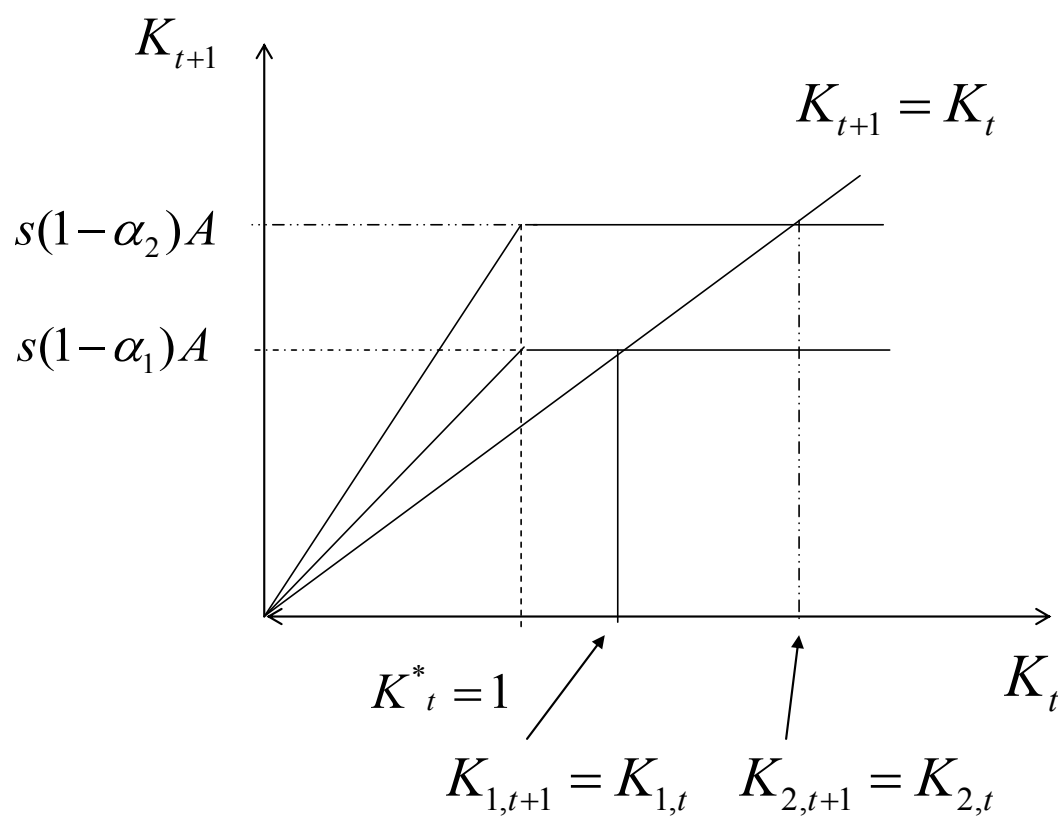

Figure 5.6 Return on Capital and Capital Stock for two Different Regions

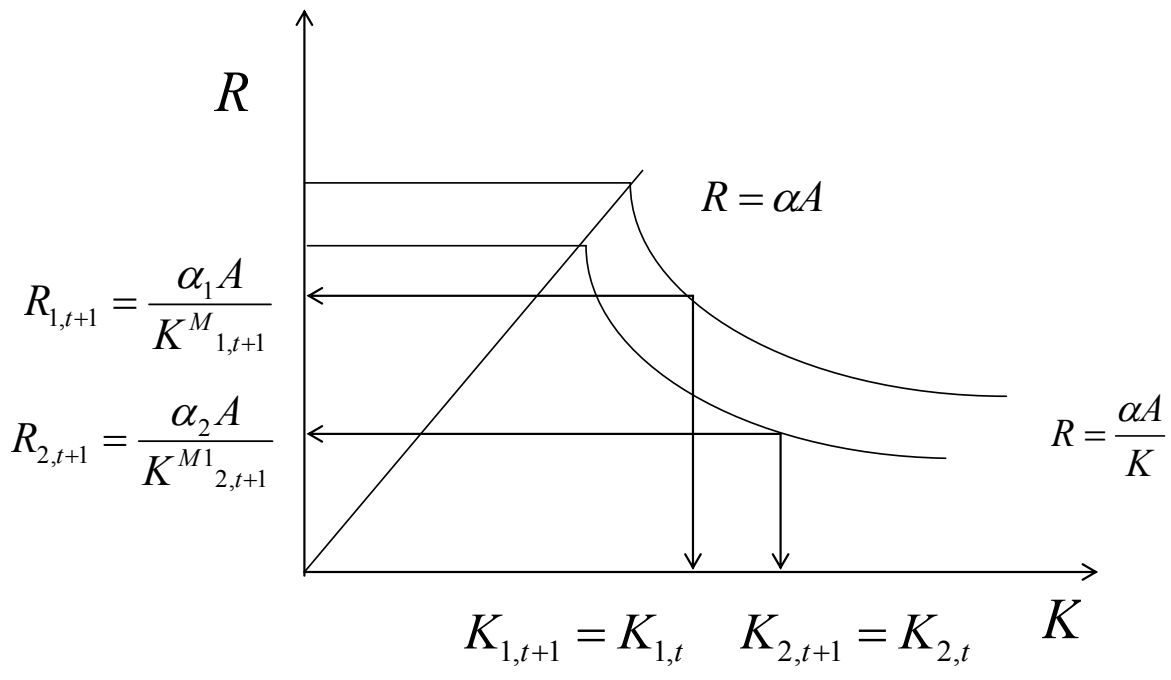




$$
R_{1, t+1}=R_{2, t+1}=R_{t+1}
$$

This is the non arbitrage condition; capital owners can make no additional profit by moving their 'savings' to the other region. After integration and opening of the capital market one single return on capital will be the result. This need not be the case for the other variables.

In autarchy both regions were in equilibrium. This is also not necessarily the case after integration of the two regions. The outflow of capital from a region could be such that the resulting stock of capital is below the equilibrium level $\left(K_{t+1}<1\right)$. For the non-arbitrage conditions we first have to discover whether the regions are in equilibrium or on a growth path after integration. For region 1 is is clear that its capital stock is increasing as long as the return on capital exceeds that of region 2 and therefore $K_{1, t+1}^{M}>K_{1, t}>1$. Region 1 is always in equilibrium after integration. We use a superscript $M$ to indicate capital mobility.

As can be seen, the over-accumulation of capital in region 1 exceeds that of the autarchy situation. It is clear that the return on capital (see equation (5.9)) in region 1 after integration will be:

$$
R_{1, t+1}=\frac{\alpha_{1} A}{K^{M}{ }_{1, t+1}}
$$

For region 2 this is less clear, however. There are 3 possibilities:

1. If capital moves to region 1 the capital stock decreases, but if it still exceeds 1 then the region will be in equilibrium again.

2. The capital stock decreases and will be below 1, and the economy will be on a growth path.

3. The worst case is that all capital moves from region 2 to region 1 , and region 2 will (economically) cease to exist.

Below we investigate the three alternatives. We indicate variables for region 2 with a superscript $M 1, M 2$ and $M 3$, indicating capital mobility case 1,2 and 3 referring to the three cases distinguished above.

\section{Case $M 1$}

In this case the equilibrium is characterized by $1<K_{2, t+1}^{M 1}<K_{2}$. (Note that $K_{2}$ is the equilibrium capital stock of region 2 in autarchy) The capital stock has decreased but still exceeds the equilibrium capital stock. Therefore we have the following interest factor after integration (see equation (5.9)): 


$$
R_{2, t+1}=\frac{\alpha_{2} A}{K_{2, t+1}^{M 1}}
$$

\section{Case $M 2$}

After integration capital accumulation in region 2 is characterized by $K_{2, t+1}^{M 2}<1<K_{2}$. In case the capital stock is below equilibrium level, the region is on a growth path. The corresponding interest rate factor in region 2 is:

$$
R_{2, t+1}=\alpha_{2} A
$$

\section{Case $M 3$}

If all capital flows to region 1 then the capital stock of region 2 will reduce to zero. In this case $K_{2, t+1}^{M 3}=0$ and the region is in a steady-state equilibrium. The appropriate nonarbitrage condition is evidently equal to equation (5.19), i.e.:

$$
R_{1, t+1}=\frac{\alpha_{1} A}{K^{M}{ }_{1, t+1}}
$$

Region 1 is the only region where capital stock has accumulated.

We can conclude that if the two regions integrate, region 1 will again be in equilibrium in period $t+1$, and that production and income equal $Y_{1, t+1}=A$, equal to the autarchy case. For region 2 two types of equilibria are possible, namely case $M 1$ and $M 3$. In case 1 the economy of region 2 again is in equilibrium. Production and output are the same as in autarchy. In the third case no capital is left and the region ceases to exist economically. The other possibility is that region 2 is on a growth path (case M2). What is clear, however, is that the equilibrium situations of both regions differ from equilibrium in autarchy, in period $t$.

\section{Proposition 5.1:}

Two regions integrating, which are in equilibrium in autarchy, will not automatically be in equilibrium after integration. The outcome depends on how the institutional arrangements influence income distribution and factor remunerations, i.e. wage rates and the return on capital. Integration will not automatically lead to an increase in efficiency. 


\section{Proof:}

Production of region 1 in autarchy equals production of region 1 after integration, that is $Y_{1}^{M}{ }_{t+1}=Y_{1}=A$. Production of region 2 in autarchy exceeds or is equal to production after integration because $0 \leq K_{2}{ }^{M}{ }_{t+1}<2-K_{1}{ }^{M}{ }_{t+1}$ and thus $0 \leq Y_{2}{ }^{M}{ }_{t+1} \leq A$. On aggregate we have $Y_{1}^{A}+Y_{2}^{A}=2 A$ and $A \leq Y_{1}^{M}{ }_{t+1}+Y_{2}^{M}{ }_{t+1} \leq 2 A$.

In the next section we shall analyze the three cases more carefully, investigating the circumstances under which each of the three cases will be applicable and discussing the consequences of the three cases with respect to regional development after integration.

\subsection{Economic Integration of Regions: Three Cases}

In this section we analyze what the economic situation in region 2 will be after integration. Two things have changed after integration. First, after opening of the capital markets there will be one market for aggregate savings of the two regions and secondly, there will be one rate of return on capital resulting from capital mobility. Depending on the relative magnitude of these two aspects, the economy of region two will be in the situation of cases $M 1, M 2$ or $M 3$, as described above.

As we have seen in the previous section, the market clearing conditions, the nonarbitrage conditions, result in a change in capital accumulation. The aggregate savings from the previous period are re-allocated according to the three non-arbitrage conditions, dependent on the case it is in. Starting from steady-state equilibrium in period $t$, the capital stocks in period $t+1$ have to match the aggregate savings after the capital markets open. The aggregate savings in case of economic integration are: ${ }^{110}$

$$
S_{t}=S_{1, t}+S_{2, t}=s\left[\left(1-\alpha_{1}\right)+\left(1-\alpha_{2}\right)\right] A>2
$$

Aggregate savings in the current period equal the capital stock in the next period, so aggregate capital accumulation equals $K^{M}{ }_{t+1}=K^{M}{ }_{1, t+1}+K^{M}{ }_{2, t+1}>2$. This is because we started from autarchy, where both regions are in a situation of equilibrium and both capital stocks exceed the optimal one. In period $t$, the return on capital in region 1 is higher than in region 2, which means that capital will flow from region 2 to region 1.

\footnotetext{
${ }^{110}$ At equilibrium in autarchy we have $S_{1, t}=s\left(1-\alpha_{1}\right) A>1$ and $S_{2, t}=s\left(1-\alpha_{2}\right) A>1$, therefore on aggregate we have $S_{1, t}+S_{2, t}=S_{t}>2$. From this it is clear that on aggregate $S_{t}=s\left[\left(1-\alpha_{1}\right)+\left(1-\alpha_{2}\right)\right] A>2$ or $S_{t}=s\left[2-\alpha_{1}-\alpha_{2}\right] A>2$.
} 


\subsubsection{Case 1: Both Regions are in Equilibrium after Integration}

Aggregate savings from both regions in the autarchy situation are sufficiently large for the equilibrium levels of capital stock of the two regions in the next period. Capital flow will stop if the return on capital in the two regions are the same, i.e. the non-arbitrage conditions, equations (5.19) and (5.20), have to hold. Equating these two results in $\frac{\alpha_{1} A}{K_{1, t+1}}=\frac{\alpha_{2} A}{K_{2, t+1}}$. From this we can derive the relation between the capital stocks in the two regions after integration:

$$
K_{1, t+1}^{M}=\frac{\alpha_{1}}{\alpha_{2}} K_{2, t+1}^{M 1}
$$

Compared with the autarchy situation we have $K_{1, t+1}^{M}>K_{1}>1$ and $K_{2}>K_{2, t+1}^{M 1}>1$. The capital stock in region 1 exceeds that of region 2 because $\frac{\alpha_{1}}{\alpha_{2}}>1$. After the capital market opens, aggregate savings of the two regions should be equal to the aggregate capital accumulation ( $S_{t}=K_{t+1}$ ). This results in the following capital stocks of region 1 and $2:{ }^{111}$

$$
K^{M}{ }_{1, t+1}=\frac{\alpha_{1}}{\alpha_{1}+\alpha_{2}} S_{t}
$$

and

$$
K_{2, t+1}^{M 1}=\frac{\alpha_{2}}{\alpha_{1}+\alpha_{2}} S_{t}
$$

This means that as long as $S_{t}>1+\frac{\alpha_{1}}{\alpha_{2}}$ holds, both regions will be in equilibrium after economic integration. This condition states that aggregate savings from the autarchy situation exceed next period's optimal capital accumulation for the two regions where $K_{2, t+1}^{M 1} \geq 1$ and $K_{1, t+1}^{M}=\frac{\alpha_{1}}{\alpha_{2}} K^{M 1}{ }_{2 t+1}>1^{112}$. Compared with the autarchy situation, production and output in the two regions remain the same, namely $Y_{1, t+1}=Y_{2, t+1}=A$. The over-accumulation of capital

$$
\begin{aligned}
& { }^{111} K_{t+1}=\frac{\alpha_{1}}{\alpha_{2}} K^{M 1}{ }_{2, t+1}+\frac{\alpha_{2}}{\alpha_{2}} K^{M 1}{ }_{2, t+1} \text {; thus we have } K^{M 1}{ }_{2, t+1}=\frac{\alpha_{2}}{\alpha_{1}+\alpha_{2}} K_{t+1} \text { and } K^{M}{ }_{1}=\frac{\alpha_{1}}{\alpha_{1}+\alpha_{2}} K_{t+1} . \\
& { }^{112} \text { Because } \frac{\alpha_{1}}{\alpha_{2}}>1 \text {, and } K_{1, t+1}=\frac{\alpha_{1}}{\alpha_{2}} K_{2, t+1}>1 \text { we have } K_{2, t+1} \geq 1 .
\end{aligned}
$$


increases in region 1 , while it simultaneously decreases in region 2 . The return on capital has changed after the opening of the capital market. This will have consequences for capital income but not for the wage incomes as they are the same as in autarchy.

\subsubsection{Case 1: Efficiency}

Looking at the economic effects of the integration of the two regions we can distinguish between long-run and short-run effects of integration. By short-run effect we mean the first period after integration and by long-run effect we mean the equilibrium situation after the integration process. In the first case $(M 1)$ both regions are in equilibrium, so long and short run coincide.

Using equation (5.23) and (5.24) gives us the capital formation after integration. Comparing with equation (5.22), the autarchy case, we find that: ${ }^{113}$

$$
K_{1, t+1}^{M}=\frac{\alpha_{1}}{\alpha_{1}+\alpha_{2}} s\left(2-\alpha_{1}-\alpha_{2}\right) A>K_{1}=s\left(1-\alpha_{1}\right) A
$$

and

$$
K_{2, t+1}^{M 1}=\frac{\alpha_{2}}{\alpha_{1}+\alpha_{2}} s\left(2-\alpha_{1}-\alpha_{2}\right) A<K_{2}=s\left(1-\alpha_{2}\right) A
$$

Note that this is the same as equation (5.24) only now we substituted equation (5.22) for the aggregate savings. In this way we can compare the autarchy situation with the case of integration.

Production and output of the two regions after integration are the same as in the autarchy case. After integration we have:

$$
Y_{1, t+1}^{M}=A \text { and } Y_{2, t+1}^{M 1}=A
$$

As in the case with production and output, the wage rates of the two regions remain the same after economic integration. The reason for this is that we only consider factor mobility of

113

$$
\begin{aligned}
& \frac{\alpha_{1}}{\alpha_{1}+\alpha_{2}}\left[\left(1-\alpha_{1}\right)+\left(1-\alpha_{2}\right)\right]>\left(1-\alpha_{1}\right)=\frac{\alpha_{1}}{\alpha_{1}+\alpha_{2}}\left\lfloor 1+\frac{\left(1-\alpha_{2}\right)}{\left(1-\alpha_{1}\right.}\right\rfloor>1=\alpha_{1}\left\lfloor 1+\frac{\left(1-\alpha_{2}\right)}{\left(1-\alpha_{1}\right.}\right\rfloor>\alpha_{1}+\alpha_{2}= \\
& \alpha_{1}+\alpha_{1} \frac{\left(1-\alpha_{2}\right)}{\left(1-\alpha_{1}\right.}>\alpha_{1}+\alpha_{2}=\frac{\left(1-\alpha_{2}\right)}{\left(1-\alpha_{1}\right.}>\frac{\alpha_{2}}{\alpha_{1}} \text {. Because } 0<\alpha_{1}<\alpha_{2}<1 \text { we have } \frac{\left(1-\alpha_{2}\right)}{\left(1-\alpha_{1}\right)}>1 \text { and } \\
& \frac{\alpha_{2}}{\alpha_{1}}<1 .
\end{aligned}
$$


capital and not labour mobility. This can be seen by looking at equation (5.8) (5.17) and (5.26). This results in:

$$
w_{1, t+1}=\left(1-\alpha_{1}\right) A=w_{1, t}<w_{2, t+1}=\left(1-\alpha_{2}\right) A=w_{2, t}
$$

The differences between wage rates still exist after integration. This is the result of neglecting labour market mobility; the difference is still determined by the different institutional arrangements. As a result the incomes of the young generation of period $t+1$ remain the same for both regions (the young generation supplies labour and receives wage income).

After we have analyzed the changes in capital stock of the two regions we continue with the return on capital. Using one of the two equations from (5.25) and inserting the nonarbitrage condition (5.19) or (5.20) ${ }^{114}$ and comparing with the autarchy situation (equation (5.17)) we find ${ }^{115}$ :

$$
R_{2}=\frac{\alpha_{2}}{s\left(1-\alpha_{2}\right)}<R_{t+1}=\frac{\left(\alpha_{1}+\alpha_{2}\right)}{s\left(2-\alpha_{1}-\alpha_{2}\right)}<R_{1}=\frac{\alpha_{1}}{s\left(1-\alpha_{1}\right)}
$$

Comparing the return on capital after integration with the return on capital in autarchy we see that the interest factors and the capital stocks have changed. The income of capital owners in region 2 - the old generation - increases, whereas the capital income of the old generation of region 1 decreases. ${ }^{116}$ It can also be seen that institutional arrangements of region 1 as well as region 2 have an influence on the return on capital and capital income. Thus, although the two regions are in equilibrium after integration, capital income of the two regions changes, so the capital owners of region 1 are hurt and the capital owners of region 2 benefit.

$$
\begin{aligned}
& { }^{114} R_{t+1}=R_{2, t+1}=\frac{\alpha_{2} A}{K^{M 1}{ }_{2, t+1}}=\frac{\alpha_{2} A}{\frac{\alpha_{2}}{\alpha_{1}+\alpha_{2}} s\left(2-\alpha_{1}-\alpha_{2}\right) A} \text { results in } R_{t+1}=\frac{\left(\alpha_{1}+\alpha_{2}\right)}{s\left(2-\alpha_{1}-\alpha_{2}\right)} . \\
& { }^{115} \text { Reformulating (4.36) leads to } \frac{\alpha_{2}}{\left(\alpha_{1}+\alpha_{2}\right)}<\frac{\left(1-\alpha_{2}\right)}{\left(2-\alpha_{1}-\alpha_{2}\right)} \text { and } \frac{\left(1-\alpha_{1}\right)+\left(1-\alpha_{2}\right)}{\left(1-\alpha_{2}\right)}<\frac{\left(\alpha_{1}+\alpha_{2}\right)}{\alpha_{2}} \text { which }
\end{aligned}
$$

reduces to $\frac{\left(1-\alpha_{1}\right)}{\left(1-\alpha_{2}\right)}<\frac{\alpha_{1}}{\alpha_{2}}$ which holds by assumption. In the same way we can show that

$\frac{\left(1-\alpha_{1}\right)}{\left(2-\alpha_{1}-\alpha_{2}\right)}<\frac{\alpha_{1}}{\left(\alpha_{1}+\alpha_{2}\right)}$

${ }^{116}$ Capital income region 1 after integration equals $R_{t+1} s\left(1-\alpha_{1}\right) A>R_{1, t} s\left(1-\alpha_{1}\right) A$. Capital income region 2 after integration equals $R_{t+1} s\left(1-\alpha_{2}\right) A<R_{2, t} s\left(1-\alpha_{2}\right) A$. 


\subsubsection{Case 2: Region 2 is on a Growth Path after Integration}

In the second case (M2), region 1 is in equilibrium and region 2 is out of equilibrium and on a growth path. Outflow of capital reduces the capital stock below the equilibrium level of capital stock of region 1. Aggregate savings from the previous autarchy situation are insufficient to reach the equilibrium level of capital accumulation in the next period in region 2. To determine the capital accumulation in the two regions after integration, we use the nonarbitrage condition. After integration the return on capital is the same in the two regions.. Therefore to find the capital stock after integration we use equations (5.19) and (5.21) which results in the following relation:

$$
\alpha_{2} A=\frac{\alpha_{1} A}{K_{1, t+1}^{M}}
$$

Reformulation of (5.29) directly gives us the capital stock in region 1:

$$
K_{1, t+1}^{M}=\frac{\alpha_{1}}{\alpha_{2}}
$$

Compared with the autarchy situation for region 1 we have $K_{1, t+1}^{M}>K_{1}>1$ and for region 2 we have the following outcome: $0<K_{2, t+1}^{M 2}<1<K_{2}$. In autarchy the return on capital is higher in region 1 and capital will flow from region 2 to region 1 until the equilibrium capital stock, $K^{M}{ }_{1, t+1}=\frac{\alpha_{1}}{\alpha_{2}}>1$ is reached. Residual savings will remain in region 2 and contribute to capital accumulation in this region. Actually, we have the following restriction on capital formation for region 2: $K_{2, t+1}^{M 2} \leq S_{t}-K^{M}{ }_{1, t+1}$. We can derive the capital stock of region 2 as a residual of aggregate savings and the capital stock of region 1. This leads to the capital stock of region 2:

$$
K_{2, t+1}^{M 2}=S_{t}-\frac{\alpha_{1}}{\alpha_{2}} \leq 1
$$

If $0<K_{2, t+1}^{M 2} \leq 1$ then region 2 is on a growth path and capital is changing over time. This is the case when the following holds: $\frac{\alpha_{1}}{\alpha_{2}} \leq S_{t} \leq 1+\frac{\alpha_{1}}{\alpha_{2}}$. This restriction states that aggregated savings exceed capital formation in region $1\left(K_{1, t+1}^{M}=\frac{\alpha_{1}}{\alpha_{2}}\right)$, but is short-term equilibrium 
capital formation in region 2 , namely $K^{M 2}{ }_{2, t+1}<1$. The resulting capital stock is less than 1 region 2 and therefore it is on a growth path. Note that this situation is not the result of insufficient aggregate savings but of increased over-accumulation of capital in the other region. If we look at income and output in region 2 we note that it will decrease after integration, because of a decrease in capital stock.

\subsubsection{Case 2: Efficiency}

If the economy is on a growth path (out of equilibrium) we have to distinguish between the short run, the first period after integration, and the long run equilibrium situation after integration.

\section{The Short-Run}

After economic integration, the over-accumulation of capital in region 1 increases, at the cost of capital formation in region 2 . In this case the level of aggregate savings in autarchy meets the following condition: $\frac{\alpha_{1}}{\alpha_{2}} \leq S_{t} \leq 1+\frac{\alpha_{1}}{\alpha_{2}}$. The capital accumulation in region 2 is below its equilibrium level in autarchy and below the optimal capital stock $\left(K_{2, t+1}^{*}=1\right)$.

If we look at the capital stock after integration, this remains the same for region 1. For region 2 this is determined by residual savings (see equation (5.31). Furthermore if we compare it with the autarchy situation (equations (5.17)) we find: ${ }^{117}$

$$
K_{1, t+1}^{M}=\frac{\alpha_{1}}{\alpha_{2}}>K_{1}=s\left(1-\alpha_{1}\right) A>1
$$

and

$$
K_{2, t+1}^{M 2}=s\left(2-\alpha_{1}-\alpha_{2}\right) A-\frac{\alpha_{1}}{\alpha_{2}}<1<K_{2}=s\left(1-\alpha_{2}\right) A
$$

Evidently the capital stock of region 1 after integration exceeds that of the autarchy situation, and for region 2 the opposite applies.

If we compare production, and income of autarchy with the production and income after economic integration we see a decrease of production and income in region 2 after

${ }^{117}$ Substituting aggregate saving (5.24) in (5.31) results in; $s\left[\left(1-\alpha_{1}\right)+\left(1-\alpha_{2}\right)\right] A-\frac{\alpha_{1}}{\alpha_{2}}<1<s\left(1-\alpha_{2}\right) A$ which

equals $s\left[\left(1-\alpha_{1}\right)+\left(1-\alpha_{2}\right)\right] A-\frac{\alpha_{1}}{\alpha_{2}}<s\left(1-\alpha_{2}\right) A$. This simplifies to $s\left(1-\alpha_{1}\right) A<\frac{\alpha_{1}}{\alpha_{2}}$. So assuming market clearing, means that savings in the current period equals investments in the next period. 
integration, whereas output remains the same in region 1. For region 2 this results in a reduction in capital stock after integration:

$$
Y_{1, t+1}{ }^{M}=A
$$

and

$$
Y_{2, t+1}^{M 2}=A K_{2, t+1}^{M 2}
$$

Note that after integration the aggregate production and income decrease. Region 2 is on a growth path $\left(K_{2, t+1}<1\right)$ and as a result aggregate output becomes:

$Y_{t+1}{ }^{M}=Y_{1, t+1}^{M}+Y_{2, t+1}^{M 2}=A+A K_{2, t+1}<2 A=Y_{1, t}+Y_{2, t}$. The decrease in overall production is caused by a decrease in income and production in region 2 . As soon as production and output reduce, wage rates and the return on capital will change. The wage rate in region 1 remains unchanged $\left(w_{1}=w_{1, t+1}\right)$. The wage rate for region 2 after integration can be found using equation (5.8) and equation (5.31) to substitute for the appropriate capital stock. Comparing this with the autarchy situation, i.e. equation (5.17), we have: ${ }^{118}$

$$
w_{2, t+1}^{M 2}=\left(1-\alpha_{2}\right)\left[s\left(2-\alpha_{1}-\alpha_{2}\right) A\right]-\frac{\alpha_{1}}{\alpha_{2}}<w_{2}=\left(1-\alpha_{2}\right) A
$$

The wage rate in region 2 is lower than in autarchy. On top of that there will be an increase of unemployment in region $2,{ }^{119}$ due to a decrease in output. Whether the wage rate in region 2 still exceeds the wage rate of region 1 depends on whether $\left(1-\alpha_{2}\right)\left(S_{t}-\frac{\alpha_{1}}{\alpha_{2}}\right) \frac{<}{>}\left(1-\alpha_{1}\right)$, which depends on the saving rate. ${ }^{120}$ Whereas the wage income of the young generation of region 1 remains unchanged, the wage income of the young generation in region 2 worsens because the wage rate decreases, as does employment.

${ }^{118}$ We have $\left(S_{t}-\frac{\alpha_{1}}{\alpha_{2}}\right)<1$ by the definition of case $M 2$, where $S_{t}=s\left[\left(1-\alpha_{1}\right)+\left(1-\alpha_{2}\right)\right] A$. Furthermore

$2<s\left(2-\alpha_{1}-\alpha_{2}\right) A<1+\frac{\alpha_{1}}{\alpha_{2}}$ because $1<s\left(1-\alpha_{1}\right) A<s\left(1-\alpha_{2}\right) A$.

${ }^{119}$ The capital stock in region 2 is now lower than in equilibrium and unemployment rate of region 2 equals

$\left(1-K_{2, t+1}\right) 100 \%=1+\frac{\alpha_{1}}{\alpha_{2}}-s\left(2-\alpha_{1}-\alpha_{2}\right)>0$.

${ }^{120}$ Reformulating $\left(1-\alpha_{2}\right)\left(S_{t}-\frac{\alpha_{1}}{\alpha_{2}}\right) \frac{\left(1-\alpha_{1}\right)}{\left(1-\alpha_{2}\right)}$ because $\frac{\left(1-\alpha_{1}\right)}{\left(1-\alpha_{2}\right)}<1$ and $\left(s\left(2-\alpha_{1}-\alpha_{2}\right) A-\frac{\alpha_{1}}{\alpha_{2}}\right)<1$. 
The return on capital after the capital market opens in case $M 2$ differs from the autarchy return on capital. Using non-arbitrage condition (5.19) or (5.23) we can determine the return on capital after integration and use this to compare integration with the autarchy case. Equation (5.23) immediately delivers us the return on capital after integration ${ }^{121}$. By comparing with autarchy we can derive the following result: ${ }^{122}$

$$
R_{2}=\frac{\alpha_{2}}{s\left(1-\alpha_{2}\right)}<R_{t+1}=\alpha_{2} A<R_{1}=\frac{\alpha_{1}}{s\left(1-\alpha_{1}\right)}
$$

The return on capital after economic integration and opening of the capital market is higher than the return on capital in region 2 under autarchy. The income increases for the capital owners of region 2 - the old generation - whereas in region 1 the income of the old generation of capital owners decreases. Capital owners in region 1, the old generation, do not benefit.

\section{The Long-Run}

In this second case, the economy of region 1 again is in equilibrium, as it was in autarchy. The economy of region 2 is on a growth path. If $S_{t}=1+\frac{\alpha_{1}}{\alpha_{2}}$, the capital stock of region 2 equals $K_{2, t+1}^{M 2}=1$, which is the optimal capital stock. If $S_{t}<1+\frac{\alpha_{1}}{\alpha_{2}}$, the worst case possible, the economy will have a negative growth rate and capital stock will decrease, finally tending to zero. This decrease is caused by the fact that the aggregate savings after the opening of the capital market, are lower than the aggregate savings in autarchy (saving in period $t+1$ and onwards). The reasoning is that the savings in region 2 will decrease thanks to lower wage rates (see equation (5.34). The savings in region 1 will remain unchanged, because the wage rate remains constant, so total savings will decrease. To prove this we have to show that the capital stock of region 2 in period $t+2$ is smaller than the capital stock in period $t+1$. Total savings in period 1 equals $S_{t}=s w_{1, t}+s w_{2, t}=s\left[\left(1-\alpha_{1}\right) A+\left(1-\alpha_{2}\right) A\right]$. In the next period

$$
\begin{aligned}
& { }^{121} \text { Using (5.19) in combination with (5.32) gives } R_{t+1}=R_{1, t+1}=\frac{\alpha_{1} A}{K_{2, t+1}^{M 1}}=\frac{\alpha_{1} A}{\frac{\alpha_{1}}{\alpha_{2}}}=\alpha_{2} A . \\
& { }^{122} \text { Reformulating results in } 1<s\left(1-\alpha_{2}\right) A<\frac{\alpha_{1}}{\alpha_{2}} \frac{\left(1-\alpha_{2}\right)}{\left(1-\alpha_{1}\right)} \text {. This holds because we know that } s\left(1-\alpha_{2}\right) A<\frac{\alpha_{1}}{\alpha_{2}} \\
& \text { and } \frac{\left(1-\alpha_{2}\right)}{\left(1-\alpha_{1}\right)}>1 \text {. Note also that } R_{t+1}=\alpha_{2} A>R_{2}=\frac{\alpha_{2} A}{K_{2}} \text { because } K_{2}>1 .
\end{aligned}
$$


saving after integration of region 1 will be the same. Saving in region 2 will decrease because production in region 2 decreases to $Y_{2, t+1}^{M 2}=A\left(S_{t}-\frac{\alpha_{1}}{\alpha_{2}}\right)$ where $\left(S_{t}-\frac{\alpha_{1}}{\alpha_{2}}\right)<1$. The corresponding wage rate and savings then equal $w^{M 2}{ }_{2, t+1}=\left(1-\alpha_{2}\right) A\left(S_{t}-\frac{\alpha_{1}}{\alpha_{2}}\right)$ and $S_{2, t+1}=s\left(1-\alpha_{2}\right) A\left(S_{t}-\frac{\alpha_{1}}{\alpha_{2}}\right)$. Total savings equal $S_{t+1}=s\left\lfloor\left(1-\alpha_{1}\right) A+\left(1-\alpha_{2}\right) A\left(S_{t}-\frac{\alpha_{1}}{\alpha_{2}}\right)\right\rfloor$.

Because $\left(S_{t}-\frac{\alpha_{1}}{\alpha_{2}}\right)<1$ savings decrease, that is, $S_{t+1}<S_{t}$. As a result the next period's capital stock in region 2 decreases as do production, the wage rate and savings in the region. For the capital stock in region 2 we find:

$$
K_{2, t+2}^{M 2}=S_{t+1}-\frac{\alpha_{1}}{\alpha_{2}}<K_{2, t+1}^{M 2}=S_{t}-\frac{\alpha_{1}}{\alpha_{2}}
$$

In the same way we can show that $K_{2, t+n}^{M 2} \leq K_{2, t+n-1}^{M 2}$ and the capital stock finally reduces to zero.

In case the capital stock of region 2 equals $K_{2, t+1}^{M 2}=1$, the corresponding wage rate equals $w_{2, t+1}=\left(1-\alpha_{2}\right) A=w_{2}$, which is the same as in the autarchy case. The return on capital becomes: $R_{t+1}=\alpha_{2} A$. The return on capital in the long run is the same as in autarchy in region 2 and is lower than the return on capital in region 1 in autarchy. Long-run regional output equals $Y_{2, t+1}^{M}=A K_{2, t+1}=A$. In this case the return on capital is different compared to the autarchic returns on capital. In the long run, the wage rate in region 2 is lower than that in autarchy. In all other case the long-run equilibrium will correspond to case $M 3$, where region 2 economically ceases to exist, viz., no production or output will be realized in this region, as we shall see below.

\subsubsection{Case 3: Region 2 Ceases to Exist after Integration}

Finally, we examine the last case, namely case $M 3$, where $K_{2, t+1}^{M 3}=0$. This situation appears when we have $2<S_{t}<K_{1, t+1}^{M}=\frac{\alpha_{1}}{\alpha_{2}}$. The capital stock reduces to zero and region 2 ceases to exist economically. Due to the opening of the capital market all savings will flow to region 1 resulting from the higher return on capital, despite the fact of over-accumulation. This is a somewhat curious situation. Although the capital stock in region 1 exceeds value 1 , the 
optimal capital stock, it still increases after economic integration, exceeding value 2 in equilibrium. Due to this increase in over-accumulation, region 2 will cease to exist economically. There will no longer be any productive activities in region 2 if the capital stock reduces to zero.

\subsubsection{Case 3: Efficiency}

In case $M 3$, aggregate savings satisfy the condition, $2<S_{t}<\frac{\alpha^{1}}{\alpha^{2}}$ and region 1 is in equilibrium after integration. This is not the case for region 2 because economically it ceases to exist. After integration we have:

$$
K_{1, t+1}^{M}=\frac{\alpha_{1}}{\alpha_{2}}>s\left(1-\alpha_{1}\right) A=K_{1}
$$

and

$$
K_{2, t+1}^{M 3}=0<s\left(1-\alpha_{2}\right) A=K_{2}
$$

There is a movement from productive use of capital in region 2 to unproductive capital accumulation in region 1 (over-accumulation of capital). All productive capital from region 2 moves to region 1. All savings from the previous period in region 2 will flow to region 1 , causing a reduction in capital formation to zero and an over-accumulation of capital in region 1. Output in region 1 will remain the same but it will disappear in region 2. Compared to the autarchy situation now we have:

$$
Y_{2, t+1}^{M 3}=0<Y_{2}=A
$$

and

$$
Y_{1, t+1}{ }^{M}=A=Y_{1}=A
$$

Moreover, aggregate production after integration is reduced to half of the autarchy output and production. We have:

$$
Y_{t+1}^{M}=Y_{1, t+1}^{M}+Y_{2, t+1}^{M 3}=A<2 A=Y_{1}+Y_{2}
$$


After integration, production decreases to the level of production in region 1 in autarchy. This also has implications for employment and for the wage rate in this region. Both employment and the wage rate in region 2 will reduce to zero ${ }^{123}$ :

$$
w_{2, t+1}=0<\left(1-\alpha_{1}\right) A=w_{1, t+1}<\left(1-\alpha_{2}\right) A=w_{2}
$$

If there is no labour mobility, economic integration causes a decrease in the wage rate and reduces employment. It is clear that the young generation suffers severely from integration as their income reduces to zero and there is no employment.

It has already been explained that returns on capital change. The return on capital can be calculated from equation (5.23). Inserting the equilibrium capital stock of region 1 gives us the following return on capital for an open capital market:

$$
R_{2}=\frac{\alpha_{2}}{s\left(1-\alpha_{2}\right)}<R_{t+1}=\frac{\alpha_{1} A}{K^{M}{ }_{1, t+1}}=\frac{\alpha_{1}}{s\left(2-\alpha_{1}-\alpha_{2}\right)}<R_{1}=\frac{\alpha_{1}}{s\left(1-\alpha_{1}\right)}
$$

If we compare the return on capital after integration with the autarchic situation of region 1 it is easy to see that $R_{t+1}<R_{1}{ }^{124}$. The capital owners from region 1 , which is the old generation, will realize a loss in income. For region 2 we conclude the opposite that is $R_{2}<R_{t+1}{ }^{125}$ holds The return on capital region 2 in autarchy is lower than the return on capital after integration. Therefore, the capital owners of region 2 gain from opening the capital markets.

Note that this scenario only develops if institutional differences are large. If aggregate savings fall short, then the following condition has to be met: $2<s\left(2-\alpha_{1}-\alpha_{2}\right) A<\frac{\alpha_{1}}{\alpha_{2}}$. This is only the case if we have at minimally, $\alpha_{1}>2 \alpha_{2}$. This indicates an extreme difference in income distribution and the institutional setting between the two regions. Note that this is also

$$
\begin{aligned}
& { }^{123} \text { The unemployment rate equals }\left(1-K_{2, t+1}^{M 3}\right) 100 \%=100 \% \text {. } \\
& { }^{124} \text { Thus } \frac{\alpha_{1}}{\left(2-\alpha_{1}-\alpha_{2}\right)}<\frac{\alpha_{1}}{\left(1-\alpha_{1}\right)} \text { which can be written as } 1<\frac{\left(1-\alpha_{1}\right)+\left(1-\alpha_{2}\right)}{\left(1-\alpha_{1}\right)} \text { which simplifies to } \\
& 1<1+\frac{\left(1-\alpha_{2}\right)}{\left(1-\alpha_{1}\right)} \text {. Because } 0<\alpha_{2}<\alpha_{1}<1 \text { we have }\left(1-\alpha_{2}\right)>\left(1-\alpha_{1}\right) \text { and } \frac{\left(1-\alpha_{2}\right)}{\left(1-\alpha_{1}\right)}>0 . \\
& { }^{125} \text { We see that } \frac{\alpha_{2}}{\left(1-\alpha_{2}\right)}<\frac{\alpha_{1}}{\left(2-\alpha_{1}-\alpha_{2}\right)} \text { which equals } \frac{\alpha_{1}}{\alpha_{2}}>\frac{\left(1-\alpha_{1}\right)+\left(1-\alpha_{2}\right)}{\left(1-\alpha_{2}\right)} \text { what can be written as } \\
& \frac{\alpha_{1}}{\alpha_{2}}>1+\frac{\left(1-\alpha_{1}\right)}{\left(1-\alpha_{2}\right)} \text {. Because } 0<\alpha_{2}<\alpha_{1}<1 \text { this implies that }\left(1-\alpha_{2}\right)>\left(1-\alpha_{1}\right) \text { and } 0<\frac{\left(1-\alpha_{1}\right)}{\left(1-\alpha_{2}\right)}<1 .
\end{aligned}
$$


the long-run equilibrium situation for case M2 as well as for case M3 (except where the residual savings equal the next period's capital stock, $K_{2, t+1}^{M 2}=1$ ).

\subsection{Summary and Comparison of Three Cases of Integration}

We now summarize the results from the previous section. Output of region 1 remains the same as in autarchy, namely:

$$
Y_{1, t+1}^{M}=A
$$

Region 1 is in equilibrium after integration in period $(t+1)$. The income and the institutional arrangements do not change and the wage rate is the same as in the autarchy situation. For all 3 cases we have the following wage rate in region 1 :

$$
w_{1, t+1}^{M}=\left(1-\alpha_{1}\right) A
$$

Due to the opening of the capital market, the capital stock in the two regions will change after integration. Depending on the aggregate savings of the previous period, $t$, the following values of capital stocks are possible (see equation (5.24), (5.30) and (5.38)):

$$
K_{1, t+1}^{M}=\left\{\begin{array}{c}
\frac{\alpha_{1}}{\alpha_{1}+\alpha_{2}} S_{t}, \quad \text { if } S_{t}>1+\frac{\alpha_{1}}{\alpha_{2}} \\
\frac{\alpha_{1}}{\alpha_{2}}, \quad \text { if } \frac{\alpha_{1}}{\alpha_{2}} \leq S_{t} \leq 1+\frac{\alpha_{1}}{\alpha_{2}} \\
S_{t}, \quad \text { if } 2<S_{t}<\frac{\alpha_{1}}{\alpha_{2}}
\end{array}\right.
$$

The following production and income can be distinguished in region $2:^{126}$ (see equation (5.26), (5.32) and (5.33)):

${ }^{126}$ Note that $Y_{1}=Y_{2}=A$ resulting in: $S_{t}-\frac{\alpha_{1}}{\alpha_{2}}=s\left(2-\alpha_{1}-\alpha_{2}\right) A-\frac{\alpha_{1}}{\alpha_{2}}$. 


$$
Y_{2, t+1}^{M}=\left\{\begin{array}{c}
A \quad \text { if } S_{t}>1+\frac{\alpha_{1}}{\alpha_{2}} \\
s\left(2-\alpha_{1}-\alpha_{2}\right) A-\frac{\alpha_{1}}{\alpha_{2}}, \quad \text { if } \frac{\alpha_{1}}{\alpha_{2}} \leq S_{t} \leq 1+\frac{\alpha_{1}}{\alpha_{2}} \\
0, \quad \text { if } 2<S_{t}<\frac{\alpha_{1}}{\alpha_{2}}
\end{array}\right.
$$

The corresponding capital stocks of region 2 after integration are (see equation (5.24),(5.31) $\&(5.38))$ :

$$
K_{2, t+1}^{M}=\left\{\begin{array}{c}
\frac{\alpha_{2}}{\alpha_{1}+\alpha_{2}} S_{t}, \quad \text { if } S_{t}>1+\frac{\alpha_{1}}{\alpha_{2}} \\
S_{t}-\frac{\alpha_{1}}{\alpha_{2}}, \text { if } \frac{\alpha_{1}}{\alpha_{2}} \leq S_{t} \leq 1+\frac{\alpha_{1}}{\alpha_{2}} \\
0, \text { if } 2<S_{t}<\frac{\alpha_{1}}{\alpha_{2}}
\end{array}\right.
$$

For the equilibrium situation the wage rate of region 2 remains unchanged compared to the autarchy situation. Production and income for the region will change, however, in cases M2 and M3. The resulting wage rates are found below (see equation (5.27),(5.34) and (5.41)):

$$
w_{2, t+1}^{M}=\left\{\begin{array}{c}
\left(1-\alpha_{2}\right) A, \text { if } S_{t}>1+\frac{\alpha_{1}}{\alpha_{2}} \\
\left(1-\alpha_{2}\right)\left(s\left(2-\alpha_{1}-\alpha_{2}\right) A-\frac{\alpha_{1}}{\alpha_{2}}\right), \text { if } \frac{\alpha_{1}}{\alpha_{2}} \leq S_{t} \leq 1+\frac{\alpha_{1}}{\alpha_{2}} \\
0<S_{t}<\frac{\alpha_{1}}{\alpha_{2}}
\end{array}\right.
$$

Using the previous results, we are now able to calculate the return on capital after integration. Again we consider three different situations. Region 1 is always in equilibrium after economic integration. Region 2 can be in equilibrium, on a growth path, or cease to exist. For region 2 this depends on the aggregate savings from the previous period and the flow of capital to region 1 due to arbitrage. Income distribution depends on the institutional setting and on the saving rate. We find the following results (see equation (5.28), (5.35) and (5.42)): 


$$
R_{t+1}=\left\{\begin{array}{c}
\frac{\alpha_{1} A}{K^{M}{ }_{1, t+1}}=\frac{\alpha_{2} A}{K^{M 1}{ }_{2, t+1}}, \text { if } S_{t}>1+\frac{\alpha_{1}}{\alpha_{2}} \\
\alpha_{2} A, \text { if } \frac{\alpha_{1}}{\alpha_{2}} \leq S_{t} \leq 1+\frac{\alpha_{1}}{\alpha_{2}} \\
\frac{\alpha_{1} A}{K^{M}{ }_{1, t+1}}, \text { if } 0<S_{t}<\frac{\alpha_{1}}{\alpha_{2}}
\end{array}\right.
$$

Given these results for period $t+1$, we are now able to look at the welfare effects of capital market integration. At best both regions are in equilibrium after integration and there is no welfare loss, nor is there any welfare gain. Integration does not lead to an increase in efficiency if regions are in equilibrium after integration. For the other two situations, where region 2 is on a growth path or ceases to exists, there is a decrease in welfare and efficiency.

In the tables below the result of economic integration for the two regions are summarized for both the short run and the long run. Note that in the tables below we have indexed the equilibrium values of the autarchy variables with a time index $t$ in order to compare it with the cases of integration. 
Table 5.1: $\quad$ Short-Run Effects Economic Integration Region 1

\begin{tabular}{|c|c|c|c|}
\hline Autarky & & Integration & \\
\hline & $M 1$ & $M 2$ & $M 3$ \\
\hline Aggregate Saving & & & \\
\hline$S_{t}=s\left[\left(1-\alpha_{1}\right)+\left(1-\alpha_{2}\right)\right] A$ & $S_{t}>1+\frac{\alpha_{1}}{\alpha_{2}}$ & $S_{t}=1+\frac{\alpha_{1}}{\alpha_{2}}$ & $S_{t}=1+\frac{\alpha_{1}}{\alpha_{2}}$ \\
\hline Wage Rate & $w_{1, t}=w_{1, t+1}$ & $w_{1, t}=w_{1, t+1}$ & $w_{1, t}=w_{1, t+1}$ \\
\hline$\left(1-\alpha_{1}\right) A$ & $\left(1-\alpha_{1}\right) A$ & $\left(1-\alpha_{1}\right) A$ & $\left(1-\alpha_{1}\right) A$ \\
\hline Return on Capital & $R_{1, t}>R_{t+1}$ & $R_{1, t}>R_{t+1}$ & $R_{1, t}>R_{t+1}$ \\
\hline$\alpha_{1}$ & $\alpha_{1}+\alpha_{2}$ & $\alpha_{2} A$ & $\alpha_{1}$ \\
\hline$s\left(1-\alpha_{1}\right)$ & $s\left\{\left(1-\alpha_{1}\right)+\left(1-\alpha_{2}\right)\right\}$ & $Y_{1, t}=Y_{1, t+1}$ & $Y_{1, t}=Y_{1, t+1}$ \\
\hline Production Income & $Y_{1, t}=Y_{1, t+1}$ & $A$ & $A$ \\
\hline$A$ & $A$ & $A$ & \\
\hline
\end{tabular}

Table 5.2: $\quad$ Short-Run Effects Economic Integration Region 2

\begin{tabular}{|c|c|c|c|}
\hline \multicolumn{1}{|c|}{ Autarky } & & Integration & \\
\hline Aggregate Saving & & $M 1$ & $M 3$ \\
\hline$S_{t}=s\left[\left(1-\alpha_{1}\right)+\left(1-\alpha_{2}\right)\right] A$ & $S_{t}>1+\frac{\alpha_{1}}{\alpha_{2}}$ & $\frac{\alpha_{1}}{\alpha_{2}}<S_{t}<1+\frac{\alpha_{1}}{\alpha_{2}}$ & $1<S_{t}<\frac{\alpha_{1}}{\alpha_{2}}$ \\
\hline Wage Rate & $w_{2, t}=w_{2, t+1}$ & $w_{2, t}>w_{2, t+1}$ & $w_{2, t}>w_{2, t+1}$ \\
\hline$\left(1-\alpha_{2}\right) A$ & $\left(1-\alpha_{2}\right) A$ & $\left.\begin{array}{l}\left(1-\alpha_{2}\right) A \times \\
{\left[s A^{\{}\left(1-\alpha_{1}\right)+\left(1-\alpha_{2}\right)\right\}-\alpha_{1} / \alpha_{2}}\end{array}\right]$ & 0 \\
\hline Return on Capital & $R_{2, t}<R_{t+1}$ & $R_{2, t}<R_{t+1}$ & $R_{2, t}>R_{t+1}$ \\
\hline$\frac{\alpha_{2}}{s\left(1-\alpha_{2}\right)}$ & $\alpha_{1}+\alpha_{2}$ & $\alpha_{2} A$ & $\alpha_{2}$ \\
\hline Production Income & $Y_{2, t}=Y_{2, t+1}$ & $Y_{2, t}>Y_{2, t+1}$ & $Y_{2, t}>Y_{2, t+1}$ \\
\hline$A$ & $A$ & $A K_{2, t+1}$ & 0 \\
\hline
\end{tabular}


Table 5.3: $\quad$ Long-Run Effects Economic Integration Region 1

\begin{tabular}{|c|c|c|c|}
\hline Autarky & & Integration & \\
\hline & $M 1$ & $M 2$ & $M 3$ \\
\hline Aggregate Saving & & & \\
\hline$S_{t}=s\left[\left(1-\alpha_{1}\right)+\left(1-\alpha_{2}\right)\right] A$ & $S_{t}>1+\frac{\alpha_{1}}{\alpha_{2}}$ & $S_{t}=1+\frac{\alpha_{1}}{\alpha_{2}}$ & $S_{t}=1+\frac{\alpha_{1}}{\alpha_{2}}$ \\
\hline Wage Rate & $w_{1, t}=w_{1, t+1}$ & $w_{1, t}=w_{1, t+1}$ & $w_{1, t}=w_{1, t+1}$ \\
\hline$\left(1-\alpha_{1}\right) A$ & $\left(1-\alpha_{1}\right) A$ & $\left(1-\alpha_{1}\right) A$ & $\left(1-\alpha_{1}\right) A$ \\
\hline Return on Capital & $R_{1, t}>R_{t+1}$ & $R_{1, t}>R_{t+1}$ & $R_{1, t}>R_{t+1}$ \\
\hline$\frac{\alpha_{1}}{s\left(1-\alpha_{1}\right)}$ & $\frac{\alpha_{1}+\alpha_{2}}{s\left\{\left(1-\alpha_{1}\right)+\left(1-\alpha_{2}\right)\right\}}$ & $\alpha_{2} A$ & $\alpha_{1}$ \\
\hline Production Income & $Y_{1, t}=Y_{1, t+1}$ & $Y_{1, t}=Y_{1, t+1}$ & $Y_{1, t}=Y_{1, t+1}$ \\
\hline$A$ & $A$ & $A$ & $A$ \\
\hline
\end{tabular}

Table 5.4: $\quad$ Long-Run Effects Economic Integration Region 2

\begin{tabular}{|c|c|c|c|}
\hline Autarky & & Integration & \\
\hline & $M 1$ & $M 2$ & $M 3$ \\
\hline Aggregate Saving & & & \\
\hline$S_{t}=s\left[\left(1-\alpha_{1}\right)+\left(1-\alpha_{2}\right)\right] A$ & $S_{t}>1+\frac{\alpha_{1}}{\alpha_{2}}$ & $S_{t}=1+\frac{\alpha_{1}}{\alpha_{2}}$ & $1<S_{t}<\frac{\alpha_{1}}{\alpha_{2}}$ \\
\hline Wage Rate & $w_{2, t}=w_{2, t+1}$ & $w_{2, t}>w_{2, t+1}$ & $w_{2, t}>w_{2, t+1}$ \\
\hline$\left(1-\alpha_{2}\right) A$ & $\left(1-\alpha_{2}\right) A$ & $\left(1-\alpha_{2}\right) A$ & 0 \\
\hline Return on Capital & $R_{2, t}<R_{t+1}$ & $R_{2, t}<R_{t+1}$ & $R_{2, t}>R_{t+1}$ \\
\hline$\frac{\alpha_{2}}{s\left(1-\alpha_{2}\right)}$ & $\alpha_{1}+\alpha_{2}$ & $\alpha_{2} A$ & $\alpha_{2}$ \\
\hline Production Income & $Y_{2, t}=Y_{2, t+1}$ & $Y_{2, t}>Y_{2, t+1}$ & $Y_{2, t}>Y_{2, t+1}$ \\
\hline$A$ & $A$ & 0 & 0 \\
\hline
\end{tabular}




\subsection{Conclusion}

In this chapter we have examined the transition from two autarchic economies into one integrated economy. The two regions differ in terms of the institutional setting and arrangements. We have used a Leontief production function with fixed technical coefficients to model the production side of the economy. Wage and capital incomes are determined by a bargaining process between wage earners and capital owners. The institutional setting supplies the rules of this bargaining process. We have assumed that the institutional setting is efficient, meaning that it prevents bargainers from investing resources to increase their bargaining position. On the other hand, it also determines the remuneration of labour and capital, but not according to the value of their marginal product. In line with Williamson (2000) we have assumed that institutions change very slowly and therefore, in our case, so do factor shares. For the consumption side we have used a two-period OLG model, which makes it possible to compare the period of autarchy of the two regions with the next period of integration of the two regions.

The results of integration between two economies are quite different from the standard models of economic integration, where under specific circumstances an increase of world welfare is possible in the long run. If remunerations are highly institutionally determined, integration will not lead to a movement of capital where it is most productive, but to the region with the highest remuneration for that factor, which is determined by institutional settings. In the region where the remuneration of capital is lowest, this could possibly result in the economy ceasing to exist. This will be the case if there are considerable differences in income distribution in the two regions.

The opening of the capital market between regions in our model does not create a Pareto improvement. At best the wage rates remain unchanged and the return on capital after integration lies between the interest factors in autarchy so there are gains and losses for the capital owners. The capital owners in the capital-poor region are harmed and the capital owners in the capital-rich region are better off. This will only happen if the over-accumulation of capital is sufficiently large. If this is not the case, the country with the higher labour share will be harmed, in both the short and long run. This is caused by the fact that capital will flow to the other region, leading to a reduction of capital goods and resulting in a decrease of production and therefore income in that region.

An important observation is that in an economy like that one described in this chapter, integration leads to a decrease in efficiency. However, this could be overcome by redistribution of savings by a central government. This does not increase efficiency as compared with no integration, because institutional settings have remained unchanged. But the over-accumulation of capital in region 1 could be reduced by a central government to the benefit of region 2 . Actually, the capital flow to region 1 could be reduced so that it matches 
the equilibrium situation of the two regional economies. This is possible because in autarchy both regions are in a situation of over-accumulation. This redistribution does not hurt region 1 's younger generation, but it hurts the older generation. The interest factor is reduced after integration and this benefits region 2's generations. Actually such intervention by a central government could avert region 2 landing on a negative growth path after integration. There would then be an overall increase in efficiency in case the two regions are integrated. However, compared with autarchy there is no increase in efficiency.

The other way to avoid negative results is to change the institutional arrangements (in the labour market). This means that the government of the region with the greatest labour share has to adjust its institutional setting in such a way that the labour share in income decreases and the incentive to export capital to the other region will diminish. This could result in a race to the bottom. This kind of policy also means that the inhabitants of this region will be harmed, and the long-run steady state will be lower than in autarchy. In addition, if we assume that a large labour share reflects a high social standard in an economy, then this policy analysis could result in a decrease of social standards.

In conclusion, we only can say that one must be very careful before recommending that the capital markets should be opened, especially when factor markets are influenced by institutional arrangements.

In the next chapter we assume that the institutional setting has positive externalities for the economy as a whole and that it has some public-good characteristics. Furthermore, we assume that the regional government can influence the institutional setting through public investments and public capital formation. The main results of this chapter will still hold within this framework, but, as we shall see, integration can lead to a Pareto improvement due to externalities. 



\title{
Chapter 6
}

\author{
Institutional Differences and \\ Productivity of Public Capital
}




\subsection{Introduction}

As we have seen, regions consistently differ in their economic performance and development ${ }^{127}$. Sometimes this results from the fact that some regions have a (comparative) advantage over others, often resulting in a higher labour productivity. This results in differences in the level of income, employment and welfare. Often, however, such differences are neither socially nor politically desirable; a more even distribution of income, wealth and welfare is favoured. Economic integration, which removes economic cross-border barriers and permits the free movement of goods, services and production factors, is seen as a strategy to reduce such regional differences ${ }^{128}$. In fact, conventional trade theory ${ }^{129}$ predicts that if cross-border barriers are removed and regions specialize according to their comparative advantage, increased trade enhances economic growth and welfare for all regions, the result being economic convergence. As such, cooperation between regions to enhance the process of economic integration can be beneficial.

In reality, however, although many cross-border barriers have indeed been removed and factor mobility has increased, we nevertheless still observe great differences between regions with respect to their economic productivity, growth and income. For example, after the re-unification of Germany, the former East Germany has still not been able to catch up with the western part of the country. In general, according to recent empirical research, convergence has not occurred; these research findings seem to support the case that the actual development has been one of divergence. What might be the reason for this development? It is often pointed out that markets, like the labour market, do not work well and are relatively rigid, which leads to immobility rather than mobility. We suspect that unvarying differentials in income and welfare between regions are also caused by other factors, which are often ignored. On the one hand, some regions have comparative physical advantages, such as a climate that is beneficial to agriculture, an advantageous location like a natural harbour, an abundance of natural resources, and so on. On the other hand, all kind of intangibles can also lead to comparative advantages, such as the legal structure, the public administration, and the public health system. These intangibles form a part of the institutional setting or structure of a region and have public good characteristics (such as a high level of non-excludability and non-rivalry).

In this chapter we extend our analysis of the effects of differences in institutional setting in the case of economic integration. In this way try to answer research question 5: What are the consequences of regional integration for efficiency when regions differ in their institutional structure and when the institutional structure generates externalities?

\footnotetext{
${ }^{127}$ See EUROSTAT http://epp.eurostat.ec.europa.eu/portal/page/portal/region_cities/regional_statistics/data/main_tables

${ }^{128}$ See for example the motivation for regional policy of the EU chapter 1.

${ }^{129}$ See for example Krugmann and Obstfeld (2002). For a more European context see Baldwin and Wyplosz (2009)
} 
We assume there is a positive relation between public capital and institutional setting, the maintenance of property rights and economic growth. To do so, as was explained in chapter 2, we use a neo-classical production function that takes public capital as one of its arguments, in addition to labour and private capital. This production function generates positive externalities in line with the suggestions made previously. These are the unpaid production factors (public capital) that enters the user's production function (see section 2.6.1).

The chapter is organized as follows. First, in section 6.2, we introduce the model used to compare regions with a difference in the productivity of their public capital. We use an OLG model combined with a log-linear utility function. This offers us an appropriate tool to investigate the consequences of integration. So we use a production function that incorporates public capital characterized by diminishing returns to scale with respect to this type of capital. One reason for this is that it allows us to incorporate congestion in case of excessive levels of (public) capital. We recall that the term congestion is a catch all expression to indicate more extensive use of resources i.e. public capital leads to diminishing returns of the resources i.e. public capital. We assume that both public and private capital is fully depreciated during its period of use as said earlier (this is common in the type of OLG model used here) To assess the effects of economic integration, in section 6.3 we first look at the economic development of the regions separately, without integration. As in chapter 5, we label this case the autarchy case. The next step (section 6.4) is to introduce economic integration, where we assume mobility of private capital, but immobility of public capital. For the labour market we assume that labour commutes, by which we mean that if the wage rate in the other region is higher, workers will work in that other region but will still spend their income in their resident region. In section 6.5 the effect of integration on overall income and production is discussed. Section 6.6 summarizes and concludes.

\subsection{Public Capital and Externalities}

In this section we describe the model used to compare the development of two different regions. Within these regions there are $n$ firms, operating under perfect competition. Both regions are identical except for the productivity of public capital, which stems from institutional differences.

\subsubsection{Productivity of Public Capital}

We start with the production function of a representative firm in one of the two regions. We assume that, besides labour and private capital, public capital also has a positive effect on 
output. However, the more a firm makes use of public capital, the smaller the productivity of public capital, resulting in an economy wide decrease of productivity. As mentioned this is labelled a congestion effect. To take account of this phenomenon the ratio of public capital and aggregate private capital is incorporated in the production function. Therefore we have chosen a production function that includes public services; in our case, the institutional setting as a productive input to private producers. If we consider the ratio public / private capital, given a stock of public capital, an increase of private capital decreases this ratio and leads to a lower contribution to income and output.

Barro and Sala-i-Martin (1992) distinguish three versions of publicly provided goods: publicly provided private goods, which are rival and non-excludable, publicly provided goods which are non-rival and non-excludable and publicly provided goods that are subject to congestion, which are rival and to some extend non-excludable. As examples of public goods contributing to output they mention highways, water and sewage systems, and law courts. This last type of publicly provided good fits best with our purpose, which is to include institutions as a productive resource. Below we give the production function for the representative firm $j$ in both regions:

$$
Y_{j}=K_{j}^{\alpha}\left(\hat{k} L_{j}\right)^{1-\alpha}\left(\frac{P}{K}\right)^{\beta} \quad j=1, \ldots, n
$$

The variables bearing the subscript $j$ are specific to a representative firm; the other variables are exogenous to a single firm. Here $K_{j}$ represents the capital stock of the $j$-th firm, and $L_{j}$ represents the number of workers in the this firm. The variable $K$ represents the total private capital stock of the region, whereas $\hat{k}=K / L$ is the region-wide capital intensity, which is exogenous to a single firm. The variable $P$ represents public capital, financed by lump sum taxes. The parameters $0<\alpha<1$ and $0<\beta<1$ indicate the productivity of private and public capital.

The positive externalities stem from the region-wide stock of capital and the capital intensity of public capital. The reason for this is that the productivity of labour increases if the region-wide capital intensity increases (unpaid production factor). The more capital available in a region, the higher the capital labour ratio and the more labour 'learns by doing'. ${ }^{130}$ Thus, on the one hand, private capital generates positive externalities by increasing the capital intensity, representing spill-over's of knowledge and ideas. On the other hand, it generates negative externalities due to the more intensive usage of publicly provided goods; in our case, a more intensive usage of the available institutions.

\footnotetext{
${ }^{130}$ See Barro \& Sala-i-Martin (1992) and (1995) for details and explanation of this mechanism.
} 
Note that the public capital stock generates positive externalities, but at a decreasing rate $^{131}$. First, if the public capital stock increases this leads to an increase of overall production by the firms. Secondly, if the private capital stock increases the externality of the public capital stock diminishes due to more intensive use. This means that there is a kind of rivalry with respect to public capital. By this we mean that private capital used by one firm can only in a limited way or not used by other firms (then it is fully rival). Recall, however, that an increase in the private capital stock generates positive externalities due to an increase in the capital labour ratio and negative externalities due to a decrease in the ratio between public private capital. The production function is linear-homogenous in the firm-specific variables $\left(K_{j}, L_{j}\right)$.

In addition, and recapitulating, the production function has the following properties: $F_{v}>0, F_{v v}<0$, , where $v=K_{j}, L_{j}, \frac{K}{L}, \frac{P}{\mathrm{~K}}$ whit $L=\sum_{j=1}^{n} L_{j}$ and $K=\sum_{j=1}^{n} K_{j}$.

\subsubsection{Firms and Externalities}

We continue with firm $j$ 's behaviour. As usual we assume that each firm maximizes its profits. Thanks to the assumption of perfect competition we can take the behaviour of a representative firm to resemble firms' behaviour in the overall economy. In case each firm maximizes its profits, the representative firm $j$ faces the following maximization problem:

$$
\max _{K_{j}, L_{j}}\left(Y_{j}-w_{j} L_{j}-R_{j} K_{j}\right)
$$

The production costs consist of labour costs and costs of capital. The costs of capital consist of depreciation, which is assumed to be $100 \%$ (depreciation rate of capital) and interest costs The wage rate $w_{j}$ and return on capital $R_{j}$ of firm $j$ can be found by taking first derivatives and setting them equal to zero. Using equation (6.2) we find the first-order condition with respect to labour and capital:

${ }^{131}$ Output increases as the ration public capital / private capital increase or $\frac{\partial Y_{j}}{\partial\left(\frac{P}{K}\right)}=\frac{Y_{j}}{\left(\frac{P}{K}\right)}=\frac{\beta}{\left(\frac{P}{K}\right)} Y_{j}>0$.

As the ratio, $\left(\frac{P}{K}\right)$, increases the contrition of public capital decreases. 


$$
\frac{\partial Y_{j}}{\partial K_{j}}=\alpha K_{j}^{\alpha-1}\left(\hat{k} L_{j}\right)^{1-\alpha}\left(\frac{P}{K}\right)^{\beta}-R_{j}=0
$$

and

$$
\frac{\partial Y_{j}}{\partial L_{j}}=(1-\alpha) K_{j}^{\alpha}(\hat{k})^{1-\alpha} L_{j}^{-\alpha}\left(\frac{P}{K}\right)^{\beta}-w_{j}=0
$$

We assumed that the economy is operating in a fully competitive environment (labour market, capital market and final goods market) so the wage rate and return on capital are the same for all firms in both regions i.e. $R_{j}=R$ and $w_{j}=w$.Equilibrium aggregate capital stock and labour is the total of capital and labour of all $n$ firms, amounting to $K=n K_{j}$ and $L=n L_{j}$ for both regions (all firms are identical). This also implies that, in equilibrium, for all $n$ firms, and the two regional economies, the capital intensity, is the same., that is. $\hat{k}=\frac{K}{L}=\frac{K_{j}}{L_{j}}$. Taking this into account we find the following equilibrium wage rate and return on capital for a representative region. First we reformulate the first order condition as follows: ${ }^{132}$

$$
R=\alpha\left(\frac{P}{K}\right)^{\beta}
$$

We find the equilibrium wage rate from the other first-order condition: ${ }^{133}$

$$
w=(1-\alpha) \hat{k}\left(\frac{P}{K}\right)^{\beta}
$$

To find the gross regional output we have to aggregate over all $n$ (identical) firms. This gives the following equation, which represents total regional output: ${ }^{134}$

${ }^{132} R=R_{j}=\alpha\left(\frac{L_{j}}{K_{j}}\right)^{1-\alpha}\left(\frac{K}{L}\right)^{1-\alpha}\left(\frac{P}{K}\right)^{\beta}$ and because $\frac{L_{j}}{K_{j}}=\frac{L}{K}$ we have $R=\alpha\left(\frac{P}{K}\right)^{\beta}$.
${ }^{133} w_{j}=w=(1-\alpha) \frac{K_{j}^{\alpha}}{L_{j}^{\alpha}} \hat{k}^{1-\alpha}\left(\frac{P}{K}\right)^{\beta}$. In equilibrium we have $\hat{k}=\frac{K}{L}=\frac{K_{j}}{L_{j}}$. Inserting this capital-labour ratio

leads to $w=(1-\alpha) \hat{k}^{\alpha} \hat{k}^{1-\alpha}\left(\frac{P}{K}\right)^{\beta}$. Finally we have the following wage rate; $w=(1-\alpha) \hat{k}\left(\frac{P}{K}\right)^{\beta}$.

${ }^{134} Y=\sum_{j=1}^{n} Y_{j}=n Y_{j}=\left(n K_{j}\right)^{\alpha}\left(\hat{k} n L_{j}\right)^{1-\alpha}\left(\frac{P}{K}\right)^{\beta}=K^{\alpha} L^{1-\alpha}\left(\frac{K}{L}\right)^{1-\alpha}\left(\frac{P}{K}\right)^{\beta}$ so $Y=K\left(\frac{P}{K}\right)^{\beta}$. 


$$
Y=K\left(\frac{P}{K}\right)^{\beta}, \text { or } Y=K^{1-\beta} P^{\beta},
$$

So in equilibrium, regional output depends on the aggregate private capital stock and on the public capital stock and a shift parameter. From this equation we can derive the social rate of return on private capital, which equals the marginal costs:

$$
\frac{\partial Y}{\partial K}=(1-\beta)\left(\frac{P}{K}\right)^{\beta}=R^{\text {social }}
$$

Comparing equation (6.3) with (6.3B) we see the difference between private and social return on capital. The social rate of return, $R^{\text {social }}$, is lower, (i.e. $\alpha>(1-\beta)$ ), equal to. (i.e. $\alpha=(1-\beta)$ ) or higher, (i.e. $\alpha<(1-\beta)$ )than the private return on capital. If the social rate of return exceeds that of the private rate of return, private investments results in positive externalities and otherwise negative externalities. Private capital accumulation can be too low if firms do not take account of the fact that private capital accumulation increases the overall capital intensity, which has a positive effect on the production of all other firms. It can be too high if firms do not take account of the negative externality of congestion, which is the result of increasing capital.

Now that the factor prices are known we can look at income shares of labour and capital. In case all markets are fully competitive, firms make no profit. As a result, total income consists of wage income and capital income. The income share of both labour and capital is fixed if a Cobb-Douglas type of production function is used: ${ }^{135}$

$$
Y=w L+R K=(1-\alpha) K\left(\frac{P}{K}\right)^{\beta}+\alpha K\left(\frac{P}{K}\right)^{\beta}
$$

\subsubsection{Private and Public Capital Accumulation}

To investigate the consequences of integration (in relation to the autarchy case) we have to look at the dynamic version of the model. First we introduce a time index $t$ for all endogenous variables. The wage rate at period $t$, (i.e. $w_{t}$ ), is given by:

${ }^{135} Y=w L+R K=(1-\alpha) \frac{K}{L}\left(\frac{P}{K}\right)^{\beta} L+\alpha\left(\frac{P}{K}\right)^{\beta} K=K\left(\frac{P}{K}\right)^{\beta}$. 


$$
w_{t}=(1-\alpha) \hat{k}_{t}\left(\frac{P_{t}}{K_{t}}\right)^{\beta}
$$

The wage rate depends on labours marginal product, which in this case depends on the capital intensity and the ratio between public and private capital, where the capital intensity depends on private capital and labour. As we have assumed that labour is constant, changes in the ratio of capital to labour depend only on a change in private capital. The return on capital, $\left(R_{t}\right)$, at period $t$ is given by:

$$
R_{t}=\alpha\left(\frac{P_{t}}{K_{t}}\right)^{\beta}
$$

Thus $R_{t}$ depends on the productivity of private capital, i.e. the parameter $\alpha$, and on the ratio between public and private capital. Next we determine both the size of private and the public capital stock. Aggregate output $Y_{t}$ at period $t$ over time is given by (see equation (6.5)):

$$
Y_{t}=K_{t}\left(\frac{P_{t}}{K_{t}}\right)^{\beta}, \text { or } Y_{t}=K_{t}^{1-\beta} P_{t}^{\beta}
$$

This equation shows that income and production depends on both the private and the public capital stock, both of them in a diminishing manner.

To examine the development of the economy we have to look at how the endogenous variables evolve over time. This is the equation of motion of the model, as we have seen previously. We restrict the analyses to two periods, corresponding to the periods before and after economic integration.

\section{Equation of Motion for Private Capital}

The first step is to determine, $K_{t+1}$, the private capital stock in period $t+1$. This capital stock equals total savings in the previous period $t$. Total aggregate savings in period $t$ are $S_{t}=\hat{s} w_{t} L$ where $\hat{s}=s(1-\tau)$ is the after tax saving rate and $\tau$ the average tax rate on wage income. As in the previous chapters we use an OLG model with two generations. ${ }^{136}$ The young generation supplies labour, resulting in a labour income that is a fixed share of total income. In our case

\footnotetext{
${ }^{136}$ In this type of OLG model with a log-linear utility function the saving rate equals $\hat{s}=\frac{1}{(2+\rho)}$ where $\rho$ is the rate of time preference.
} 
this equals $w_{t} L=(1-\alpha) Y_{t}$. We know the income share of wage income from equation (6.4A) and therefore we also know the savings. ${ }^{137}$ Labour income after taxes, not used for consumption, represents savings. These current savings are the next period's private capital stock, that is $S_{t}=K_{t+1}$ and this is the equation of motion for the private capital stock of the regional economy. As a result we find the following private capital stock of period $t+1$ :

$$
K_{t+1}=S_{t}=\hat{s}(1-\alpha) K_{t}\left(\frac{P_{t}}{K_{t}}\right)^{\beta}
$$

\section{Equation of Motion for Public Capital}

We use the same procedure for the public capital stock. The public capital stock in period $t+1$, $P_{t+1}$, is financed by taxes and equals the tax revenues of the previous period $t$. So total tax revenues in period $t$ are given by $T_{t}=\tau w_{t} L$. The public capital stock in period $t+1$ is equal to the previous period's $(t)$ tax revenues. If taxes are levied on labour income, the public capita stock in period $t+1$ amounts to:

$$
P_{t+1}=T_{t}=\tau(1-\alpha) K_{t}\left(\frac{P_{t}}{K_{t}}\right)^{\beta}
$$

Using the previous equation in combination (6.9) with equation (6.8) we determine the ratio between public and private capital, which is fixed:

$$
\frac{P_{t+1}}{K_{t+1}}=\frac{\tau}{\hat{s}}
$$

We have seen that the ratio of public and private capital depends on two parameters: the overall tax rate and the saving rate; that is $\tau$ and, $\hat{s}$ and is constant. This also implies that the return on private capital is constant at equilibrium. Now that we know the relation between public and private capital we can rewrite the production function as follows:

$$
Y_{t}=\left(\frac{\tau}{\hat{s}}\right)^{\beta} K_{t} \text { or } Y_{t}=A K_{t}
$$

$$
{ }^{137} w_{t}=(1-\alpha) \frac{K_{t}}{L}\left(\frac{P_{t}}{K_{t}}\right)^{\beta} \text { and } w_{t} L=(1-\alpha) K_{t}\left(\frac{P_{t}}{K_{t}}\right)^{\beta} \text { so } S_{t}=\hat{s}(1-\alpha) K_{t}\left(\frac{P_{t}}{K_{t}}\right)^{\beta}
$$


where $A=\left(\frac{\tau}{\hat{s}}\right)^{\beta}$. We note that the resulting production function, equation (6.11), resembles that of the AK production functions used in endogenous growth theory. The capital market is in equilibrium if $S_{t}=K_{t+1}$. Substituting aggregate savings and using the equilibrium ratio between public and private capital we find the following income relation: ${ }^{138}$

$$
Y_{t+1}=\hat{s}(1-\alpha)\left(\frac{\tau}{\hat{s}}\right)^{\beta} Y_{t}
$$

The growth factor can now be calculated quite easily from equation (6.12). It is:

$$
1+g=\frac{Y_{t+1}}{Y_{t}}=\hat{s}(1-\alpha)\left(\frac{\tau}{\hat{s}}\right)^{\beta}
$$

As can be seen, growth depends not only on the propensity to save, $\hat{s}(1-\alpha)$ and the tax rate, $\tau$, but also on the productivity of public capital, $\beta$ and the ratio between tax and saving rate from wage income, $\left(\frac{\tau}{\hat{s}}\right)$. Assuming no population growth this is also the per capita growth. The growth rates of consumption, private and public capital formation and per capita consumption are the same as the growth rate of income. ${ }^{139}$

${ }^{138} Y_{t+1}=K_{t+1}\left(\frac{\tau}{\hat{s}}\right)^{\beta}$ so $Y_{t+1}=S_{t}\left(\frac{\tau}{\hat{s}}\right)^{\beta}$ and $Y_{t+1}=\hat{s}(1-\alpha) Y_{t}\left(\frac{\tau}{\hat{s}}\right)^{\beta}$. From this the growth rate can be derived,

which equals $(1+g)=\frac{Y_{t+1}}{Y_{t}}=\hat{s}(1-\alpha)\left(\frac{\tau}{\hat{s}}\right)^{\beta}$.

${ }^{139}$ From (6.8) and (6.10) $K_{t+1}=\hat{s}(1-\alpha) K_{t}\left(\frac{\tau}{\hat{s}}\right)^{\beta}$. The growth rate equals $\frac{K_{t+1}}{K_{t}}=\hat{s}(1-\alpha) A=(1+g)$.

From (6.10) $\frac{P_{t+1}}{K_{t+1}}=\frac{P_{t}\left(1+g_{p}\right)}{K_{t}(1+g)}=\frac{\tau}{\hat{s}}$ thus $g=g_{p}$ and $\frac{P_{t+1}}{P_{t}}=(1+g)$. The resource constraint equals

$Y_{t}=C_{t}+K_{t+1}+P_{t+1}$ and $(1+g) Y_{t}=Y_{t+1}=C_{t+1}+(1+g) K_{t+1}+(1+g) P_{t+1}$. This results in

$C_{t+1}=(1+g) C_{t}$ or $\frac{C_{t+1}}{C_{t}}=(1+g)$. 


\subsection{Productivity of Public Capital: the Autarchy Case}

In this section we examine the autarchy case. By autarchy we mean that there is no labour or capital mobility. The two regions differ only in respect of the efficiency of public capital.

We start with the situation in which region 1 has a comparative advantage (more efficient public capital) over the region 2 , due to a different institutional setting. We take $h(h \geq 1)$ as a scale parameter for the productivity of public capital. Higher productivity is associated with a higher value of the parameter. For the least productive region we set the value of $h$ as 1 . The production of region 1 has to be adjusted for the productivity of public capital $(h>1)$. This results in adjustments of the production function for a representative firm in region 1 and 2 . For any firm $j$ we have the following production functions in both regions:

$$
Y_{1, j}=K_{1, j}^{\alpha}\left(\hat{k}_{1, j} L_{1, j}\right)^{1-\alpha}\left(\frac{h P_{1, j}}{K_{1, j}}\right)^{\beta}
$$

and

$$
Y_{2, j}=K_{2, j}{ }^{\alpha}\left(\hat{k}_{2, j} L_{2, j}\right)^{1-\alpha}\left(\frac{P_{2, j}}{K_{2, j}}\right)^{\beta}
$$

In order to compare the two regions we rearrange the production functions. The region-wide aggregated production functions are written as:

$$
Y_{1, t}=h^{\beta} K_{1, t}\left(\frac{P_{1, t}}{K_{1, t}}\right)^{\beta}
$$

and

$$
Y_{2, t}=K_{2, t}\left(\frac{P_{2, t}}{K_{2, t}}\right)^{\beta}
$$

We have seen that the parameter $h^{\beta}$ can be viewed as a productivity parameter. Here it indicates the fact that region 1 is more productive than region 2 . The income of region 1 exceeds that of region 2, even though the private and public capital stocks in both regions are the same. From equations (6.16) and (6.17) it can be seen that given the same stock of public and private capital, the difference in income is entirely the result of a difference in the productivity of public capital. Consequently, the wage rate and the return on capital in region 1 will be higher than those in region 2 . 


$$
R_{1, t}=\alpha h^{\beta}\left(\frac{P_{1, t}}{K_{1, t}}\right)^{\beta}>R_{2, t}=\alpha\left(\frac{P_{2, t}}{K_{2, t}}\right)^{\beta}
$$

and

$$
w_{1, t}=(1-\alpha) h^{\beta} k_{1, t}\left(\frac{P_{1, t}}{K_{1, t}}\right)^{\beta}>w_{2, t}=(1-\alpha) k_{2, t}\left(\frac{P_{2, t}}{K_{2, t}}\right)^{\beta}
$$

Comparing the regions we can see that the differences in return on capital, wage rate and income depend on the productivity of public capital. Using the results from the previous section, we can summarize the differences of the two regions in the case of autarchy:

$$
\begin{aligned}
& R_{1, t}=h^{\beta} R_{2, t} \\
& w_{1, t}=h^{\beta} w_{2, t} \\
& Y_{1, t}=h^{\beta} Y_{2, t}
\end{aligned}
$$

\section{Equations of Motion for Public Capital}

We assume that the government has a balanced budget and that public investment is financed by taxes on labour income. Using the budget constraint of the two regions, $P_{1, t+1}=T_{1, t}$ and $P_{2, t+1}=T_{2, t}$, we can calculate the level of public investment. We know the total tax revenues from the previous period, so the level of public investment in regions 1 and 2 are respectively:

$$
P_{1, t+1}=\tau(1-\alpha) Y_{1, t}
$$

and

$$
P_{2, t+1}=\tau(1-\alpha) Y_{2, t}
$$

These are the two equations of motion for public capital in the different regions. Comparing the two regions we can see that public investment in region 1 exceeds that in region 2 by a factor $h^{\beta}\left(Y_{1, t}=h^{\beta} Y_{2, t}\right.$, see equation (6.16) and (6.17)). This is due to higher tax revenues from a higher productivity of public investment in region 1, which has resulted in a higher income in the previous period.

\section{Equations of Motion for Private Capital}

For private capital formation we have market clearing for region 1 and 2 separately. This means we have $K_{1, t+1}=S_{1, t}$ and $K_{2, t+1}=S_{2, t}$. For the equations of motion for private capital we get: 


$$
K_{1, t+1}=\hat{s}(1-\alpha) Y_{1, t} \text { and } \frac{P_{1, t+1}}{K_{1, t+1}}=\left(\frac{\tau}{\hat{s}}\right)
$$

and

$$
K_{2, t+1}=\hat{s}(1-\alpha) Y_{2, t} \text { and } \frac{P_{2, t+1}}{K_{2, t+1}}=\left(\frac{\tau}{\hat{s}}\right)
$$

As with public capital, the private capital stock in region 1 is higher than the capital stock in region 2 thanks to more savings resulting from a greater income in the previous period. We can now calculate the ratio of public and private capital. As has been noted before, this ratio is an argument in the production function, and is needed to calculate level of income in both regions and their growth rates. Inserting the result of equation (623) and (6.24) in equation (6.16) and (6.17) we find the following development of income over time in the two regions.

$$
Y_{1, t+1}=h^{\beta} \hat{s}(1-\alpha)\left(\frac{\tau}{\hat{s}}\right)^{\beta} Y_{1, t}
$$

and

$$
Y_{2, t+1}=\hat{s}(1-\alpha)\left(\frac{\tau}{\hat{s}}\right)^{\beta} Y_{2, t}
$$

Equation (6.26) is equivalent to the one we derived in the previous section evidently. The development of income in region 1 is $h^{\beta}$ times greater thanks to the higher productivity of capital, due to a better institutional structure. The corresponding growth factors of region 1 and 2 are given by:

$$
1+g_{1}=\frac{Y_{1, t+1}}{Y_{1, t}}=h^{\beta} \hat{s}(1-\alpha)\left(\frac{\tau}{\hat{s}}\right)^{\beta} .
$$

and

$$
1+g_{2}=\frac{Y_{2, t+1}}{Y_{2, t}}=\hat{s}(1-\alpha)\left(\frac{\tau}{\hat{s}}\right)^{\beta} .
$$

Complementary to equation (6.20A), we can summarize the result below:

$$
\begin{aligned}
& P_{1, t+1}=h^{\beta} P_{2, t+1} \\
& K_{1, t+1}=h^{\beta} K_{2, t+1} \\
& Y_{1, t+1}=h^{\beta} Y_{2, t+1}
\end{aligned}
$$




$$
\left(1+g_{1}\right)=h^{\beta}\left(1+g_{2}\right)
$$

It is clear that private and public capital formation, income development and the growth in region 1 is $h^{\beta}$ times greater than in region 2 . This means that the development of both regions diverges due to the difference in the productivity of public capital resulting from different institutions. Recall that we have assumed that regions are identical in all other respects. This difference in institutional setting makes public capital in one region more productive than in the other. In autarchy there will be no convergence.

As was mentioned above, autarchy is simply a reference case. The question, of course, is what will be the effect of economic integration with free mobility of factors of production? Will the regions converge? This question is addressed in the next section.

\subsection{Economic Integration: from Autarchy to Mobility}

To investigate the consequences of economic integration we now extend the model by allowing for mobility of labour and capital. At the same time, public capital remains completely immobile between the integrating regions.

We assume that the tax rate is unchanged and is the same for both regions. We assume that both regions have an identical quantity of resources in the first period $(t)$ and that free trade occurs, just after period $t$, in period $(t+1)$. The consequences of factor mobility are that wages and return on private capital are equalized through arbitrage between the two regions in period $(t+1)$.

As we have seen in the previous section, the return on private capital in region 1 exceeds that of region 2. The same applies for the wage rate. Savings will therefore flow from region 2 to 1 , while labour will also move from region 2 to 1 . This arbitrage process will continue until the factor prices are the same in both regions. If factor prices are equalized, then there is no incentive for arbitrage. The non-arbitrage condition is equality between the factor prices in the two regions, so there is no longer any movement of savings and labour between the two regions.

We first look at the implication of the non-arbitrage conditions for the capital and the labour market in the two regions. Then we shall take a brief look at the aggregate savings in the two regions, after which we pay attention to public capital formation resulting from integration. Due to differences in return on capital and a change in income this has an effect on public capital formation and the overall productivity of the two regions. Finally, we shall see what the effects are on income and growth. 


\subsubsection{The Arbitrage Process after Integration}

The wage rate and the return on capital in region 1 exceed those of region 2 . Therefore both capital and labour will flow from region 1 to region 2 until the wage rate and the return on capital are equal in the two regions. The two non-arbitrage conditions are then met and the flow of labour and capital will stop. To gain a first impression of what this means for the two economies we use equation (6.15) and (6.16). We investigate the effect of a small change of capital on production and income. We therefore differentiate both equations with respect to capital to obtain the following result:

$$
\frac{\partial Y_{1, t}}{\partial K_{1, t}}=h^{\beta}(1-\beta)\left(\frac{P_{1, t}}{K_{1, t}}\right)^{\beta}>0 \text { and } \frac{\partial Y_{2, t}}{\partial K_{2, t}}=(1-\beta)\left(\frac{P_{2, t}}{K_{2, t}}\right)^{\beta}>0
$$

The flow of capital runs from region 2 to region 1 (thus $\frac{\partial Y_{1, t}}{\partial K_{1, t}}>0$ and $\frac{\partial Y_{2, t}}{\partial K_{2, t}}<0$ ).

Output in region 1 increases, while it decreases in region 2, because $\frac{\partial Y_{1, t}}{\partial K_{1, t}}>\frac{\partial Y_{2, t}}{\partial K_{2, t}}$ and because $h^{\beta}>1$, overall production is increasing if there is a small increase of capital in region 1. The reason for this is that capital is used more productively in region 1 . This leads to an increase in efficiency.

To find the non-arbitrage conditions we replace the inequality signs in equations (6.18) and (6.19) by equalities, After integration, the arbitrage process results in one wage rate and return on capital for the two regions. Starting with the capital market we derive the nonarbitrage condition. This means that in equilibrium we have $R_{1, t+1}=R_{2, t+1}=R_{t+1}$. This in turn leads to the following non-arbitrage condition for the capital market: ${ }^{140}$

$$
h \frac{P_{1, t+1}}{K_{1, t+1}}=\frac{P_{2, t+1}}{K_{2, t+1}} \text { or } K_{1, t+1}=h \frac{P_{1, t+1}}{P_{2, t+1}} K_{2, t+1}
$$

Capital between the two regions will be divided in line with the overall productivity, which is also determined by the productivity of public capital.

$$
\begin{aligned}
& { }^{140} \text { Using equation (6.18) to find } R_{1, t+1}=R_{2, t+1} \text { results in } \alpha\left(\frac{h P_{1, t+1}}{K_{1, t+1}}\right)=\alpha\left(\frac{P_{2, t+1}}{K_{2, t+1}}\right) \text { or } \frac{h P_{1, t+1}}{K_{1, t+1}}=\frac{P_{2, t+1}}{K_{2, t+1}} \text {. From this } \\
& \text { we find } K_{1, t+1}=\frac{h P_{1, t+1}}{P_{2, t+1}} K_{2, t+1} \text {. }
\end{aligned}
$$


We can use the same approach for the labour market. Integration will eventually lead to equalized wage rates. There will be one wage rate for the labour market, thus $w_{1, t+1}=w_{2, t+1}=w_{t+1}$. We can equalize the wage rates for the two regions using equation (6.19). From the non-arbitrage condition of the capital market we know the relation between public and private capital for the two regions. Using this non-arbitrage condition of the capital market (the ratio between public and private capital) we find the non-arbitrage condition for the labour market. This results in the equation below ${ }^{141}$ :

$$
\frac{K_{1, t+1}}{L_{1, t+1}}=\frac{K_{2, t+1}}{L_{2, t+1}}=\hat{k}_{t+1}
$$

The non-arbitrage condition of the labour market indicates that, after integration, in equilibrium, the capital-labour ratio is the same for the two regions. Recall our assumption that free trade occurs just after period $t$ and therefore the non-arbitrage conditions hold in period $t+1$. It is clear that factor mobility leads to an increase in the wage rate and return on capital in region 2, while those rates decrease simultaneously in region 1 (see equations (6.19) and (6.20A). What is also clear is that capital formation increases in region 1 while it decreases in region 2. At a first glance it is less clear what will happen with income and growth in the two regions. We shall turn to these effects shortly (section 6.4.4). Now, though, we deal first with capital accumulation (sections 6.4.2 and 6.4.3).

\subsubsection{Private and Public Capital after Integration}

Let us maintain the assumptions that both regions have identical tax rates and spend their tax revenues only on their own public capital and that their budgets are balanced.

\section{Equations of Motion of Public Capital after Integration}

The public capital stocks for regions 1 and 2 are given by: $P_{1, t+1}=\tau(1-\alpha) Y_{1, t}$ and $P_{2, t+1}=\tau(1-\alpha) Y_{2, t}$. Public capital formation in period $t+1$ is determined by the income of the two regions in period $t$, similar to the autarchy case, so public capital formation for both regions after integration (period $t+1$ ) will also be similar to the autarchy case.

\footnotetext{
${ }^{141} \mathrm{We}$ use (6.19) to equate the wage rates which gives us: $(1-\alpha) \hat{k}_{1, t+1}\left(\frac{h P_{1, t+1}}{K_{1, t+1}}\right)^{\beta}=(1-\alpha) \hat{k}_{2, t+1}\left(\frac{P_{2, t+1}}{K_{2, t+1}}\right)^{\beta}$. From (6.29) we know that $\left(\frac{h P_{1, t+1}}{K_{1, t+1}}\right)=\left(\frac{P_{2, t+1}}{K_{2, t+1}}\right)$ thus $\hat{k}_{1, t+1}=\hat{k}_{2, t+1}=\hat{k}_{t+1}=\hat{k}$.
} 
With regard to private capital formation, however this will not be the case. The introduction of capital mobility leads to market clearing for both regions simultaneously. Savings - viz., capital accumulation - will be divided according the productivity of capital. After integration has taken place, aggregate savings are the sum of savings in the autarchy case, $S_{t}=S_{1, t}+S_{2, t}$ where $S_{1, t}=\hat{s}(1-\alpha) Y_{1, t}$ and $S_{2, t}=\hat{s}(1-\alpha) Y_{2, t}$. The non-arbitrage condition (6.30) gives us the relation between capital formation in the two in period $(t+1)$. The ratio of the public capital stocks can easily be calculated if we know the level and ratio of public capital of the two regions. Using equation (6.20B) it is straight forward to derive the ratio between public capital of the two regions:

$$
\frac{P_{1, t+1}}{P_{2, t+1}}=h^{\beta}
$$

Using the non-arbitrage condition for the capital market, equation (6.30) and the relation between public capitals of the two regions, equation (6.31) gives us the following relation between the private capital stocks of the two regions: ${ }^{142}$

$$
K_{1, t+1}=h^{(\beta+1)} K_{2, t+1}
$$

This relation tells us how capital will be divided between the two regions in case of factor mobility, when the productivity of public capital differs in the two regions. Given the aggregate savings before integrations, capital stock in region 1 exceeds that of the autarchy case. In case of autarchy, capital stock in region 1 is $h^{\beta}$ times higher than the capital stock in region 2, whereas the capital mobility is $h^{(\beta+1)}$ times higher (see equation (6.32)). This is caused by a higher return on capital in region 1 compared with region 2 .

\subsubsection{Aggregate (Private) Savings and Private Capital}

\section{Equations of Motions for Private Capital after Integration}

After integration, the aggregate savings of the previous period will be distributed over private capital in the two regions consistent with equation (6.32). We simplify somewhat by expressing aggregate savings and capital formation in terms of regional savings and capital formation. Total saving can be expressed in terms of income of region 1 or 2 using the

${ }^{142}$ Non-arbitrage condition capital market (6.30) $K_{1, t+1}=h \frac{P_{1, t+1}}{P_{2, t+1}} K_{2, t+1}$ and inserting $\frac{P_{1, t+1}}{P_{2, t+1}}=h^{\beta}$ (6.31) results in equation (6.32). 
identity $Y_{t}=Y_{1, t}+Y_{2, t}$. To compare the case of autarchy with the case of integration we assume that in period $t$ income and production in region 1 and 2 are the same, that is, $Y_{1, t}=Y_{2, t}$. Expressing total savings in terms of aggregate income and production of the two regions results in:

$$
S_{t}=\hat{s}(1-\alpha) Y_{t}
$$

The same can be done with the total private capital stock. Market clearing ensures that aggregate savings equal capital formation in region 1 and 2 . The capital formation in the two regions can be calculated using the market clearing condition. To do so we use equation (6.32) to find the following levels of capital formation: ${ }^{143}$

$$
K_{2, t+1}^{M}=\hat{s}(1-\alpha)\left(\frac{1}{1+h^{1+\beta}}\right) Y_{t}
$$

We use the superscript $M$ to refer to the situation of factor mobility. After we have found capital formation in region 2 we can find the capital formation of region 1 using equation (6.32). The result is shown below.

$$
K_{1, t+1}^{M}=\hat{s}(1-\alpha)\left(\frac{h^{1+\beta}}{1+h^{1+\beta}}\right) Y_{t}
$$

As we might have expected, part of the savings from region 2 are used for capital accumulation in region 1 . To see this we use the case as reference and conclude that $K_{1, t+1}^{M}>K_{1, t+1}$ and $K_{2, t+1}^{M}<K_{2, t+1}$ because $0<\left(\frac{1}{1+h^{1+\beta}}\right)<1 / 2$ and $1 / 2<\left(\frac{h^{1+\beta}}{1+h^{1+\beta}}\right) \cdot{ }^{144}$

If the stock of private capital changes and public capital remains the same, the ratio of the two also changes. The ratios between public and private capital stocks ${ }^{145}$ are:

${ }^{143}$ We have $K_{t+1}=K_{1, t+1}+K_{2, t+1}$. Inserting (6.32) $K_{1, t+1}=h^{(\beta+1)} K_{2, t+1}$ results in $K_{t+1}=\left(1+h^{(\beta+1)}\right) K_{2, t+1}$. The equating of motion $S_{t}=K_{t+1}$ results in: $\hat{S}(1-\alpha) Y_{t}=K_{1, t+1}+K_{2, t+1}$. Substituting (6.32) results in $\hat{s}(1-\alpha) Y_{t}=h^{(\beta+1)} K_{2, t+1}+K_{2, t+1}$, finally leading to (6.34) and (6.35).

${ }^{144}$ By assumption $Y_{1, t}=Y_{2, t}$ and $Y_{1, t}+Y_{2, t}=Y_{t}$ thus we have $Y_{1, t}=Y_{2, t}=\frac{1}{2} Y_{t} K_{1, t+1}=\hat{s}(1-\alpha) \frac{1}{2} Y_{t}$ and $K_{2, t+1}=\hat{s}(1-\alpha) \frac{1}{2} Y_{t}$. See equation (6.23) and (6.24). 


$$
\frac{P_{1, t+1}}{K_{1, t+1}^{M_{1,+}}}=\frac{\tau(1-\alpha) Y_{1, t}}{\hat{s}(1-\alpha)\left(\frac{h^{1+\beta}}{1+h^{1+\beta}}\right) Y_{t}}=\frac{\tau}{\hat{s}}\left(\frac{1+h^{1+\beta}}{2 h^{1+\beta}}\right)
$$

and

$$
\frac{P_{2, t+1}}{K_{2, t+1}^{M}}=\frac{\tau(1-\alpha) Y_{2, t}}{\hat{s}(1-\alpha)\left(\frac{1}{1+h^{1+\beta}}\right) Y_{t}}=\frac{\tau}{\hat{s}}\left(\frac{1+h^{1+\beta}}{2}\right)
$$

In region 1, the ratio between the public and private capital stock increases due to an increase in private capital, while in region 2 it decreases due to a decrease in the private capital stock. We verify this by comparing the ratio with the autarchy reference case, which results in:

$\frac{P_{1, t+1}}{K^{M}{ }_{1, t+1}}>\frac{P_{1, t+1}}{K_{1, t+1}} \quad$ and $\quad \frac{P_{2, t+1}}{K_{2, t+1}^{M}}<\frac{P_{2, t+1}}{K_{2, t+1}}$ because $K_{1, t+1}^{M}>K_{1, t+1} \quad$ and $K_{2, t+1}^{M}<K_{1, t+1} \quad$ or alternatively $0<\left(\frac{1+h^{1+\beta}}{2 h^{1+\beta}}\right)<1$ and $1<\left(\frac{1+h^{1+\beta}}{2}\right)$. The flow of savings from region 2 to region 1 will continue until the non-arbitrage condition is met, i.e. just as long as $R_{1, t+1}>R_{2, t+1}$, savings will flow to region 1 until $R_{1, t+1}=R_{2, t+1}=R_{t+1}$.

We see the same kind of movement in the labour market. Workers of region 2 move to region 1 to work there because wages are higher. This also means that employment in region 2 will decrease. ${ }^{146}$ The ratio between public and private capital in region 1 decreases, while it increases in region 2. This influences the productivity of capital because we assumed decreasing returns to scale due to congestion problems associated with public capital when private capital is increasing.

Summarizing we can say that integration has two opposite effects for region 1. First, private capital accumulation increases due to higher return on (private) capital and secondly the productivity of public capital decreases due to increased private capital formation, which causes congestion. The opposite effects occur in region 2. Private capital formation decreases but there is a simultaneous increase in the productivity of public capital due to reduced congestion. On aggregate, however, integration leads to a more efficient allocation of private capital and an increase in the productivity of public capital.

\footnotetext{
${ }^{145}$ We have substituted $Y_{1, t}=Y_{2, t}=\frac{1}{2} Y_{t}$.

${ }^{146}$ The non-arbitrage condition of the labour market tells us that the capital-labour ratio is equal across the regions, so we have $\frac{K_{2, t+1}^{M}}{L_{21, t+1}^{M}}=\frac{K_{2, t+1}}{L_{2, t+1}}=\hat{k}$ and because $K_{2, t+1}^{M}<K_{2, t+1}$ we have $L_{2, t+1}^{M}<L_{2, t+1}$.
} 


\subsubsection{Effects on Income and Growth}

Using the new ratio of public and private capital, we can now determine private capital formation and the production and income of the two regions in period $t+1$. It should be noted that we can use the results from the section 6.3 for the two regions. The only thing that differs is that aggregate savings (and thus the capital stock) are allocated differently between the two regions due to capital mobility. Applying this leads to the following results: ${ }^{147}$

$$
Y_{1, t+1}^{M}=h^{\beta} \hat{s}(1-\alpha)\left(\frac{2 h^{1+\beta}}{1+h^{1+\beta}}\right)^{1-\beta}\left(\frac{\tau}{\hat{s}}\right)^{\beta} Y_{1, t}
$$

and

$$
Y_{2, t+1}^{M}=\hat{s}(1-\alpha)\left(\frac{2}{1+h^{1+\beta}}\right)^{1-\beta}\left(\frac{\tau}{\hat{s}}\right)^{\beta} Y_{2, t}
$$

It is clear that region 1 benefits from economic integration. If we compare the autarchy production and income with the above result we see that $Y_{1, t+1}^{M}>Y_{1, t+1}$ because $\left(\frac{2 h^{1+\beta}}{1+h^{1+\beta}}\right)^{1-\beta}>1$. Income decreases in the less productive region, region 2 . It is easy to verify that $Y_{2, t+1}^{M}<Y_{2, t+1}$, because $\left(\frac{2}{1+h^{1+\beta}}\right)^{1-\beta}<1$. The income difference of the two regions can

\footnotetext{
${ }^{147}$ Using equation (6.16) and (6.17) and inserting (6.34) and (6.35) and the public / private capital ratios of (6.36) gives; $Y_{1, t+1}=h^{\beta} K_{1, t+1}\left(\frac{P_{1, t+1}}{K_{1, t+1}}\right)^{\beta}=h^{\beta} \hat{s}(1-\alpha)\left(\frac{h^{1+\beta}}{1+h^{1+\beta}}\right)^{1-\beta}\left[\frac{\tau}{2 \hat{s}}\right]^{\beta} Y_{t}$. Next we can substitute $Y_{t}=2 Y_{1, t}$ resulting in: $Y_{1, t+1}=h^{\beta} \hat{s}(1-\alpha)\left(\frac{2 h^{1+\beta}}{1+h^{1+\beta}}\right)^{1-\beta}\left[\frac{\tau}{\hat{s}}\right]^{\beta} Y_{1, t}$. For region 2 we have $Y_{2, t+1}=K_{2, t+1}\left(\frac{P_{2, t+1}}{K_{2, t+1}}\right)^{\beta}=\hat{s}(1-\alpha)\left(\frac{1}{1+h^{1+\beta}}\right)^{1-\beta}\left(\frac{\tau}{2 \hat{s}}\right)^{\beta} Y_{t}$ substituting $Y_{t}=2 Y_{2, t}$ results in: $Y_{2, t+1}=\hat{s}(1-\alpha)\left(\frac{2}{1+h^{1+\beta}}\right)^{1-\beta}\left[\frac{\tau}{\hat{s}}\right]^{\beta} Y_{2, t}$. Note that $\left[\frac{\tau}{2 \hat{s}}\right]^{\beta} 2 Y_{1, t}=\left[\frac{\tau}{\hat{s}}\right]^{\beta} 2^{1-\beta} Y_{1, t}$.
} 
be derived from the above results. If we express region 1's output in terms of region 2's output we find the following result: ${ }^{148}$

$$
Y_{1, t+1}^{M}=h^{1+\beta-\beta^{2}} Y_{2, t+1}^{M}
$$

The income in region 1 is $h^{1+\beta-\beta^{2}}$ times higher than in region 2 . If we compare this with the situation of autarchy, ${ }^{149}$ where the income is $h^{\beta}$ time higher, we can see that income differences are increasing. Additionally we can also straight forward calculate the growth rates of the two regions in case of capital mobility:

$$
\left(1+g^{M_{1}}\right)=h^{\beta} \hat{s}(1-\alpha)\left(\frac{2 h^{1+\beta}}{1+h^{1+\beta}}\right)^{1-\beta}\left(\frac{\tau}{\hat{s}}\right)^{\beta}
$$

and

$$
\left(1+g_{2}^{M}\right)=\hat{s}(1-\alpha)\left(\frac{2}{1+h^{1+\beta}}\right)^{1-\beta}\left(\frac{\tau}{\hat{s}}\right)^{\beta}
$$

We conclude that differences between the two regions are increasing due to economic integration:

$$
\left(1+g^{M}{ }_{1}\right)=h^{1+\beta-\beta^{2}}\left(1+g^{M}{ }_{2}\right)
$$

Now we can see what the consequences are for the two regions if they integrate. Summarizing the results we have:

$$
\begin{aligned}
& P_{1, t+1}=P_{2, t+1} \\
& K_{1, t+1}^{M}=h^{1+\beta} K_{2, t+1}^{M} \\
& Y_{1, t+1}^{M}=h^{1+\beta-\beta^{2}} Y_{2, t+1}^{M}
\end{aligned}
$$

${ }^{148}$ The factor equals $\frac{h^{\beta}\left(\frac{2 h^{1+\beta}}{1+h^{1+\beta}}\right)^{1-\beta}}{\left(\frac{2}{1+h^{1+\beta}}\right)^{1-\beta}}=h^{\beta+(1+\beta)(1-\beta)}=h^{\beta+1-\beta^{2}}$ because $0<\beta<1$ and $0<\beta^{2}<1$ we have $\beta<\beta+1-\beta^{2}<\beta+1$.

${ }^{149}$ Equation (6.20B) where $Y_{1, t}=h^{\beta} Y_{2, t}$. 


$$
\left(1+g_{1}\right)=h^{1+\beta-\beta^{2}}\left(1+g_{2}\right)
$$

Using equations (6.20B) and (6.20C), we can conclude that differences between the two regions are increasing as a result of economic integration. Whereas in case of autarchy the difference was a factor $h^{\beta}$, in case of economic integration this increases to $h^{1+\beta-\beta^{2}}$. This means that the difference in output due to economic integration increases by a factor $h^{1-\beta^{2}}$. If we look at the growth rates, the difference also increases by a factor $h^{1-\beta^{2}}$. The result brings us to the proposition below.

\section{Proposition 6.1:}

Economic integration of two regions, with difference in productivity reflecting differences in institutions, leads to divergence instead of convergence of the two regions.

\section{Proof:}

We prove this by comparing the levels of output of the two regions in case of autarchy and in case of factor mobility. Because $0<\beta<1$ and thus $h^{1+\beta}>h^{1+\beta-\beta^{2}}>h^{\beta}>1$ we have $Y_{1, t+1}^{M}>Y_{1, t+1}$ and $Y_{2, t+1}>Y_{2, t+1}^{M}$. Furthermore, we know that $Y_{1, t+1}>Y_{2, t+1}$ and this results in: $Y_{1, t+1}^{M}>Y_{1, t+1}>Y_{2, t+1}>Y_{2, t+1}^{M}$

\subsection{Is Economic Integration Efficient?}

In this section we look at the overall income development and growth rates that result from economic integration between regions with a different institutional setting.

The aggregate income of the two regions is $Y_{t}=Y_{1, t}+Y_{2, t}$. We assume that in autarchy

reference case income and output are the same for both regions that is $Y_{1, t}=Y_{2, t}=\frac{1}{2} Y_{t}$ in period $t$.

For the next period $(t+1)$ we have two different regimes, which we have to compare. We look first at the (continuation of) the case of autarchy and secondly at the case of factor mobility $(M)$.

\section{Autarchy.}


Overall income can be found by aggregating the income of the two regions, simply building on the results of the previous sections. Equations (6.25) and 6.26) are used to find the overall income development and growth rate: ${ }^{150}$

$$
Y_{t+1}=Y_{1, t+1}+Y_{2, t+1}=\left(1+h^{\beta}\right) \frac{\hat{s}(1-\alpha)}{2}\left(\frac{\tau}{\hat{s}}\right)^{\beta} Y_{t}
$$

and

$$
(1+g)=\left(1+h^{\beta}\right) \frac{\hat{s}(1-\alpha)}{2}\left(\frac{\tau}{\hat{s}}\right)^{\beta}
$$

The share of income between the two regions equals $\frac{1}{\left(1+h^{\beta}\right)}$ for region 2 and $\frac{h^{\beta}}{\left(1+h^{\beta}\right)}$ for region 1 . Note that if there are no differences in public capital $(h=1)$, then the share of income for both regions equals $50 \%$.

\section{Factor Mobility}

Using equation (6.20C) gives us the following overall results for income development and growth rate in the case of factor mobility: ${ }^{151}$

${ }^{150}$ Total output equals $Y_{t+1}=Y_{1, t+1}+Y_{2, t+1}$. Adding up (6.25) qnd (6.26) after we have substituted $Y_{1, t}=Y_{2, t}=\frac{1}{2} Y_{t}$ we find $Y_{t+1}=\left(1+h^{\beta}\right) \frac{\hat{s}(1-\alpha)}{2}\left(\frac{\tau}{\widehat{s}}\right)^{\beta} Y_{t}$, aggregate output in autarchy case.

${ }^{151}$ Total output equals $Y^{M}{ }_{t+1}=Y^{M}{ }_{1, t+1}+Y^{M}{ }_{2, t+1}$. Using equations (6.37) and (6.38) substituting $Y_{1, t}=Y_{2, t}=\frac{1}{2} Y_{t}$ results in : $Y_{1, t+1}^{M}=h^{\beta} \frac{\hat{s}(1-\alpha)}{2}\left(\frac{2 h^{1+\beta}}{1+h^{1+\beta}}\right)^{1-\beta}\left(\frac{\tau}{\hat{s}}\right)^{\beta} Y_{t}$ and $Y_{2, t+1}^{M}=\frac{\hat{s}(1-\alpha)}{2}\left(\frac{2}{1+h^{1+\beta}}\right)^{1-\beta}\left(\frac{\tau}{\hat{s}}\right)^{\beta} Y_{t}$. Adding up results in $Y^{M}{ }_{t+1}=\left(1+h^{\beta}\right) \frac{\hat{s}(1-\alpha)}{2}\left[\frac{\tau}{\hat{s}}\right]^{\beta}\left(\frac{2 h^{1+\beta}}{1+h^{1+\beta}}+\frac{2}{1+h^{1+\beta}}\right)^{1-\beta} Y_{t}$. This we simplify by bringing 2 out of the brackets which results in: $Y^{M}{ }_{t+1}=\left(1+h^{\beta}\right) \frac{\hat{s}(1-\alpha)}{2}\left[\frac{\tau}{\hat{s}}\right]^{\beta} Y_{t}\left(\frac{2\left(1+h^{1+\beta}\right)}{1+h^{1+\beta}}\right)^{1-\beta}$. Canceling $\left(1+h^{1+\beta}\right)$ leaves $Y^{M}{ }_{t+1}=\left(1+h^{\beta}\right) \frac{\hat{s}(1-\alpha)}{2} 2^{1-\beta}\left[\frac{\tau}{\hat{s}}\right]^{\beta} Y_{t}$, which reduces to $Y_{t+1}^{M}=\left(1+h^{\beta}\right) \frac{\hat{s}(1-\alpha)}{2^{\beta}}\left[\frac{\tau}{\hat{s}}\right]^{\beta} Y_{t}$. 


$$
Y_{t+1}^{M}=Y_{1, t+1}^{M}+Y_{2, t+1}^{M}=\left(1+h^{\beta}\right) \frac{\hat{s}(1-\alpha)}{2^{\beta}}\left(\frac{\tau}{\hat{s}}\right)^{\beta} Y_{t}
$$

and

$$
\left(1+g^{M}\right)=\left(1+h^{\beta}\right) \frac{\hat{s}(1-\alpha)}{2^{\beta}}\left(\frac{\tau}{\hat{s}}\right)^{\beta}
$$

This allows us to see the consequences of economic integration, by comparing this result to the autarchy case, given the restriction on the parameters, $0 \leq \beta \leq 1$ and $h \geq 1$. This leads to the next proposition concerning the two regions we have been considering.

\section{Proposition 6.2:}

Economic integration of two regions that differ in institutions (public capital in this case), is efficient because it leads to an overall increase in aggregate income and output.

\section{Proof:}

The proof is by comparing the aggregate output of the two regimes (autarchy and factor mobility). From equation (6.44A) and (6.45A) we can easily see that the following relation holds. For $0<\beta<1$ we have $2^{\beta}<2$ which implies that:

$$
Y_{t+1}^{M}=\left(1+h^{\beta}\right) \frac{\hat{s}(1-\alpha)}{2^{\beta}}\left(\frac{\tau}{\hat{s}}\right)^{\beta} Y_{t}>\left(1+h^{\beta}\right) \frac{\hat{s}(1-\alpha)}{2}\left(\frac{\tau}{\hat{s}}\right)^{\beta} Y_{t}=Y_{t+1}
$$

We conclude that income differences between regions are smaller in case of autarchy than in case of factor mobility. Aggregate income in case of mobility exceeds that in case of autarchy. We can also conclude that in case of economic integration there are losers and winners. The region with a less efficient institutional setting and thus public capital stock will see a decrease of income and output. The more productive region benefits from the integration process due to an increase in income. However, the integration process is not a zero sum game. On aggregate, overall income and output will increase through economic integration.

\subsection{Summary of the Results and Conclusions}

The main results of this chapter are summarized in the two tables below. We may conclude that if regions have different institutional settings, resulting in difference in overall productivity this will result in different economic development in autarchy. As an indicator of 
institutional efficiency we have incorporated the ratio between public and private capital in the regions' production function, contributing to the regional output in a decreasing manner.

If regions integrate we observe a movement of capital from the less productive region to the more productive one, resulting from a difference in return on private capital. This has two consequences. For the more productive region return on private capital decreases together with return on public capital due to the congestion effect, but output increases. For the less productive region the reverse happens: return on private and public capital increases but output decreases. This arbitrage process continues until the private returns on capital between the two regions equalize, but it results in a divergence in the economic development of the two regions compared to the autarchy situation. The more productive region gains and the less productive region loses from integration. The overall picture, though, is that integration increases efficiency and the overall economic development of the two regions. However, only one of the regions will gain and the other will lose. It is questionable whether the two regions would be willing to integrate. There is no incentive for the losing region to co-operate in the integration process.

This co-ordination problem is addressed in the next chapter, together with the coordination problem arising from a refusal not to compete, which was raised in chapter 4. 
Chapter 6

\begin{tabular}{|c|c|c|c|}
\hline \multirow[t]{2}{*}{ Table 6.1} & \multicolumn{3}{|c|}{ Economic Development of Different Regions in Autarchy } \\
\hline & Region 1 & Region 2 & Difference \\
\hline $\begin{array}{l}\text { Production } \\
\text { Function }\end{array}$ & $Y_{1, j}=K_{1, j}^{\alpha}\left(\hat{k} L_{1, j}\right)^{1-\alpha}\left(\frac{h P_{1, j}}{K_{1, j}}\right)^{\beta}$ & $Y_{2, j}=K_{2, j}^{\alpha}\left(\hat{k} L_{2, j}\right)^{1-\alpha}\left(\frac{P_{2, j}}{K_{2, j}}\right)^{\beta}$ & \\
\hline $\begin{array}{l}\text { Regional } \\
\text { Output }\end{array}$ & $Y_{1, t+1}=h^{\beta} K_{1, t+1}\left(\frac{P_{1, t+1}}{K_{1, t+1}}\right)^{\beta}$ & $Y_{2, t+1}=K_{2, t+1}\left(\frac{P_{2, t+1}}{K_{2, t+1}}\right)^{\beta}$ & $Y_{1, t+1}=h^{\beta} Y_{2, t+1}$ \\
\hline Wage Rate & $w_{1, t+1}=(1-\alpha) h^{\beta} \hat{k}_{1, t+1}\left(\frac{P_{1, t+1}}{K_{1, t+1}}\right)^{\beta}$ & $w_{2, t+1}=(1-\alpha) \hat{k}_{2, t+1}\left(\frac{P_{2, t+1}}{K_{2, t+1}}\right)^{\beta}$ & $w_{1, t+1}=h^{\beta} w_{2, t+1}$ \\
\hline $\begin{array}{l}\text { Return on } \\
\text { Capital }\end{array}$ & $R_{1, t+1}=\alpha \frac{Y_{1, t+1}}{K_{1, t+1}}=\alpha h^{\beta}\left(\frac{P_{1, t+1}}{K_{1, t+1}}\right)^{\beta}$ & $R_{2, t+1}=\alpha \frac{Y_{2, t+1}}{K_{2, t+1}}=\alpha\left(\frac{P_{2, t+1}}{K_{2, t+1}}\right)^{\beta}$ & $R_{1, t+1}=h^{\beta} R_{2, t+1}$ \\
\hline $\begin{array}{l}\text { Public Capital } \\
P_{t+1}=T_{t}=\tau Y_{t}\end{array}$ & $P_{1, t+1}=\tau(1-\alpha) Y_{1, t}$ & $P_{2, t+1}=\tau(1-\alpha) Y_{2, t}$ & $P_{1, t+1}=P_{2, t+1}$ \\
\hline $\begin{array}{l}\text { Private Capital } \\
K_{t+1}=S_{t}\end{array}$ & $K_{1, t+1}=\hat{s}(1-\alpha) Y_{1, t}$ & $K_{2, t+1}=\hat{s}(1-\alpha) Y_{2, t}$ & $K_{1, t+1}=h^{\beta} K_{2, t+1}$ \\
\hline $\begin{array}{l}\text { Ratio } \\
P_{t+1} / K_{t+1}=P / K\end{array}$ & $\frac{\tau}{\hat{s}}$ & $\frac{\tau}{\hat{s}}$ & \\
\hline Regional Output & $Y_{1, t+1}=h^{\beta} \hat{s}(1-\alpha)\left(\frac{\tau}{\hat{s}}\right)^{\beta} Y_{1, t}$ & $Y_{2, t+1}=\hat{s}(1-\alpha)\left(\frac{\tau}{\hat{s}}\right)^{\beta} Y_{2, t}$ & \\
\hline $\begin{array}{l}\text { Growth Rate } \\
Y_{t+1} / Y_{t}=1+g\end{array}$ & $1+g_{1}=h^{\beta} \hat{s}(1-\alpha)\left(\frac{\tau}{\hat{s}}\right)^{\beta}$ & $1+g_{2}=\hat{s}(1-\alpha)\left(\frac{\tau}{\hat{s}}\right)^{\beta}$ & $\begin{array}{l}1+g_{1, t}= \\
h^{\beta}\left(1+g_{2, t}\right)\end{array}$ \\
\hline $\begin{array}{l}\text { Total Output } \\
Y_{t+1}=Y_{1, t+1}+Y_{2, t+1}\end{array}$ & $Y_{t+1}=\left(1+h^{\beta}\right) \frac{\hat{s}(1-\alpha)}{2}\left(\frac{\tau}{\hat{s}}\right)^{\beta} Y_{t}$ & & \\
\hline
\end{tabular}




\begin{tabular}{|c|c|c|c|}
\hline Table 6.2 & Integration and Economic I & Development of Dif & ent Regions \\
\hline & Region 1 & Region 2 & Difference \\
\hline $\begin{array}{l}\text { Return on Capital } \\
R_{t+1}=R_{1, t+1}=R_{2, t+1}\end{array}$ & $\begin{array}{l}\alpha\left(\frac{h P_{1, t+1}}{K_{1, t+1}}\right)=\alpha\left(\frac{P_{2, t+1}}{K_{2, t+1}}\right) \Rightarrow \\
K_{1, t+1}=\frac{h P_{1, t+1}}{P_{2, t+1}} K_{2, t+1}\end{array}$ & & \\
\hline $\begin{array}{l}\text { Wage } \\
w_{t+1}=w_{1, t+1}=w_{2, t+1}\end{array}$ & $\begin{array}{l}(1-\alpha) \hat{k}_{1, t+1}\left(\frac{h P_{1, t+1}}{K_{1, t+1}}\right)^{\beta}=(1-\alpha) \\
k_{1, t+1}=k_{2, t+1}=k\end{array}$ & $\hat{k}_{2, t+1}\left(\frac{P_{2, t+1}}{K_{2, t+1}}\right)^{\beta} \Rightarrow$ & \\
\hline $\begin{array}{l}\text { Aggregate Savings } \\
S_{t}=S_{1, t}+S_{2, t}\end{array}$ & $\begin{array}{l}S_{t}=\hat{s}(1-\alpha)\left(Y_{1, t}+Y_{2, t}\right) \Rightarrow \\
S_{t}=\hat{s}(1-\alpha) Y_{t}\end{array}$ & & \\
\hline $\begin{array}{l}\text { Private Capital } \\
S_{t}=K_{1, t+1}^{M}+K_{2, t+1}^{M}\end{array}$ & $\begin{array}{l}K_{1, t+1}^{M_{1}}= \\
\hat{s}(1-\alpha)\left(\frac{h^{1+\beta}}{1+h^{1+\beta}}\right) Y_{t}\end{array}$ & $\begin{array}{l}K_{2, t+1}^{M}= \\
\hat{s}(1-\alpha)\left(\frac{1}{1+h^{1+\beta}}\right) Y_{t}\end{array}$ & $\begin{array}{l}K_{1, t+1}^{M}= \\
h^{(1+\beta)} K_{2, t+1}^{M}\end{array}$ \\
\hline $\begin{array}{c}\text { Public Capital } \\
P_{t+1}=T_{t}=\tau Y_{t}\end{array}$ & $P_{1, t+1}=\tau(1-\alpha) Y_{1, t}$ & $P_{2, t+1}=\tau(1-\alpha) Y_{2, t}$ & $P_{1, t+1}=P_{2, t+1}$ \\
\hline $\begin{array}{l}\text { Ratio Public/Private } \\
P_{t+1} / K^{M}{ }_{t+1}=P / K\end{array}$ & $\frac{\tau}{\hat{s}}\left(\frac{1+h^{1+\beta}}{2 h^{1+\beta}}\right)$ & $\frac{\tau}{\hat{s}}\left(\frac{1+h^{1+\beta}}{2}\right)$ & $\begin{array}{l}h^{1+\beta}\left(P_{1, t+1} / K_{1, t+1}\right)= \\
\left(P_{2, t+1} / K_{2, t+1}\right)\end{array}$ \\
\hline $\begin{array}{l}\text { Regional } \\
\text { Output }\end{array}$ & $\begin{array}{l}Y_{1, t+1}= \\
h^{\beta}\left(\frac{2 h^{1+\beta}}{1+h^{1+\beta}}\right)^{1-\beta} \times \\
\hat{s}(1-\alpha)\left(\frac{\tau}{\hat{s}}\right)^{\beta} Y_{1, t}\end{array}$ & $\begin{array}{l}Y_{2, t+1}= \\
\left(\frac{2}{1+h^{1+\beta}}\right)^{1-\rho} \times \\
\hat{s}(1-\alpha)\left(\frac{\tau}{\hat{s}}\right)^{\beta} Y_{2, t}\end{array}$ & $Y_{1, t+1}=h^{1+\beta-\beta^{2}} Y_{2, t+1}$ \\
\hline $\begin{array}{l}\text { Growth Rate } \\
Y_{t+1} / Y_{t}=1+g\end{array}$ & & & $\begin{array}{l}1+g_{1}= \\
h^{1+\beta-\beta^{2}}\left(1+g_{2}\right)\end{array}$ \\
\hline $\begin{array}{l}\text { Total Output } \\
Y^{M}{ }_{t+1}=Y_{1, t+1}^{M}+Y_{2, t+1}^{M}\end{array}$ & $Y_{t+1}^{M}=\left(1+h^{\beta}\right) \frac{\hat{s}(1-\alpha)}{2^{\beta}}\left(\frac{\tau}{\hat{s}}\right)$ & $Y_{t}$ & \\
\hline
\end{tabular}





\section{Chapter 7}

Coordination between Regions:

An Application of the Coase Theorem 


\subsection{Introduction}

As the previous chapters have shown, competition between regions for innovative firms as well as economic integration (in terms of capital mobility) could result in a surplus, but not all participating regions will benefit from competition and economic integration. More specifically, we have concluded that:

- without capital mobility, competition between regions for firms does not increase efficiency (chapter 3 and 4) and at best does not increase inefficiency. However, if one region invests in an effort to attract firms, other regions must follow to retain a chance of winning the competition;

- $\quad$ without capital mobility, assuming that two regions are involved, competition between these two regions for innovative firms (that create positive externalities) will decrease overall efficiency and will result in a welfare loss for one region and a welfare increase for the other (chapter 4);

- with capital mobility, if factor remunerations are highly institutionally determined, capital will move to the region with the highest remuneration, which is not necessarily the most productive. Whether or not overall efficiency increases depends on the level of accumulation of capital. If efficiency does increase, though, it will not be a Pareto improvement because one region will be worse off (chapter 5);

- $\quad$ with capital mobility and including public capital as a productive source, overall efficiency is increased, but again there will not be a Pareto improvement because one region will be worse off (chapter 6).

In short, generally no competition should be preferred to competition, but integration (in this case capital mobility) can result in an overall increase in welfare, though not necessarily in a Pareto improvement. In other words, if regions were to coordinate their actions, they could either prevent wasteful competition or - with integration - a surplus or potential Pareto improvement could be generated. In this chapter we analyze the conditions under which such fruitful coordination between regions could take place, applying the Coase theorem. This is the last research question; Can the coordination problems resulting from competition and economic integration be solved?

We start this chapter by summarizing the problems we encountered in chapters 4 and 6 , in terms of game theory (section 7.2). In the remaining part of the chapter we investigate the possible consequences of different rules on the outcome of the coordination (or bargaining) process. Different rules are perceived here as different institutional settings resulting in a different legal system. To analyze the consequences of different law systems, we split the remainder of the chapter into two parts.

In the first part we start by summarizing the model of Schweizer (1988) on the Coase theorem as a point of reference. The advantage of Schweizer's model is that his interpretation 
is regarded as clear and thorough. The model will therefore be used to highlight the most important properties of Coase's theorem (section 7.3). We extend his model in the following two ways. First we extend the model by incorporating incomplete contracts (section 7.4), meaning we allow for ex-post renegotiation. Such renegotiations take place within a certain legal system. We introduce the legal system as 'the rules of the game'. Disputes about contracts are resolved in court, if a compromise can not be found between the contractors. At first we assume that the legal system for resolving such disputes is costless to both the plaintiff and defendant. We show that a credibility problem can emerge depending on how property rights are distributed. This credibility problem prevents an efficient solution from being reached through trading property rights. Second, in section 7.5 we further extend Schweizer's model, relaxing the above assumption to investigate the more realistic case that going to court is not cost-free. In the last part of the paper (section 7.4) we add some more realistic features to our approach. We analyze the two most prominent civil law systems, the Anglo Saxon (AS) and Roman (R) civil law system. An important difference between the two systems is that in the AS system both the plaintiff and the defendant have to pay for their own efforts to win the lawsuit, whatever the outcome result of the lawsuit may be. The efforts needed to win a lawsuit are the costs of the lawyers, the costs of experts, costs of witnesses etc. In contrast to the AS system, the R system is characterized by the fact that the losing party in court has to bear all costs, including those of the winning party. Section 7.6 concludes.

\subsection{Rationales for Coordination}

In chapters 4 and 6 we came to the conclusion that a situation of no competition is preferred to competition because it increases efficiency, and that integrating economic activities is preferred to the autarchy situation. In both cases, however, there is only one region that benefits while the other does not. This means that both refraining from competition and economic integration do not lead to a Pareto improvement, and as a result potential welfare gains will not be realized. This is not a desirable outcome, and the question is how to avoid such situations. Before turning to that question, though, we summarize the results of chapters 4 and 6 in terms of strategies of two players and the expected pay-offs to the two players.

\subsubsection{Can Competition be Avoided?}

In chapter 4 we saw that competition between regions does not increase efficiency but, on the contrary, has an adverse effect on efficiency. If competition does not contribute to efficiency a crucial question is: can competition between the two regions be avoided? In other words, 
could regions coordinate their actions to avoid wasteful competition? Not competing would make both regions better off, but as soon as one region starts the competition game the other region has to follow. There is an incentive for both players to deviate from cooperation and compete. There are two strategies available for the two players, region 1 and region 2 . The first one is to compete with an effort level of respectively $e_{1}^{*}=\frac{1}{4} \Delta Y_{1}$, and $e_{2}^{*}=\frac{1}{4} \Delta Y_{2}$. In case the contribution of the firm is the same for the competing region $\left(\Delta Y_{1}=\Delta Y_{2}\right)$ we additionally have $e^{*}{ }_{1}=e^{*}{ }_{2}=e^{*}=\frac{1}{4} \Delta Y$. The other alternative is not to compete, with a corresponding effort level of $e_{1}=e_{2}=0$. In chapter 4 we explained why regions have incentives to compete for firms with each other. We also showed that they will invest in efforts to attract the firm. It has also been shown that the effort levels of the competing regions influences the probability that the firm will settle in one of the competing regions. If the effort levels are known, the expected pay-offs can be determined. Knowing the effort levels we can find the net expected gains in case of competition and no competition. The extensive form of the game is summarized in the figure below:

Figure 7.1 Strategies and Pay-off of the Competition Game

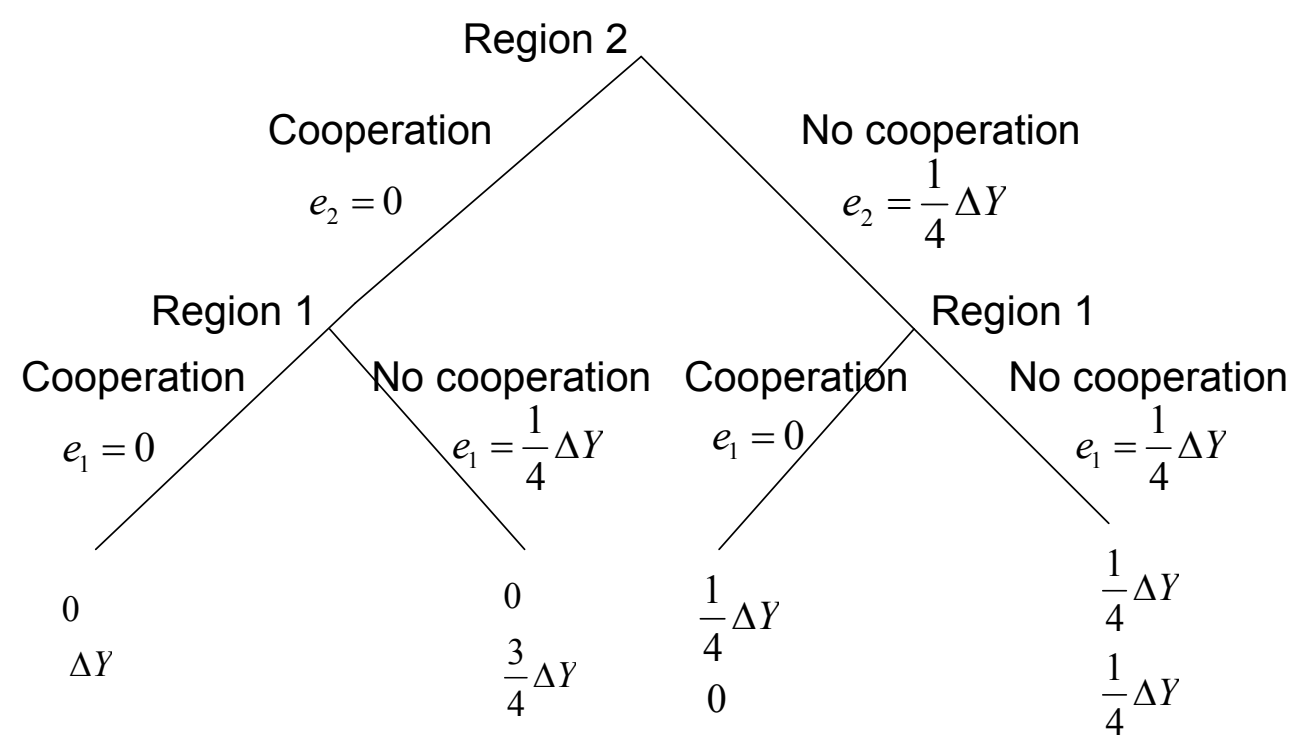


It is common to note the pay-off of the first player first and the pay-off of the second player second. Because in our case region 2 is the first player to start the game, the pay-off of region 2 has been put first. Thus for example $\left(0, \Delta Y_{1}\right)$ means that the pay-off of the first player, region 2, is 0 and that of second player, region 1, equals $\Delta Y_{1}=\Delta Y$. We assume that competitors will only take the benefits to their own region into account and not the benefits to the competing region.

We first start with a strategy of no competition. In this case region 1 is the winner because the firm has a preference to settle in region 1 . Thus the pay-off for region 1 equals $\Delta Y_{1}$ and the pay-off for region 2 equals 0 . If region 2 offers a subsidy, that is $e_{2}=\frac{1}{4} \Delta Y_{2}$, and region 1 does not $\left(e_{1}=0\right)$, the firm will settle in region 2 . The pay-off for region 2 equals $\frac{3}{4} \Delta Y_{2}$ whereas the pay-off for region 1 reduces to zero. If both regions offer a subsidy, that is $e_{1}=\frac{1}{4} \Delta Y_{1}$ and $e_{2}=\frac{1}{4} \Delta Y_{2}$, and if the benefits to the firm of settling in a region are the same for the two regions, the probability that the firm will settle is $\frac{1}{2}$ for both regions. The corresponding expected pay-off for the two regions then becomes $\frac{1}{4} \Delta Y_{1}$ and $\frac{1}{4} \Delta Y_{2}$. Table 7.1 shows that for region 2 the no-competition strategy $\left(e_{2}=0\right)$ is dominated by the competition strategy $\left(e_{2}=\frac{1}{4} \Delta Y_{2}\right)$. If region 2 chooses $e_{2}=0$ then region 1 will surely choose $e_{1}=0$. This results in a pay-off for region 2 and 1 of $0, \Delta Y_{1}$, respectively. If region 2 chooses $e_{2}=\frac{1}{4} \Delta Y_{2}$ then region 1 chooses $e_{1}=\frac{1}{4} \Delta Y_{1}$ and the pay-offs are $\frac{1}{4} \Delta Y_{2}, \frac{1}{4} \Delta Y_{1}$, respectively. Whatever region 1 does, competition is the best strategy for region 2 because the expected pay-off always exceeds that of the expected pay-off from not competing. It is also clear from the table that on aggregate a strategy of no competition is superior to the other strategies. The equilibrium strategy is $e^{*}{ }_{1}=\frac{1}{4} \Delta Y_{1}=e^{*}{ }_{2}=\frac{1}{4} \Delta Y_{2}$, which is a Nash equilibrium, which means that none of the players has an incentive to deviate from the equilibrium. Both regions (players) chose to compete and have no incentive to cooperate that is 'not to compete'. This results in the following proposition.

\section{Proposition 7.1:}

Competition between regions for innovation cannot be avoided. 


\section{Proof:}

The extensive form of the game in figure 7.1 can be solved by backward induction, starting with region 1. If region 2 has chosen not to compete the best action of region 1 is not to compete because the pay-off exceeds that of competition $\left(\Delta Y_{1}>\frac{3}{4} \Delta Y_{1}\right)$. If region 2 decides to compete, the best action of region 1 is also to compete because the expected pay-off exceeds that of not competing $\frac{1}{4} \Delta Y_{1}>0$. Region 2 knows the actions of region 1 . If region 2 chooses to cooperate that is no competition it knows that region 1 will also choose no competition. This results in an expected pay-off of 0 . If region 2 chooses to compete it knows region 1 also will compete. Thus the expected pay-off equals $\frac{1}{4} \Delta Y_{2}>0$ and thus region 2 will choose competition.

Let us now assume that both regions are not pleased with the result. The overall best strategy is not to compete and cooperate but in that case only one region benefits, viz., the region that would eventually have lost the competition. Could the two regions conclude a credible agreement to refrain from competition and arrange a compensation scheme? Let us assume that no competition occurs and the firm eventually decides to settle in region 1 . The surplus of cooperation equals $\Delta Y_{1}$ (i.e. the benefits to region 1 of the firm's settlement) which can be used by region 1 to compensate region 2 in the amount of $\frac{1}{4} \Delta Y_{1}=\frac{1}{4} \Delta Y_{2}$, which equals the reservation utility of region 2, i.e. the expected net pay-off from competition. After compensation the benefits to region 1 would amount to the same as in the competition case, if it had won the game. The problem, of course, is that if one region follows the no-competition strategy it does not know whether the other region will stick to the agreement (that is: not competing and paying compensation). It depends on the enforcement mechanisms (which are part of the institutional setting) whether the regions can compel each other to uphold the agreement.

\subsubsection{Can the Possible Benefits of Economic Integration be Reaped?}

In chapter 6 we encountered the problem that economic integration does not result in a Pareto improvement but - compared to the autarchy situation - an overall surplus can be achieved. Assuming region 1 is the region that benefits from integration, we can again draw up a game tree (figure 7.2). Region 1 is the region that takes the initiative, because it benefits. We assume that in general there are some costs, denoted by $C$, associated with integration but 
they are small compared to the expected pay-offs from cooperation. These costs have to be subtracted from the net pay-off of integration. After economic integration, both regions must at least be as well off as in the case of autarchy. From chapter 6 we know that integration leads to an overall improvement of production and income, $\Delta Y^{M}=Y^{M}{ }_{t+1}-Y_{t+1}>0$ (the surplus of integration), so an overall improvement is possible. At the same time, integration leads to a decrease of income and production for the less productive region (region 2), and to an increase for the more productive region (region 1), that is $\Delta Y_{2}^{M}=Y_{2, t+1}^{M}-Y_{2, t+1}<0$ (negative effect of integration for region 2) and $\Delta Y_{1}^{M}=Y^{M}{ }_{1, t+1}-Y_{1, t+1}>0$ (positive effect of integration for region 1).

Figure 7.2 Pay off Cooperation versus No Cooperation

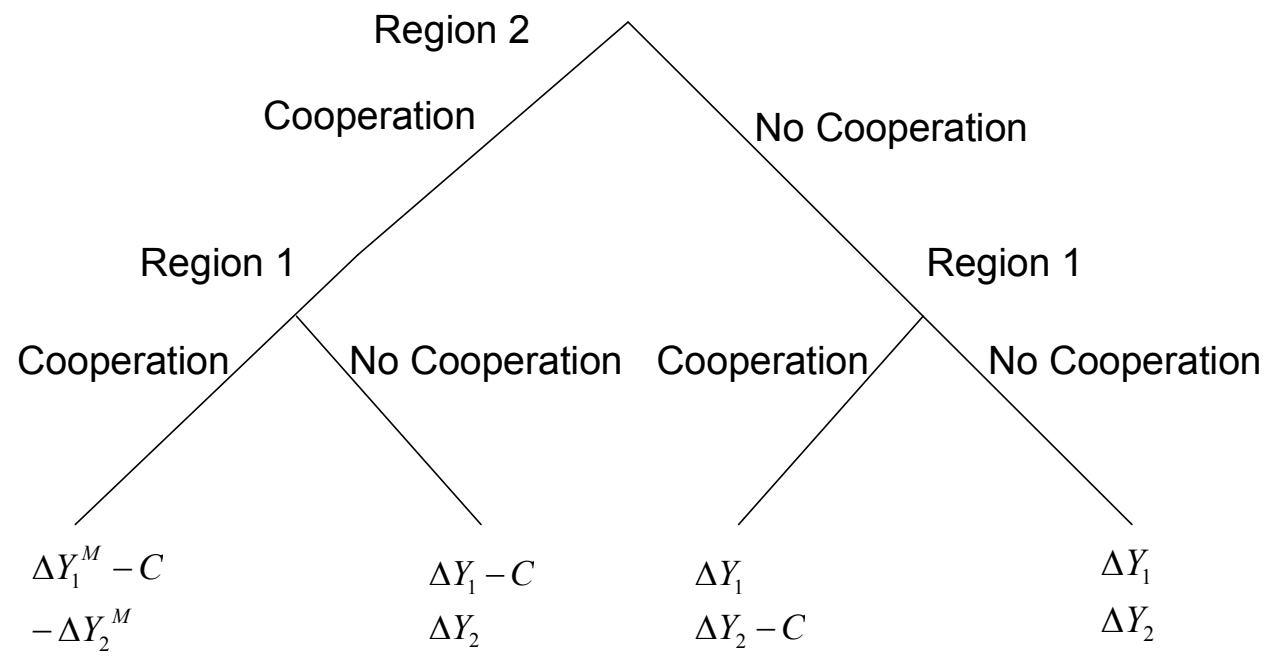

Obviously, assuming the regions make their policy autonomously, region 2, the less productive region, does not want to cooperate and economic integration will not occur. No potential increase in efficiency will be realized.

\section{Proposition 7.2:}

In the case of economic integration between different regions through capital mobility there is no incentive for less productive regions to cooperate. As a result no economic integration occurs, which results in an efficiency loss. 


\section{Proof:}

For region 2 no cooperation is the dominant strategy. If region 1 wants to cooperate the best strategy for region 2 is no cooperation because $\Delta Y_{2}>\Delta Y_{2}^{M}<0$. Region 2 does not benefit from integration and will not cooperate. If region 1 does not cooperate the best strategy for region 2 is again not to cooperate because $\Delta Y_{2}>\Delta Y_{2}-C$. Knowing this the best strategy of region 1 is also no cooperation because $\Delta Y_{1}>\Delta Y_{1}-C$. However, integration would lead to an increase in efficiency because $\Delta Y^{M}>0$.

Again, the question is under what circumstances both regions are willing to cooperate. This will be the case if there are incentives for both regions to cooperate. If the level of income of both regions after economic integration exceeds that of the autarchy situation there is a surplus. Because region 1 will benefit most from integration, it will try to persuade region 2 to cooperate. It can offer region 2 compensation for the loss of income resulting from economic integration. Region 2 is willing to cooperate as long as the income level associated with integration plus the compensation received from region 1 exceeds the income of the autarchy situation. On the other hand, the compensation paid by region 1 to region 2 should not exceed the benefits of cooperation that is, the benefits from integration.

Formally, we have a surplus of $\Delta Y^{M}=\left(Y^{M}{ }_{t+1}-Y_{t+1}\right)>0$. A Pareto improvement is possible if all regions have an income level, resulting from cooperation, which is as least as good as that in autarchy. We have the following restriction for cooperation (participation constraint):

$$
Y_{1, t+1}^{M} \geq Y_{1, t+1} \text { and } Y_{2, t+1}^{M}+Z_{2} \geq Y_{2, t+1}
$$

The variable $Z_{2}$ is the compensation paid by region 1 to region 2. Because region 1 will not pay more than is necessary, the 'greater than' sign can be replaced by an equality. ${ }^{152}$ In determining the compensation, region 1 has to take account of its income restriction. The maximum compensation offered by the more productive region (region 1) is the difference between income under the regime of capital mobility and that in case of autarchy. This means we have the following restriction for region $i$ with respect to the compensation to be paid:

$$
Z_{2}=Y_{2, t+1}-Y_{2, t+1}^{M}=-\Delta Y_{2} \leq Y_{1, t+1}^{M}-Y_{1, t+1}=\Delta Y_{1}
$$

\footnotetext{
${ }^{152}$ That is $Y_{2, t+1}^{M}+Z_{2}=Y_{2, t+1}$, a common assumption because region 1 is the principal, so to speak. Of course, a different distribution of the gains could be made, such as $\frac{1}{2}, \frac{1}{2}$.
} 
The compensation region 2 receives from region 1 should be at least as large as the decrease in income of region 2 resulting from integration. On the other hand, it should be less than the increase of income and production of region 1 resulting from integration. If this condition is fulfilled both regions are willing to cooperate and a Pareto improvement can be realized.

\section{Proposition 7.3:}

In case of capital mobility between different regions, cooperation can be established by a redistribution of the gains from economic integration.

\section{Proof:}

We have shown that $\Delta Y^{M}>0$; Using this we have $\Delta Y^{M}{ }_{1}+\Delta Y^{M}{ }_{2}>0$ and thus $\Delta Y_{1}^{M}>-\Delta Y_{2}^{M}$, therefore $\left(Y_{1, t+1}^{M}-Y_{1, t+1}\right)>\left(Y_{2, t+1}-Y^{M}{ }_{2, t+1}\right)^{153}$.

The problem outlined here is essentially the same as the one discussed in the previous subsection. Regions will only engage in an agreement on integration (and the corresponding compensation scheme) if such an agreement can be credibly upheld.

\subsection{The Coase Theorem}

Our point of departure is the model developed by Schweizer (1988). Let us assume that there are two agents $\mathrm{A}$ and $\mathrm{B}$. Agent $\mathrm{A}$ is involved in an activity $x$ which generates a positive utility and Agent $B$ enjoys activity $y$. Agent $B$, however, values Agent A's activity $x$ negatively. Agent A's activity $x$ causes a negative externality for Agent B. This can be expressed with the following utility functions. For simplicity, we assume that both players are risk neutral and that both utility functions are additively separable we have;

Agent A's utility function:

$$
U=A(x)
$$

And agent B's utility function:

$$
V=B(y)-S(x, y)
$$

\footnotetext{
${ }^{153}$ Note that $-\Delta Y_{2}^{M}=\left(Y_{2, t+1}-Y^{M}{ }_{2, t+1}\right)$.
} 
The disutility (negative externality) of Agent $\mathrm{B}$ resulting from agent A's activity $x$ is represented in the function $S(x, y)$, where the function has the following properties: $\mathrm{S}$ is increasing in both variables $x, y$ and for all $x, y$ and the cross partial derivative $S_{x y}(x, y)$ is always positive. The functions $\mathrm{A}$ and $\mathrm{B}$ are concave and twice differentiable, so that:

$$
\begin{aligned}
& A_{x}(x)>0 \text { for } x<x^{*} \text { and } A_{x}(x)<0 \text { for } x>x^{*} \text { and } A_{x x}(x)<0 \text { for } x>0 \text { and, } \\
& B_{y}(y)>0 \text { for } y<y^{*} \text { and } B_{y}(y)<0 \text { for } y>y^{*} \text { and } B_{y y}(y)<0 \text { for } y>0
\end{aligned}
$$

An efficient solution will be achieved when the optimal levels of $x$ and $y$ are determined simultaneously. This can be realized if both players cooperate, or if a benevolent dictator ${ }^{154}$ decides on the activities $x, y$. In both cases this leads to the following maximization problem.

$$
\underset{x, y}{\operatorname{Max}}(U+V)=\underset{x, y}{\operatorname{Max}}\{A(x)+B(y)-S(x, y)\}
$$

The first-order conditions of (7.4) are given by:

$$
\begin{aligned}
& \frac{\partial(U+V)}{\partial x}=A_{x}(x)-S_{x}(x, y)=0 \text { i.e. the activity level of } \mathrm{A} \text { is } x=x^{E} \\
& \frac{\partial(U+V)}{\partial y}=B_{y}(y)-S_{y}(x, y)=0 \text { i.e. the activity level of B is } x=x^{E}
\end{aligned}
$$

The efficient levels of activity $x$ and $y$ are given by $x^{E}$ and $y^{E}$, respectively, where the superscript $E$ indicates that the solution is efficient. There is no guarantee that the two agents will cooperate, or in other words, there is no incentive for cooperation. If agent A maximizes his own utility, this exceeds the cooperative outcome and there is no incentive for cooperation. A non-efficient outcome is then the result.

Next we turn to Coase's solution. Property rights have to be assigned first. There are two possibilities: agent $\mathrm{A}$ is not liable $(n)$ for the externality, which means that agent A owns the property rights; the other possibility is that agent $\mathrm{A}$ is liable $(l)$ for the externality. In this situation agent $\mathrm{B}$ owns the property rights. If the property rights are tradable, then independently of the distribution of the property rights, the same efficient solution can be achieved. We explain both cases below. It is important that property rights can be traded. If this is not the case then there will be no possibility of a more efficient reallocation and as such

${ }^{154}$ The one dictator that knows all utility functions agents involved and has perfect information. 
there will be no gains in efficiency and welfare. Note that such a trading system and the administration of property rights can be quite complicated and costly.

\subsubsection{Agent A Owns the Property Rights}

We start with Agent $A$ owning the property rights. In this situation agent $\mathrm{A}$ is not liable for causing externalities. We use a superscript $n$ to indicate that the agent is not liable. Let us first introduce the concept of reservation utility, i.e. $\bar{U}=A\left(x^{n}\right)$. This is the utility an agent can achieve by making full use of his property rights. This, than clearly is the activity level which maximizes agent A's utility and where $A_{x}\left(x^{n}\right)=0$ holds. The reservation utility thus amounts to $\bar{U}=A\left(x^{n}\right)$. This generates negative externalities for agent $\mathrm{B}$ because A owns the property rights and this is a fact of life for agent $\mathrm{B}$. What can agent $\mathrm{B}$ do in order to increase his utility? Agent $B$ can propose that agent A reduce his activity and if Agent A does so he is compensated by agent B for decreased utility. Agent B proposes that agent A should reduce his activity $\left(x=x^{A}\right)$ in return for compensation of $Z^{A}$. The superscript $\mathrm{A}$ indicates that agent A receives compensation from agent $B$. After receiving the compensation, the outcome, utility $U$, for agent $\mathrm{A}$ should be equal to or exceed the reservation utility of agent $\mathrm{A}$ :

$$
U=A\left(x^{A}\right)+Z^{A} \geq \bar{U}
$$

Agent B evidently wants to maximize his utility, including the compensation to be paid to agent A. Therefore agent B will only pay the minimum amount of compensation to A. This means that equation (7.5) holds strictly. We can derive the minimum compensation to be paid from equation (7.5):

$$
Z^{A}=A\left(x^{n}\right)-A\left(x^{n}\right)
$$

To maximize his utility, agent $\mathrm{B}$ has to take his own activity level into account, the activity level it wants from agent $\mathrm{A}$ and the compensation to be paid, which depends on the activity levels of $x$ and $y$. This leads to the following optimization problem of agent B:

$$
\underset{x, y}{\operatorname{Max} V}=B(y)-S(x, y)-\left[A\left(x^{n}\right)-A(x)\right]
$$

It should be noted that activity level $x^{n}$ maximizes the utility of agent $\mathrm{A}$ which than as a result is given for agent $\mathrm{B}$. In this situation, agent $\mathrm{B}$ determines both activity levels $x$ and $y$. This process can be described as a game consisting of three sequential stages: 
Stage $1 \quad B$ proposes a contract to $A$ for payment $Z^{A}$ if A reduces his activity to $x=x^{A} \leq x^{n}$

Stage 2 A makes a decision about the contract:

Accept and reduce activity level to $x=x^{A}$ if $Z^{A} \geq\left[A\left(x^{n}\right)-A(x)\right]$

Reject and keep activity level $x=x^{n}$ if $Z^{A}<\left[A\left(x^{n}\right)-A(x)\right]$

Stage 3 B makes a decision about his activity level y depending on the action of A in stage 2 (best response function):

If $\mathrm{A}$ has rejected and decides $x=x^{n}$ then $\mathrm{B}$ decides $y=y^{n}$

If $\mathrm{A}$ accepted and decides $x=x^{A}$ then B decides $y=y^{A}$.

Above we have assumed that $B(y)-S(x, y)-\left[A\left(x^{n}\right)-A(x)\right]>B\left(y^{n}\right)-S\left(x^{n}, y^{n}\right)$. This means that the cooperative solution is superior to the non-cooperative outcome. There is a possible surplus in case of cooperation. If this is not the case then there are no (negative) externalities and there would be no trading in property rights. ${ }^{155}$ Using the first-order condition of equation (7.7) we get:

$$
\begin{aligned}
& \frac{\partial V}{\partial x}=-S_{x}(x, y)+A_{x}(x)=0 \text { i.e. the activity level of } A \text { is } x=x^{A}=x^{E} \text { and } \\
& \frac{\partial V}{\partial y}=B_{y}(y)-S_{y}(x, y)=0 \text { i.e. the activity level of } B \text { equals } y=y^{A}=y^{E}
\end{aligned}
$$

We can see directly that the results of $x$ and $y$ coincide with the efficient solution. Note that there are distributional differences if it is compared with the efficient solution of the previous section. This is due to the fact that agent A receives compensation, which resulted from the fact that agent $\mathrm{A}$ owns the property rights. Note, however, that $\mathrm{A}$ is compensated by $\mathrm{B}$ for reducing his output.

\subsubsection{Agent B Owns the Property Rights}

Next we look at the case where agent B owns the property rights. In this situation agent $\mathrm{A}$ is liable for causing the externality and agent B not. The same approach as above is applied to analyze the consequences of agent B owning the property rights. In this case agent A will

\footnotetext{
${ }^{155}$ Cooperation between the agents creates a "surplus" because, depending on the assignment of property rights, one of the agents receives a reservation utility, so we have a Pareto improvement. If no surplus creation were possible the situation is apparently efficient. Bargaining will not take place. After assigning the property rights one of the agents will stop its economic activities. We have then reached a corner solution. These kinds of possibilities are not taken into account here. A related problem which prevents "Coasian" bargaining, namely the income effects, is not addressed here.
} 
have to compensate agent $\mathrm{B}$ for causing the externality due to the activity $x$. Now agent A will propose compensation to agent B for generating an externality through $x$. Therefore agent $\mathrm{A}$ needs to know the minimum utility level at which $\mathrm{B}$ is willing to accept the externality caused by A. This is the reservation utility of agent B which equals $\bar{V}=B\left(y^{l}\right)$ where $B_{y}\left(y^{l}\right)=0$. As before this is the utility of B making full use of its property rights and has to be compensated. Any $x$ will generate negative externalities; only for $x=0$ do we have $S(x, y)=0$. Agent B is willing to accept the proposal for compensation if the following condition is satisfied:

$$
V=B(y)-S(x, y)+Z^{B} \geq \bar{V}
$$

Here $Z^{B}$ is the amount of compensation to be paid by agent $\mathrm{A}$ to agent $\mathrm{B}$, which is why we have used a superscript $B$. The total utility of $y$, the negative externality and the compensation should exceed that of the reservation utility. Agent A will not pay more than necessary and thus the optimal compensation for agent $\mathrm{A}$ to be paid to agent $\mathrm{B}$ then becomes:

$$
Z^{B}=B\left(y^{l}\right)-[B(y)-S(x, y)]
$$

This is the utility of agent B without externalities by A, the first term, and the utility in case of externalities caused by agent $\mathrm{A}$, the term between square brackets. Note that the compensation depends on $x, y$ and $y^{l}$ where the last one is given for agent A. Agent A can now determine its activity level, $x$, because it knows the corresponding compensation needed for every level of $x$ to be paid. Maximizing its utility, agent A then faces the following maximization problem:

$$
\underset{x, y}{\operatorname{Max}} U=A(x)-\left[B\left(y^{l}\right)-\{B(y)-S(x, y)\}\right]
$$

As before, we can describe the three sequential stages of the game:

Stage $1 A$ proposes a contract to $B$ to pay $Z^{B}$ so that $\mathrm{B}$ allows $\mathrm{A}$ to increase A's activity level $x^{B} \geq x^{l}$

Stage 2 B decides about the contract:

Accept if $Z^{B} \geq\left[B\left(y^{l}\right)-\{B(y)-S(x, y)\}\right]$, and reduce his activity to $y=y^{B}<y^{l}$ and allows $\mathrm{A}$ to increase his activity to $x=x^{B}>x^{l}$;

Reject if $Z^{B}<\left[B\left(y^{l}\right)-\{B(y)-S(x, y)\}\right]$ and keep activity $y=y^{l}$ and stick to Agent A keeping his activity level to $x=x^{l}$; 
Stage 3 A decides about his activity level $x$ depending on the action of B in stage 2:

If agent $\mathrm{B}$ decides in favour of activity level $y=y^{l}$ than $x=x^{l}$;

If agent B decides in favour of activity level $y=y^{B}<y^{l}$ than $x=x^{B}>x^{l}$.

Note that activity level $x^{l}=0$ because at that level there are no externalities for agent $\mathrm{B}$, see equation (7.2). Starting at stage 3, A has to decide about his activity level $x$. After $x$ is known this automatically results in activity level $y$ of agent $\mathrm{B}$ and so the resulting compensation $Z^{B}$ is determined (the best response function of $A$ ). The compensation $Z^{B}$ is therefore endogenous. This results in the following first-order condition of the maximization problem of A.

$$
\begin{array}{ll}
\frac{\partial U}{\partial x}=-S_{x}(x, y)+A_{x}(x)=0 & \text { The activity level of } A \text { equals } x=x^{B}=x^{E} \\
\frac{\partial U}{\partial y}=B_{y}(y)-S_{y}(x, y)=0 & \text { The activity level of } B \text { equals } y=y^{B}=y^{E}
\end{array}
$$

Assigning property rights to agent $B$ and trading thus leads to an efficient allocation because utility maximization leads to the same first-order conditions as in the cooperative situation and the situation where the property right were assigned to agent $\mathrm{A}$. We see that whichever way the (tradable) property rights are distributed, an efficient allocation (solution) will result. The outcome with respect to the activity levels resembles the ones of the previous case and the cooperative solution. Note, however, that here too there are distributional effects. ${ }^{156}$ These are is caused by transferring compensation from agent $\mathrm{A}$ to agent $\mathrm{B}$ and vice versa.

\subsection{Incomplete Contracts}

If property rights are assigned, the legal system should supply proper safeguards and guarantee the enforcement of property rights by resolving any dispute. Now, suppose that the agreements between the agents of the previous section are set down in a contract which contains the bargained activity levels and the compensation. The question is, will the contract

\footnotetext{
${ }^{156}$ In case agent A owns the property rights $(A)$ we have; $U^{A}=A(x)+\left[A\left(x^{n}\right)-A\left(x^{E}\right)\right]$ and $V^{A}=B\left(y^{E}\right)-S\left(x^{E}, y^{E}\right)-\left[A\left(x^{n}\right)-A\left(x^{E}\right)\right]$. When B owns the property rights than we have $V^{B}=B\left(y^{E}\right)-S\left(x^{E}, y^{E}\right)+\left\lfloor B\left(y^{l}\right)-\left\{B\left(y^{B}\right)-S\left(x^{E}, y^{E}\right)\right\}\right\rfloor$ and $U^{B}=A\left(x^{E}\right)-\left[B\left(y^{l}\right)-\left\{B\left(y^{E}\right)-S\left(x^{E}, y^{E}\right)\right\}\right]$. On aggregate they are the same. The distribution (of utility) changes depending on the assignment of the property rights.
} 
hold? Suppose that the contracts which are accepted by the agents are incomplete. This means that renegotiations ex-post cannot be excluded. We assume that the agents make use of the existing legal system when there is a conflict regarding the contract on property rights. For both agents the contractual agreements are observable, but they are not verifiable before the court. The outcome of the lawsuit is uncertain to the agents beforehand. For now we assume that going to court to enforce a contract is costless. We shall relax this assumption later.

Due to the possibility of renegotiation, the following question arises: are the contracts credible ex-post, or, in other words, is there a problem of moral hazard?

Below we investigate this credibility problem for the two different assignments of property rights, namely:

I Agent A owns the property rights.

Will agent $\mathrm{B}$ then ex post pay $Z^{A}$ to agent $\mathrm{A}$ ?

II Agent B owns the property rights.

Will agent $\mathrm{A}$ then ex post pay $Z^{B}$ to agent $\mathrm{B}$ ?

It will become clear that the credibility of the contracts depends to a great degree on the distribution of the property rights.

\subsubsection{Agent A Owns the Property Rights}

In the first case, where agent A owns the property rights, no moral hazard problem arises. If agent $\mathrm{B}$ does not stick to the agreement, agent $\mathrm{A}$ will increase his activity to $x=x^{n}$ instead of $x=x^{A}$. This is the "not liable" solution which is not in the interest of agent B. There is no incentive to breach the contract. Formally, there are two options for agent B ex-post, namely keeping to the agreement which is laid down in the contract or breaching the contract. This results in the following to alternatives for agent $\mathrm{B}$ :

a) Pay the compensation

b) Do not to pay the compensation

The game ends if agent B chooses a) because contractual agreements are held by both agents. This is the efficient (ex-ante) solution of the previous section. If agent B does not pay the compensation and breaches the contract, agent $\mathrm{A}$ has to decide how to respond to this contract breach. Agent can respond in the following way: 
b1) He can decide not to go to court but instead increase his output to $x=x^{n}$, to the non cooperative level, which maximizes his pay-off.

b2) He can keep the activity level at $x=x^{A}$ and go to court and try to enforce the payment $Z^{A}$.

To discover which alternative is preferred, we compare the expected pay-offs of all strategies. Let us first consider a). The pay-offs can be calculated by inserting the respective activity levels $x^{A}$ and $y^{A}$ in the utility functions of both agents, while keeping in mind that the activity levels $x=x^{A}$ and $y=y^{A}$ coincide with the efficient outcome of the previous section. The pay-off for agent $\mathrm{A}$ who receives the compensation is:

$$
U^{A^{*}}=A\left(x^{A}\right)+Z^{A}
$$

For agent $\mathrm{B}$ who pays the compensation the pay-off is:

$$
V^{A^{*}}=B\left(y^{A}\right)-S\left(x^{A}, y^{A}\right)-Z^{A}, \text { where } Z^{A}=\left[A\left(x^{n}\right)-A\left(x^{A}\right)\right]
$$

The superscript $A^{*}$ indicates this is an efficient solution in case agent $\mathrm{A}$ owns the property rights. Next we turn to $b$ ). Agent $B$ does not pay the agreed compensation, and therefore we have $Z^{A}=0$. If agent $\mathrm{B}$ does not stick to the ex-ante agreement then agent $\mathrm{A}$ has no reason to keep his part of the agreement. Agent A will increase his activity level to $x^{n}$ because that increases his utility. Agent's B best reaction is to choose activity level $y^{n}$. (The reader may notice that this is the "not liable" case.). Using the utility functions of the two agents we find the following pay-offs:

$$
U^{A}=A\left(x^{n}\right)
$$

and

$$
V^{A}=B\left(y^{n}\right)-S\left(x^{n}, y^{n}\right)
$$

This is the same as the non-cooperative solution. What remains is the last possibility, b2). Because we assume that the outcome of a lawsuit is uncertain we must know the probabilities that the agents will win their case in court. Let $\operatorname{Pr}^{A}$ be the probability that agent A wins the lawsuit in case of a dispute. We take this probability as exogenously given. This assumption will be relaxed later. Obviously we have $0<\operatorname{Pr}^{A}<1$ and $\operatorname{Pr}^{A}=\left(1-\operatorname{Pr}^{B}\right)$ where $\operatorname{Pr}^{B}$ is the probability that agent $\mathrm{B}$ wins the case in court. The probabilities are mutually exclusive 
because either agent $\mathrm{A}$ or agent $\mathrm{B}$ wins the court case. Of course there are other possible outcomes of the court case, but these will not be taken into consideration. Taking this into account, we have the following expected pay-offs for the two agents:

$$
E\left(U^{A}\right)=A\left(x^{A}\right)+\operatorname{Pr}^{A} Z^{A}
$$

and

$$
E\left(V^{A}\right)=B\left(y^{A}\right)-S\left(x^{A}, y^{A}\right)-\operatorname{Pr}^{A} Z^{A}
$$

It is easy to see that the (expected) pay-offs now also depend on the court's decision. This is the probability of getting the compensation allocated by the court, or, in other words, the expected compensation or - in still other words - the expected pay-off of going to court. Note that in principle this also leads to an efficient allocation. Below we have represented the game in the extensive form, which allows us to solve the game.

Rewriting equation $(7.13 \mathrm{~A})$ we can easily see that $E\left(U^{A}\right)<U^{A} 157$. This means that if agent $\mathrm{B}$ does not pay the compensation, agent $\mathrm{A}$ will not go to court. Instead of that agent $\mathrm{A}$ will chose $x^{n}$ because this results in the highest utility for agent A. Knowing this, agent B can calculate its utility pay-off of not paying the compensation. If agent $B$ does not pay - that is he chooses action $\mathrm{b}$ ) - then agent $\mathrm{A}$ chooses action $\mathrm{b} 2$ ); that is, increasing the activity level from $x^{A}$ up to $x^{n}$.

\footnotetext{
${ }^{157}$ Rewrite (7.13A) as $E\left(U^{A}\right)=A\left(x^{A}\right)+\operatorname{Pr}^{A}\left[A\left(x^{n}\right)-A\left(x^{A}\right)\right]$ which equals $E\left(U^{A}\right)=A\left(x^{A}\right)+\left(1-\operatorname{Pr}^{B}\right)\left[A\left(x^{n}\right)-A\left(x^{A}\right)\right]$. Rearranging results in $E\left(U^{A}\right)=A\left(x^{n}\right)-\operatorname{Pr}^{B}\left[A\left(x^{n}\right)-A\left(x^{A}\right)\right]$ and because $x^{A}<x^{n}$ we have $A\left(x^{A}\right)<A\left(x^{n}\right)$ and thus $E\left(U^{A}\right)<U^{A}$.
} 
Figure 7.3 The game if A owns the Property Rights

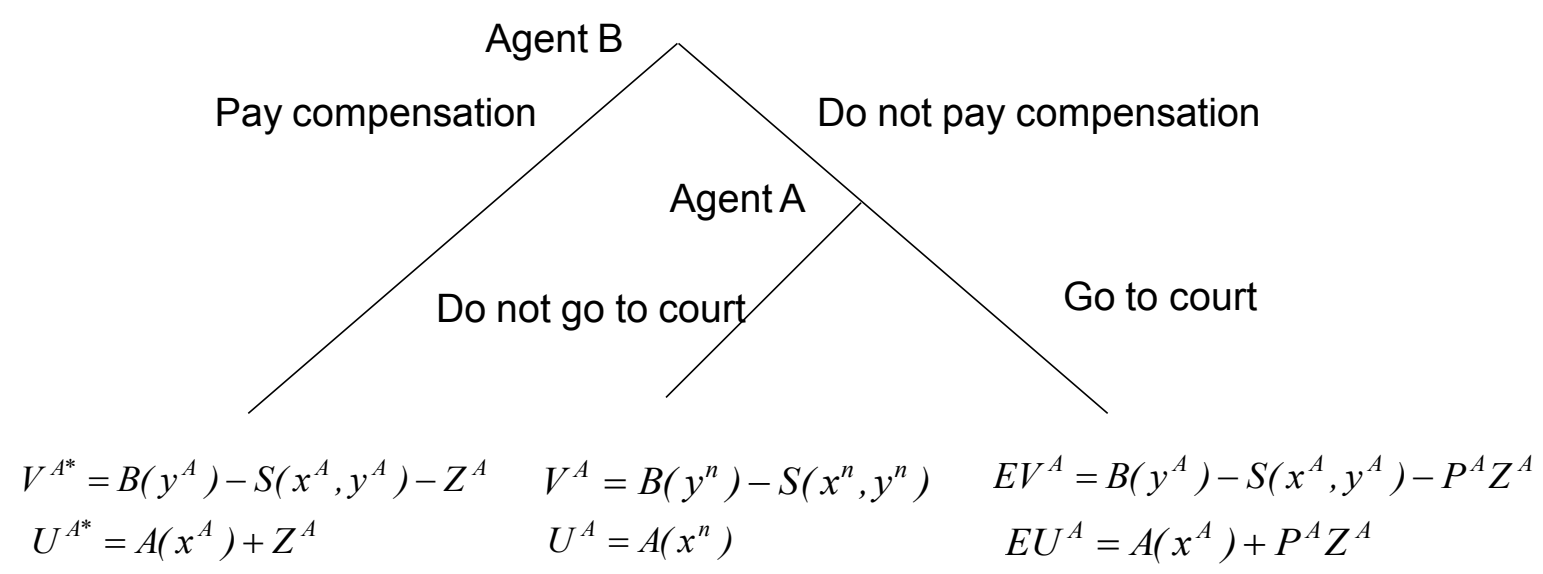

Now that agent B knows that A chooses $x^{n}$ the pay-off of action b) can be calculated. Breaching the contract ex-post results in a pay-off of $V^{A}=B\left(y^{n}\right)-S\left(x^{n}, y^{n}\right)$. Knowing that agent $\mathrm{B}$ can compare the pay-off of keeping the contract with breaching the contract: the payoff $V^{A^{*}}$ has to be compared with $V^{A}$. Because $V^{A^{*}}>V^{A 158}$ agent $\mathrm{B}$ will choose a) that is, paying the compensation. Note that this has to hold because otherwise agent A would not be willing to bargain and trade property rights and there would ex-ante never have been a contact between the two parties. We can summarize the game by looking at figure 7.3.

We can conclude that agent A will not go to court if agent B does not pay, but will increase his activity level up to $x=x^{n}$ to maximize its utility. By increasing its output to the non-cooperative level agent $\mathrm{A}$ receives a higher utility than going to court. In the case where agent $\mathrm{A}$ owns the property rights there is no moral hazard and no credibility problem.

\subsubsection{Agent B Owns the Property Rights}

In the second case agent $\mathrm{B}$ owns the property rights. We also investigate whether there is a moral hazard problem in this constellation of property rights. After the signing the ex-ante

\footnotetext{
${ }^{158}$ In the previous section we have show that $x=x^{A}$ and $y=y^{A}$ is efficient thus $V^{A^{*}}+U^{A^{*}}>V^{A}+U^{A}$. Besides that, $U^{A^{*}}=U^{A}$ thus $V^{A^{*}}>V^{A}$.
} 
contract which takes note of the agreed compensation with agent $\mathrm{B}$, agent $\mathrm{A}$ has two options ex-post:

c) Pay the compensation

d) Do not pay the compensation

If agent $\mathrm{A}$ chooses $\mathrm{c}$ ) then the game ends and an efficient allocation is the result. If agent $\mathrm{A}$ does not pay the compensation, there are two possibilities for agent $\mathrm{B}$, namely:

d1) Agent B does not go to court and accepts the breach of contract, or

d2) Agent B goes to court and tries to enforce the contract.

The decision, naturally, depends on the expected pay-offs. The pay-offs of c) we already know from the previous sections. For agent A the pay-off is:

$$
U^{B^{*}}=A\left(x^{B}\right)-Z^{B}
$$

For agent B who is compensated for the externality the pay-off is:

$$
V^{B^{*}}=B\left(y^{B}\right)-S\left(x^{B}, y^{B}\right)+Z^{B}
$$

Here $Z^{B}=\left[B\left(y^{l}\right)-\left\{B\left(y^{B}\right)-S\left(x^{B}, y^{B}\right)\right\}\right.$. Activity levels $x^{B}$ and $y^{B}$ again represent the efficient outcome as we have seen in the previous section. The superscript $B^{*}$ is used to indicate that $\mathrm{B}$ owns the property rights and that it is an efficient solution. Compared with the previous case there is no difference except for a difference of income distribution. Where, in the previous case, agent $\mathrm{B}$ had to pay for the compensation, now agent B receives the compensation.

We continue with the case where A breaches the contract and does not pay the compensation. If agent $\mathrm{B}$ decides not go to court he will receive no compensation for sure and so $Z^{B}=0$. Using this we can find the corresponding pay-off for both agents if agent $\mathrm{B}$ does not go to court. Using equation (7.14A) and (7.14B) and inserting $Z^{B}=0$ we find the following pay-offs:

$$
V^{B}=B\left(y^{B}\right)-S\left(x^{B}, y^{B}\right)
$$

and

$$
U^{B}=A\left(x^{B}\right)
$$


Note that this is the same result as the 'liable' solution from section 7.3 (see equations (7.12A) and (7.12B)). The alternative action of agent B is to go to court, that is $\mathrm{d} 2$ ). If agent $\mathrm{B}$ goes to court he does not know the court's decision beforehand. Agent B therefore calculates the expected pay-off of going to court. This is the probability that agent B will win the case multiplied by the amount of compensation. Going to court results in an expected pay-off for agent $\mathrm{B}$ and $\mathrm{A}$ (note that we have $\operatorname{Pr}^{B}=\left(1-\operatorname{Pr}^{A}\right)$ ):

$$
E\left(V^{B}\right)=B\left(y^{B}\right)-S\left(x^{B}, y^{B}\right)+\operatorname{Pr}^{B} Z^{B}
$$

and

$$
E\left(U^{B}\right)=A\left(x^{B}\right)-\operatorname{Pr}^{B} Z^{B}
$$

Now we have the pay-off for the two actions, going to court and not going, we can compare the results. Looking at equation (7.16A) and (7.15A) we see that $E\left(V^{B}\right)=V^{B}+\operatorname{Pr}^{B} Z^{B}$ and therefore $E\left(V^{B}\right)>V^{B}$. The expected pay-off of going to court exceeds that of not going to court. As a result, agent B chooses to go to court. Knowing that agent B will go to court if agent $\mathrm{A}$ breaches the contract, agent $\mathrm{A}$ has to decide which action to take. This depends on the expected pay-off of the two alternative actions, namely upholding and breeching the contract, that is, c) or d). Again we compare the expected pay-offs of upholding the contract and breaching it. The pay-offs are noted in equations (7.14A) and (7.16B), respectively. Rearranging equation $(7.16 \mathrm{~B})^{159}$ results in the following expected pay-off: $E\left(U^{B}\right)=U^{B^{*}}+\operatorname{Pr}^{A} Z^{B}$ so we have $E\left(U^{B}\right)>U^{B^{*}}$. This can also be seen by directly inspecting the two equations because we have $0<\operatorname{Pr}^{B}<1$ and thus $\operatorname{Pr}^{B} Z^{B}<Z^{B}$. The pay-off from breaching the contract exceeds the pay-off from upholding it. Thus agent A chooses d), breaching the contract ex-post.

We resume the game in extensive form below. The previous solution can easily be verified using the game tree of figure 7.4.

\footnotetext{
${ }^{159} E\left(U^{B}\right)=A\left(x^{B}\right)-\left(1-\operatorname{Pr}^{A}\right) Z^{B}=A\left(x^{B}\right)-Z^{B}+\operatorname{Pr}^{A} Z^{B}$. Using (7.14A) we find $E\left(U^{B}\right)=U^{B^{*}}+\operatorname{Pr}^{A} Z^{B}$.
} 
Figure 7.4: $\quad$ The Game if B owns the Property Rights

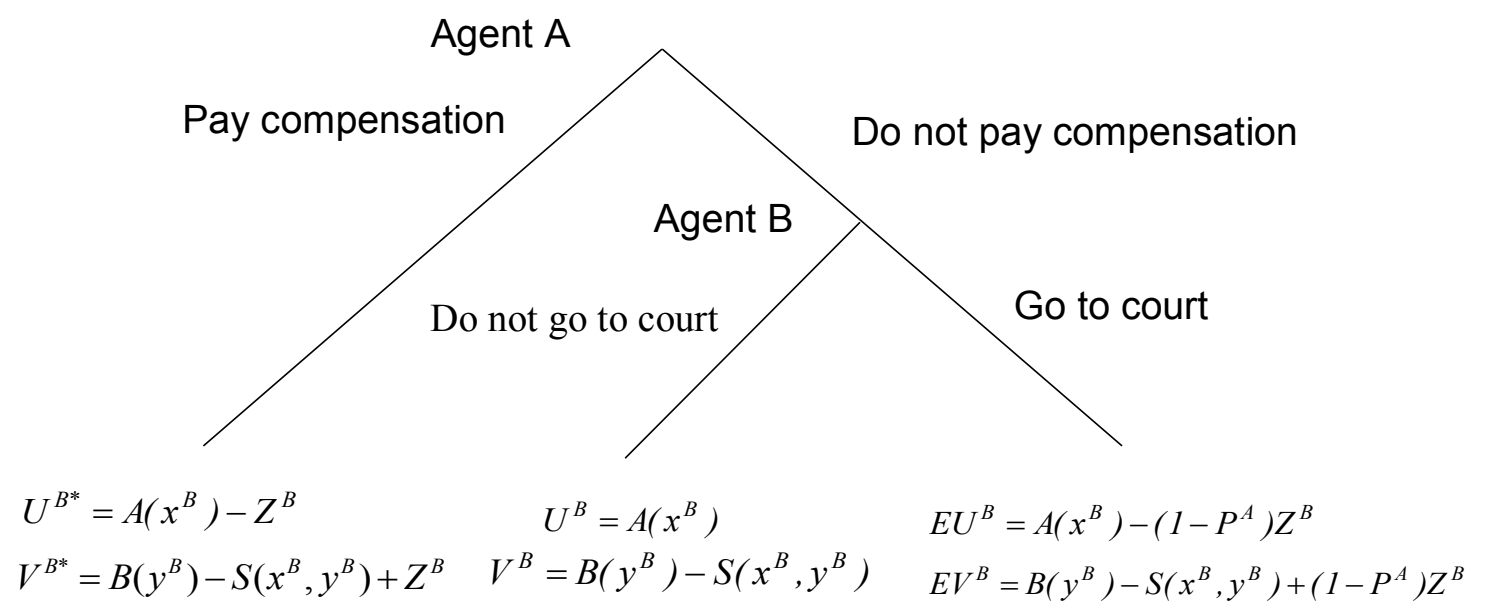

Agent $\mathrm{A}$ does not adhere to the contractual agreement to pay $Z^{B}$. As long as there is any chance of winning the case before the court, agent A will not pay the compensation. This is due to the fact that contracts are incomplete.

This result can have serious implications for the ex-ante decisions. If agent B knows that ex-post the contract will not hold he will not accept an agreement ex-ante. This means that there will be no trading of property rights and a possible efficient solution will not be reached. This in turn means that this property rights assignment leads to a hold-up. There will be no trade in property rights and as a result no increase in welfare.

\section{Proposition 7.4:}

If contracts are incomplete, the assignment of property rights does have an influence on efficient allocation, through trading property rights, in case of externalities.

In the next section we investigate the effect of costs associated with going to court to resolve disputes over property rights. That is, we assume positive transaction costs. 


\subsection{Costly Lawsuits}

If agents go to court to resolve contractual problems, all kinds of (transaction) costs will emerge, such as payments to lawyers and suchlike. If the agents decide to go to court they also have to take into consideration the effort they need to invest to win the case before the court. We assume that the higher an agent's relative effort, the higher his probability of winning the lawsuit. To model these features we once again make use of the contest economic theory and a contest success function (CSF). We concentrate on the case where agent B owns the property rights and agent $\mathrm{A}$ is 'liable'. This assignment of the property rights leads to possible opportunistic behaviour, as we have seen in the previous section, which is of interest as such.

\subsubsection{The Probability of Winning a Lawsuit}

We assume that the probability that agent A will win the lawsuit depends on how much effort he is willing to invest as well as on his opponent's effort level and the assignment of the property rights. The probability that an agent will win the lawsuit is endogenously determined by the effort levels of the competing agents. Besides that, the agent who owns the property right has a comparative advantage before the court. We can write the probability function as follows: $\operatorname{Pr}^{A}=\operatorname{Pr}\left(e^{A}, e^{B}, \theta\right)$, where the variables $e^{A}$ and $e^{B}$ are the efforts levels (respectively the costs of going to court) of agent A and agent $\mathrm{B}$. We use the parameter $\theta$ as an indicator of the comparative advantage of the agent who owns the property rights. We use the following contest success function to take care of these features:

$$
\operatorname{Pr}^{A}\left(e^{A}, e^{B}\right)=\left\{\begin{array}{l}
\frac{\theta e^{A}}{\theta e^{A}+e^{B}} \text { if } e^{A}>0 \\
0 \text { if } e^{A}=e^{B}=0
\end{array}\right.
$$

and

$$
\operatorname{Pr}^{B}\left(e^{A}, e^{B}\right)=\left\{\begin{array}{l}
\frac{e^{B}}{\theta e^{A}+e^{B}} \text { if } e^{A}>0 \\
1 \text { if } e^{A}=e^{B}=0
\end{array}\right.
$$

This probability tells us that in case B owns the property rights and A breaches the contract, agent $\mathrm{A}$ will lose the case before the court. There is a possibility of winning the case only if he invests in effort by, for example, hiring good lawyers. The more effort is invested, the 
greater the probability of winning the case before the court. The parameter $\theta$ reflects the burden of proof. As noted above, the probability also depends on the distribution of the property rights. Because of the fact that the property rights are assigned to agent $\mathrm{B}$, agent $\mathrm{A}$ carries the burden of proof and therefore we have the following restriction: $0<\theta<1^{160}$. The more severe the burden of proof, the smaller the parameter $\theta$ and the more secure are the property rights. If agents $\mathrm{A}$ and $\mathrm{B}$ do not invest in any effort, that is, $e^{A}=e^{B}=0$, then the probability of winning the case before the court reduces to 0 for agent $A$ while for agent $\mathrm{B}$ it equals 1. This is a consequence of the legal system and the fact that agent $\mathrm{B}$ owns the property rights. If agent $\mathrm{A}$ breaches the contract and $\mathrm{B}$ goes to court, agent $\mathrm{A}$ has to invest in effort or otherwise agent A will definitely lose the case. We can see this by substitution of $e^{A}=e^{B}=e$ in equation (7.17) resulting in $\operatorname{Pr}^{A}\left(e^{A}, e^{B}\right)=\frac{\theta}{1+\theta}<\frac{1}{2}<\frac{1}{1+\theta}=\operatorname{Pr}^{B}\left(e^{A}, e^{B}\right)$.

\subsubsection{Agent B Owns the Property Rights}

We have seen in the previous section that a credibility problem arises and moral hazard occurs when agent $\mathrm{A}$ is 'liable' and has to compensate agent $\mathrm{B}$ who owns the property rights. Agent A has to offer compensation for causing the externality. Because of the presence of a credibility problem we confine our attention to this case. We also investigate the role of the legal system and whether it is possible to resolve the credibility problem. In a broader sense we could investigate whether the institutional setting has an influence on efficiency in case of externalities.

The question therefore is: do different rules lead to different (more or less efficient) outcomes of an (economic) game? To keep the problem manageable we only distinguish between two different sets of rules, i.e. two civil law systems, namely:

1. The Anglo-Saxon (AS) civil law system with the rule that every agents pays for his own effort; and

2. Roman (R) civil law, where the rule is that the losing agent has to pay all the costs.

The approach is exactly the same as in the previous section. The extension is that going to the court is costly and agents have to incorporate these costs in their decision process. Furthermore, the probability is now endogenous, depending on the efforts of the agents.

\footnotetext{
${ }^{160}$ The closer $\theta$ approaches zero the harder it will become for agent A to win the lawsuit. If $\theta=1$, the burden of proof is equally distributed between agents $\mathrm{A}$ and $\mathrm{B}$.
} 


\subsubsection{The Anglo-Saxon Civil Law System (AS)}

Let us start by investigating the Anglo-Saxon civil law system, where we use the superscript $(A S)$ to indicate the legal system under which decisions are made. If agent $\mathrm{B}$ owns the property rights there are again two options for agent $\mathrm{A}$. Note that the activity levels $(x, y)$ are fixed ex-ante and are laid down in the contractual agreements. For convenience we summarize the possible options for both agents. For agent A we have the following:

c) Pay the compensation

d) Do not pay the compensation (which results in contract breach).

If agent $\mathrm{A}$ chooses $\mathrm{d})$, agent $\mathrm{B}$ has two options:

d1) Agent B does not go to court and accepts the contract breach, or alternatively

d2) Agent B goes to court and tries to enforce the contract.

Regarding option c), as before there is no problem. The pay-offs can be found in equations (7.14A) and (7.14B). The pay-offs are already known for option $\mathrm{d} 1$ ), too, where agent A does not pay the compensation. They can be found in equations (7.15A) and (7.15B). Only $\mathrm{d} 2$ ) differs, because the outcome now depends on the legal system. Whether agent $B$ goes to court (chooses d2) depends on the expected pay-off. In the Anglo-Saxon case efforts are fully at the expense of the players. The expected pay-off therefore decreases with the cost the agent has to incur by going to court, i.e. the investment in effort. The expected pay-off (utility) of agent B is then given by:

$$
E\left(V^{A S}\right)=B\left(y^{B}\right)-S\left(x^{B}, y^{B}\right)+\operatorname{Pr}^{B} Z^{B}-e^{B}
$$

Comparing these results with the previous outcome we see that equation (7.19) resembles equation (7.16A) except for the last term, $e^{B}$, which represents the costs the agent incurs by in going to court and the probability of winning the case before the court, which is explicitly defined by equation (7.17) and is endogenous. Recall that the probability of winning in court depends on the investment in effort made by both agents $\left(e^{A}, e^{B}\right)$ and the jurisdictional setting of the property rights incorporated in the parameter $\theta$.

If agent $\mathrm{A}$ wins the lawsuit, agent $\mathrm{B}$ will not receive compensation. If agent $\mathrm{A}$ loses the lawsuit, agent $\mathrm{B}$ will receive the compensation. Besides that, agent $\mathrm{B}$ will also have to invest in effort to win the lawsuit. The expected pay-off to agent $\mathrm{B}$ if agent $\mathrm{A}$ breaches the contract, resulting in a court case, equals:

$$
E\left(U^{A S}\right)=A\left(x^{B}\right)-\operatorname{Pr}^{B} Z^{B}-e^{A}
$$


This result too is very similar to that of equation (7.16B) except for the last term $e^{A}$. Besides that, the probability, which is endogenous, depends on the effort made by both agents, the jurisdictional allocation of the property rights, and the probability according to equation (7.17).

The pay-off depends on the probability of winning the lawsuit and the associated costs in terms of effort. The probability is influenced by both the effort levels $\left(e^{A}, e^{B}\right)$ and the distribution of property rights, the burden of proof $(\theta)$ as explained in section (7.5.1). This can be seen if we look at the second and third term of equations (7.19) and (7.20). The expected pay-off of going to court depends on the cost of doing so. On the one hand it decreases the expected pay-off of the two agents because of the costs. On the other hand it influences the probability of winning before court. Note that this probability depends on the level off effort (costs) of both agents, see equation (7.16).

Before we can compare the pay-offs, we have to find the effort level (costs) agents are willing to invest in order to win the lawsuit. Both agents maximize their expected pay-offs. Differentiating equation (7.19) and (7.20) with respect to the efforts results in the following first-order conditions:

$$
\frac{\partial E\left(V^{A S}\right)}{\partial e^{B}}=\frac{\partial \operatorname{Pr}^{B}}{\partial e^{B}} Z^{B}-1=0
$$

and

$$
\frac{\partial E\left(U^{A S}\right)}{\partial e^{A}}=-\frac{\partial \operatorname{Pr}^{B}}{\partial e^{A}} Z^{B}-1=0
$$

Using equations (77.21) and (7.22), we can easily calculate the optimum effort levels, which equal $e^{A}=e^{B}=e^{161}$. If we know that the effort levels are equal as between the two agents, we find the following optimum effort level: ${ }^{162}$

\footnotetext{
${ }^{161}$ Substituting the (7.17) in (7.21) and (7.22) and next taking the partial derivative from (7.21) and (7.22) results in; $\frac{\partial E\left(V^{A S}\right)}{\partial e^{B}}=\frac{\theta e^{A}}{\left(\theta e^{A}+e^{B}\right)^{2}} Z^{B}-1=0$ and $\frac{\partial E\left(U^{A S}\right)}{\partial e^{B}}=\frac{\theta e^{B}}{\left(\theta e^{A}+e^{B}\right)^{2}} Z^{B}-1=0$ which results in $\theta e^{A} Z^{B}=\theta e^{B} Z^{B}=\left(\theta e^{A}+e^{B}\right)^{2}$ and thus $e^{A}=e^{B}=e$. ${ }^{162}$ Inserting $e^{A}=e^{B}=e$ in (7.21) or (7.22) leads to $\frac{\theta e}{(\theta e+e)^{2}} Z^{B}=1$ and $e^{2}(1+\theta)^{2}=e \theta Z^{B}$ resulting in $e=\frac{\theta Z^{B}}{(1+\theta)^{2}}$.
} 


$$
e^{A}=e^{B}=e=\frac{\theta Z^{B}}{(1+\theta)^{2}}
$$

The optimum effort level depends on the compensation, $Z^{B}$, and the burden of proof. The greater the compensation, of course, the greater is the expected pay-off to both agents. The more severe the burden of the proof, that is, the lower the value of parameter $\theta$, the lower is the investment in effort. The reason for this is that for agent $\mathrm{A}$ it decreases the probability of winning in court, while for agent $B$ it increases the probability of winning in court, see equation (7.17). Using the optimum effort level of agent $\mathrm{A}$ we can determine the pay-offs to the two agents from going to court. First we calculate the probabilities from equation (7.17). After inserting $e^{A}=e^{B}=e$ we find the following probabilities:

$$
\operatorname{Pr}^{A}\left(e^{A}, e^{B}\right)=\frac{\theta e}{\theta e+e}=\frac{\theta}{1+\theta} \text { and } \quad \operatorname{Pr}^{B}\left(e^{A}, e^{B}\right)=\frac{e}{\theta e+e}=\frac{1}{1+\theta}
$$

The probability depends solely on the burden of proof, parameter $\theta$. The probabilities of winning the case in court also sum to $\frac{\theta}{1+\theta}+\frac{1}{1+\theta}=1$. Note that in equilibrium the probability does not depend on the effort level of the contestants. Inserting the probabilities from (7.17B) and the optimum effort level from (7.23) in (7.19) and (7.20) results in the following expected pay-offs ${ }^{163}$ for agent $\mathrm{A}$ and $\mathrm{B}$ if they decide to go to court:

$$
E\left(V^{A S}\right)=B\left(y^{B}\right)-S\left(x^{B}, y^{B}\right)+\frac{1}{(1+\theta)^{2}} Z^{B}
$$

and $^{164}$

$$
\begin{aligned}
& { }^{163} E\left(V^{A S}\right)=B\left(y^{B}\right)-S\left(x^{B}, y^{B}\right)+\operatorname{Pr}^{B} Z^{B}-e^{B} \text { Using (7.17B) } \operatorname{Pr}^{B}=\frac{1}{1+\theta} \text { and (7.23)for } \\
& e^{B}=e^{A}=e=\frac{\theta Z^{B}}{(1+\theta)^{2}} \text { results in } E\left(V^{A S}\right)=B\left(y^{B}\right)-S\left(x^{B}, y^{B}\right)+\frac{1}{1+\theta} Z^{B}-\frac{\theta}{(1+\theta)^{2}} Z^{B} \text { which equals } \\
& E\left(V^{A S}\right)=B\left(y^{B}\right)-S\left(x^{B}, y^{B}\right)+\frac{1}{(1+\theta)^{2}} Z^{B} . \\
& { }^{164} E\left(U^{A S}\right)=A\left(x^{B}\right)-\operatorname{Pr}^{B} Z^{B}-e^{A} \text { Using (7.17B) } \operatorname{Pr}^{B}=\frac{1}{1+\theta} \text { and }(7.23) \text { for } e^{B}=e^{A}=e=\frac{\theta Z^{B}}{(1+\theta)^{2}} \text { gives } \\
& E\left(U^{A S}\right)=A\left(x^{B}\right)-\frac{Z^{B}}{1+\theta}-\frac{\theta Z^{B}}{(1+\theta)^{2}} \text { resulting in } E\left(U^{A S}\right)=A\left(x^{B}\right)-\frac{1+\theta}{(1+\theta)^{2}} Z^{B}-\frac{\theta}{(1+\theta)^{2}} Z^{B}
\end{aligned}
$$




$$
E\left(U^{A S}\right)=A\left(x^{B}\right)-\frac{1+2 \theta}{(1+\theta)^{2}} Z^{B} Z^{B}
$$

If we look at the expected pay-off we see that it depends solely on the burden of proof, parameter $\theta$. We can see that the more severe the burden of the proof is, the lower the expected pay-off to agent $\mathrm{A}$ and the higher the expected pay-off to agent $\mathrm{B}$. The more secure the property rights are, the lesser the incentive to breach the contract because the expected pay-off is lower.

The decision of agent $A$, whether or not to pay the compensation depends on what agent B will do in the two cases. For agent B it is beneficial to go court because the expected pay-off of going to court exceeds that of not going. Using equation (7.24) with the fact that, 0 $<\theta<1$, it is easy to verify that:

$$
E\left(V^{A S}\right)>V^{B}
$$

Agent B will go to court if agent A does not pay the compensation. Agent A knows this and, based on that knowledge, he will choose d) because this alternative maximizes his pay-off. Again we verify this by comparing the pay-offs:

$$
E\left(U^{A S}\right)>U^{B^{*}}
$$

Despite the fact that agent A knows that agent B will go to court if the compensation will not be paid, there is an incentive for agent $A$ to breach the contract. This is caused by the fact that there is still a probability that agent A will win his case in court, as a result of contract incompleteness between the two agents. There is thus an incentive to breech the contract.

Note that this is equivalent to the outcome of section 7.3.2. Below the game is summarized in extensive form. The above solution can easily be verified by using backward induction.

$$
\begin{aligned}
& \text { Rearranging equation (7.25) we find } E\left(U^{A S}\right)=A\left(x^{B}\right)-\frac{1+\theta}{(1+\theta)^{2}} Z^{B}-\frac{\theta}{(1+\theta)^{2}} Z^{B} \text { which finally results in; } \\
& E\left(U^{A S}\right)=A\left(x^{B}\right)-\frac{1+2 \theta}{(1+\theta)^{2}} Z^{B} . \text { Note that } \frac{1+2 \theta}{(1+\theta)^{2}}<1 \text { because, } 1+2 \theta<1+2 \theta+\theta^{2} .
\end{aligned}
$$


Figure 7.5 The Game under Anglo-Saxon Legal System in Extensive Form

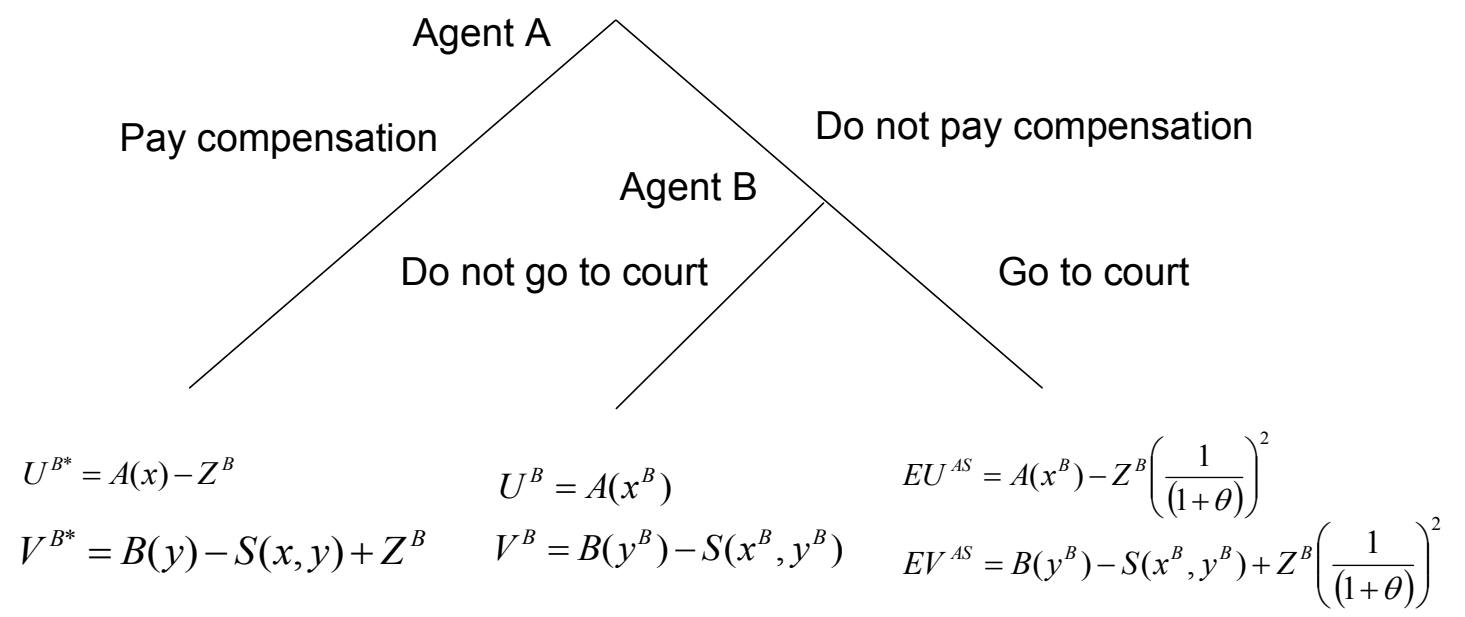

Note too the resemblance of the expected pay-offs in the two cases, that is the resemblance of equation (7.16A) to equation (7.24) and of (7.16B) to (7.25). Apparently the AS legal setting does not provide sufficient safeguards to protect against the contracting agents' opportunistic behaviour. This legal system affords insufficient security to the property rights, which leads to the proposition below:

\section{Proposition 7.5:}

The Anglo-Saxon legal system (where the rule is that agents have to pay for their own costs if they decide to go to court) does not resolve the credibility problem in case one of the agents owns the property rights and the other is liable.

We can conclude that there will be no trading of property rights and therefore an efficiency loss is the result because externalities are not internalized. In the case of the AS legal system we can describe this as a hold-up situation, because agents will not trade property rights and the potential increase in welfare is not realized. The AS legal system does not protect the agents against opportunistic behaviour. 


\subsubsection{The Roman Civil Law System}

We now turn to the Roman civil law system. Note that, compared with the AS legal system, only the pay-offs of the going to court strategy (d2) will be different. The great difference is that the agent who loses the lawsuit must pay all costs of the lawsuit, including his opponent's. We use the superscript $\mathrm{R}$ to indicate that we are dealing with the Roman legal system. We have to modify the expected pay-off function to incorporate the elements of the $\mathrm{R}$ legal system. If agent $\mathrm{B}$ wins the lawsuit, he will receive the compensation. In addition to that, agent $\mathrm{B}$ does not have to pay his costs for the lawsuit. He only has to pay the costs in case agent $\mathrm{A}$ wins, in which case he not only has to pay his own costs but also those of his opponent, agent $\mathrm{A}$. The total cost of the lawsuit are the effort invested by the two agents, that is: $\left(e^{A}+e^{B}\right)$. The expected costs for agent $\mathrm{B}$ equal the probability agent $\mathrm{A}$ will win the lawsuit multiplied by the total costs, that is, $\operatorname{Pr}^{A}\left(e^{A}, e^{B}, \theta\right) \times\left[e^{A}+e^{B}\right]$. The expected pay-off to agent $\mathrm{B}$ of going to court is now given by:

$$
E\left(V^{R}\right)=B\left(y^{B}\right)-S\left(x^{B}, y^{B}\right)+\operatorname{Pr}^{B} Z^{B}-\operatorname{Pr}^{A} \times\left[e^{A}+e^{B}\right]
$$

If we compare the expected pay-off with the one in the AS system, equation (7.19), we see that instead of sure cost, $e^{B}$ for agent $\mathrm{B}$ we now have the expected cost, $\operatorname{Pr}^{B} \times\left[e^{A}+e^{B}\right]$, of losing the game.

Naturally, the expected pay-offs to agent A also differs from the previous case. If agent $\mathrm{A}$ loses his case in court he has to pay the compensation, his own costs and those of agent $\mathrm{B}$. The probability of losing the game equals $\left(1-\operatorname{Pr}^{A}\right)=\operatorname{Pr}^{B}$. Taking this into account, the expected pay-off becomes:

$$
E\left(U^{R}\right)=A\left(x^{B}\right)-\operatorname{Pr}^{B} Z^{B}-\operatorname{Pr}^{B} \times\left[e^{A}+e^{B}\right]
$$

If agent $\mathrm{A}$ wins the lawsuit, all costs of the efforts will be reimbursed by agent $\mathrm{B}$. If agent $\mathrm{A}$ loses the lawsuit he must pay the compensation to agent $B$ and the costs of the efforts of both players. Again, if we compare this with the AS system, equation (7.30), we see that the difference is that in the $\mathrm{AS}$ system the costs $e^{A}$, are for sure. In the $\mathrm{R}$ system they are expected costs, namely, $\operatorname{Pr}^{B} \times\left[e^{A}+e^{B}\right]$.

Again agents not only have to decide whether or not to go to court, they also have to decide, if they do go to court, how much effort they are willing to invest in order to win the lawsuit. If both agents maximize their expected utility, this leads to the following first-order conditions, which are derived from (7.29) and (7.30): 


$$
\frac{\partial E\left(V^{R}\right)}{\partial e^{B}}=\frac{\partial \operatorname{Pr}^{B}}{\partial e^{B}} Z^{B}-\frac{\partial \operatorname{Pr}^{A}}{\partial e^{B}}\left(e^{A}+e^{B}\right)-\operatorname{Pr}^{A}=0
$$

and

$$
\frac{\partial E\left(U^{R}\right)}{\partial e^{A}}=\frac{\partial \operatorname{Pr}^{B}}{\partial e^{A}} Z^{B}-\frac{\partial \operatorname{Pr}^{B}}{\partial e^{A}}\left(e^{A}+e^{B}\right)-\operatorname{Pr}^{B}=0
$$

Because agent $\mathrm{B}$ is the one who wants to enforce the contract he first calculates the optimum effort level. From (7.31) we can derive that $(\theta-1) e^{A}=Z^{B} .{ }^{165}$ Using these results we can determine the optimum effort levels of the two agents willing to invest in order to win their case in court. This leads to the following effort levels:

$$
e^{A}=\frac{-1}{(1-\theta)} Z^{B}
$$

Taking into account the assumption $0<\theta<1$, we get the result that $e^{A}<0$. Because only nonnegative effort levels are allowed, we end up in a corner solution, namely:

$$
e^{A}=0
$$

If agent $B$ recognizes that the optimum effort level of agent $A$ is zero, the best he can do is also an effort level of zero, see equation (7.17). The pay-off is the same as not going to court. Because of the assignment of the property rights to agent B he will surely win because agent A will not go to court at all. From the other second-order condition we can see that the effort level becomes:

$$
e^{B}=\frac{\theta}{(1-\theta)} Z^{B}
$$

${ }^{165}$ Inserting $\frac{\partial \operatorname{Pr}^{B}}{\partial e^{B}}, \frac{\partial \operatorname{Pr}^{A}}{\partial e^{B}}$ and $\operatorname{Pr}^{A}$ results in

$\frac{\partial E\left(V^{R}\right)}{\partial e^{B}}=\frac{\theta e^{A}}{\left(\theta e^{A}+e^{B}\right)^{2}} Z^{B}+\frac{\theta e^{A}}{\left(\theta e^{A}+e^{B}\right)^{2}}\left(e^{A}+e^{B}\right)-\frac{\theta e^{A}}{\left(\theta e^{A}+e^{B}\right)}=0$ which equals

$\frac{\partial E\left(V^{R}\right)}{\partial e^{B}}=\frac{\theta e^{A}}{\left(\theta e^{A}+e^{B}\right)^{2}} Z^{B}+\frac{\theta e^{A}}{\left(\theta e^{A}+e^{B}\right)^{2}}\left(e^{A}+e^{B}\right)-\frac{\theta e^{A}}{\left(\theta e^{A}+e^{B}\right)^{2}}\left(\theta e^{A}+e^{B}\right)=0$ which simplifies to $Z^{B}+\left(e^{A}+e^{B}\right)-\left(\theta e^{A}+e^{B}\right)=0$ that is $(\theta-1) e^{A}=Z^{B}$. 
This, however, is not a feasible solution because, given the effort level of agent $\mathrm{A}, e^{A}=0$, any positive investment in effort will decrease his pay-off, see equation (7.29). Note that from equation (7.17) we have $\operatorname{Pr}^{A}=0$ and $\operatorname{Pr}^{B}=1$ if $e^{A}=0$. The underlying reason is that agent $\mathrm{A}$ will not invest and therefore there are no expected gains from breaching the contract, see equation (7.30). As a result, the optimum effort of agent B will equal zero.

$$
e^{B}=0
$$

The pay-off of the different strategies can now be compared. If we insert (7.34) in (7.29) we find that:

$$
E\left(V^{R}\right)=B\left(y^{B}\right)-S\left(x^{B}, y^{B}\right)+Z^{B}=V^{B^{*}}
$$

If we compare this we see that $E\left(V^{R}\right)>V^{B}$. Agent B will go to court if agent A breaches the contract, or if agent A chooses d), agent B will opt for d1). With this information we can compare the pay-offs of c) and d) for agent A. Substituting the optimum effort levels in equation (7.30) gives us:

$$
E\left(U^{R}\right)=A\left(x^{B}\right)-Z^{B}=U^{B^{*}}
$$

Figure 7.6 The Game under Roman Legal System in Extensive form

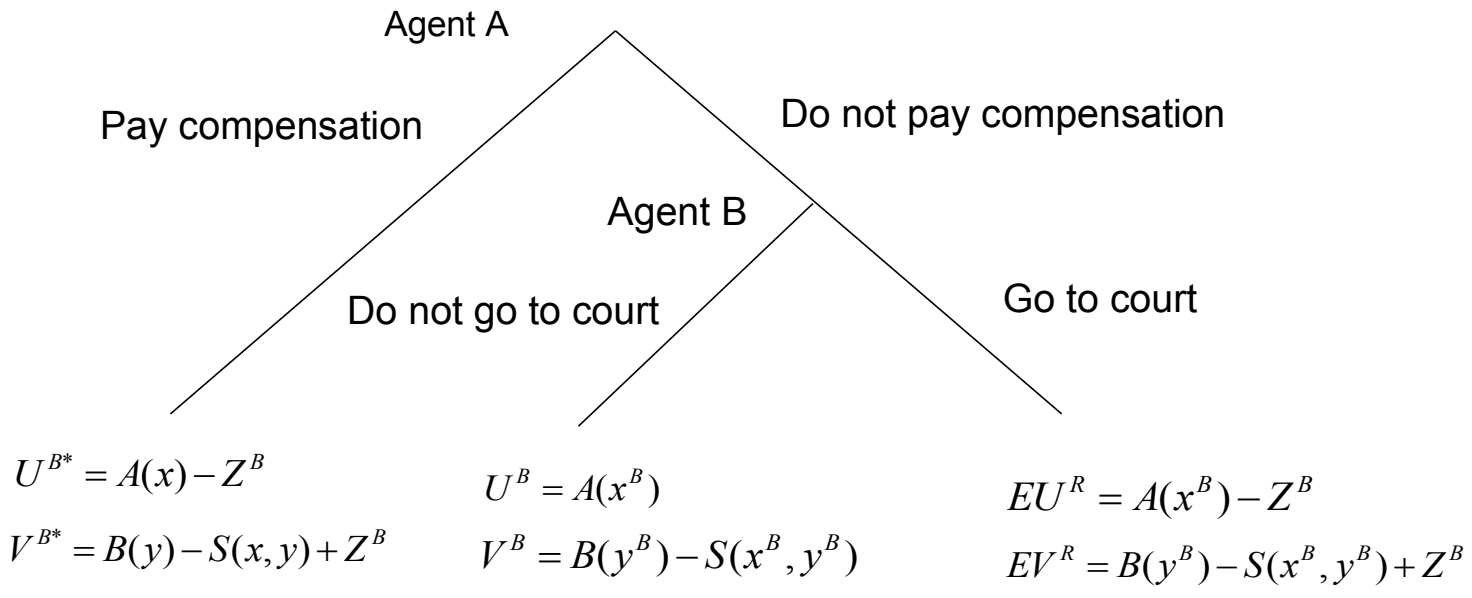


We can conclude that $E\left(U^{R}\right)=U^{B^{*}}$. We conclude that for agent A there is no incentive to breach the contract because the expected gains from doing so are zero. Once again we summarize and write the game in extensive form. The above solution can be verified using the game tree of figure 7.6.

If we look at these results we can conclude that the $\mathrm{R}$ legal system has resolved the credibility problem. Both agents will stick to the ex-ante contract and there will be no holdup. This means that 'Coasian' bargaining will lead to an efficient solution of externalities. This leads to the proposition below.

\section{Proposition 7.6:}

The Roman legal system (where the losing agent has to pay for the costs) does resolve the credibility problem; 'Coasian' bargaining allows an efficient solution to be attained.

\subsection{Conclusion}

In this chapter we have analyzed whether a decentralized Coasean bargaining process between regions on the benefits of non-competition and of integration is feasible. If regions agree on a compensation scheme by means of a contract, then the main problem is the credibility of such a contract. As point of departure we took a game theoretic setting following the model of Schweizer (1988). Additionally to this model we assumed that contracts are incomplete and that renegotiations cannot be excluded. This opens the door to possible opportunistic behaviour by the regions. Usually the legal system tries to prevent this kind of behaviour as much as possible. We showed that, depending on the distribution of property rights, agents behave opportunistically. In the case where the agent that causes the externality is liable, a credibility problem appears. This results in a hold-up situation: no property rights are traded ex-ante due to ex-post opportunistic behaviour. This then prevents an efficient solution being reached by trading property rights. The other possibility, where the agent who causes the externality is not liable, does not give rise to a credibility problem. As a result, the efficient allocation will be reached by trading property rights.

We continued with an investigation of whether the legal system is able to resolve the credibility problem in case the agent who causes the externality is liable. A distinction was made between the Anglo-Saxon (AS) legal system and the Roman (R) legal system. In the AS system each agent has to pay for his own costs incurred during the lawsuit dealing with conflicts of property rights. In the R system the agent that loses has to pay the entire burden of costs. We showed that the credibility problem cannot be resolved under the AR legal system. The Roman system resolves the credibility problem due to the rule that the losing agent has to 
pay the entire burden of costs. This allowed us to conclude that the Coase theorem works better under the Roman legal system than under the Anglo-Saxon one. 



\section{Chapter 8}

Conclusions 


\subsection{Introduction}

Our research objective was to analyze the consequences of regional competition for efficiency - within the context of economic integration - with special emphasis on the interaction between regions with differing institutional structures. In this final chapter we review the main conclusions that follow from this analysis.

We focus on the three major parts of the thesis. In section 8.2 we first discuss the results of chapters 3 and 4, which analyzed competition between regions (attempting to attract innovative firms to settle). Subsequently, in section 8.3 we focus on the results of chapters 5 and 6, which dealt with economic integration (as the result of cooperation between regions) and institutional differences. In section 8.4 we discuss the coordination problems that follow from chapters 3-6 and the way they could be solved by Coasean bargaining.

Finally, section 8.5 addresses the merits and demerits of this research as well as possible avenues for future research in this field.

\subsection{Competition between Regions: Does it Increase Efficiency? ${ }^{166}$}

In chapter 3 we analyzed competition between regional systems of governance. We used some relatively unconventional economic tools to describe the process of competition between regions. Focusing on the increasing economic activity of a region thanks to the settling of new firms (which increase regional product, employment, income and image), we assumed that that is the incentive for regional policymakers to attract firms and to compete with other regions. We borrowed the contest success function, which is extensively used in the economic theory of contest and conflict, to model competition between regions. We drew a distinction between two types of competition: competition with full liability and with limited liability. With full liability regions invest before they know that the firm will settle, while the limited liability regions only invest if the firm actually settles. By their investment the regions attempt to increase the probability that the firm will settle in their region. The decision about how much to invest depends on the expected gains when the firm settles.

After having modelled the process of competition we investigated the consequences of competition between regions and drew some conclusions. First, we concluded that this kind of competition might lead to inefficiencies, resulting in a decrease in welfare. The reason for this in case of full liability is that the competing regions all invest but the firm chooses only one region in which to settle, that is the investments by all the regions is wasted. In case of limited liability the firm benefits from the regional investment and as such increases its profits. This kind of competition is less wasteful in comparison to the full liability case. If the number of

\footnotetext{
${ }^{166}$ An allocation of resources is efficient or Pareto optimal if there exist no alternative allocation that is unanimously preferred to the given allocation, see section 2.2.
} 
regions increases, the investments decrease because the probability of winning also decreases, as do the expected gains. In the full liability case, however, the amount of wasted investment increases with an increasing number of regions. In case of limited liability an increase in the number of competing regions will lead to an increase in the investments and subsidies offered. Furthermore, the possibility that the firm does not settle in the region where it can produce at minimum costs also increases as a result of the competition game.

Secondly, we came to the conclusion that competition cannot be avoided. If one region starts the competition, the other regions will have to follow. If they do not, then the probability that the firm will settle will decrease dramatically. Furthermore, it seems likely that in case of full liability firms will try to restrict competition to two regions, because that maximizes the firm's profits. In case of limited liability there is an incentive for the firm to involve as many regions as possible in the competition game because the more competing regions there are, the higher the amount of investments and subsidies on offer.

In general we can conclude from chapter 3 that policies to encourage regions and their governments to compete with other regions most probably will not lead to the expected efficiency gains. As such it is questionable whether such policies will have a positive effect on regional development. One may also doubt whether this competition increases the competitiveness of a region, for two reasons. First, firms can settle in regions with a lower comparative advantage and therefore become involved in a less efficient mode of production. Secondly, resources spent by local governments to attract firms just increase the firm's profit but they do not contribute to the long-run improvement of the region's competitiveness.

In chapter 4 we continued to analyze the effects of regional competition on welfare. The analyses of chapter 3 were extended by focusing specifically on the role of innovative firms. Innovative firms generate positive externalities which increase the competitiveness of a region and as a result have a positive effect on regional development. This was modelled using recent Endogenous Growth Theory, where innovations are endogenously determined. The firm's firm behaviour was modelled and we then looked at the consequences of externalities for regional development. These advantages are the incentive for regional politicians and policy makers to favour innovative firms. However, because of externalities, the process will have positive spill-over's on other competing regions, which will in all likelihood not be taken into account by the decision makers.

We adopted the same approach to modelling as in chapter 3 . However, we restricted the analyses to the full liability case and two competing regions. The incentive for regional politicians and policy makers is the positive effect of an innovative firm on the region, its competitiveness and economic development. Competition between regions to attract firms will be inefficient for the region and will only increase the firm's profits. If one region is offering a subsidy, i.e. starts competing, it is rational for all other regions to offer subsidies too. No region is better off at the end of the competition, because the probability of attracting 
firms remains the same for the competing regions. The difference from the previous chapter is that innovation leads to positive externalities, which means both of the two regions involved will benefit wherever the firm settles (although regional politicians and policy makers will not realize this). These externalities give regions the opportunity to resolve the coordination problem. If they agree not to compete then the settlement will have positive effects for both regions. If, furthermore, regions agree to share the benefits of the innovative firms, competition could be avoided. This thus creates an incentive for the regions not to compete.

Because firms' investments in innovation generate externalities, the level of the firms' investments in innovation is generally too low, because these externalities are not taken into account by the firms as they make their investment decisions. To internalize these externalities, firms could be financially supported to increase investment in innovation. In the last part of chapter 4 we looked into a situation in which a region tries to increase the amount of investment with the help of a subsidy. Thanks to asymmetric information this is not possible; the amount of investment will remain below the efficient level of investment. Because the returns on investment in innovation will decrease as total investment increases, the firm will invest up to the level of the overall return on capital. Additional financial resources will not be invested in innovation because alternative investments are more profitable. Granting financial support for investment in innovation in the form of by subsidies will only enhance the firms' profits, but not their investments in innovation.

\subsection{Economic Integration and Different Institutions}

In chapter 5 we focused on short-term cooperation and the integration of regions with different institutional settings. We analyzed the transition from two autarchic economies to one integrated economy where factors of production are mobile between regions, especially in the case of capital mobility. Furthermore, we assumed that the two regions differ regarding the institutional setting and arrangements. This means we have assumed different social standards embedded in the institutional setting. We used a Leontief production function with fixed technical coefficients to model the production side of the economy. Wage and capital incomes are determined by a bargaining process between labourers and capital owners. The institutional setting supplies the rules of the bargaining process. In our case it prevents the bargainers from investing resources to improve their bargaining position. On the other hand, it also determines the remuneration of labour and capital but not according the value of their marginal product.

The results are quite different from the standard economic (overlapping generations) models, where, under certain circumstances, an increase of the world's welfare is possible in the long run. In the standard model this is caused by the fact that capital is mobile and after 
integration it is used in the most productive way. If, however, remunerations are highly institutionally determined, integration will not lead to a movement of capital to where it is most productive, but to the region with the highest remuneration for that factor, which is determined by institutional setting and not its productivity. In the model used, this could result in the fact that the economy of the region where the remuneration of capital is lowest will cease to exist. This is the case if there are considerable differences in the income distribution of the two regions. To prevent this situation, the institutional setting will most probably have to change. The economy with the higher social standards (labour share in income) is compelled to reduce its standards and change its institutional setting in order to survive economically. This could result in a race to the bottom of social standards, so the workers will only receive their subsistence level of income or will vanish.

The opening of the capital market between regions in this model does not create a Pareto improvement, because at best the wage rates remain unchanged and the return on capital after integration lies between the returns on capital in autarchy. This means that the capital owners in the capital-poor region are harmed and the capital owners in the capital-rich region are better off. This case will only result if the over-accumulation of capital is sufficiently large. If this is not so, the region with the greater labour share will be harmed, in both the short and the long run. This is caused by the fact that integration will cause capital to flow to the other region. This leads to a reduction of capital goods and results in a decrease of production and therefore income in the region.

The only way to avoid these results is to change the institutional arrangements (in the labour market). This means that the government of the region with the higher labour share has to adjust its institutional setting in such a way that the labour share in income decreases so that the incentive to export capital to the other region will diminish. This will be a race to the bottom; however, this kind of policy also means that the inhabitants of this region will be harmed, because the long run steady state will be lower than in autarchy. In addition, if we assume that a high labour share reflects a high social standard in an economy, then this policy could result in a decrease of social standards.

In conclusion, we must emphasize that one must be very careful before recommending that capital markets be opened up, especially when factor markets are influenced by institutional arrangements. Related to the EU, it is questionable whether the EU should open its capital markets to countries where the employees have no rights and where human rights are ignored. It appears to be impossible to compete with countries like China or India, where child labour is available, employees are exploited and in general the labour share of income is low. To ignore the role of institutional settings and arrangements can have far-reaching consequences.

Additionally, it should be noted that we could substitute the Leontief production function without any problem by an AK production function, which is part of new growth 
theory. Such a model was introduced in chapter 6, where we assumed that the institutional setting has positive externalities for the economy as a whole and that it has some public good characteristics. Furthermore, we assumed that the local government can influence the institutional setting through public investments and public capital formation. The main results of chapter 5, however, re-cast in this framework, show that, due to externalities, integration can now lead to a Pareto improvement.

In chapter 6 we focused on regional economic development and the role of public capital. We assumed that institutional settings play a role in economic development. A beneficial institutional environment can have a positive effect on economic activity. In particular, it can prevent resources being used for non-productive applications such as rent seeking. Institutions, however, do not descend like manna from heaven. Societies invest in institutions, which are the architecture of the rules of the game. This can be called one of the intangible assets of a region. These intangible assets generate externalities and as such contribute positively to economic development. The analysis of the previous chapter was extended by adjusting the model to incorporate the abovementioned aspects. For the production side of the economy we used a Cobb-Douglas type of production function where factors of production are substitutable. Wage and return on capital are determined according to their marginal productivity. We assumed that there is a relation between institutional setting and public capital and investments. We have to take account of the fact that the more advanced an economy is (greater private capital stock), the more pressure there will be on institutional setting and public capital. We therefore took the ratio of public to private capital as an argument of the production function. Besides that, we also included the external effect of learning-by-doing by incorporating the capital intensity in the production function.

As noted, the differences in institutional setting can be quite substantial. To analyze the consequence for the process of integration we compared the autarchy situation with that of economic integration in terms of capital mobility. We assumed that regions differ in the productivity of 'public capital' due to differences in institutional setting. In such a situation factor mobility will not (automatically) lead to convergence between regions. However, on aggregate, economic development and growth will benefit from integration between different regions thanks to a more efficient use of resources. As a result the more productive regions benefit from integration and the other regions face a loss. The reason for this is that the return on capital also differs due to differences in productivity. After integration capital flows to the more productive region until returns on capital have converged. The more productive region has witnessed an increase in capital intensity, which results in positive external effects. The opposite effect occurs in the less productive region. That the returns on capital converge is caused by the fact that the productivity of public capital decreases if private capital increases. For the less productive regions the productivity of public capital increases if the private capital stock decreases because it flows to the more productive region. There is now less 
congestion in the less productive region. On aggregate, however, integration has positive effects due to the more efficient reallocation of capital. This is caused by the externality captured in the capital intensity. As a result, the more productive region is in favour of integrating economic activities and capital mobility, whereas the less productive region does not support this. In this situation, in which one of the parties does not want to co-operate, possible externalities cannot be realized through integration.

Subsequently, we have looked at how this hold-up situation might be resolved. In this case the more productive region will have to convince the other region to co-operate. Both regions will have to benefit from economic integration. Part of the gains for the more productive region could be used for redistribution to the less productive region. This is the incentive for that region to cooperate, and to choose in favour of economic integration. This compensation for the less productive region has to be at least as good as in the case of autarchy. In that case the region is indifferent and will cooperate. In this way integration leads to an improvement of overall welfare and each region has an incentive to cooperate. Apart from letting the market do the work, additional policies have to be formulated to make economic integration beneficial to both regions.

\subsection{Solving the Coordination Problem: Applying the Coase Theorem}

In chapter 7 , the previous chapter, we analyzed some of the coordination problems that emerge in case of externalities, especially those arising from chapters 4 and 6 . The main idea is that if regions could bargain about how to distribute aggregate benefits, such problems could be solved.

We started by revisiting the Coase theorem. As point of departure we took a gametheoretic setting following the model of Schweizer (1988). In addition to this model we assumed that contracts are incomplete and that renegotiations cannot be excluded. This opens the door to possible opportunistic behaviour. Normally, the legal system tries to prevent this kind of behaviour as far as possible. We showed that, depending on the distribution of property rights, agents behave opportunistically. A credibility problem appears in the case the agent who causes the externality is liable. This results in a hold-up situation; no property rights are traded ex-ante due to ex-post opportunistic behaviour. This in turn prevents an efficient solution from being reached by trading property rights. The other possibility is where the agent who causes the externality is not liable, and as a result there is no credibility problem. As a result an efficient allocation will be reached by trading property rights.

We continued with an investigation of whether a legal system is able to solve the credibility problem in the case where the agent who causes the externality is liable. A distinction was made between the Anglo Saxon (AS) and the Roman (R) legal system. In the 
AS system each of the agents has to pay for his own costs incurred during the lawsuit concerning conflicts of property rights. In case of the $\mathrm{R}$ system the losing agent has to pay all costs. We showed that the credibility problem cannot be solved in case of the Anglo Saxon legal system. The Roman system resolves the credibility problem due to the rule that the losing agent has to pay all costs. From this we were able to conclude the Roman legal system seems to be consistent with the intent of the Coase theorem rather than the Anglo Saxon one.

\subsection{Avenues for Further Research}

In answering the research questions we have used some common and some less common economic theories to model the possible behaviour of regions. The real world, of course, is much more complicated than the models used in this research suggest, which means that many items could not be fully addressed. Without pretending to be complete, the following observations on this thesis research could serve as an indicator to further research.

First, in line with our research approach, the analysis is highly stylized, assuming archetypical regions and simple decision-making processes. More detailed research could be done, based on case studies, into how regions actually compete and decide on competition. This could result in more information on whether or not our choice to use the economic theory of contest to describe the competition game is valid.

Secondly, there are clearly many policy instruments which can be used to improve regional development and the competitiveness of regions. This thesis has focused on one instrument only: attracting (innovative) firms by direct grants. Further research could be done into the use of other policy instruments for competition (and its effect on efficiency). Such an extension should involve the origins and possibilities for competitive use of regional institutional settings, in this research simply modelled as a comparative advantage or as public capital.

Thirdly, in this research economic integration has been reduced to free trade of goods/services and capital mobility. This does not do full justice to the complicated process of European economic integration. Labour mobility (relatively low but increasing in Europe) should be incorporated into our models for further analysis. Furthermore, in this research we have limited ourselves to production externalities and have disregarded all kinds of other externalities that play a part in a common market. In addition to that we have largely ignored insights from the new economic geography on firms' location behaviour (linkages, clustering).

Finally, in this research we have deliberately steered clear of the policy implications of our findings, especially the implications for the institutional and fiscal set-up of the European 
Union. In light of our findings, further research can be envisaged into the coordination capacity of the EU and the merits and demerits of EU regional policy. 



\section{Appendix 1}

The Contest Success Function 


\section{A.1.1 Introduction}

Below we describe and review the most important properties of the Contest Success Function (CSF) as it is used in the subsequent chapters of this research.

\section{A.1.2 Contests}

Konrad (2007 pp. 1) notes that competition in which goods or rents are allocated as a function of the various efforts expended by players in trying to win these goods or rents is a very common phenomenon. This competition is sometimes called contest or tournament. Some examples are; marketing litigation, relative award scheme's in internal labour market, beauty contests, influence activities, education filters, R\&D contest, and electoral competition in political markets, military conflicts and sports. A description and overview of a number of contest types and applications is provided in Konrad (2007) pp. 6-19. A somewhat more formal description of a contest can be found in Chorgon (2007), p. 3.

A contest is defined by the following elements;

- A finite set of agents, also called contenders or contestants, denoted by $N=\{1,2, \ldots, i, \ldots, n\}$

- A set of possible actions (effort, investment), $e_{i}$ taken by the agent before the prize is allocated, yielding in a vector of effort levels, $e_{i}, e_{-i}=\left\{e_{1}, e_{2}, ., e_{n}\right\}$. Here $e_{-i}=\sum_{k=1}^{n} e_{k}$ for $k \neq i$. These actions determine the probability of obtaining the prize of some size of B. They can be interpreted as the position taken by the agents before the contest starts.

- A prize, where valuation may be different for the competing agents, that is $v_{i}(B)$ as $i$ 's value of winning

- A function, relating the actions taken by agents in to the probabilities of obtaining the prize. This function is called 'Contest Success Function', (CSF). This is a functional relation between the vector of efforts and the probabilities for different agents or contestants winning the prize, $\operatorname{Pr}_{i}=\operatorname{Pr}_{i}\left(e_{i}, e_{-i}\right)$

- A function that for each possible action yields the cost of this action. This is called the cost function, that is $C_{i}\left(e_{i}\right)$ and $\frac{\partial C_{i}\left(e_{i}\right)}{\partial e_{i}}>0$ and $\frac{\partial^{2} C_{i}\left(e_{i}\right)}{\partial e_{i}^{2}} \geq 0$. Most of the time it is assumed that the costs of effort are linear, that is $C\left(e_{i}\right)=e_{i}$ where and $\frac{\partial C_{i}\left(e_{i}\right)}{\partial e_{i}}=1$ and $\frac{\partial^{2} C_{i}\left(e_{i}\right)}{\partial e_{i}^{2}}=0$ 
- A set of possible payoff functions that relates the expected benefits consisting of the valuation of the price times the probability of winning the prize minus the cost, of effort choice of agents (contestants), which equals $E\left(P O_{i}\right)=\operatorname{Pr}_{i}\left(e_{i}, e_{-i}\right) v_{i}(B)-C\left(e_{i}\right)$ or $E\left(P O_{i}\right)=\operatorname{Pr}_{i}\left(e_{i}, e_{-i}\right)\left[v_{i}(B)-C\left(e_{i}\right)\right]$.

Rai and Sarin (2009) note on page 3 that; 'a contest is a non co-operative game between multiple agents'. Agents make irreversible investments, which can be effort, money, or any other valuable resource depending on the context, to increase their probability of winning the contest and obtaining a private price.

\section{A.1.3 Contest Success Function}

The key element of models of contest is the CSF. It relates the investment made by all contesting agents with the winning probabilities of the contesting agents. Skaperdas (1996) was the first one who axiomized two frequently used types of CSF's, namely one in which the winning probability depends on the ratio of player's investment where the winning probability depends on the difference in investments. Each agent has a single type of investment and agents with equal investment have equal winning probability. Clark and Riis (1998) extended the axiomization of Skaperdas for contesting agents who differ in relevant personal contesting characteristics. This is what they call an unfair contest compared to the fair contest of Skaperdas, where contestants have the same characteristics. In the latter case winning probabilities do not only depend on agents investments but also on agents contesting characteristics. Rai and Sarin (2009) generalized the aximization of CSF for allowing having multiple types of investments. The winning probability does not only depend on investment and characteristic of the contesting agents but on the types of investments made by the contesting agents. The effective investment determines the winning probability. Agents combine their technology and various actual investments to produce effective investments, which in turn determine the winning probability. The technology can be different for the contesting agents. This is actually the type of CSF function we use successively in our research.

\section{A.1.4 Types of Contest Success Functions}

Below we shortly describe the two most common used CSF. A widely used form of contest success function is the following additive form. For $n$ contestants this results in; 


$$
\operatorname{Pr}_{i}\left(e_{i}, e_{-i}\right)=\left\{\begin{array}{l}
\frac{f\left(e_{i}\right)}{f\left(e_{1}\right)+f\left(e_{2}\right)+\ldots f\left(e_{i}\right)+\ldots f\left(e_{n}\right)}=\frac{f\left(e_{i}\right)}{\sum_{h=1}^{n} f\left(e_{h}\right)} \text { if } f\left(e_{1}\right)+, \ldots,+f\left(e_{n}\right)>0 \\
\frac{1}{n} \quad \text { otherwise }
\end{array}\right.
$$

where $\operatorname{Pr}_{i}\left(e_{i}, e\right)$ is the probability of contestant $i$ which depends on his own effort and effort of all other competing contestants. Here $f($.$) is a non negative and increasing function. The$ function $f\left(e_{i}\right)$ describes how effective the effort of agent $i$ is in determining the probability, where $e_{i}$ for $i=1, \ldots, n$ is the efforts level of contestant $i=1, \ldots, n$. It measures the impact of effort of contestant $i$ on the probability of contestant $i$ to win the contest. One can say that the functional form $f($.) is the technology available to the contestants to transform effort in probability. Next to that, $\frac{f\left(e_{i}\right)}{\sum^{n} f\left(e_{h}\right)}$ measures the relative effect effort of contestant $i$ on the

$$
\sum_{h=1}^{n} f\left(e_{h}\right)
$$

probability.

The two most common and applied type of contests success functions in Ratio form are the power or "Tullock" CSF and the difference form or logit CSF. Below we review the most important properties of the Contest Success Function in ratio form.

\section{A.1.5 The Power Ratio Form or "Tullock" Contest Success Function}

The most common used functional form is that of the power ratio form. Than the technology of contest results in $f\left(e_{i}\right)=e_{i}^{m}$ with $m>0$. The parameter $m$ reflects the effectiveness of technology of effort. For $0<m<1$, the technology exhibits decreasing returns to scale. In case $m=1$ there are constant returns to scale where as for $m>1$ there are increasing return to scale. This technology could be compared with a production function. In the additive form the Contest Success Function takes the following form

$$
\operatorname{Pr}_{i}\left(e_{i}, e_{-i}\right)=\frac{e_{i}^{m}}{\sum_{k}^{n} e_{k}{ }^{m}}=\frac{e_{i}^{m}}{e_{i}^{m}+e_{-i}^{m}}
$$

Here $e_{-i}=\sum_{k=1}^{n} e_{h}$ for $k \neq i$. In this case the probability of winning the contest by agent $i$ depends on the ratio of the effort level of contestant $i$ and the $n-1$ contesting parties, that is 
$e_{i} / e_{-i}$. This can easily be seen by reformulating the above probability as $\operatorname{Pr}_{i}\left(e_{1}, e_{-i}\right)=\frac{1}{1+\left(\frac{e_{-i}}{e_{i}}\right)^{m}}$.If it is a symmetric game, that is the contestants have the same characteristics all effort levels are identical thus $e_{i}=\hat{e}$ for $i=1, . ., n$. In case of "constant return" thus $m=1$ if there are two contestants the probability to win equals $\frac{1}{2}$. If there are $n$ contestants taking part of the game we have $e_{-i}=(n-1) \hat{e}$. The probability is the quotient of the number of contestants taking part of the contest, that is $\operatorname{Pr}_{i}\left(e_{i}, e_{-i}\right)=\frac{1}{1+n-1}=\frac{1}{n} \cdot{ }^{167}$

\section{A.1.6 The Logit or Difference Form of Contest Success Function}

The other well known functional form is that of the ratio form in difference form or the logit form. In this case we have the following function, $f\left(e_{i}\right)=\exp ^{k e_{i}}$, here $k$ is a parameter. The corresponding CSF in difference form is:

$$
\operatorname{Pr}_{i}\left(e_{i}, e_{-i}\right)=\frac{\exp ^{k e_{i}}}{\exp ^{k \sum_{h=1}^{n} e_{h}}}=\frac{\exp ^{k e_{i}}}{\exp ^{k e_{i}}+\exp ^{k e_{-i}}}=\frac{1}{1+\exp ^{k\left(e_{-i}-e_{i}\right)}}
$$

The probability to win the contest depends on the difference in effort level between the contestants involved in the competition game. In case of a two players' symmetric game $\left(e_{1}=e_{2}\right)$ we see that $\operatorname{Pr}_{1}\left(e_{1}, e_{2}\right)=\frac{1}{1+\exp ^{k\left(e_{2}-e_{1}\right)}}=\frac{1}{2}=\frac{1}{1+\exp ^{k\left(e_{1}-e_{2}\right)}}=\operatorname{Pr}_{2}\left(e_{1}, e_{2}\right)$. If there are $\mathrm{n}$ competitors in a symmetric game that is $e_{i}=\hat{e}$ for $i=1, \ldots, n$ and $e_{-i}=(n-1) \hat{e}$ this results in a probability of winning the game that equals $\operatorname{Pr}_{i}\left(e_{i}, e_{-i}\right)=\frac{1}{1+\exp ^{k\left(e_{-i}-e_{i}\right)}}=\frac{1}{1+\exp ^{k \hat{e}(n-2)}}$.

Note that difference form gives different results if there is large effort which differs by a small amount. For example in case of two players and the effort levels are successively $e_{1}=10001$ and $e_{1}=10002$. One would expect both competitors to have about equal

$$
{ }_{167}\left(\frac{e_{-i}}{e_{i}}\right)=\left(\frac{(n-1) \hat{e}}{\hat{e}}\right)=(n-1) \text { and so } \operatorname{Pr}_{i}\left(e_{1}, e_{-i}\right)=\frac{1}{1+\left(\frac{e_{-i}}{e_{i}}\right)}=\frac{1}{1+(n-1)}=\frac{1}{n}
$$


probabilities to win. This is not the case where we apply the difference form this results in $\operatorname{Pr}_{1}\left(e_{1}, e_{2}\right)=\frac{1}{1+\exp ^{(10002-10001)}}=\frac{1}{1+\exp }<\frac{1}{2}$.

\section{A.1.7 Axiom's of Contest Success Functions}

Below we show review in short the general accepted axiom's CSF must full fill where we follow Skaperdas (1996), Clark \& Riis (1998) and Rai \& Sarin (2007, 2009). The two above describes ratio form of contest success functions are the only one's that full fill these axioms.

\section{A1 Probability Axiom}

An important property of probabilities is that they sum up to unity, which is called the probability axiom that is:

$$
\sum \operatorname{Pr}_{i}\left(e_{i}, e_{-i}\right)=\frac{\sum f\left(e_{i}\right)}{f\left(e_{1}\right)+\ldots f\left(e_{n}\right)}=1
$$

As is obvious the probabilities of al contestant to win the game should ad up to one.

For the "Tullock" and the logit form Contest Success Function this equals:

$$
\sum \operatorname{Pr}_{i}\left(e_{i}, e_{-i}\right)=\frac{\sum e_{i}^{m}}{\sum e_{i}^{m}}=1 \text { and } \sum \operatorname{Pr}_{i}\left(e_{i}, e_{-i}\right)=\frac{\sum \exp ^{k e_{i}}}{\exp ^{k \sum e_{i}}}=\frac{\exp ^{k \sum e_{i}}}{\exp ^{k \sum e_{i}}}=1
$$

\section{A2/3 Axiom of Independence of Irrelevant Alternatives}

This axiom requires that the outcome of the contest is determined by the amount of effort invested by the contesting parties, but not by the amount of effort invested by a third party not participating in the contest. This is called the Independence or Irrelevant Alternatives property. Formally this is written as:

$$
\operatorname{Pr}_{i}\left(e_{i}, e_{-h}\right)=\frac{\operatorname{Pr}_{i}\left(e_{i}, e\right)}{1-\operatorname{Pr}_{h}\left(e_{h}, e\right)}
$$

Suppose there are $n$ players than the probability that player $i$ wins if player $h$ does not participate in the game $\left(e_{h}=0\right)$ is equal to the probability that player $i$ wins the game given that player $h$ does not win the game. Note that the probability that $h$ wins the game equals 1 
minus that player $h$ does not win the game, that is $\left(1-\operatorname{Pr}_{h}\left(e_{h}, e_{-i}\right)\right)$. Taken this into account it is easy to show that Axiom 3 holds ${ }^{168}$. For both types of contest success functions the Axiom holds. In this axiom Clark and Riis (1998) combined the axioms of consistency and independency of Skaperdas (1996).

\section{A4 Axiom of Marginal Effect}

If contestant $i$ increases his effort level the probability to win the game increases and the probability to win the game decreases if any others players effort increases. This is called the Axiom of marginal effect. This can be seen by taking the derivative of the contest success function with respect to his own effort, $e_{i}$ and the effort level of competing players in the contest game. This results in:

$$
\frac{\partial \operatorname{Pr}_{1}\left(e_{i}, e_{-i}\right)}{\partial e_{i}}>0 \text { and } \frac{\partial \operatorname{Pr}_{i}\left(e_{i}, e_{-i}\right)}{\partial e_{j}}<0
$$

\section{The power form or "Tullock" CSF}

For the "Tullock type" the derivative of CSF with respect to contestant $i$ 's own effort this results in:

$$
\frac{\partial \operatorname{Pr}_{1}\left(e_{i}, e_{-i}\right)}{\partial e_{i}}=\frac{m e_{i}^{m-1}\left(e_{i}^{m}+e^{m}\right)-m e_{i}^{m-1} e^{m}}{\left(e_{i}^{m}+e^{m}\right)^{2}}=\frac{m e_{i}^{m-1} e^{m}}{\left(e_{i}^{m}+e^{m}\right)^{2}}>0 \quad i=1, \ldots, n
$$

The derivative with respect to other competitors equals:

$$
\begin{aligned}
& { }^{168} \operatorname{Pr}_{i}\left(e_{i}, e_{-h}\right)=\frac{f\left(e_{i}\right)}{f\left(e_{1}\right)+. .+f\left(e_{h-1}\right)+f\left(e_{h+1}\right)+, \ldots,+f\left(e_{n}\right)}, \text { which can be written as follows: } \\
& \frac{\operatorname{Pr}_{i}\left(e_{i}, e_{-i}\right)}{1-\operatorname{Pr}_{h}\left(e_{h}, e_{-i}\right)}=\frac{\frac{f\left(e_{i}\right)}{f\left(e_{1}\right)+, \ldots,+f\left(e_{n}\right)}}{1-\frac{f\left(e_{h}\right)}{f\left(e_{1}\right)+, \ldots,+f\left(e_{n}\right)}}=\frac{\frac{f\left(e_{i}\right)}{f\left(e_{1}\right)+, \ldots,+f\left(e_{n}\right)}}{\frac{f\left(e_{1}\right)+, \ldots,+f\left(e_{n}\right)}{f\left(e_{1}\right)+, \ldots,+f\left(e_{n}\right)}-\frac{f\left(e_{h}\right)}{f\left(e_{1}\right)+, \ldots,+f\left(e_{n}\right)}} \text { which reduces to: } \\
& \frac{f\left(e_{i}\right)}{\frac{f\left(e_{1}\right)+, \ldots,+f\left(e_{h-1}\right)+, \ldots,+f\left(e_{n}\right)}{f\left(e_{1}\right)+, \ldots,+f\left(e_{h+1}\right)+, \ldots,+f\left(e_{n}\right)}}=\frac{f\left(e_{i}\right)}{f\left(e_{1}\right)+, \ldots,+f\left(e_{h-1}\right)+f\left(e_{h+1}\right)+, \ldots,+f\left(e_{n}\right)}=\operatorname{Pr}_{i}\left(e_{i}, e_{-h}\right)
\end{aligned}
$$




$$
\frac{\partial \operatorname{Pr}_{i}\left(e_{i}, e_{-i}\right)}{\partial e_{j}}=\frac{-m e_{j}^{m-1} e_{i}^{m}}{\left(e_{i}^{m}+e_{-i}^{m}\right)^{2}}<0 \quad j=1, \ldots, n \text { and } j \neq i \text { (A1.8) }
$$

The second order condition equals ${ }^{169}$ :

$$
\frac{\partial \operatorname{Pr}_{i}^{2}\left(e_{i}, e_{-i}\right)}{\partial e_{i}{ }^{2}}=\frac{m e_{i}^{m-2} e_{-i}{ }^{m}\left[(m-1) e_{-i}{ }^{m}-(m+1) e_{i}{ }^{m}\right]}{\left(e_{i}^{m}+e_{-i}{ }^{m}\right)^{3}}
$$

The sign of the second order condition depends on the sign between the square brackets which depends on the parameter $m$ and on the efforts levels $e_{i}{ }^{m}, e_{-i}{ }^{m}$. In case $0<m \leq 1$ we have $\left[(m-1) e_{-i}^{m}-(m+1) e_{i}^{m}\right]<0$ and thus:

$$
\frac{\partial \operatorname{Pr}_{i}^{2}\left(e_{i}, e_{-i}\right)}{\partial e_{i}^{2}}<0
$$

In case $m>1$ and the sign depends on whether $\left[(m+1) e_{i}{ }^{m}<(m-1) e_{-i}{ }^{m}<(m+1) e_{i}{ }^{m}\right]$ From this we can derive that:

$$
0<\frac{\partial \operatorname{Pr}_{i}^{2}\left(e_{i}, e_{-i}\right)}{\partial e_{i}^{2}}<0 \text { if }\left(\frac{(m-1)}{(m+1)}\right)^{1 / m}<\frac{e_{i}}{e_{-i}}<\left(\frac{(m-1)}{(m+1)}\right)^{1 / m}
$$

The sign depends on the ratio of the effort levels. For example if there are $n$ contestants in a contest ( that is $e_{i}=\hat{e}$ for $i=1, \ldots, n$ and $e_{-i}=(n-1) \hat{e}$ ) we have the following condition:

$$
\begin{aligned}
& { }_{169} \frac{\partial \operatorname{Pr}_{1}^{2}\left(e_{i}, e_{-1}\right)}{\partial e_{i}{ }^{2}}=\frac{(m-1) m e_{i}^{m-2} e_{-i}{ }^{m}\left(e_{i}^{m}+e_{-i}{ }^{m}\right)^{2}-2\left(e_{i}{ }^{m}+e_{-i}{ }^{m}\right) m e_{i}^{m-1} m e_{i}^{m-1} e_{-i}{ }^{m}}{\left(e_{i}{ }^{m}+e_{-i}{ }^{m}\right)^{4}}= \\
& \frac{(m-1) m e_{i}^{m-2} e_{-i}{ }^{m}\left(e_{i}{ }^{m}+e_{-i}{ }^{m}\right)-2 m e_{i}^{m-1} m e_{i}^{m-1} e_{-i}{ }^{m}}{\left(e_{i}{ }^{m}+e_{-i}{ }^{m}\right)^{3}} \text {. Reducing by the common factor we find: } \\
& \frac{m e_{i}^{m-2} e_{-i}{ }^{m}\left[(m-1)\left(e_{i}{ }^{m}+e_{-i}{ }^{m}\right)-2 m e_{i}{ }^{m}\right]}{\left(e_{i}{ }^{m}+e_{-i}{ }^{m}\right)^{3}}=\frac{m e_{i}^{m-2} e_{-i}{ }^{m}\left[m\left(e_{-i}{ }^{m}-e_{i}{ }^{m}\right)-\left(e_{-i}{ }^{m}+e_{i}{ }^{m}\right)\right]}{\left(e_{i}{ }^{m}+e_{-i}{ }^{m}\right)^{3}} \text {. This results in: } \\
& \frac{m e_{i}^{m-2} e_{-i}{ }^{m}\left[(m-1) e_{-i}{ }^{m}-(m+1) e_{i}^{m}\right]}{\left(e_{i}^{m}+e_{-i}{ }^{m}\right)^{3}} .
\end{aligned}
$$




$$
\left(\frac{(m-1)}{(m+1)}\right)^{1 / m}<\frac{1}{(n-1)}<\left(\frac{(m-1)}{(m+1)}\right)^{1 / m}
$$

If we take for example $m=1$ and two contestants, the ratio equals $0<1$.

We restrict to the case most common in economic that of decreasing and constant returns to scale. In that case for $0<m \leq 1$ we have:

$$
\frac{\partial \operatorname{Pr}_{i}^{2}\left(e_{i}, e_{-i}\right)}{\partial e_{i}^{2}}<0 \text { for } i=1, \ldots, n
$$

That means additionally that if effort level is increasing, the probability increases but at a decreasing rate.

\section{Difference form of CSF}

For the difference form of CSF we have the following derivatives;

$$
\frac{\partial \operatorname{Pr}_{i}\left(e_{i}, e_{-i}\right)}{\partial e_{i}}=\frac{k \exp ^{k\left(e_{-i}-e_{i}\right)}}{\left(1+\exp ^{k\left(e_{-i}-e_{i}\right)}\right)^{2}}>0
$$

and

$$
\frac{\partial \operatorname{Pr}_{i}\left(e_{i}, e_{-i}\right)}{\partial e_{j}}=-\frac{k \exp ^{k\left(e_{-i}-e_{i}\right)}}{\left(1+\exp ^{k\left(e_{-i}-e_{i}\right)}\right)^{2}}<0 \quad j=1, \ldots, n \text { and } j \neq i
$$

If there are two contestants in a symmetric contest, that is $e_{1}=e_{2}=\hat{e}$ than the derivative equals $\frac{\partial \operatorname{Pr}_{i}\left(e_{1}, e_{2}\right)}{\partial e_{i}}=\frac{k}{4}>0$ for $i=1,2$. If the number of contestants increases than, $e_{-i}-e_{i}=(n-2) \hat{e}>0$ and thus the probability also increases but at a decreasing rate as the number of contestants increases. If contestant $i$ increases its effort, the probability of winning the contest increases and on the other hand if contestant $j$ increases its effort level the probability of contestant $i$ to win the game decreases. The second derivative equals ${ }^{170}$ :

$$
\begin{aligned}
& \frac{\partial^{2} \operatorname{Pr}_{i}\left(e_{i}, e_{-i}\right)}{\partial e_{i}^{2}}=\frac{-k^{2} \exp ^{k\left(e_{-i}-e_{i}\right)}\left(1+\exp ^{k\left(e_{-i}-e_{i}\right)}\right)^{2}-\left\{2\left(1+\exp ^{k\left(e_{-i}-e_{i}\right)}\right)\left(-k \exp ^{k\left(e_{-i}-e_{i}\right)}\right)\right\}\left(k \exp ^{k\left(e_{-i}-e_{i}\right)}\right)}{\left(1+\exp ^{k\left(e_{-i}-e_{i}\right)}\right)^{4}}= \\
& \frac{-k^{2} \exp ^{k\left(e_{-i}-e_{i}\right)}\left(1+\exp ^{k\left(e_{-i}-e_{i}\right)}\right)+2 k^{2} \exp ^{k\left(e_{-i}-e_{i}\right)} \exp ^{k\left(e_{-i}-e_{i}\right)}}{\left(1+\exp ^{k\left(e_{-i}-e_{i}\right)}\right)^{3}}=
\end{aligned}
$$




$$
\frac{\partial^{2} \operatorname{Pr}_{i}\left(e_{i}, e_{-i}\right)}{\partial e_{i}^{2}}=\frac{k^{2} \exp ^{k\left(e_{-i}-e_{i}\right)}\left[\exp ^{k\left(e_{-i}-e_{i}\right)}-1\right]}{\left(1+\exp ^{k\left(e_{-i}-e_{i}\right)}\right)^{3}} \geq 0
$$

In case there are two contestants in a symmetric game than $e_{1}=e_{2}=\hat{e}$ and $\frac{\partial^{2} \operatorname{Pr}_{i}\left(e_{1}, e_{2}\right)}{\partial e_{i}^{2}}=0$ for $i=1,2$. In case there are more than 2 contestants and $e_{-i}-e_{i}=(n-2) \hat{e}>0$ than $\frac{\partial^{2} \operatorname{Pr}_{i}\left(e_{i}, e\right)}{\partial e_{i}^{2}}>0$ because the term between square brackets is positive.

\section{A5 Homogeneity Axiom}

An other important property is that the CSF function is homogeneous of the degree zero. If both contestants increase their effort (effective) level with the same factor, the probability to win remains unchanged.

This is an important property for contest where contestants can have multiple types of investment and effort levels.

$$
\operatorname{Pr}_{i}\left(\lambda e_{i}, \lambda e_{-i}\right)=\frac{f\left(\lambda e_{1}\right)}{f\left(\lambda e_{1}\right)+, \ldots,+\left(\lambda e_{n}\right)}=\frac{\lambda^{m} f\left(e_{i}^{m}\right)}{\lambda^{m} f\left(e_{1}^{m}\right)+, \ldots,+\lambda^{m} f\left(e_{n}^{m}\right)}=\frac{f\left(e_{i}^{m}\right)}{f\left(e_{1}^{m}\right)+, \ldots,+f\left(e_{n}^{m}\right)}=\operatorname{Pr}_{i}\left(e_{i}, e_{-i}\right)
$$

If all contestants increase their effort level by the same amount this does not lead to an increase in the probability to win the game. The increase of contestant I is just offset by the same increase of all other contestants

The power form or "Tullock" CSF function this can be easy observed because we have;

$$
\operatorname{Pr}_{i}\left(\lambda e_{i}, \lambda e_{-i}\right)=\frac{\left(\lambda e_{i}\right)^{m}}{\sum\left(\lambda e_{i}\right)^{m}}=\frac{\lambda^{m} e_{i}^{m}}{\lambda^{m}\left(e_{i}^{m}+e_{-i}^{m}\right)}=\frac{e_{i}^{m}}{\left(e_{i}^{m}+e_{-i}^{m}\right)}=\operatorname{Pr}_{i}\left(e_{i}, e_{-i}\right)
$$

$\frac{k^{2} \exp ^{k\left(e_{-i}-e_{i}\right)}\left(2 \exp ^{k\left(e_{-i}-e_{i}\right)}-\left(1+\exp ^{k\left(e_{-i}-e_{i}\right)}\right)\right.}{\left(1+\exp ^{k\left(e_{-i}-e_{i}\right)}\right)^{3}}$ which results finally in:

$\frac{\partial^{2} \operatorname{Pr}_{i}\left(e_{i}, e_{-i}\right)}{\partial e_{i}^{2}}=\frac{k^{2} \exp ^{k\left(e_{-i}-e_{i}\right)}\left(\exp ^{k\left(e_{-i}-e_{i}\right)}-1\right)}{\left(1+\exp ^{k\left(e_{-i}-e_{i}\right)}\right)^{3}}$ 
For the contest success function in difference form this axiom is not appropriate. It can be easily seen that homogeneous of the degree zero is not the case. Increasing effort by multiplying by $\lambda$ results in:

$$
\operatorname{Pr}_{i}\left(\lambda e_{i}, \lambda e_{-i}\right)=\frac{1}{1+\exp ^{k\left(\lambda e_{-i}-\lambda e_{i}\right)}}=\frac{1}{1+\exp ^{k \lambda\left(e_{-i}-e_{i}\right)}} \neq \operatorname{Pr}_{i}\left(e_{i}, e_{-i}\right)
$$

For this type of CSF an alternative axiom is formulated by Skaperdas (1996).

\section{A5, Constant Difference (of Effort)}

The difference between the efforts of the contestants determines the probability of winning the contest. If the effort level changes but the difference remains unchanged, the probability remains unchanged. In the above this means that:

$$
\operatorname{Pr}_{i}\left(e_{i}+c, e_{-i}+c\right)=\frac{1}{1+\exp ^{k\left(e_{-i}+c-e_{i}-c\right)}}=\operatorname{Pr}_{i}\left(e_{i}, e_{-i}\right)
$$

Both types of CSF are the only one's who satisfy the axiom's A1-A5/A5' In our research we have made use of the first type of CSF because the provided examples in the literature where the power function is used fits best our objective's. Below we will review one more aspect of the "Tullock" or power form CSF function which is important for our research.

\section{A.1.8 A-Symmetric Contests}

Before it is assumed that the characteristics and the types of the contestants is the same. As to say we considered symmetric game. Clark and Riis extended the axiomatic approach of Skaperdas by allowing for different types of players. Rai and Sarin not only for different characteristics of the contestants but also allowed for different types of investment in effort. Clark \& Riis and Rai \& Sarin prove that the five axioms also hold for the "Tullock" type of CSF for contestants with different characteristics and different types of investments. When the contestants have the same characteristic and investments this can be seen as a symmetric or fair game. When contestants have different characteristic and different levels of investment in effort, this can be seen as an a-symmetric or un-fair game. Rai \& Sarin therefore introduce the effective effort or investment level, which is determined by the characteristic of the different contestants, investments in effort level as a choice variable and fixed investment of the contestant which is not a choice variable. The relation between the characteristics of the contestant, the fixed investments and the investment in effort Rai and Sarin (2009) call 
"production function" of effective effort level. In case there is a linear relation we have the following "production function of effective effort"

$$
e_{i}=\theta_{i} \widetilde{e}_{i}+\mu_{i}
$$

Here $e_{i}$ is the effective effort level which is determined by the characteristics of individual contestants. This is expressed in the parameter $\theta_{i}>0$, which can differ between the contesting agents. The fixed investments of the contestant are expressed by the parameter $\mu_{i}>0$ which can also differ between contestants. The investment in effort by contestant that is $\tilde{e}_{i}$ is the choice variable. Rai \& Sarin prove that as long as all the production functions of the contestants is homogeneous of the same degree greater than zero, than only the "Tullock" form of contest success function satisfies the five axioms. Next to the linear function also other non linear functions can be used as shown by the authors. Because we want to model competition between regions who differ in characteristics this is a suitable approach. Using the effective effort level and substituting it in the previous CSF we find;

$$
\operatorname{Pr}_{i}\left(\widetilde{e}_{i}, \widetilde{e}_{-i}\right)=\frac{\left(\theta_{i} \widetilde{e}_{i}+\mu_{i}\right)^{m}}{\sum\left(\theta_{i} \widetilde{e}_{i}+\mu_{i}\right)^{m}}
$$

The parameter $\frac{\mu_{i}}{\sum \mu_{i}}$ can be interpreted as the prior winning probability of contestant $i$ (see Corchon (2000) and Rai \& Sarin (2009)). Thus the prior winning probability is where non of the contestants exert any effort or in other words, $\widetilde{e}_{i}=0$ for $i=1, \ldots, n$. Using this the probability becomes:

$$
\operatorname{Pr}_{i}(0,0)=\frac{\mu_{i}^{m}}{\sum \mu_{i}^{m}}
$$

The prior winning probability is thus influenced by the characteristic of the contestants. Note that compared to the previous situation where the characteristics of all contestant were the same and the probability was $\frac{1}{n}$ this need not be the case.

Of course the structure of the game is the same that also means that the structure of the solution is the same. Using this knowledge we can use the results of the symmetric game to 
find out the results in case of a-symmetric games. Replacing and inserting $e_{1}=\theta_{1} \widetilde{e}_{1}+\mu_{1}$ and $e_{2}=\theta_{2} \widetilde{e}_{2}+\mu_{2}$ gives us the reaction functions in case of a-symmetric contest games.

\section{A.1.9 Expected Pay-off in Participating in Contests}

In our research we make use of such a "Tullock" contest where we assume that technology of effort is linear that is it exhibits constant returns to scale therefore $m=1$. Next to that we assume that the cost function of effort is also linear which results in $C\left(e_{1}\right)=e_{1}$. Now we can formulate the expected pay off for the contestant is it takes part of the competition game. We also assume that the valuation of the price for all competitors is the same and constant, that is $v_{i}(B)=b$. The net pay off for the contestants in case of two players becomes;

$$
E\left(P O_{i}\right)=\operatorname{Pr}_{i}\left(e_{i}, e_{-i}\right) v_{i}(B)-C\left(e_{i}\right) \text { for } i=1,2
$$

and

$$
E\left(P O_{i}\right)=\operatorname{Pr}_{i}\left(e_{i}, e_{-i}\right)\left[v_{i}(B)-C\left(e_{i}\right)\right] \text { for } i=1,2
$$

For the "Tullock" CSF with linear cost of effort the competition game this reduces to:

$$
E\left(P O_{1}\right)=\frac{e_{1}}{e_{1}+e_{2}} b-e_{1} \text { and } E\left(P O_{2}\right)=\frac{e_{2}}{e_{1}+e_{2}} b-e_{2}
$$

and

$$
E\left(P O_{1}\right)=\frac{e_{1}}{e_{1}+e_{2}}\left[b-e_{1}\right] \text { and } E\left(P O_{2}\right)=\frac{e_{2}}{e_{1}+e_{2}}\left[b-e_{2}\right]
$$

The two players want to maximize expected pay off with respect to the invested effort. The first order condition for a maximum is respectively

$$
\begin{aligned}
& \frac{\partial E\left(P O_{i}\right)}{\partial e_{i}}=\frac{\partial \operatorname{Pr}_{i}\left(e_{i}, e_{-i}\right)}{\partial e_{i}} v_{i}(B)-\frac{\partial C\left(e_{i}\right)}{\partial e_{i}}=0 \text { and } \\
& \frac{\partial E\left(P O_{i}\right)}{\partial e_{i}}=\frac{\partial \operatorname{Pr}_{i}\left(e_{i}, e_{-i}\right)}{\partial e_{i}}\left[v_{i}(B)-C\left(e_{i}\right)\right]-\frac{\partial C\left(e_{i}\right)}{\partial e_{i}} \operatorname{Pr}_{i}\left(e_{i}, e_{-i}\right)=0
\end{aligned}
$$

For the "Tullock" CSF with linear cost of effort in a players game, the first order condition equals: 


$$
\frac{\partial E\left(P O_{1}\right)}{\partial e_{1}}=\frac{e_{2} b}{\left(e_{1}+e_{2}\right)^{2}}-1=0 \text { and } \frac{\partial E\left(P O_{2}\right)}{\partial e_{2}}=\frac{e_{1} b}{\left(e_{1}+e_{2}\right)^{2}}-1=0
$$

and $^{171}$

$$
\frac{\partial E\left(P O_{1}\right)}{\partial e_{1}}=\frac{-e_{1}^{2}-2 e_{1} e_{2}+e_{2} b}{\left(e_{1}+e_{2}\right)^{2}}=0 \text { and } \frac{\partial E\left(P O_{2}\right)}{\partial e_{2}}=\frac{-e_{2}^{2}-2 e_{1} e_{2}+e_{1} b}{\left(e_{1}+e_{2}\right)^{2}}=0
$$

The second order condition equals ${ }^{172}$;

$$
\frac{\partial E^{2}\left(P O_{1}\right)}{\partial e_{1}^{2}}=-\frac{2 e_{2} b}{\left(e_{1}+e_{2}\right)^{3}}<0 \text { and } \frac{\partial E^{2}\left(P O_{2}\right)}{\partial e_{2}^{2}}=-\frac{2 e_{1} b}{\left(e_{1}+e_{2}\right)^{3}}<0
$$

and $^{173}$

$$
\frac{\partial E^{2}\left(P O_{1}\right)}{\partial e_{1}^{2}}=-\frac{2 e_{2}\left(e_{2}+b\right)}{\left(e_{1}+e_{2}\right)^{3}}<0 \text { and } \frac{\partial E^{2}\left(P O_{1}\right)}{\partial e_{2}^{2}}=-\frac{2 e_{1}\left(e_{1}+b\right)}{\left(e_{1}+e_{2}\right)^{3}}<0
$$

\section{Nash equilibrium}

Because as well effort level, as the price of the contest are positive the second order is negative. That means there is an interior solution which results in a Nash equilibrium (see for example Nti (1997) pp 45-46, Corchon (2007) pp. 13-14, for a more general case of CSF functions), which is a maximum and symmetric. From the two first order condition we see that $e_{1}=e_{2}$ We can also use the two first order conditions to determine the reaction function of the two contesting players ${ }^{174}$.

${ }^{171}$ Differentiating (A1.21) results in $\frac{\partial E\left(P O_{1}\right)}{\partial e_{1}}=\frac{\left(b-e_{1}\right)\left(e_{1}+e_{2}\right)-e_{1}\left(e_{1}+e_{2}\right)-e_{1}\left(b-e_{1}\right)}{\left(e_{1}+e_{2}\right)^{2}}$. Setting this FOC equal to 0 and rearranging leads to (A1.21).

${ }^{172}$ Differentiating the first equation of (A1.21) results in: $\frac{\partial E^{2}\left(P O_{1}\right)}{\partial e_{1}^{2}}=\frac{\left(e_{1}+e_{2}\right)^{2}-2\left(e_{1}+e_{2}\right) e_{2} b}{\left(e_{1}+e_{2}\right)^{4}}$ which results in the first equation of (A1.22).

${ }^{173}$ Differentiating the second equation of (A1.21) results in:

$\frac{\partial E^{2}\left(P O_{1}\right)}{\partial e_{1}^{2}}=\frac{\left(-2 e_{1}-2 e_{2}\right)\left(e_{1}+e_{2}\right)^{2}-2\left(e_{1}+e_{2}\right)\left[-e^{2}-2 e_{1} e_{2}+e_{2} b\right]}{\left(e_{1}+e_{2}\right)^{4}}=$ $\frac{-2 e_{1}^{2}-2 e_{1} e_{2}-2 e_{1} e_{2}-2 e_{2}^{2}+2 e_{1}^{2}+4 e_{1} e_{2}-2 e_{2} b}{\left(e_{1}+e_{2}\right)^{3}}$, which results in the second equation of (A1.22).

${ }^{174}$ We assume positive effort levels, $e_{1}>0$ and $e_{2}>0$ which means the solutions $e_{1}=-e_{2}-\sqrt{e_{2} b}$ and $e_{2}=-e_{1}-\sqrt{e_{1} b}$ are not feasible. For the second reaction function we note that because $\left(e_{1}+e_{2}\right)^{2}>0$ we 


$$
e_{1}=-e_{2}+\sqrt{e_{2} b} \text { and } e_{2}=-e_{1}+\sqrt{e_{1} b}
$$

and

$$
e_{1}=-e_{2}+\sqrt{e_{2}\left(e_{2}+b\right)} \text { and } e_{2}=-e_{1}+\sqrt{e_{1}\left(e_{1}+b\right)}
$$

Using the two reaction function the Nash equilibrium can be shown graphically as is done below.

Figure A1.1 Contest Game $\quad E\left(P O_{i}\right)=\frac{e_{i}}{e_{1}+e_{2}} b-e_{i} i=1,2$

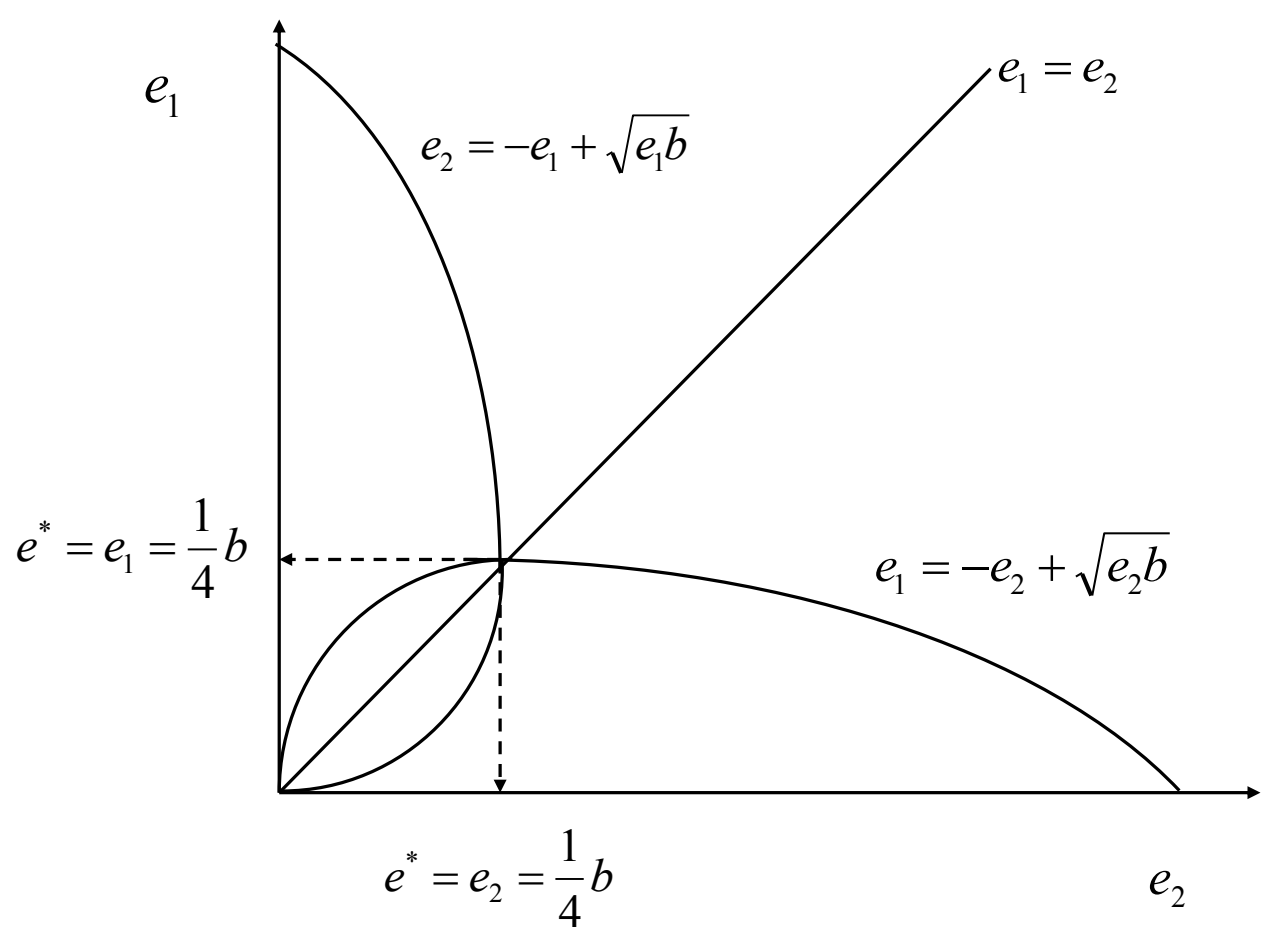

have $-e_{1}^{2}-2 e_{1} e_{2}+e_{2} b=0$ and $-e_{2}^{2}-2 e_{1} e_{2}+e_{1} b=0$. For the first equation fix $e_{2}$ and for the second fix $e_{2}$ both equations can be solved which results in the second equation of (A1.23). 
Figure A1.2 Contest Game $\quad E\left(P O_{i}\right)=\frac{e_{i}}{e_{1}+e_{2}}\left[b-e_{i}\right] i=1,2$

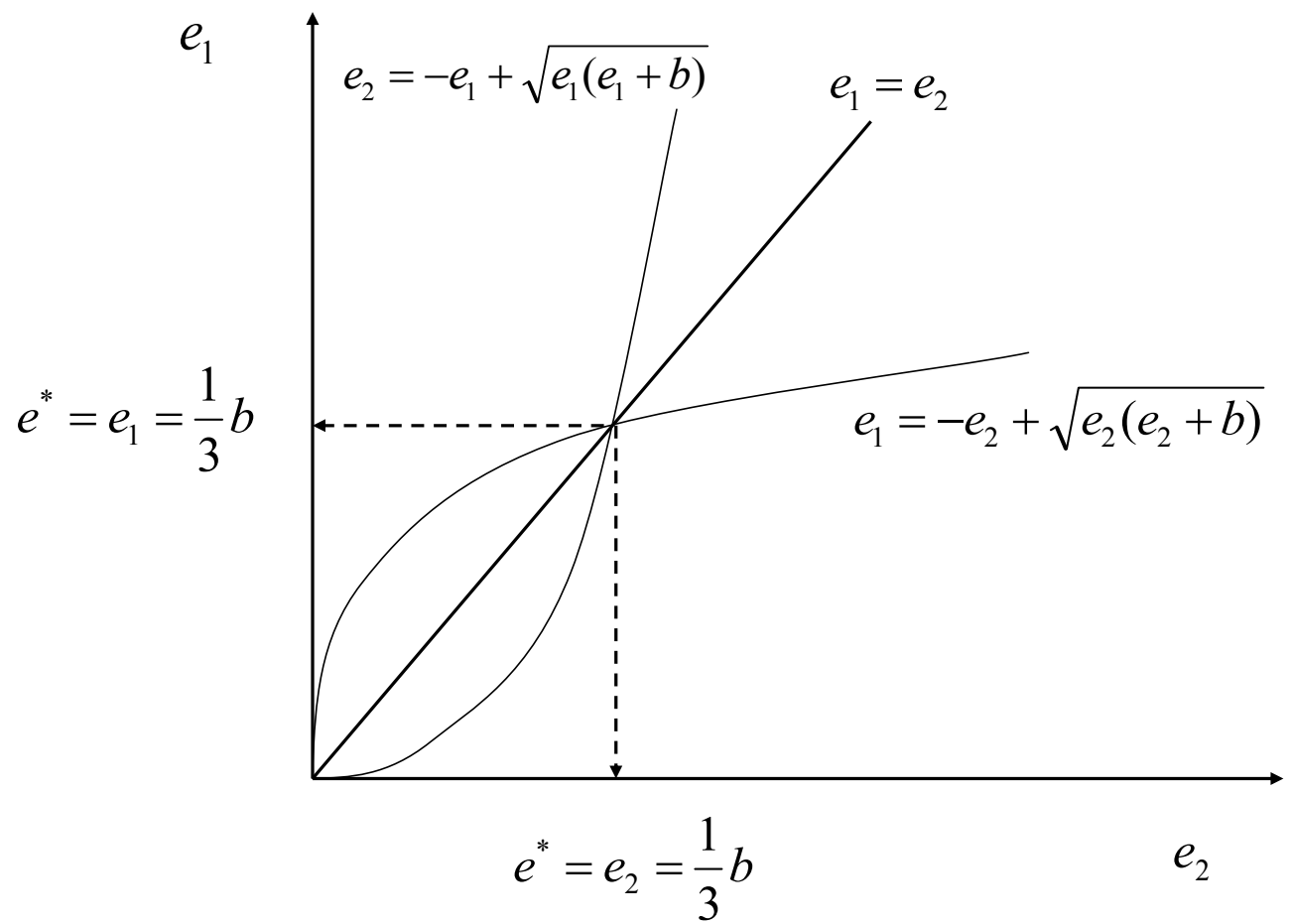

For $e_{1}=e_{2}=e$ from (A1.23) we have $2 e=\sqrt{e b}$ resulting in $e=\frac{1}{4} b$, and $2 e=\sqrt{e(e+b)}$ resulting in $e=\frac{1}{3} b$. The two Nash equilibriums are thus $e^{*}=\frac{1}{4} b$ and $e^{*}=\frac{1}{3} b$.

The above describe contests is a symmetric contest where all contesting agents are the same. Evidently the outcome in terms of effort is also the same. As should be obvious the probability of winning the game is also the same that is each contestant has a probability of $50 \%$ winning the game. Just inserting $e_{1}=e_{2}$ in the CSF function this can be seen. Note that this is also the probability of winning the game when contestants do not invest in effort to win the game.

To see whether the participants of the game benefit we look at the expected pay off. For two contestants they are respectively ${ }^{175}$;

${ }^{175}$ Inserting the optimal effort $e^{*}=\frac{1}{4} b=e_{1}^{*}=e_{2}^{*}$ level in the expected pay off results in $E\left(P O_{1}\right)=\frac{1}{2} b-\frac{1}{4} b$ and $E\left(P O_{2}\right)=\frac{1}{2} b-\frac{1}{4} b$. 


$$
E\left(P O_{1}^{*}\right)=\frac{1}{4} b \text { and } E\left(P O_{2}^{*}\right)=\frac{1}{4} b
$$

Compared with not participating in the game both contestants will loose in term of net expected pay-off. Not participating in the game means that the level of effort is zero or the two agents. The expected pay of in this case equals for the two agent $E\left(P O_{1}\right)=\frac{1}{2} b$ and $E\left(P O_{2}\right)=\frac{1}{2} b$. This is however not a stable equilibrium. If one of the contestants starts the game the other has to follow. A small increase in effort of one of the two contestants will increase the net expected pay off (first derivative) be decrease the net expected pay off of the other contestant. There fore the other agent will increase its effort level to. This until the new Nash equilibrium is reached.

\section{A-Symmetric Contests}

Before we considered a symmetric game. This game can easily be transferred in a asymmetric contest game. Using this knowledge we can use the results of the symmetric game to find out the results in case of a-symmetric games. Replacing and inserting $e_{1}=\theta_{1} \widetilde{e}_{1}+\mu_{1}$ and $e_{2}=\theta_{2} \widetilde{e}_{2}+\mu_{2}$ gives us the reaction functions in case of a-symmetric contest games ${ }^{176}$

$$
\widetilde{e}_{1}=-\frac{1}{\theta_{1}}\left[\theta_{2} \widetilde{e}_{2}+\left(\mu_{1}+\mu_{2}\right)\right]+\frac{1}{\theta_{1}} \sqrt{\left(\theta_{2} \widetilde{e}_{2}+\mu_{2}\right) b}
$$

and

$$
\widetilde{e}_{2}=-\frac{1}{\theta_{2}}\left[\theta_{1} \widetilde{e}_{1}+\left(\mu_{1}+\mu_{2}\right)\right]+\frac{1}{\theta_{2}} \sqrt{\left(\theta_{1} \widetilde{e}_{1}+\mu_{1}\right) b}
$$

As in case of a symmetric game this also leads to an interior solution and a Nash equilibrium. Using the previous results easily gives us the solution in the a-symmetric case where the contestants have different characteristic;

$$
e_{1}=\theta_{1} \widetilde{e}_{1}+\mu_{1}=\frac{1}{4} b \quad \widetilde{e}_{1}=\frac{1}{\theta_{1}}\left(\frac{1}{4} b-\mu_{1}\right)
$$

and

$$
e_{2}=\theta_{2} \widetilde{e}_{2}+\mu_{2}=\frac{1}{4} b \quad \widetilde{e}_{2}=\frac{1}{\theta_{2}}\left(\frac{1}{4} b-\mu_{2}\right)
$$

${ }^{176}$ This leads to $\left(\theta_{1} \widetilde{e}_{1}+\mu_{1}\right)=-\left(\theta_{2} \widetilde{e}_{2}+\mu_{2}\right)+\sqrt{\left(\theta_{2} \widetilde{e}_{2}+\mu_{2}\right) b}$ 
Where as in the symmetric case the effort level is always positive this need not be the case with a-symmetric contests. Note also the invested effort levels differ due to the difference in characteristic. Despite the difference in effort level the effective effort level is the same and so the probability to win the game. Where in case of symmetric contestant the probability to win the game remains the same this is not the case with differences in characteristic of the contestants. We can show that by setting the effort level equal to zero $\left(\widetilde{e}_{1}=\widetilde{e}_{2}=0\right)$ and substituting this in the CSF function. Then we find the following probabilities of the contestants;

$$
\operatorname{Pr}_{1}\left(e_{1}=0, e_{2}=0\right)=\frac{\mu_{1}}{\mu_{1}+\mu_{2}}>\frac{\mu_{2}}{\mu_{1}+\mu_{2}}=\operatorname{Pr}_{2}\left(e_{1}=0, e_{2}=0\right) \text { if } \mu_{1}>\mu_{2}
$$

In case both contestants invest in effort than this results in a probability of $50 \%$ because;

$$
\operatorname{Pr}_{1}\left(e_{1}=e, e_{2}=e\right)=\frac{e}{2 e}=\operatorname{Pr}_{2}\left(e_{1}=e, e_{2}=e\right)=\frac{1}{2}
$$

Where before the contest the contestant with the most favourable characteristics also had the highest probability to win the price after participating in the contest both contestant have an equal probability to win the contest. Apparently the comparatively unfavourable characteristics $\left(\mu_{2}<\mu_{1}\right)$ can be compensated by additional effort of the agent $\left(. \widetilde{e}_{2}>\widetilde{e}_{1}\right)$. 


\section{Appendix 2}

\section{Best Response Function, CSF,}

Full and Limited Liability 


\section{A.2.1 Regional Competition; the Full Liability Case}

Calculating the optimum effort level we use the first order condition (FOC) for the full liability case for $n$ competing regions.

\section{FOC $n$ regions}

The gains for a region attracting a firm equals $\Delta Y$. The effort level of the regions 1,2..n equals $e_{1}, e_{2}, \ldots . e_{n}$. Next to that the comparative advantage region $1,2 . ., n$ equals $\mu_{1}, \mu_{2}, \ldots . \mu_{n}$. Maximization of the expected pay off for region $i$ leads to the following optimization problem:

$$
\max _{e_{i}} L=\frac{e_{i}+\mu_{i}}{e_{i}+\mu_{i}+e_{-i}+\mu_{-i}} \Delta Y-e_{i} \quad i=1 . . n
$$

Where $-i$ equals all other $n-1$ competing regions except region $i$ and $e_{-i}+\mu_{-i}=\sum_{k}^{n}\left(e_{k}+\mu_{k}\right)$ for $k \neq i$. The First Order Condition region $i$ (For two regions substitute $i=1$ and $-i=2$ )

$$
\frac{\partial L}{\partial e_{i}}=\left\{\frac{e_{i}+\mu_{i}+e_{-i}+\mu_{-i}-\left(e_{i}+\mu_{i}\right)}{\left(e_{i}+\mu_{i}+e_{-i}+\mu_{-i}\right)^{2}}\right\} \Delta Y-1=0 \quad i=1 . . n
$$

\section{Best response function}

From the first order condition we can derive the best response functions. Reformulating leads to:

$$
\Delta Y\left(e_{-i}+\mu_{-i}\right)=\left(e_{i}+\mu_{i}+e_{-i}+\mu_{-i}\right)^{2}
$$

and

$$
\left(e_{i}+\mu_{i}+e_{-i}+\mu_{-i}\right)=+/-\sqrt{\Delta Y\left(e_{-i}+\mu_{-i}\right)}
$$

The resulting best response function:

$$
e_{i}+\mu_{i}=-e_{-i}-\mu_{-i}+\sqrt{\Delta Y\left(e_{-i}+\mu_{-i}\right)} \text { for all } i=1,2, \ldots . n
$$

\section{Optimum specific investment or effort level}

Next we can calculate the optimal effort levels. FOC $n$ regions result in $n$ equation with $n$ unknown variables, $e_{1}, e_{2}, \ldots, e_{n}$. 


$$
\begin{aligned}
& e_{2}+\mu_{2}+e_{3}+\mu_{3}+\ldots . e_{n}+\mu_{n}=\frac{1}{\Delta Y}\left(e_{1}+\mu_{1}+e_{2}+\mu_{2}+\ldots \ldots \ldots . . e_{n}+\mu_{n}\right)^{2} \\
& 2 \quad e_{1}+\mu_{1}+e_{3}+\mu_{3}+\ldots . e_{n}+\mu_{n}=\frac{1}{\Delta Y}\left(e_{1}+\mu_{1}+e_{2}+\mu_{2}+\ldots \ldots \ldots . . e_{n}+\mu_{n}\right)^{2}
\end{aligned}
$$$$
n-1 \quad e_{1}+\mu_{1}+e_{2}+\mu_{2}+\ldots . e_{n}+\mu_{n}=\frac{1}{\Delta Y}\left(e_{1}+\mu_{1}+e_{2}+\mu_{2}+\ldots \ldots \ldots . . e_{n}+\mu_{n}\right)^{2}
$$$$
n \quad e_{1}+\mu_{1}+e_{2}+\mu_{2}+\ldots . e_{n-1}+\mu_{n-1}=\frac{1}{\Delta Y}\left(e_{1}+\mu_{1}+e_{2}+\mu_{2}+\ldots \ldots \ldots . . e_{n}+\mu_{n}\right)^{2}
$$

Assuming comparative advantage of regions, that is: $u_{1}>u_{2}>\ldots u_{i}>u_{j} . .>u_{n}$,

Next subtracting equation 1 from 2 we get: $e_{1}+\mu_{1}-\left(e_{2}+\mu_{2}\right)=0$. For $n$ regions this results in $e_{1}+\mu_{1}=e_{2}+\mu_{2}=\ldots \ldots \ldots \ldots e_{i}+\mu_{i}=\ldots \ldots . . e_{n}+\mu_{n}=e_{i}+\mu_{i}$.

We can now derive the optimum investment / subsidy or effort level. The right-hand side of equation $1 . . n$ sums to $(n-1)\left(e_{i}+\mu_{i}\right)$ and the left-hand side of equation $1 . . \mathrm{n}$ sums to $(n-1) \frac{1}{\Delta Y}\left(e_{i}+\mu_{i}\right)^{2}$. This results in an optimum investment / subsidy or effort level of

$$
(n-1)\left(e_{i}+\mu_{i}\right) \Delta Y=\left[n\left(e_{i}+\mu_{i}\right)\right]^{2}
$$

The optimum effort level becomes;

$$
e_{i}^{*}=\frac{(n-1)}{n^{2}} \Delta Y-u_{i}
$$

\section{A.2.2 Regional Competition; the Limited Liability Case}

Calculating the optimum effort level we use the first order condition (FOC) for the limited liability case for $n$ competing regions.

\section{$N$ competing regions limited liability}

Gains from attracting firms to region $i$ equal $\Delta Y$ and specific investment or effort level of region $i$ equals $e_{i}$. Maximization the expected pay off for region $i$ than results in the following optimazation problem. 


$$
\max _{e_{i}} L=\frac{e_{i}+\mu_{i}}{e_{i}+\mu_{i}+e_{-i}+\mu_{-1}}\left(\Delta Y-e_{i}\right)
$$

$-i=$ all other $n-1$ competing regions except region $i$ and $\quad e_{-i}+\mu_{-i}=\sum_{k}^{n}\left(e_{k}+\mu_{k}\right)$ for $k \neq i$ The first order condition for regions $i=1 \ldots n$ is:

$$
\frac{\partial L}{\partial e_{i}}=\frac{\left\{\left(\Delta Y-e_{i}\right)-\left(e_{i}+\mu_{1}\right)\right\} \times\left\{e_{i}+\mu_{i}+e_{-i}+\mu_{-i}\right\}-\left(e_{i}+\mu_{i}\right)\left(\Delta Y-e_{i}\right)}{\left(e_{i}+\mu_{i}+e_{-i}+\mu_{-i}\right)^{2}}=0
$$

Because $\left(e_{i}+\mu_{i}+e_{-i}+\mu_{-i}\right)>0$ we have the following:

$$
\left\{\left(\Delta Y-e_{i}\right)-\left(e_{i}+\mu_{i}\right)\right\} \times\left\{e_{i}+\mu_{i}+e_{-i}+\mu_{-i}\right\}-\left(e_{i}+\mu_{i}\right)\left(\Delta Y-e_{i}\right)=0
$$

From rearranging this expression we get:

$$
\begin{aligned}
& \left(\Delta Y-e_{i}\right)\left(e_{i}+\mu_{i}\right)+\left(\Delta Y-e_{i}\right)\left(e_{-i}+\mu_{-i}\right)-\left(e_{i}+\mu_{i}\right)^{2}-\left(e_{i}+\mu_{i}\right)\left(e_{-i}+\mu_{-i}\right)-\left(\Delta Y-e_{i}\right)\left(e_{i}+\mu_{i}\right) \Rightarrow \\
& \left(\Delta Y-e_{i}\right)\left(e_{-i}+\mu_{-i}\right)-\left(e_{i}+\mu_{i}\right)^{2}-\left(e_{i}+\mu_{i}\right)\left(e_{-i}+\mu_{-i}\right) \\
& \left(\Delta Y+\mu_{i}-e_{i}-\mu_{i}\right)\left(e_{-i}+\mu_{-i}\right)-\left(e_{i}+\mu_{i}\right)^{2}-\left(e_{i}+\mu_{i}\right)\left(e_{-i}+\mu_{-i}\right) \\
& \left(\Delta Y+\mu_{i}\right)\left(e_{-i}+\mu_{-i}\right)-\left(e_{i}+\mu_{i}\right)\left(e_{-i}+\mu_{-i}\right)-\left(e_{i}+\mu_{i}\right)^{2}-\left(e_{i}+\mu_{i}\right)\left(e_{-i}+\mu_{-i}\right)
\end{aligned}
$$

which results in:

$$
\left(e_{i}+\mu_{i}\right)^{2}-2\left(e_{i}+\mu_{i}\right)\left(e_{-i}+\mu_{-i}\right)+\left(e_{-i}+\mu_{-i}\right)\left(\Delta Y+\mu_{i}\right)=0
$$

If we start with identical regions with the same comparative advantage then $\mu_{1}=\mu_{2}=\ldots . .=\mu_{n}=\mu$, we can derive a best response function for region $i$.

Note that for region $i$ the optimum effort of all other regions and the surplus are given, i.e., $\left(e_{-i}+\mu_{-i}\right)\left(\Delta Y+\mu_{i}\right)$ and $\left(e_{-i}+\mu_{-i}\right)$. Note too that if regions are equal the outcome of the optimum effort should also be the same. From equation (A2.13) we have:

$$
e_{i}+\mu_{i}=-\left(e_{-i}+\mu_{-i}\right)+\sqrt{\left(e_{-i}+\mu_{-i}\right)^{2}+\left(e_{-i}+\mu_{-i}\right)\left(\Delta Y+\mu_{i}\right)}
$$

Finally the best response function for region $i$ results in: 


$$
e_{i}+\mu_{i}=-\left(e_{-i}+\mu_{-i}\right)+\sqrt{\left(e_{-i}+\mu_{-i}\right)\left(e_{-i}+\mu_{-i}+\Delta Y+\mu_{i}\right)}
$$

Now we turn to the optimum effort level in case of $n$ competing regions. Using the FOC (3C.3) and the fact that $\left(e_{1}+\mu_{1}\right)=\ldots \ldots=\left(e_{n}+\mu_{n}\right)$ and knowing that $-i$ equals $n-1$ competing regions $\left\{e_{i}+\mu_{i}+e_{-i}+\mu_{-i}\right\}=n\left(e_{i}+\mu_{i}\right)$

$$
\begin{aligned}
& \left\{\left(\Delta Y-e_{i}\right)-\left(e_{i}+\mu_{i}\right)\right\} \times n\left(e_{i}+\mu_{i}\right)-\left(e_{i}+\mu_{i}\right)\left(\Delta Y-e_{i}\right)=0 \\
& n\left(e_{i}+\mu_{i}\right)^{2}-(n-1)\left(e_{i}+\mu_{i}\right)\left(\Delta Y-e_{i}\right)=0 \\
& n\left(e_{i}+\mu_{i}\right)=(n-1)\left(\Delta Y-e_{i}\right) \\
& (n+n-1) e_{i}=(n-1) \Delta Y-n \mu_{i}
\end{aligned}
$$

The optimum effort level becomes:

$$
e_{i}=\frac{(n-1) \Delta Y-n \mu}{2 n-1}
$$

This corresponds to equation (2.37) in the text. In case of two regions we can substitute $n=2$ and find the results in equation (2.28)

\section{A.2.3 Comparative Statics of the Limited Liability Case}

The two best response functions in case of limited liability are both function of endogenous variables $e_{1}$ and $e_{2}$ and exogenous variable $u_{1}$ and $u_{2}$. The implicit function theorem can be used to analyze the effect of a change of a exogenous variable on the endogenous variable. Recall the two First Order Conditions:

$$
\frac{\partial L}{\partial e_{1}}=\frac{\left(\Delta Y-e_{1}\right)}{e_{1}+\mu_{1}+e_{2}+\mu_{2}}-\frac{\left(\Delta Y-e_{1}\right)\left(e_{1}+\mu_{1}\right)}{\left(e_{1}+\mu_{1}+e_{2}+\mu_{2}\right)^{2}}-\frac{\left(e_{1}+\mu_{1}\right)}{e_{1}+\mu_{1}+e_{2}+\mu_{2}}=0
$$

and 


$$
\frac{\partial L}{\partial e_{2}} \frac{\left(\Delta Y-e_{2}\right)}{e_{1}+\mu_{1}+e_{2}+\mu_{2}}-\frac{\left(\Delta Y-e_{2}\right)\left(e_{2}+\mu_{2}\right)}{\left(e_{1}+\mu_{1}+e_{2}+\mu_{2}\right)^{2}}-\frac{\left(e_{2}+\mu_{2}\right)}{e_{1}+\mu_{1}+e_{2}+\mu_{2}}=0
$$

We now calculate de derivatives of the first and the second equation with respect to $u_{1}$.

After that we evaluate the equilibrium situation and calculate $\frac{\partial e_{1}}{\partial \mu_{1}}$ and $\frac{\partial e_{2}}{\partial \mu_{1}}$ :

$$
\begin{aligned}
& \frac{\partial^{2} L}{\partial e^{2}{ }_{1}{ }_{\substack{\mu_{1}=\mu_{2}=\mu \\
e_{1}=e_{2}=e}}}=-\frac{e+\Delta Y 2 \mu}{4(e+\mu)^{2}} \\
& \frac{\partial^{2} L}{\partial e_{1} \partial e_{2}} \underset{\substack{\mu_{1}=\mu_{2}=\mu \\
e_{1}=e_{2}=e}}{ }=\frac{1}{4(e+\mu)} \\
& \frac{\partial^{2} L}{\partial e_{1} \partial \mu_{1} \underset{\substack{\mu_{1}=\mu_{2}=\mu \\
e_{1}=e_{2}=e}}{ }}=\frac{\Delta Y+\mu}{4(e+\mu)^{2}}
\end{aligned}
$$

Doing the same for the second equation results in:

$$
\begin{aligned}
& \frac{\partial^{2} L}{\left.\partial e_{2}^{2}\right|_{\substack{\mu_{1}=\mu_{2}=\mu \\
e_{1}=e_{2}=e}}}=-\frac{e+\Delta Y+2 \mu}{4(e+\mu)^{2}}
\end{aligned}
$$

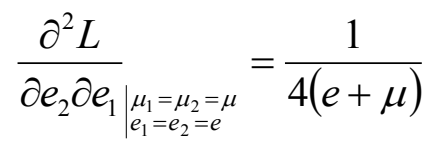

$$
\begin{aligned}
& \frac{\partial^{2} L}{\partial e_{2} \partial \mu_{1}} \underset{\substack{\mu_{1}=\mu_{2}=\mu \\
e_{1}=e_{2}=e}}{ }=\frac{1}{4(e+\mu)}
\end{aligned}
$$

Next we construct the matrices M, M' and M" in order to calculate the derivatives:

$$
M=\left\lfloor\begin{array}{c}
\frac{\partial^{2} L}{\partial e^{2}} \ldots \frac{\partial^{2} L}{\partial e_{1} \partial e_{2}} \\
\frac{\partial^{2} L}{\partial e_{2} \partial e_{1}} \ldots \frac{\partial^{2} L}{\partial e_{2}^{2}}
\end{array}\right\rfloor=\left\lfloor\begin{array}{c}
-\frac{e+\Delta Y+2 \mu}{4(e+\mu)^{2}} \ldots \frac{1}{4(e+\mu)} \\
\frac{1}{4(e+\mu)} \ldots-\frac{e+\Delta Y+2 \mu}{4(e+\mu)^{2}}
\end{array}\right\rfloor
$$




$$
\begin{aligned}
& M^{\prime}=\left\lfloor\begin{array}{l}
\frac{\partial^{2} L}{\partial e_{1} \partial \mu_{1}} \ldots \frac{\partial^{2} L}{\partial e_{1} \partial e_{2}} \\
\frac{\partial^{2} L}{\partial e_{2} \partial \mu_{1}} \ldots \frac{\partial^{2} L}{\partial e^{2}{ }_{2}}
\end{array}\right\rfloor=\left\lfloor\begin{array}{l}
\frac{\Delta Y+\mu}{4(e+\mu)^{2}} \ldots . \frac{1}{4(e+\mu)} \\
\frac{1}{4(e+\mu)} \ldots-\frac{e+\Delta Y+2 \mu}{4(e+\mu)^{2}}
\end{array}\right\rfloor \\
& M^{\prime \prime}=\left\lfloor\begin{array}{l}
\frac{\partial^{2} L}{\partial e^{2}} \ldots \cdot \frac{\partial^{2} L}{\partial e_{1} \partial \mu_{1}} \\
\frac{\partial^{2} L}{\partial e_{2} \partial e_{1}} \ldots \frac{\partial^{2} L}{\partial e_{2} \partial \mu_{1}}
\end{array}\right\rfloor=\left\lfloor\begin{array}{l}
-\frac{e+\Delta Y+2 \mu}{4(e+\mu)^{2}} \ldots \cdot \frac{\Delta Y+\mu}{4(e+\mu)^{2}} \\
\frac{1}{4(e+\mu)} \cdots \cdots \cdots \cdot \frac{1}{4(e+\mu)}
\end{array}\right\rfloor
\end{aligned}
$$

Calculate the determinant of the matrices:

$$
\begin{aligned}
& |M|=\frac{(\Delta Y+\mu)(2 e+\Delta Y+3 \mu)}{16(e+\mu)^{4}} \\
& \left|M^{\prime}\right|=\frac{\left(e \Delta Y-\mu G+\Delta Y^{2}+3 \Delta Y \mu+\mu^{2}-e^{2}\right)}{16(e+\mu)^{4}} \\
& \left|M^{\prime \prime}\right|=-\frac{1}{16(e+\mu)^{2}}
\end{aligned}
$$

Calculating, $\frac{\partial e_{1}}{\partial \mu_{1}}, \frac{\partial e_{2}}{\partial \mu_{1}}$ and substituting the equilibrium value $e=e^{*}=(\Delta Y-2 \mu) / 3$ we get:

$$
\begin{aligned}
& \frac{\partial e_{1}}{\partial \mu_{1 \mid e=e^{*}=(\Delta Y-2 \mu) / 3}}=-\frac{\left|M^{\prime}\right|}{|M|}=-\frac{\left(e \Delta Y-\mu e+\Delta Y^{2}+3 \Delta Y \mu+\mu^{2}-e^{2}\right)}{\left(Y_{m}+\mu\right)\left(2 G+Y_{m}+3 \mu\right)}=-\frac{11}{15}
\end{aligned}
$$

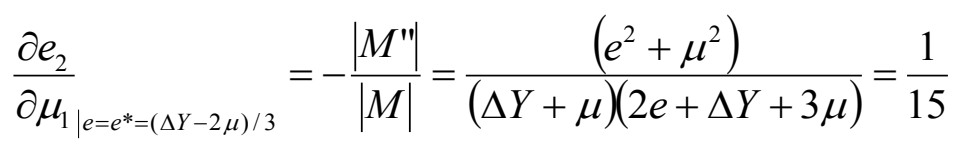





\section{Appendix 3}

Cobb-Douglas and Leontief

Production Function 


\section{A.3.1 Introduction}

In this appendix we briefly review the production functions that are used in this research. We start in section A.3.1 with the Neo Classical production function, the Cobb-Douglas production function (in section A3.2.) and the Leontief production function (in section A.3.4). In section A.3.3 and A.3.5 we consider the production function in the aggregate economy, and the development of the capital stock.

Because consumer behaviour is modelled in a two period overlapping generations (OLG) context we pay some attention to dynamic inefficiency (section A.3.6), both for a Cobb-Douglas production function and a Leontief production function.

We continue with externalities in a Cobb-Douglas Production function. First we consider the case of exogenous technological change (section A.3.7), as in neo classical growth theory. Subsequently we look at technological progress as an endogenous economic process by means of development of the overall capital intensity resulting (section A.3.8), as in the (new) endogenous growth theory. Finally the role of public capital as a productive source and its externalities are examined (section A.3.9).

\section{A.3.2 The Neo Classical Production Function}

An important property of the Neo Classical production function (of a representative firm $j$ ) is that it exhibits constant returns to scale with respect to the inputs labour and capital. The general formulation is as follows:

$$
Y_{j}=F\left(K_{j}, L_{j}\right)
$$

or in intensive form

$$
y_{j}=f\left(k_{j}\right) \text { with } y_{j}=Y_{j} / L_{j} \text { and } k_{j}=K_{j} / L_{j}
$$

Here $K_{j}$ represents the capital stock of the $j$-th firm, $L_{j}$ represents the number of workers of the $j$-th firm and $k_{t}=K_{t} / L_{t}$ is the capital labour ratio ${ }^{177}$. Another important property of the neo classical production function is that the marginal product of factors of production is both positive but decreasing. For the above production function this results in the following condition:

\footnotetext{
${ }^{177}$ Due to the fact that the production function exhibits constant returns to scale, the production function can be written in terms of capital per unit labour.
} 


$$
\begin{aligned}
& \frac{\partial F}{\partial K_{j}}>0, \frac{\partial^{2} F}{\partial K_{j}^{2}}<0 \text { for all } K_{j} \text { and } \frac{\partial F}{\partial L_{j}}>0, \frac{\partial^{2} F}{\partial L_{j}{ }^{2}}<0 \text { for all } L_{j} \text { and } \\
& \frac{\partial f}{\partial k_{j}}>0, \frac{\partial^{2} f}{\partial k_{j}{ }^{2}}<0 \text { for all } k_{j}
\end{aligned}
$$

The first derivative is positive and the second is negative. The marginal products of capital, labour and capital per unit labour are positive but decreasing, and

$$
\begin{aligned}
& \lim _{K_{j} \rightarrow \infty} \frac{\partial F}{\partial K_{j}}=0, \lim _{L_{j} \rightarrow \infty} \frac{\partial F}{\partial L_{j}}=0 \text { and } \lim _{k_{j} \rightarrow \infty} \frac{\partial f}{\partial k_{j}}=0 \text { and } \\
& \lim _{K_{j} \rightarrow 0} \frac{\partial F}{\partial K_{j}}=\infty, \lim _{L_{j} \rightarrow 0} \frac{\partial F}{\partial L_{j}}=\infty \text { and } \lim _{k_{j} \rightarrow 0} \frac{\partial f}{\partial k_{j}}=\infty
\end{aligned}
$$

The latter conditions are called the Inada condition.

Another important property of this production function is that it is homogeneous of degree 1 . That is $F\left(\lambda L_{j}, \lambda K_{j}\right)=\lambda F\left(L_{j}, K_{j}\right)$ which states that if all inputs are multiplied by the same factor $\lambda$ then output $F(.,$.$) is also multiplied by that same factor. In case \lambda=1$ the production function exhibits constant returns to scale. If the amount of capital and labour is doubled than output is also doubled. If only labour or capital is doubled, output will increase less than double. This is the result of positive but decreasing marginal product of production factors. In case we keep labour constant, that is $\bar{L}_{j}$, we come to the following figure below, where output depends on the input of capital. 
Figure A3.1 Production Function with decreasing Returns to Capital

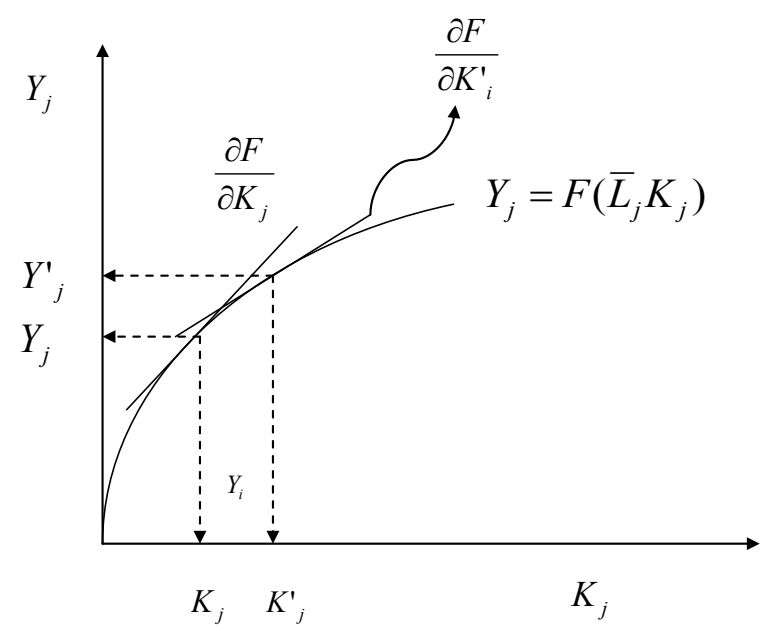

Figure A3.2 Production Function in intensive Form with decreasing Returns to Capital

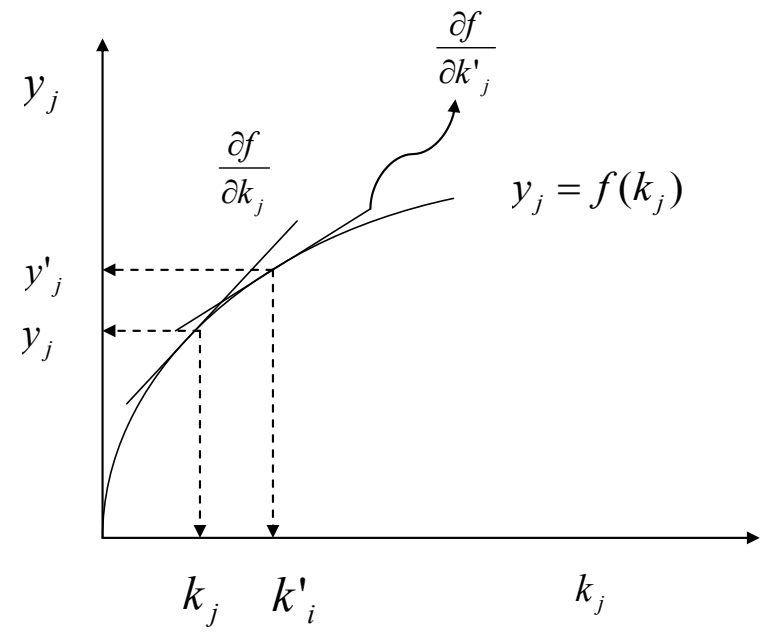


From the figure above we can see that output increases as the input of capital increases, but in a diminishing way. The shape of the production function equals $\frac{\partial F}{\partial K_{j}}$ which is the marginal product. As the amount of capital increases the marginal product of capital decreases, that is $\frac{\partial F}{\partial K^{\prime}{ }_{j}}<\frac{\partial F}{\partial K_{j}}$ as can be seen in the figure. For the intensive form production function we have a similar graph.

If the amount of capital per unit labour increases, output still increases but in a decreasing way $\left(\frac{\partial f}{\partial k_{j}^{\prime}}<\frac{\partial f}{\partial k_{j}}\right)$ thus the marginal product decreases $\left(\frac{\partial^{2} f}{\partial{k_{j}}^{2}}<0\right)$.

One more important property of homogeneous functions is Euler's theorem. Euler's theorem states that if $f(x)$ is a homogeneous function of the degree $\lambda$ then for all $x$ we have $x_{1} \frac{\partial f}{\partial x_{1}}+x_{2} \frac{\partial f}{\partial x_{2}}+\ldots \ldots .,+x_{n} \frac{\partial f}{\partial x_{n}}=\lambda f(x)$. Applying this to a homogeneous production function of degree 1 (that is $\lambda=1$ ) as in equation (A3.1) this results in:

$$
Y_{j}=K_{j} \frac{\partial F}{\partial K_{j}}+L_{j} \frac{\partial F}{\partial L_{j}} \text { or in intensive form } \quad y_{t}=k_{t} \frac{\partial F}{\partial K_{j}}+\frac{\partial F}{\partial L_{j}}
$$

If firms maximize their profit with respect to the inputs labour and capital this results in the wage rate and the return on capital. The profit function for the firm $i$ can be written as follows:

$$
\pi_{j}=Y_{j}-w_{j} L_{j}-R_{j} K_{j} \text { or in intensive form } \pi_{j}=L_{j} f\left(k_{t}\right)-w_{j} L_{j}-R_{j} K_{j}
$$

Here $\pi_{j}$ is the period profit of the $j$-th firm. If firms maximize profit with respect to the inputs, we find the wage rate and the return on capital, which equal the marginal product of labour and capital. The wage rate is denoted by $w_{i}$ and $R_{j}$ is the return on capital ${ }^{178}$. We find the following first order condition:

\footnotetext{
${ }^{178}$ We assume that capital is fully depreciated after use, the depreciation rate is $100 \%$. That means that $R_{j}=r_{j}+\delta$, where $r_{j}$ is the real interest rate and $\delta(=1)$ is the depreciation rate. Rhus $R_{j}=1+r_{j}$.
} 


$$
\frac{\partial \pi_{j}}{\partial L_{j}}=\frac{\partial F}{\partial L_{j}}-w_{j}=0 \text { or in intensive form }{ }^{179} \frac{\partial \pi_{j}}{\partial L_{j}}=f\left(k_{j}\right)-k_{j} \frac{\partial f}{\partial k_{j}}-w_{j}=0
$$

and

$$
\frac{\partial \pi_{j}}{\partial K_{j}}=\frac{\partial F}{\partial K_{j}}-R_{j}=0 \text { or in intensive form }{ }^{180} \frac{\partial \pi_{j}}{\partial K_{j}}=\frac{\partial f}{\partial k_{j}}-R_{j}=0
$$

From the two first order conditions above we can see that the wage rate equals the marginal product of labour. Furthermore it can bee seen that the marginal product of capital should be equal to the return on capital.

\section{A.3.3 Cobb-Douglas Production Function}

A widely used type of production function in economics is the Cobb-Douglas production function. In our research we have also made use of this type of production function. Therefore we pay attention on the most important features of this type of production function with respect to previous analyses. The Cobb-Douglas production function has the following structure:

$$
Y_{j}=L_{j}^{1-\alpha} K_{j}^{\alpha}
$$

or in intensive form

$$
y_{j}=k_{j}^{\alpha} \text { where } y_{j}=\frac{Y_{j}}{L_{j}} \text { and } k_{j}=\frac{K_{j}}{L_{j}}
$$

with $0<\alpha<1$. The marginal product of capital and labour are positive but decreasing and are respectively:

$$
\frac{\partial Y_{j}}{\partial K_{j}}=\alpha L_{j}^{1-\alpha} K_{j}^{\alpha-1}>0 \text { and } \frac{\partial^{2} Y_{j}}{\partial K_{j}^{2}}=-\alpha(1-\alpha) L_{j}^{1-\alpha} K_{j}^{\alpha-2}<0
$$

And

$$
\begin{aligned}
& { }_{179} \frac{\partial \pi_{j}}{\partial L_{j}}=f\left(k_{j}\right)-L_{j} \frac{\partial f}{\partial k_{j}} \frac{K_{j}}{L_{j}^{2}}-w_{j}=0 \text { which can also be written as } w_{j}=f\left(k_{j}\right)-k_{j} f^{\prime}\left(k_{j}\right) . \\
& 180 \frac{\partial \pi_{j}}{\partial K_{j}}=L_{j} \frac{\partial f}{\partial k_{j}} \frac{L_{j}}{L_{j}^{2}}-R_{j}=0 \text { or } R_{j}=\frac{\partial f}{\partial k_{j}}=f^{\prime}\left(k_{j}\right) .
\end{aligned}
$$




$$
\frac{\partial Y_{j}}{\partial L_{j}}=(1-\alpha) L_{j}^{-\alpha} K_{j}^{\alpha}>0 \text { and } \frac{\partial^{2} Y_{j}}{\partial L_{j}^{2}}=-\alpha(1-\alpha) L_{j}^{-1-\alpha} K_{j}^{\alpha}<0
$$

The return on capital and the wage rate are equal to the marginal product of capital and labour, so we have:

$$
R_{j}=\alpha L_{j}^{1-\alpha} K_{j}^{\alpha-1} \quad \text { or in intensive form } \quad R_{j}=\alpha k_{j}^{\alpha-1}
$$

and

$$
w_{j}=(1-\alpha) L_{j}^{-\alpha} K_{j}^{\alpha} \quad \text { or in intensive form } \quad w_{j}=(1-\alpha) k_{j}^{\alpha}
$$

The return on capital and the wage rate can also be expressed in the capital-labour ratio ${ }^{181}$. As before the aggregate production function for the economy as a whole has the same characteristic as for the individual firm. This also implicates that for the overall economy there is one wage rate and one rate of return on capital.

\section{A.3.4 Equilibrium Income and Capital Stock (Cobb-Douglas production function)}

To see how the economy evolves over time we can look at the development of labour and capital stock. Because we have assumed labour to be constant we can limit ourselves to the development of capital stock.

The equation of motion (i.e. the relation between current period's savings and next period's capital stock) actually connects the consumption side with the production side of the economy. Capital stock is an element in the production function which is generated by the consumption side by not consuming final goods:

$$
S_{t}=K_{t+1} \quad \text { or in intensive form } \quad s_{t}=k_{t+1}
$$

The savings results from consumer behaviour. Savings in the OLG model equals:

${ }^{181} w_{j}=f\left(k_{j}\right)-f^{\prime}\left(k_{j}\right) k_{j}=k^{\alpha}-\alpha k^{\alpha-1} k=(1-\alpha) k$ and $(1+r)=f^{\prime}\left(k_{j}\right)=\alpha k^{\alpha-1}$.

Income per unit labour equals the wage rate plus capital per unit of labour times return on capital.

$Y_{j}=w_{j} L_{j}+R_{j} K_{j}$, per unit labour we have $Y_{j} / L_{j}=y_{j}=w_{j}+R_{j} k_{j}$ where $k_{j}=K_{j} / L_{j}$ thus

$f\left(k_{j}\right)-f^{\prime}\left(k_{j}\right) k_{j}+f^{\prime}\left(k_{j}\right) k_{j}=f\left(k_{j}\right)$. In case of a Cobb Douglas production function this equals

$(1-\alpha) k_{j}^{\alpha}+\alpha k_{j}^{\alpha-1} k_{j}=k^{\alpha}=y$. 


$$
S_{t}=L_{t} S_{t}=\hat{s} L_{t} w_{t} \quad \text { or in intensive form } \quad s_{t}=\hat{s} w_{t}
$$

where $\hat{s}=\frac{1}{2+\rho}$. The labour share of income was found in equation (A3.9). If we substitute the wage rate in the above equation of savings we get the following equation of motion:

$$
K_{t+1}=\hat{s}(1-\alpha) L^{1-\alpha} K_{t}^{\alpha} \text { or in intensive forms } k_{t+1}=\hat{s}(1-\alpha) k_{t}^{\alpha 182}
$$

The equation of motion is a non-linear first order difference equation. The economy is in equilibrium if the output per unit labour and thus the capital-labour ratio does not change over time. This is the case if $k_{t+1}=k_{t}=k^{*}$. Inserting the equilibrium condition in the above equation results in the following equilibrium capital-labour ratio and the output per unit labour:

$$
k^{*}=[\hat{s}(1-\alpha)]^{1 /(1-\alpha)} \text { and } \quad y^{*}=f\left(k^{*}\right)=\left(k^{*}\right)^{\alpha}=[\hat{s}(1-\alpha)]^{\alpha /(1-\alpha)}
$$

From the above we conclude that the optimal capital-labour ratio depends on the saving rate and the share of wage income in total income. Similarly income per unit labour also depends on the saving rate and labour share of income, but also on the productivity parameter of capital that is $\alpha$. A graphical exposition is depicted in the figures A3.3 and A3.4 below

To check whether this solution is stable we have to determine the shape of the equation of motion and whether it meets the condition of stability (See for example Zhang (2007) pp. 87). In case of the first order difference equation this means that

${ }^{182}$ In case of population growth we have the following equation of motion $k_{t+1}=\frac{1}{(1+n)} \hat{s}(1-\alpha) k_{t}^{\alpha}$. Equilibrium capital stock equals $k^{*}=\left[\frac{1}{(1+n)} \hat{s}(1-\alpha)\right]^{1 /(1-\alpha)}$. 
Figure A3.3 Equilibrium Income and Capitals Stock with a Cobb Douglas Production Function

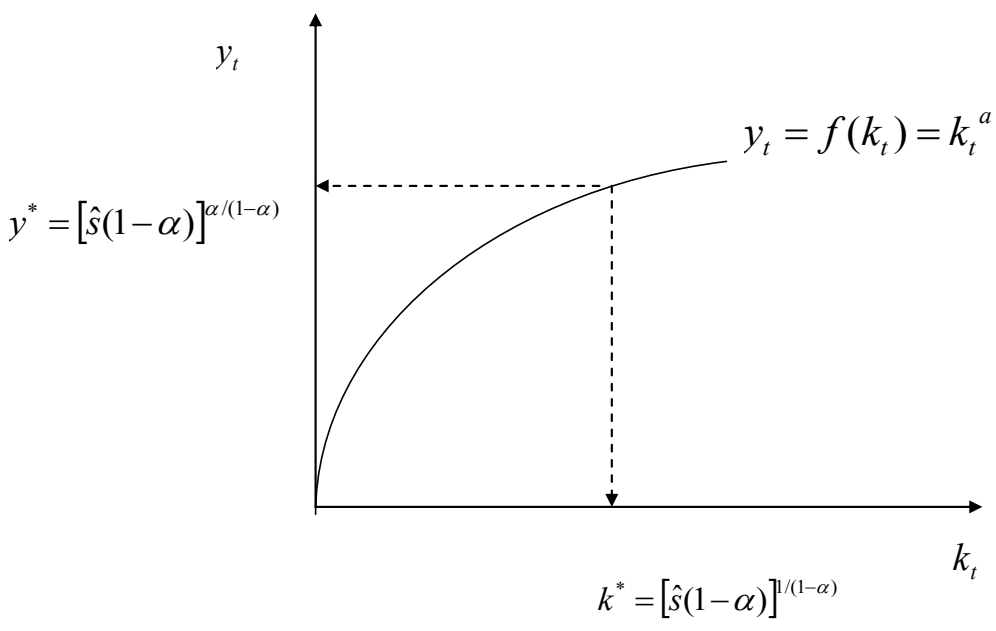

Figure A3.4 Equation of Motion and Optimal Capital Stock with a Cobb Douglas Production Function

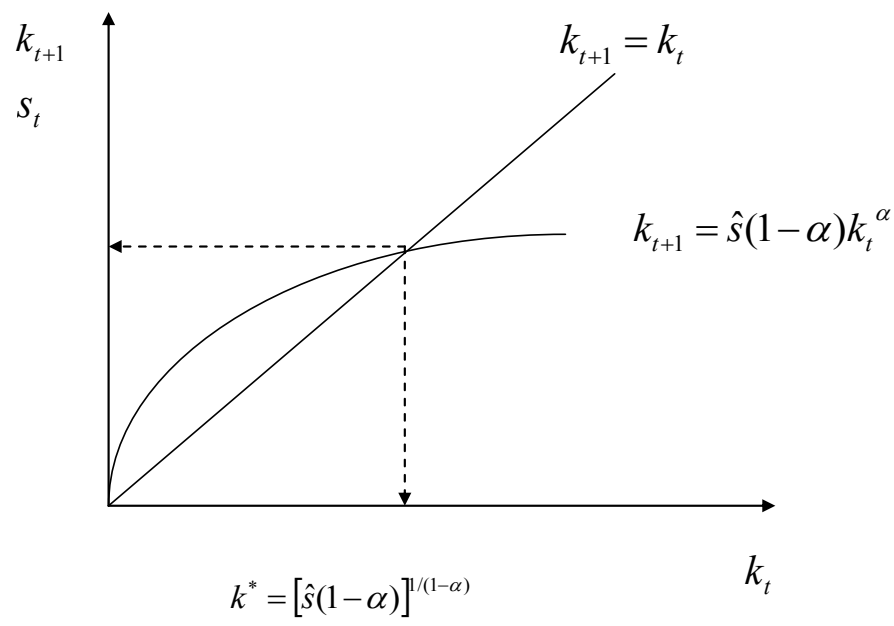


$-1<d k_{t+1} / d k_{t}<1$. Using this for equation (A3.12) we find that: $\frac{d k_{t+1}}{d k_{t}}=\hat{s} \alpha(1-\alpha) k_{t}^{\alpha-1}$. If we substitute the equilibrium value of the capitals stock we have the following result: $\frac{d k_{t+1}}{d k_{t \mid k_{t}=k_{t+1}=k^{*}}}=\alpha$. Because $0<\alpha<1$ the solution is stable ${ }^{183}$. The figures below represent the equation of motion, the equilibrium condition and the corresponding optimal capital stock. The other variables of the model can be solved easily using the previous results.

\section{A.3.5 Leontief Production Function}

In the neo classical production function, the inputs (capital and labour) are substitutable. Depending on the relative price and their productivity firms chose an optimal combination of the two inputs. It is not fully realistic to assume that at any instant the two factors of production are interchangeable. Another extreme is that the inputs are fixed and that there is no possibility of substitution. This is the assumption made by the Leontief production function which is commonly used in the Harrod-Domar growth model. In describing the Leontief production function and the Harrod-Domar growth model we follow De la Grandville \& Solow (2009) and Agion \& Howitt (2009).

The Leontief production function has fixed technology coefficients, $Y=F(K, L)=\min \{A K, B L\}$ where $\mathrm{A}$ and $\mathrm{B}$ are these fixed coefficients. One unit of output requires $\frac{1}{A}$ of capital and $\frac{1}{B}$ of labour.

$$
Y=\min \{A K, B L\} \quad \text { or in intensive form } \quad y=\frac{Y}{L}=\min \{A k, B\}
$$

The Leontief production function is homogeneous of degree 1, because if we multiply $K$ and $L$ by $\lambda$, this results in $Y$ being multiplied by $\lambda$. If capital or labour falls short of the minimum requirement it cannot be compensated by substituting by the other input. As a result

$$
\begin{aligned}
& { }^{183} k=[\hat{s}(1-\alpha)]^{1 /(1-\alpha)} \text { thus } k^{1-\alpha}=\hat{s}(1-\alpha) \text { and } k^{\alpha-1}=\frac{1}{k^{1-\alpha}}=\left\lfloor\frac{1}{\hat{s}(1-\alpha)}\right\rfloor \text { which results in } \\
& d k_{t+1} / d k_{t \mid k_{t}=k_{t+1}=k^{*}}=\hat{s} \alpha(1-\alpha)\left\lfloor\frac{1}{\hat{s}(1-\alpha)}\right\rfloor=\alpha .
\end{aligned}
$$


Figure A3.5 Leontief Production Function with fixed technical Coefficients

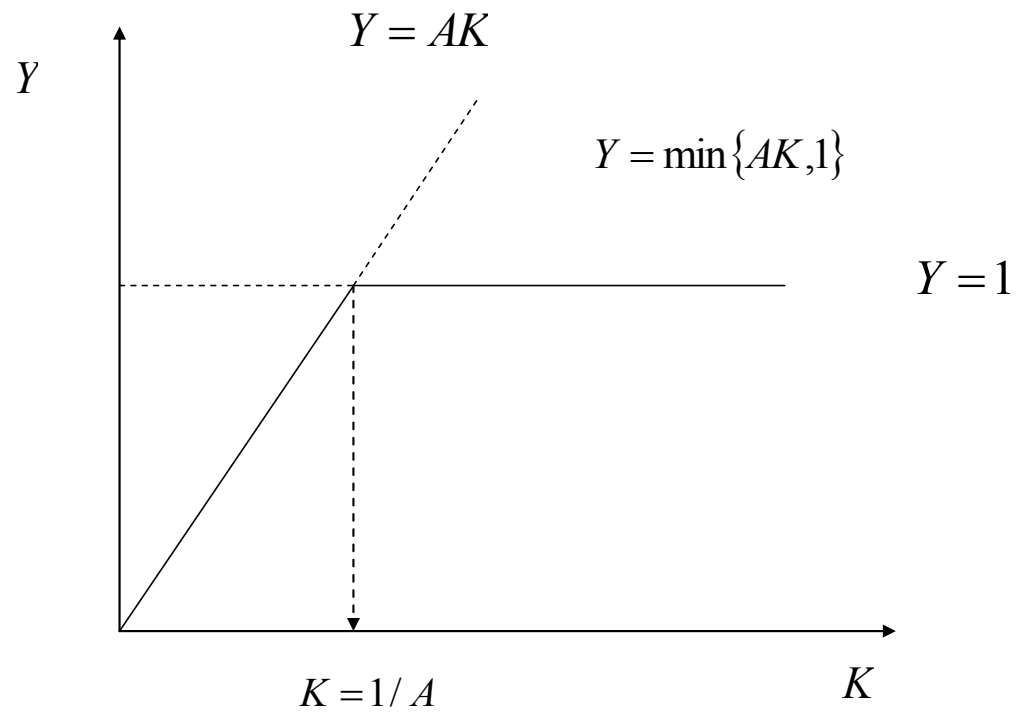

Figure A3.6 Leontief Production Function in Intensive Form with fixed technical Coefficients

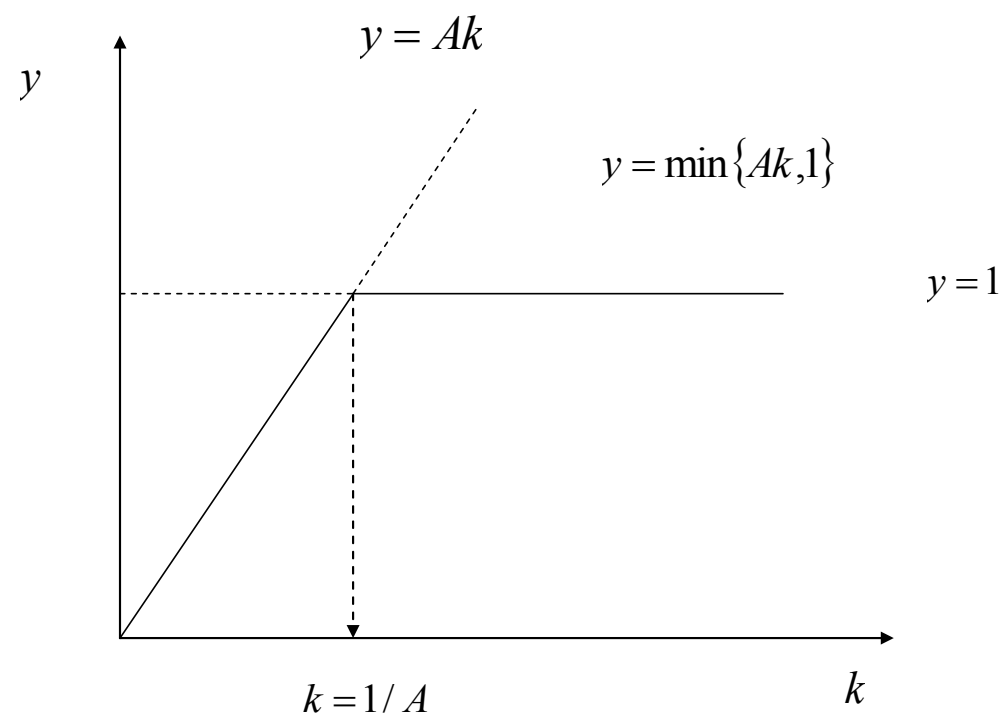


there will either be a surplus of capital or of labour. In the Harrod-Domar growth model capital is the limiting factor, that is $A K<B L$ and $Y=A K$. Because capital stock is accumulated by the economy's savings, this will also determine growth and development of the economy. The economy will be on a growth path up to the point that $A K=B L$. Passing this point economic development will be determined by the development of $B L$, that is the labour force and the development of the technical coefficients. We can depict the Leontief production as follows below.

The Leontief production function can also be expressed in units of labour which results in its intensive form. Because we have normalized labour equal to 1 both graph's look the same. Below in the figure, the Leontief production function is depicted in intensive form.

\section{A.3.6 Equilibrium Income and Capital Stock (Leontief production function)}

Using the equation of motion from the section A3.3 we can analyse the development of the capital stock and the resulting income. Contrary to section A.3.3 income cannot be determined by the marginal productivity of the factors of production as these will be equal to $A$ and zero in case $Y=A K$, and zero and $B$ in case $Y=B L$. That means that we will have to fill in the equation of motion.

We assume that savings are a fixed percentage of total income $(\bar{s})$ so we have the following relation ${ }^{184}$ :

$$
S_{t}=K_{t+1} \quad \text { or in intensive form } \quad s_{t}=k_{t+1}
$$

Given that savings are a fixed percentage of income we have the following aggregate savings:

$$
S_{t}=\min \left\{\bar{s} A K_{t}, \bar{s}\right\} \quad \text { or in intensive form } \quad S_{t}=\min \left\{\bar{s} A k_{t}, \bar{s}\right\}
$$

This results in $K_{t+1}=\bar{s} A K_{t}$ for $A K_{t}<1$ and $K_{t+1}=\bar{s}$ for $A K_{t} \geq 1$. In the last case the capital stock is fixed at $\bar{s}$ and thus is in equilibrium. In the first case there is an equilibrium if $K_{t+1}=K_{t}$, that is if $\bar{s}=\frac{1}{A}$ which will only accidentally the case. There are two other possibilities namely $\bar{s}>\frac{1}{A}$ and $\bar{s}<\frac{1}{A}$. If $\bar{s}>\frac{1}{A}$ the capital stock will increase in time up to the point that $K_{t+1}=\bar{s}$. Because $Y_{t+1}=A K_{t+1}=A s Y_{t}$ and because $A \bar{s}>1$, income will grow

\footnotetext{
${ }^{184}$ For a continues time version with population growth we refer to Grandville, de La and Solow (2009) pp. 48-52
} 
over time with $\frac{Y_{t+1}}{Y_{t}}=(1+g)$ where $g$ is the growth rate. This process will continue up to the point where $A K_{t}=1$. Then savings will be $\bar{s}$ and income will be equal $Y_{t}=1$. In the other case we can see that the capital stock is decreasing over time because $A \bar{s}<1$. The capital stock and thus income will reduce to zero: $Y_{t}=K_{t}=0$. The two possibilities can be found in the two figures below.

\section{A.3.7 Dynamic Inefficiency}

As explained in chapter 2 and in the appendix on the OLG-model, private decision making does not automatically result in an efficient allocation, i.e. a capital-labour ratio which leads to the highest possible consumption of the young and old generation. In this section we have a closer look at this dynamic inefficiency, both for a Cobb Douglas production function and a Leontief production function.

\section{Cobb-Douglas Production Function.}

Total resources in the economy are used for consumption of the old and young generation and savings of the young generation which results in the next period's capital stock:

$$
Y_{t}=C_{t}+K_{t+1} \text { or in intensive form } \quad y_{t}=k_{t+1}+c_{t}
$$

Next we have to determine the capital stock by which consumption is maximized. The easiest way to resolve the problem is maximizing consumption because this automatically results in utility maximization. To find the capital stock that maximizes consumption we first reformulate the above equation as follows:

$$
c=k^{\alpha}-k
$$


Figure A3.7 Equilibrium Income and Capitals Stock with a Leontief Production Function $\bar{s}>1 / A$

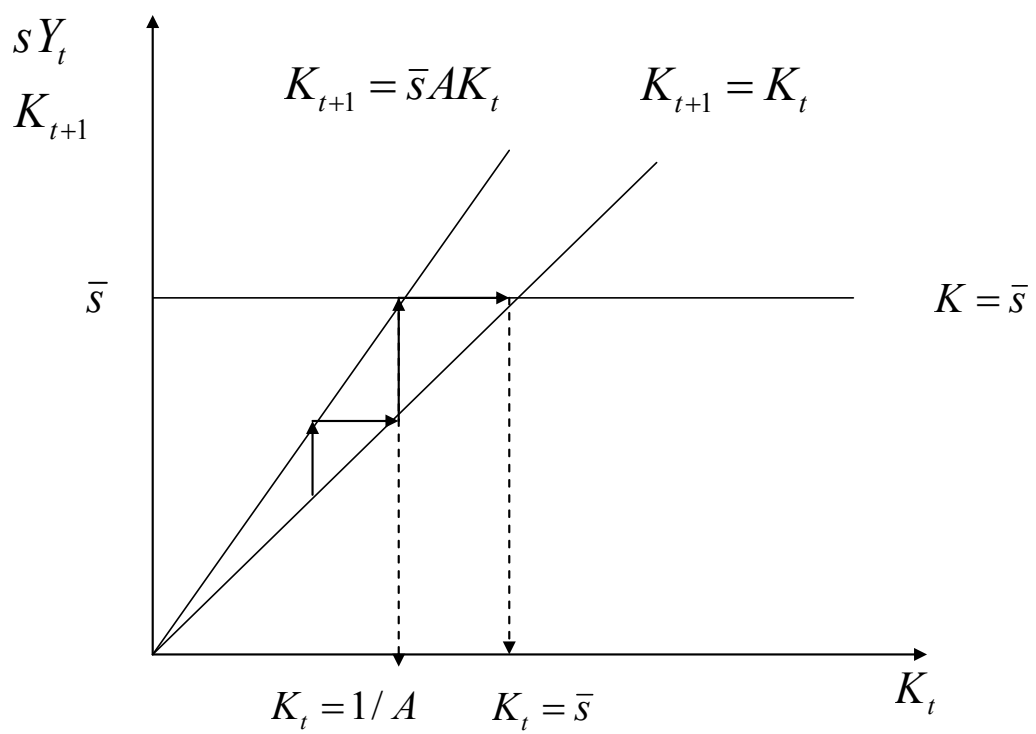

Figure A3.8 Equilibrium Income and Capitals Stock with a Leontief Production Function $\bar{s}<1 / A$

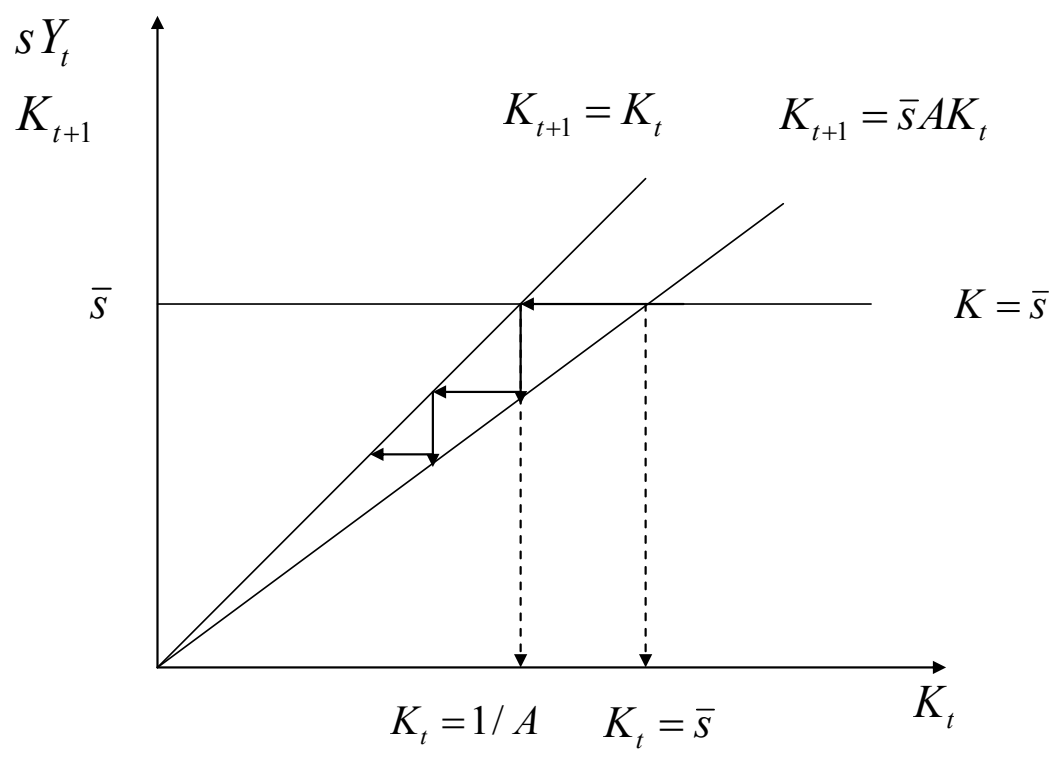


The first order condition with respect to capital stock equals ${ }^{185}$ :

$$
\frac{d c}{d k}=\alpha k^{\alpha-1}-1=0
$$

The optimal capital stock can be found from the first order condition and equals ${ }^{186}$ :

The optimal capital stock can be found from the first order condition and equals ${ }^{187}$ :

$$
k^{G R}=\alpha^{1 /(1-\alpha)}
$$

The optimal capital stock is indicated with $G R$ which comes from Golden Rule of capital accumulation. If we compare this with decentralized decision making we see that:

$$
\alpha^{1 /(1-\alpha)}=k^{G R}<>k=[\hat{s}(1-\alpha)]^{1 /(1-\alpha)}
$$

Below these results are shown in a graph.

Only accidentally will the result from decentralized decision making coincide with the golden rule of accumulation. If this is not the case we have either over-accumulation or underaccumulation of capital. In both cases inefficient allocation is the result. A different allocation would lead to a higher level of consumption and to a Pareto improvement.

\section{The Leontief Production Function}

The same can be done for the Leontief type of production function. We only will pay attention to the case where $\bar{s} A>1$ resulting in an equilibrium with positive capital stock and production and income.

\footnotetext{
${ }^{185}$ In case of population growth the following first order condition applies; $\frac{d c}{d k}=\alpha k^{\alpha-1}-(1+n)=0$.

${ }^{186} \alpha k^{\alpha-1}=1$, resulting in: $\alpha=k^{1-\alpha}$ or $k=\alpha^{1 /(1-\alpha)}$. In case of population growth we have $k=\left[\frac{\alpha}{1+n}\right]^{1 /(1-\alpha)}$.

${ }^{187} \alpha k^{\alpha-1}=1$, resulting in: $\alpha=k^{1-\alpha}$ or $k=\alpha^{1 /(1-\alpha)}$. In case of population growth we have $k=\left[\frac{\alpha}{1+n}\right]^{1 /(1-\alpha)}$.
} 
Figure A3.9 Golden Rule of Capital Accumulation and Dynamic Inefficiency with a Cobb Douglas Production Function

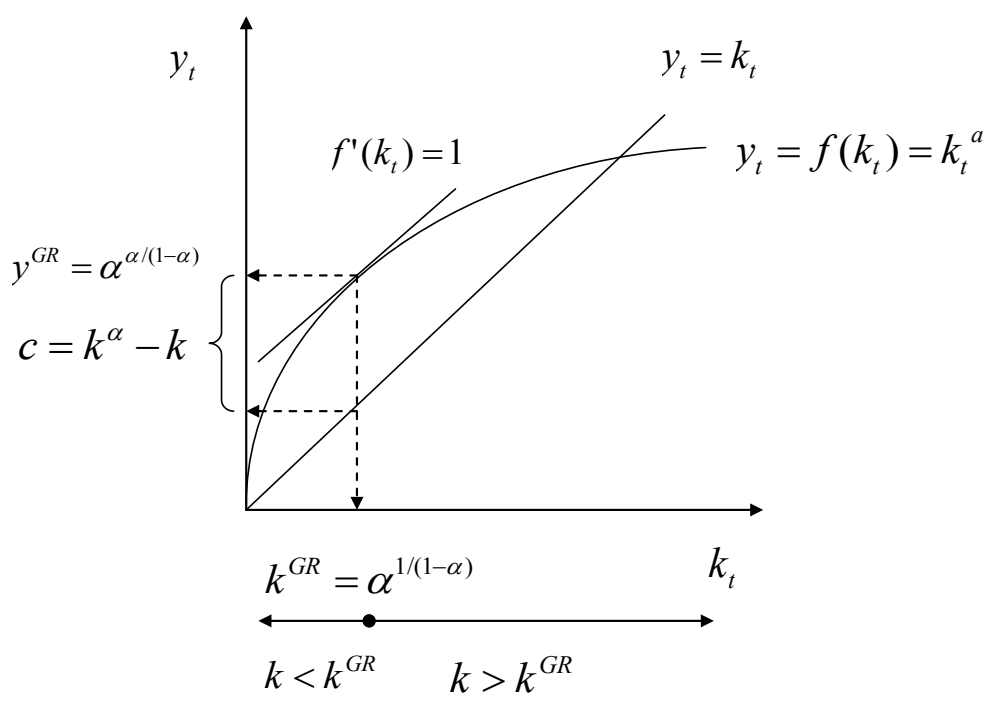

Figure A3.10 Golden Rule of Capital Accumulation and Dynamic Inefficiency with a Leontief Production Function $\bar{s}>1 / A$

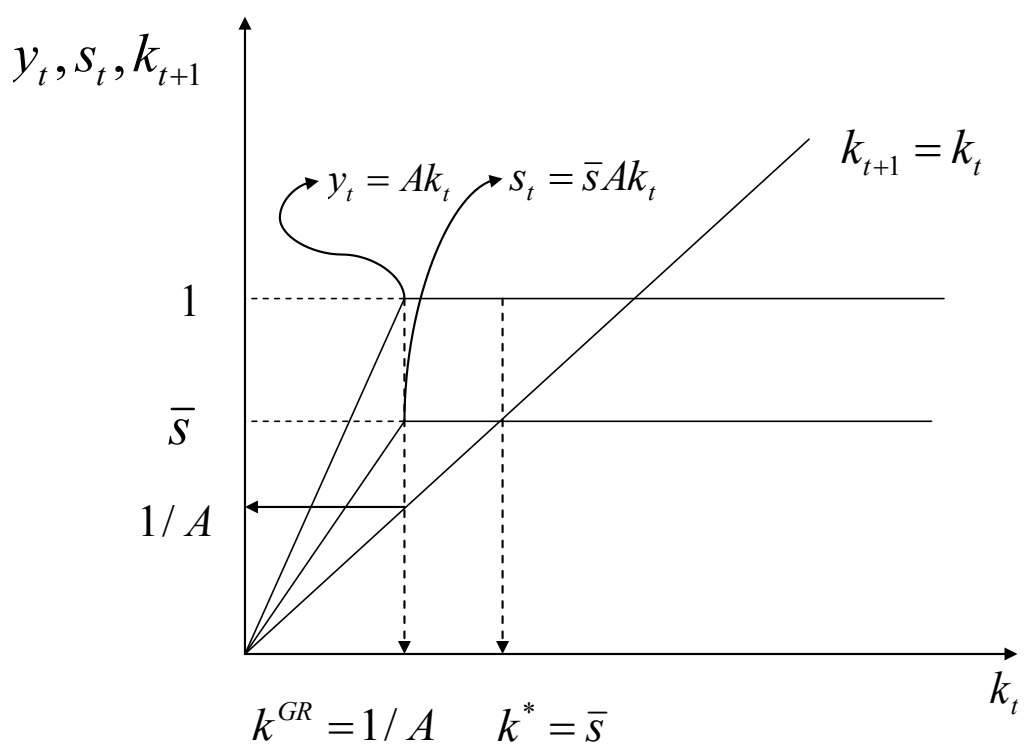


The optimal capital stock (golden rule) realizing the level of production and income of $Y=1$ equals $K=\frac{1}{A}$. The optimal savings resulting from consumer behaviour equals $S=\bar{s}$ and because $\bar{s}>\frac{1}{A}$, the equilibrium capital stock exceeds that of the optimal capital stock. In other words, by reducing savings to $\bar{s}=\frac{1}{A}$ income remains the same, but consumption increases (with $\left.\bar{s}-\frac{1}{A}\right)$. Consumption equals $(1-\bar{s})$ but it could be $\left(1-\frac{1}{A}\right)$ which can also be seen from the figure below.

\section{A.3.8 Cobb-Douglas Production Function Exogenous Technological Change and Externalities}

To incorporate exogenous technological progress which increases labour productivity effective labour is introduced which is defined as:

$$
E_{j, t}=A_{t} L
$$

The variable $A_{t}$ is the exogenous technological progress developing at a fixed rate over time. Using the effective labour as an argument in the Cobb-Douglas production function leads to the following adjusted production function:

$$
Y_{j, t}=\left(A_{t} L_{j, t}\right)^{1-\alpha} K_{j, t}^{\alpha} \text { or in intensive form } \frac{Y_{j, t}}{L_{j, t}}=y_{j, t}=A_{t} k_{j, t}^{\alpha 188}
$$

where $0<\alpha<1$. The marginal product of capital is positive but decreasing:

$$
\frac{\partial Y_{j, t}}{\partial K_{j, t}}=\alpha\left(A_{t} L_{j, t}\right)^{1-\alpha} K_{j, t}^{\alpha-1}>0 \text { and } \frac{\partial^{2} Y_{j, t}}{\partial K_{j, t}^{2}}=-\alpha(1-\alpha)\left(A_{t} L_{j, t}\right)^{1-\alpha} K_{j, t}^{\alpha-2}<0
$$

The marginal product of effective labour which equals the marginal product of labour without technical progress is positive and decreasing:

${ }^{188}$ Dividing by effective labour we have $\frac{Y_{j, t}}{A_{t} L_{j, t}}=k_{j, t}{ }^{\alpha}$ thus $\frac{Y_{j, t}}{L_{j, t}}=A_{t} k_{j, t}{ }^{\alpha}$. 


$$
\frac{\partial Y_{j, t}}{\partial\left(A_{t} L_{j, t}\right)}=(1-\alpha)\left(A_{t} L_{j, t}\right)^{-\alpha} K_{j, t}{ }^{\alpha}>0 \text { and } \frac{\partial^{2} Y_{j, t}}{\partial L_{j, t}^{2}}=-\alpha(1-\alpha)\left(A_{t} L_{j, t}\right)^{-1-\alpha} K_{j, t}{ }^{\alpha}<0
$$

The marginal product of labour of course differs. The reason is that labour productivity is increasing resulting from technological progress which of course also has a positive effect on the marginal product of labour. The marginal product changes to ${ }^{189}$

$$
\frac{\partial Y_{t}}{\partial L_{t}}=(1-\alpha) A_{t}^{(1-\alpha)} L_{t}^{-\alpha} K_{t}^{\alpha} \text { and } \frac{\partial^{2} Y_{t}}{\partial L_{t}^{2}}=-\alpha(1-\alpha) A_{t}^{(1-\alpha)} L_{t}^{-1-\alpha} K_{t}^{\alpha}<0
$$

The return on capital and the wage rate are equal to the marginal product of capital and labour. If the economy is fully competitive we have the following overall return on capital and wage rate ${ }^{190}$ :

$$
R_{t}=\alpha\left(A_{t} L\right)^{1-\alpha} K_{t}^{\alpha-1} \text { or in intensive form } R=\alpha k_{t}^{\alpha-1}
$$

and

$$
w_{t}=A_{t}(1-\alpha)\left(A_{t} L\right)^{-\alpha} K_{t}^{\alpha} \text { intensive form } w_{t}=A_{t}(1-\alpha) k_{t}^{\alpha}
$$

The solution for $k$ of the model is the same as in the case of no technological progress (see the previous section) but now the equilibrium values are expressed in units of effective labour. Note that the interest rate equals that of the economy without technological progress and therefore is constant. The wage rate however deviates with the multiplicative factor $A_{t}$ from the economy with no technological progress. Due to improved labour productivity resulting from technological progress the wage rate is increasing (its marginal product is increasing) over time with a growth rate of $A_{t}$. If $w$ is the equilibrium wage rate in the economy without technological progress, then in case of technological progress the wage rate equals $w_{t}=A_{t} \hat{w}$. Of course income is distributed over factor inputs according to their marginal product, that is:

$$
Y_{t}=w_{t} L_{t}+\left(1+r_{t}\right) K_{t}=A_{t} L_{t}(1-\alpha)\left(A_{t} L_{t}\right)^{-\alpha} K_{t}^{\alpha}+\alpha\left(A_{t} L_{t}\right)^{1-\alpha} K_{t}^{\alpha-1} K_{t}=\left(A_{t} L_{t}\right)^{1-\alpha} K_{t}^{\alpha}
$$

and for the intensive form;

$$
\begin{aligned}
& { }_{189} \frac{\partial Y_{t}}{\partial L_{t}}=\frac{\partial Y_{t}}{\partial\left(A_{t} L_{t}\right)} \frac{\partial\left(A_{t} L_{t}\right)}{\partial L_{t}}=(1-\alpha)\left(A_{t} L_{t}\right)^{-\alpha} A_{t} K_{t}^{\alpha} \\
& { }^{190} w_{i}=f\left(k_{i}\right)-f^{\prime}\left(k_{i}\right) k_{i}=k^{\alpha}-\alpha k^{\alpha-1} k=(1-\alpha) k_{i} \text { and }(1+r)=f^{\prime}\left(k_{i}\right)=\alpha k^{\alpha-1} .
\end{aligned}
$$




$$
y_{t}=w_{t}+A_{t} k_{t}\left(1+r_{t}\right)=A_{t}(1-\alpha) k_{t}^{\alpha}+A_{t} k_{t} \alpha k_{t}^{\alpha-1}=A_{t} k_{t}^{\alpha}=A_{t} f\left(k_{t}\right)
$$

The next step is to use the equation of motion to determine the development over time or economic growth. We have $s_{t}=A_{t} k_{t+1}$ and $s_{t}=\hat{s} w_{t}=\hat{s} A_{t}(1-\alpha) f\left(k_{t}\right)=\hat{s} A_{t}(1-\alpha) k^{\alpha}{ }_{t}$ which results in the following equation of motion:

$$
k_{t+1}=\hat{s}(1-\alpha) k^{\alpha}
$$

Note that the savings are expressed in units of labour $\left(L_{t}\right)$ whereas the capital-labour ratio is expressed in efficiency units $\left(E_{t}=A_{t} L_{t}\right)$. In equilibrium (where the capital-labour ration does not change over time, that is $k_{t}=k_{t+1}=k_{t}$ ) we then have:

$$
k=\hat{s}(1-\alpha) k^{\alpha} \text { or } k^{*}=[\hat{s}(1-\alpha)]^{1 /(1-\alpha)}
$$

The capital effective labour ratio $\left(k=K_{t} / A_{t} L\right)$ is constant in equilibrium but the capitallabour rate $\left(K_{t} / L=A_{t} k\right)$ is increasing over time and is depending on the exogenous technological progress because the only time variable in the expression is that of the development of technological progress, $A_{t}$.

Using the optimal capital stock and substituting this in the production function gives us the development of output per unit labour over time:

$$
y_{t}=A_{t}[\hat{s}(1-\alpha)]^{\alpha /(1-\alpha)} \text { and } Y_{t}=L y_{t}=A_{t} L[\hat{s}(1-\alpha)]^{\alpha /(1-\alpha)}
$$

Because we have assumed that there is no population growth, the development income only depends on the rate of technological change. The corresponding growth rates are respectively;

$$
\frac{Y_{t+1}}{Y_{t}}=\frac{y_{t+1}}{y_{t}}=\frac{A_{t+1}[\hat{s}(1-\alpha)]^{\alpha /(1-\alpha)}}{A_{t}[\hat{s}(1-\alpha)]^{\alpha /(1-\alpha)}}=\frac{A_{t+1}}{A_{t}}=(1+g)
$$

As noticed before the growth of the economy solely depends on the growth rate of technology which is exogenously determined. 


\section{A.3.9 Learning by Doing and Externalities, in the Context of Cobb- Douglas Production Function}

In this approach the economy wide capital intensity (capital-labour ratio) is seen as a yardstick for technological development. Combining the effect of learning by doing in terms of capital intensity with a Cobb-Douglas production function, results in the following production function for a representative firm:

$$
Y_{j}=A K_{j}^{\alpha}\left(\hat{k} L_{j}\right)^{1-\alpha} \text { where } \hat{k}=\hat{k}_{t}=K_{t} / L
$$

$K_{t}$ equals the aggregate capital stock and $L_{t}$ is the total labour force of the economy at time $t$.

For an individual firm $j$ the capital intensity $\hat{k}$ is given but for the economy as a whole it is endogenously determined by the aggregate capital stock and labour force representing the stock of knowledge or technological progress and therefore equals $\hat{k}_{t}$. If this production function is in use by firms we have the following profit function:

$$
\pi_{j}=A K_{j}^{\alpha}\left(\hat{k} L_{j}\right)^{1-\alpha}-w_{j} L_{j}-R_{j} K_{j}
$$

Profit maximization by the representative firm $j$ results in the wage rate and the return on capital which equals the marginal product of labour and capital. Using the first order approach we find:

$$
\frac{\partial \pi_{j}}{\partial L_{j}}=(1-\alpha) A K_{j}^{\alpha} \hat{k}\left(\hat{k} L_{j}\right)^{-\alpha}-w_{j}=0
$$

and

$$
\frac{\partial \pi_{j}}{\partial K_{j}}=\alpha A K_{j}^{\alpha-1}\left(\hat{k} L_{j}\right)^{1-\alpha}-R_{j}=0
$$

Assuming that the economy operates under perfect competition, all firms are identical and the economy wide wage rate is the same as is the return on capital. In case there are $m$ firms the capitals stock equals $m K_{j}=K$ and the labour force equals $m L_{j}=L$. This implies that at any time $t$ we have $\frac{K_{j}}{L_{j}}=\frac{K_{t}}{L}=\hat{k}=\hat{k}_{t}=k_{t}$. The corresponding economy wide wage rate and return on capital then become: 


$$
\begin{array}{lll}
w_{t}=(1-\alpha) A \frac{K_{t}}{L} & \text { in intensive form } & w_{t}=(1-\alpha) A k_{t} \\
R=\alpha A & \text { in intensive form } & \frac{R}{L}=\alpha \frac{A}{L_{t}}
\end{array}
$$

Aggregate economy wide production then equals: ${ }^{191}$

$$
Y_{t}=A K_{t} \quad \text { in intensive form } \quad y_{t}=A k_{t}
$$

As the production function for the individual firm exhibits decreasing returns to scale in the inputs labour and capital, on aggregate the production function is characterized by constant returns to scale in capital.

Production and income are distributed over labour income of the young generation and capital income of the old generation according to:

$$
Y_{t}=w_{t} L_{t}+R K_{t}=(1-\alpha) A K_{t}+\alpha A K_{t}
$$

in intensive form

$$
y_{t}=A k_{t}=w_{t}+R k_{t}=(1-\alpha) A k_{t}+\alpha A k_{t}
$$

Next, using the equation of motion, we find the development of income over time:

$$
s_{t}=k_{t+1} \text { and } s_{t}=\hat{s} w_{t}=\hat{s}(1-\alpha) A k_{t}=k_{t+1}
$$

and

$$
S_{t}=s_{t} L_{t}=k_{t+1} L_{t+1} \text { and } S_{t}=\hat{s} w_{t} L_{t}=\hat{s}(1-\alpha) A K_{t}=K_{t+1}
$$

In case there is no population growth we have $L_{t}=L_{t+1}=L$ and therefore $L_{t+1} k_{t}=L_{t} k_{t+1}=K_{t+1}$. Next, using the production function we find:

$$
Y_{t+1}=A K_{t+1} \Rightarrow Y_{t+1}=A \hat{s}(1-\alpha) A K_{t} \text { and } y_{t+1}=A k_{t+1} \Rightarrow y_{t+1}=A \hat{s}(1-\alpha) A k_{t}
$$

The growth rate equals $\frac{y_{t+1}}{y_{t}}=\frac{Y_{t+1}}{Y_{t}}=\hat{s}(1-\alpha) A$.

${ }^{191} Y_{t}=\sum_{j=1}^{m} A K_{j}^{\alpha}\left(\hat{k} L_{j}\right)^{1-\alpha}=A \hat{k}^{1-\alpha} \sum_{j=1}^{m} K_{j}^{\alpha} \sum_{j=1}^{m} L_{j}^{1-\alpha}=A\left(\frac{K_{t}}{L}\right)^{1-\alpha} K_{t}^{\alpha} L^{1-\alpha}=A K_{t}$ 


\section{A.3.10 Public Capital and Externalities, in the Context of a Cobb-Douglas Production Function}

Starting from the results of the previous section, we now introduce public capital, which results in the following production function for a representative firm:

$$
Y_{j}=A K_{j}^{\alpha}\left(\hat{k} L_{j}\right)^{1-\alpha}\left(\frac{P}{K}\right)^{\beta}
$$

Here $\hat{k}=\hat{k}_{t}=\frac{K_{t}}{L}$ is the economy wide capital-labour ratio which is given for the individual firm. The ratio public-private capital contributes to the firm's output, but in a decreasing way, and takes into account possible congestion in public capital. The parameter $0<\beta<1$ represents the productivity of public capital.

Public capital formation is financed by tax revenues and we assume that current tax revenues increase public capital which contributes to the economy's output in the next period. Furthermore we assume a balanced budget of the government. Taxes are proportional on wage income and the parameter $\tau$ is the tax rate. This results in the following equation on the motion of public capital:

$$
P_{t+1}=T_{t}=\tau w_{t} L
$$

Private capital formation still results from the equation of motion of private capital that is:

$$
K_{t+1}=S_{t}=\hat{s}(1-\tau) w_{t} L
$$

The wage rate and the private return on capital equal their marginal product, that is:

$$
\frac{\partial Y_{j}}{\partial K_{j}}=\alpha K_{j}^{\alpha-1}\left(\hat{k} L_{j}\right)^{1-\alpha}\left(\frac{P}{K}\right)^{\beta}-R=0
$$

and

$$
\frac{\partial Y_{j}}{\partial L_{j}}=(1-\alpha) K_{j}^{\alpha}\left(\hat{k} L_{j}\right)^{-\alpha} \hat{k}\left(\frac{P}{K}\right)^{\beta}-w=0
$$

For the economy in equilibrium the capital-labour ratio of the firm equals the economy wide capital-labour ratio. We also know from the equations of the motion of public and private capital thus on aggregate we have the following production function: 


$$
Y_{t}=A K_{t}\left(\frac{P_{t}}{K_{t}}\right)^{\beta}
$$

The economy wide wage rate and return on capital than equal:

$$
w_{t}=(1-\alpha) \hat{k}_{t}\left(\frac{P_{t}}{K_{t}}\right)^{\beta} \text { where } k_{t}=K_{t} / L
$$

and

$$
R_{t}=\alpha\left(\frac{P_{t}}{K_{t}}\right)^{\beta}
$$

If taxes are levied on wage income, see equation (A3.50) and therefore the ratio public-private capital is constant:

$$
\frac{P_{t+1}}{K_{t+1}}=\frac{\tau w_{t} L}{\hat{s}(1-\tau) w_{t} L}=\frac{\tau}{\hat{s}(1-\tau)}=\frac{P_{t}}{K_{t}}=\frac{P}{K}
$$

Inserting this in the aggregate production function results in:

$$
Y_{t}=A K_{t}\left(\frac{\tau}{\hat{s}(1-\tau)}\right)^{\beta} \Rightarrow Y_{t}=\hat{A} K_{t} \text { where } \hat{A}=A\left(\frac{\tau}{\hat{s}(1-\tau)}\right)^{\beta}
$$

This is the same type of production function as we derived in the previous section. Output is linearly depending on capital stock. The parameters $A$ and $\hat{A}$ however are different. Note also that the return on private capital is fixed:

$$
R=\alpha\left(\frac{\tau}{\hat{s}(1-\tau)}\right)^{\beta}
$$

The 'firm' wage rate is increasing in the capital-labour ratio;

$$
w_{t}=(1-\alpha)\left(\frac{\tau}{\hat{s}(1-\tau)}\right)^{\beta} \hat{k}_{t}
$$


We can also see what the contribution of public capital is to the economy. Using the aggregate production function we can derive the marginal product of public capital:

$$
Y_{t}=A K_{t}^{1-\beta} P_{t}^{\beta} \text { and } \frac{\partial Y}{\partial P}=\frac{\beta A K_{t}^{1-\beta} P_{t}^{\beta}}{P_{t}}=\frac{\beta Y_{t}}{P_{t}}
$$

Now it is also easy to determine the optimal level of public capital. That is where the marginal benefits (contribution to output) equals the marginal costs in terms of resources (final output) used. Any increase in public capital is at costs of one unit of output, thus the marginal cost equals 1 .This is of course the raised taxes in terms of output. Thus we have:

$$
\frac{\beta Y_{t}}{P_{t}}=1 \text { or } \beta=\frac{P_{t}}{Y_{t}}=\frac{\tau(1-\alpha) Y_{t}}{Y_{t}}=\tau(1-\alpha) \text { resulting in } \tau=\frac{\beta}{1-\alpha}
$$

Note also that setting the tax rate $\tau=\frac{\beta}{1-\alpha}$ will also result in optimal growth for the economy. Because firms do not take into account the congestion effect of their investments the capital stock is too high. By reducing savings by taxing income the private capital stock decreases (reflected in the term $1 /(1-\alpha)$ ) and the public capital stock increases $(\beta)$ and congestion is reduced. 


\section{Appendix 4}

The Dixit-Stiglitz Model of

Monopolistic Competition 


\section{A.4.1 Introduction}

In this appendix we will pay attention to the Dixit-Stiglitz model of Monopolistic Competition. The reason for this is the origin of profit in monopolistic competition firms can make (in our case use for investments in innovation). This is not possible in a perfect competitive environment. Other market forms like monopoly, oligopoly and monopolistic competition do allow firms to make profits. The market of monopolistic competition appears to be suitable for our analysis. Dixit \& Stiglitz (1977) were the first to model the key elements of monopolistic competition in a canonical way in their path breaking journal article, 'Monopolistic Competition and Optimum Product Diversity'.

In this appendix we successively review the basic elements of the Dixit-Stiglitz model of monopolistic competition. In section 4.2. we summarize the most important aspects of monopolistic competition necessary to understand its working. After that we review the most common used Dixit-Stiglitz "Lite" model of monopolistic competition. We pay successively attention to consumer behaviour, and the resulting demand for varieties (sections 4.4-4.5) We continue with describing firm behaviour and competition in section 4.6. In the last section (4.7) we pay attention on the implication of 'the large number' assumption of the model.

\section{A.4.2 Monopolistic Competition}

For a long time two types of markets dominated economics: perfect competition and monopoly. In the case of monopoly, a single firm has exclusive control over the market and its output is determined by profit maximisation. The collective market demand function is also the demand function the monopolist is facing. We assume that the demand decreases as the price increases. For the monopolist profit is maximized when marginal cost equals marginal revenue. Profit consists of revenues minus costs and thus we have $\pi(q)=p(q) q-C(q)$. Profit depends on the firm's output and demand. The revenue is quantity $(q)$ times price $(p(q))$, where the price depends on the quantity produced and sold, if we use an inverted demand function. Setting the first derivative equal to zero gives us the optimal quantity. That is $\frac{\partial p(q)}{\partial q} q+p(q)=\frac{\partial C(q)}{\partial q}$. On the left hand side we have the marginal revenue which equals the marginal cost on the right hand side. From this the mark up and the 
optimal price can be calculated which equals ${ }^{192} \cdot p=\frac{M C}{1-1 / \varepsilon_{D}}$ with $\varepsilon_{D}$ is the price elasticity of demand, which is negative.

Note the difference with the case of perfect competition where we have $\pi(q)=p q-C(q)$. Here the market price is exogenous and determined by the market. Profit maximization then leads to $p=\frac{\partial C(q)}{\partial q}=M C(q)$. Output in case of perfect competition exceeds that in case of monopoly; perfect competition is efficient, but monopoly leads to inefficiency.

Between these two extreme cases many markets of "imperfect competition" exist. The most prominent one are oligopoly and monopolistic competition. There have been several attempts to model these kinds of hybrid markets. For the case of oligopoly the best known are the duopoly models developed by Cournot and Bertrand.

With respect to monopolistic competition two important publications stand out: The Economics of Imperfect Competition by Robinson and The Theory of Monopolistic Competition by Chamberlain. The latter publication has been most influential. Chamberlain makes four important assumptions underlying monopolistic competition (as cited by Brakman \& Heijdra (2004); Bishop (1967) pp. 252).

1 The number of sellers in a group of firms is sufficiently large so that each firm takes the behaviour of other firms in the group as given.

2 The group is well defined and small relative to the economy.

3 Products are physically similar but economically differentiated; buyers have preferences for all types of products.

4 There is free entry and exit.

The monopolistic feature lies in the fact that each product is economically different. That gives the producer certain monopoly power. Each producer faces his own demand curve. The large number of firms, free entry and the physical similarity of products make the market competitive.

In the model of monopolistic competition the firm maximizes its profit by determining the optimal price or quantity, similar to the monopoly case. Remember that every firm faces

$$
\begin{aligned}
& { }^{192} \text { Dividing both term by } p \text { results in } p\left(\frac{\partial p}{\partial q} \frac{q}{p}+1\right)=M C \text {, With } \frac{\partial p}{\partial q} \frac{q}{p}=\frac{1}{\frac{\partial q}{\partial p} \frac{p}{q}}=\frac{1}{-\varepsilon_{D}} \text { where } \\
& \varepsilon_{D}=-\frac{\partial q}{\partial p} \frac{p}{q} \text { is the price elasticity of demand. }
\end{aligned}
$$


its own demand curve, and that the cost structure of all firms is identical. As long as firms make a profit other firms are entering because of profit opportunities (free entry). Part of the market goes to the new firms offering their product to consumers. As long as firms are entering the market the already existing firms face a decrease in demand and in profit. This process continues until the profit reduces to zero. Then no firms will enter the market anymore. At this point the price will be equal to the average cost. That means that in equilibrium the price (in the case of monopolistic competition) equals the average costs. There will be no more firms entering the market and no firms will exit the market. This point, where average costs equals the market price, also determines the firms output. Thus in equilibrium we have $p=\frac{M C}{1-1 / \varepsilon_{D}}=A C(q)$ where $A C(q)$ stands for the firm's average costs.

There have been several attempts to model this kind of hybrid markets. The problem is that the results are very much depending on the assumptions made. This has changed after Dixit \& Stiglitz (1977) published their seminal article "Monopolistic competition and optimal product variety". In this article they described the market for monopolistic competition. According to Neary (2002, p. 3) their prime concern, and a classical issue in industrial organization, was to describe the social optimality of monopolistic competition. Would the market of monopolistic competition produce too many varieties? Would the industry operate with excess capacity that means at prices above the minimum of the average costs?

Their innovative approach provided a framework for modelling many features in other branches of economics like trade analysis and economic geography. Besides that it stands at the basis of NGT. Especially the innovative technical tools Dixit \& Stiglitz introduced make their approach applicable to many topics in economics and imperfect competition. Brakman \& Heijdra (2004, p.11) note 'The reason for the success is that Dixit \& Stiglitz managed to formulate a canonical model of Chamberlain's monopolistic competition which is both easy to use and captures the key aspects of Chamberlain's model. Although their approach is somewhat unrealistic it has nevertheless become the workhorse incorporating monopolistic competition, increasing returns to scale, and endogenous product variety.' As lined out by Neary (2000a) pp.1-5 the main contributions of the Dixt-Stiglitz model are:

- The definition of an industry (or large group of firms) is simplified: all product varieties are symmetric and are combined in a constant-elasticity-of-substitution (CES) aggregation function.

- Overall utility is separable and homothetic in its arguments, implying that we can use two stage optimization procedure. In the first stage usually a Cobb-Douglas specification is used and in the second stage a CES utility function. 
- On the production side, technology features increasing returns to scale at firm level. The typical formulation models the average cost curve as a rectangular hyperbola. All firms are symmetrical.

The driving force of the Dixit-Stiglitz model is that more varieties increase consumers' utility.

\section{A.4.3 Dixit-Stiglitz "Lite"}

In this section we shortly resume and describe the Dixit-Stiglitz model of monopolistic competition. We concentrate on what Neary (2000a, p.5) calls the Dixit-Stiglitz lite model. In describing the model we follow Neary (2000a) and Baldwin et al. (2003, pp. 38-44).

Our approach is as follows. First we formulate the utility function. Next we derive the demand for all different goods applying standard microeconomic consumer theory.

With respect to the utility (production) function it is assumed that it is separable and convex. The following 3 restrictions are imposed on the 'lite' version of the Dixit-Stiglitz model;

- Symmetry of argument

- CES specification

- Cobb-Douglas form

Imposing these restrictions on the Dixit \& Stiglitz model results in the following functional form of the utility function:

$$
u=U\left(x_{0}, y\right)=x_{0}^{1-\alpha} y^{\alpha}
$$

where $y \equiv\left[\sum_{i=1}^{n} y_{i} \frac{\sigma-1}{\sigma}\right]^{\frac{\sigma}{\sigma-1}}$. The function $u$ is the utility function of a representative consumer with Cobb-Douglas structure where $0<\alpha<1$. The variable $x_{0}$ is a consumption good and we set its price equal to 1 . The variable $y$ is an index of differentiated goods which has a CES specification. The parameter $\sigma>1$ is the elasticity of substitution, and $y_{i}$ for $i=1, \ldots, n$ are differentiated goods produced in another sector which appear symmetric in the index $y$. 


\section{A.4.4 Consumer Behaviour; Utility Maximization}

The utility maximization problem of a representative consumer can be split in two optimization problems. First between consumption goods $x_{0}$ and $y$. This is called the first stage optimization. Next between the different goods, $y_{i}$ for $i=1, \ldots, n$, which is called the second stage optimization problem.

\section{The first stage optimization}

The first stage optimization problem can be formulated as follows:

$$
\underset{x_{0}, y}{\operatorname{Max}} x_{0}^{1-\alpha} y^{\alpha} \text { s.t } x_{0}+\bar{p} y \leq I
$$

The variable $I$ indicates an exogenous given income and the variable $\bar{p}$ is a price index of $y$. The resulting Lagrange formulation of the optimization problem equals:

$$
£=x_{0}^{1-\alpha} y^{\alpha}-\lambda\left[x_{0}-\bar{p} y-I\right]
$$

The 3 FOC's of this maximization problem (setting the derivatives of the endogenous variable $x_{0}, y$ and the Lagrange multiplier, $\lambda$ to zero) are:

$$
\begin{aligned}
& \frac{\partial £}{\partial x_{0}}=(1-\alpha) x_{0}^{-\alpha} y^{\alpha}-\lambda=0 \text { thus we have }(1-\alpha) x_{0}^{-\alpha} y^{\alpha}=\lambda \\
& \frac{\partial £}{\partial y}=\alpha x_{0}^{1-\alpha} y^{\alpha-1}-\lambda q=0 \text { thus we have } \frac{\alpha x_{0}^{1-\alpha} y^{\alpha-1}}{\bar{p}}=\lambda \\
& \frac{\partial £}{\partial \lambda}=\left[x_{0}-\bar{p} y-I\right]=0
\end{aligned}
$$

From the first two FOC's (A4.2) and (A4.3) we get the relative share of the consumption goods, $x_{0}$ and $y$ :

$$
(1-\alpha) x_{0}^{-\alpha} y^{\alpha}=\frac{\alpha x_{0}^{1-\alpha} y^{\alpha-1}}{\bar{p}} \text { or } x_{0}=\frac{(1-\alpha)}{\alpha} \bar{p} y
$$

Substituting this equation (A4.5) in the budget constraint, (A4.4), gives us the share of expenditure on the two goods: 


$$
\frac{(1-\alpha)}{\alpha} \bar{p} y+\bar{p} y=I \text { or } y=\alpha \frac{I}{\bar{p}} \quad \text { and } x_{0}=(1-\alpha) I
$$

Note that because the price of $x_{0}$ is normalized to 1 , no price of $x_{0}$ appears in its share of expenditure.

\section{The second stage optimization}

The second stage optimization, i.e. determining the expenditure shares of all different types of consumption goods $y_{i}$ for $i=1, \ldots, n$, equals:

$$
\underset{y_{i}}{\operatorname{Max}}\left[\sum_{i=1}^{n} y_{i}^{\frac{\sigma-1}{\sigma}}\right]^{\frac{\sigma}{\sigma-1}} \quad \text { s.t } \quad \bar{p} y=\sum_{i=1}^{n} p_{i} y_{i} \leq \alpha \mathbf{I}, \text { for } i=1, . ., n
$$

The Lagrange equation of the maximization problem equals:

$$
£=\left[\sum_{i=1}^{n} y_{i}^{\frac{\sigma-1}{\sigma}}\right]^{\frac{\sigma}{\sigma-1}}-\lambda\left[\sum_{i=1}^{n} p_{i} y_{i}-\alpha I\right] \text { for } i=1, . ., n
$$

The $n+1$ FOC for $i=1, . ., n$ different goods and with respect to the Lagrange multiplier are respectively ${ }^{193}$ :

$$
\begin{aligned}
& \frac{\partial £}{\partial y_{i}}=\left[\sum_{i=1}^{n} y_{i}^{\frac{\sigma-1}{\sigma}}\right]^{\frac{\sigma}{\sigma-1}-1} y_{i}^{\frac{-1}{\sigma}}-\lambda p_{i}=0 \text { for } i=1, . ., n \\
& \frac{\partial £}{\partial \lambda}=\left\lfloor\sum_{i=1}^{n} p_{i} y_{i}-\alpha I\right\rfloor=0
\end{aligned}
$$

From the first FOC the relation between the different consumption goods $y_{i}$ for $i=1, . . n$ can be found ${ }^{194}$ :

${ }_{193} \frac{\partial £}{\partial y_{i}}=\frac{\sigma}{\sigma-1}\left[\sum_{i=1}^{n} y_{i}^{\frac{\sigma-1}{\sigma}}\right]^{\frac{\sigma}{\sigma-1}-1} \frac{\sigma-1}{\sigma} y_{i}^{\frac{\sigma-1}{\sigma}-1}-\lambda p_{i}=0$ which cn be simplified to: 


$$
\frac{y_{i}}{y_{j}}=\left(\frac{p_{i}}{p_{j}}\right)^{-\sigma} \quad \text { for } i=1, \ldots, n, i=1, \ldots, n \text { and } i \neq j
$$

As in traditional consumer theory, the share of the different goods depends on their relative price.

\section{Direct optimization}

The same results can be obtained by straight away optimization. Because of the CobbDouglas structure, the share of expenditure between $x_{0}$ and $y$ is fixed and is determined by the technical parameter $\alpha$. We have the following optimization problem:

$$
\underset{x_{0}, y_{i}, i=1, \ldots, n}{\operatorname{Max}} x_{0}^{1-\alpha}\left[\sum_{i=1}^{n} y_{i}^{\frac{\sigma-1}{\sigma}}\right]^{\alpha \frac{\sigma}{\sigma-1}} \text { s.t } \quad x_{0}+\sum_{i=1}^{n} p_{i} y_{i} \leq I
$$

Therefore we formulate the following Lagrange function:

$$
£=x_{0}^{1-\alpha}\left[\sum_{i=1}^{n} y_{i} \frac{\sigma-1}{\sigma}\right]^{\alpha \frac{\sigma}{\sigma-1}}-\lambda\left[x_{0}+\sum_{i=1}^{n} p_{i} y_{i}-I\right]
$$

From that we can derive the following $n+2$ FOC's:

$$
\begin{aligned}
& \frac{\partial £}{\partial x_{0}}=(1-\alpha) x_{0}^{-\alpha}\left[\sum_{i=1}^{n} y_{i}^{\frac{\sigma-1}{\sigma}}\right]^{\alpha \frac{\sigma}{\sigma-1}}-\lambda=0 \\
& \frac{\partial £}{\partial y_{i}}=\alpha \frac{\sigma}{\sigma-1} x_{0}^{1-\alpha}\left[\sum_{i=1}^{n} y_{i}^{\frac{\sigma-1}{\sigma}}\right]^{\alpha \frac{\sigma}{\sigma-1}-1} \frac{\sigma-1}{\sigma} y_{i}^{\frac{\sigma-1}{\sigma}-1}-p_{i} \lambda=0 \text { for } i=1, \ldots, n \\
& \frac{\partial £}{\partial \lambda}=\left\lfloor x_{0}+\sum_{i=1}^{n} p_{i} y_{i}-I\right\rfloor=0
\end{aligned}
$$

${ }_{194} \lambda=\left[\sum_{i=1}^{n} y_{i}^{\frac{\sigma-1}{\sigma}}\right]^{\frac{\sigma}{\sigma-1}-1} y_{i}^{\frac{-1}{\sigma}} \frac{1}{p_{i}}=\left[\sum_{j=1}^{n} y_{j}^{\frac{\sigma-1}{\sigma}}\right]^{\frac{\sigma}{\sigma-1}-1} y_{j}^{\frac{-1}{\sigma}} \frac{1}{p_{j}}$ or $y_{i}^{-\frac{1}{\sigma}} \frac{1}{p_{i}}=y_{j}^{-\frac{1}{\sigma}} \frac{1}{p_{j}}$ and $\left(\frac{y_{i}}{y_{j}}\right)^{-\frac{1}{\sigma}}=\frac{p_{i}}{p_{j}}$. for $i=1, \ldots, n, j=1, \ldots, n$ and $i \neq j$ which results in equation (A4.9). 
Using the second FOC and multiplying by $y_{i}{ }^{195}$ results in: $\frac{y_{i}^{\frac{-1}{\sigma}}}{p_{i}}=\frac{y_{j} \frac{-1}{\sigma}}{p_{j}}$ which equal the results of equation (A4.9).

\section{Expenditure share of goods}

We can now easily calculate the shares of the consumption good $x_{0}$ and the differentiated goods, $y_{i}$ for $i=1, . ., n$. Summing over $i=1, . ., n$ results in ${ }^{196}$ :

$$
\sum_{i=1}^{n} p_{i} y_{i}=\frac{\alpha x_{0}}{(1-\alpha)}
$$

Using this result and substituting in the budget constraint delivers ${ }^{197}$ :

$$
x_{0}=(1-\alpha) I
$$

and

$$
\sum_{i=1}^{n} p_{i} y_{i}=\alpha I
$$

Fixed shares of income are devoted to the different types of consumption goods, $x_{0}$ and. $\sum_{i=1}^{n} p_{i} y_{i}$

$$
\begin{aligned}
& { }^{195} \alpha x_{0}^{1-\alpha}\left[\sum_{i=1}^{n} y_{i}^{\frac{\sigma-1}{\sigma}}\right]^{\alpha \frac{\sigma}{\sigma-1}-1} y_{i}^{\frac{\sigma-1}{\sigma}}-p_{i} y_{i} \lambda=0 \text { or } \alpha x_{0}^{1-\alpha}\left[\sum_{i=1}^{n} y_{i}^{\frac{\sigma-1}{\sigma}}\right]^{\alpha \frac{\sigma}{\sigma-1}-1} \frac{y_{i}^{\frac{-1}{\sigma}}}{p_{i}}=\lambda \text { for } i=1, . ., n \\
& { }^{196} \alpha x_{0}^{1-\alpha}\left[\sum_{i=1}^{n} y_{i}^{\frac{\sigma-1}{\sigma}}\right]^{\alpha \frac{\sigma}{\sigma-1}-1} \sum_{i=1}^{n} y_{i}^{\frac{\sigma-1}{\sigma}}=\lambda \sum_{i=1}^{n} p_{i} y_{i} \Rightarrow \alpha x_{0}^{1-\alpha}\left[\sum_{i=1}^{n} y_{i}^{\frac{\sigma-1}{\sigma}}\right]^{\alpha \frac{\sigma}{\sigma-1}}=\lambda \sum_{i=1}^{n} p_{i} y_{i} \Rightarrow \\
& \frac{\alpha x_{0}{ }^{1-\alpha}\left[\sum_{i=1}^{n} y_{i}^{\frac{\sigma-1}{\sigma}}\right]^{\alpha \frac{\sigma}{\sigma-1}}}{\lambda}=\sum_{i=1}^{n} p_{i} y_{i} \Rightarrow \frac{\alpha x_{0}{ }^{1-\alpha}\left[\sum_{i=1}^{n} y_{i} \frac{\sigma-1}{\sigma}\right]^{\alpha \frac{\sigma}{\sigma-1}}}{(1-\alpha) x_{0}{ }^{-\alpha}\left[\sum_{i=1}^{n} y_{i}^{\frac{\sigma-1}{\sigma}}\right]^{\alpha \frac{\sigma}{\sigma-1}}} \Rightarrow \sum_{i=1}^{n} p_{i} y_{i}=\frac{\alpha x_{0}{ }^{1-\alpha}}{(1-\alpha) x_{0}{ }^{-\alpha}} . \\
& 197 x_{0}+\frac{\alpha x_{0}}{(1-\alpha)}=I \text { or } x_{0}(1-\alpha)+\alpha x_{0}=(1-\alpha) I .
\end{aligned}
$$




\section{A.4.5 Demand for Different Types of Goods}

With the results above we can find the individual demand for the different types of $y_{i}$ for $i=1, \ldots, n$. We take equation (A4.9) we can derive the direct demand curve and the inverse demand curve. This is of interest because we want to show that as well Betrand as Cournot competition leads to the same results.

\section{The direct demand curve}

Using (A4.9) and multiply it by the price, $p_{i}$ and than aggregate over the $n$ individual goods, we find:

$$
\frac{p_{i} y_{i}}{y_{j}}=\frac{p_{i}^{1-\sigma}}{p_{j}^{-\sigma}} \Rightarrow \frac{\sum_{i=1}^{n} p_{i} y_{i}}{y_{j}}=\frac{\sum_{i=1}^{n} p_{i}^{1-\sigma}}{p_{j}^{-\sigma}}
$$

Combining this with the previous results from equations (A4.15) delivers $\frac{\alpha I}{y_{j}}=\frac{\sum_{i=1}^{n} p_{i}^{1-\sigma}}{p_{j}{ }^{-\sigma}}$. This results in the following direct demand curve;

$$
y_{j}=\alpha I \frac{p_{j}^{-\sigma}}{\sum_{i=1}^{n} p_{i}^{1-\sigma}}
$$

Some time this is also written as $y_{j}=\alpha I \frac{p_{j}^{-\sigma}}{\bar{p}^{1-\sigma}} \quad j=1, \ldots, n$ whereHere $\bar{p}$ is a price index, which is called the CES aggregate of price or true price index $\bar{p}=\left(\sum_{i=1}^{n} p_{i}^{(1-\sigma)}\right)^{\frac{1}{1-\sigma}}$.

The demand for consumption good $y_{i}$ depends on income which is exogenous, its own price and the prices of all other goods. Note that from equation (A4.17) the expenditure share of variety $j$ with respect to total expenditure on varieties equals:

$$
s_{j}=\frac{p_{j} y_{j}}{\alpha I}=\frac{p_{j}{ }^{1-\sigma}}{\sum_{i=1}^{n} p_{i}^{1-\sigma}}
$$




\section{The inverse demand curve}

Here also equation (A4.6) can be used to determine the inverse demand curve. Rewriting (A.6) as $\left(\frac{y_{i}}{y_{j}}\right)^{-1 / \sigma}=\frac{p_{i}}{p_{j}}$ and multiplying by $y_{j}$ leads to $\frac{y_{i}^{1-1 / \sigma}}{y_{j}{ }^{-1 / \sigma}}=\frac{p_{i} y_{i}}{p_{j}}$ and summing up the numerator gives $\frac{\sum y_{i}^{1-1 / \sigma}}{y_{j}^{-1 / \sigma}}=\frac{\sum p_{i} y_{i}}{p_{j}} \Rightarrow \frac{\alpha I}{p_{j}}=\frac{\sum y_{i}^{1-1 / \sigma}}{y_{j}^{-1 / \sigma}}$ and this results in the following inverse demand curve:

$$
p_{j}=\alpha I \frac{y_{j}^{-1 / \sigma}}{\sum y_{i}^{1-1 / \sigma}}
$$

If we compare the two demand curves we see that they have a similar structure.

\section{A.4.6 Firm Behaviour; Profit Maximization and Competition}

Because firm will produce a unique variety and thus acts as a monopolist and will charge a price in excess of the marginal costs. The mark-up over the marginal costs depends on the price elasticity. With respect to production costs it is assumed that all firms producing different varieties have the same fixed and marginal (variable) costs. This results in the following homothetic cost function;

$$
C\left(y_{j}\right)=c_{j} y_{j}+F_{j} \text { for } j=1, \ldots, n
$$

where $c_{j}$ are the variable / marginal cost for variety $j$ and $F$ are the fixed costs for variety $i$. From the cost function it is clear that the production of variety's exhibits increasing returns to scale internal to the firm because the average costs are decreasing $\left(A C\left(y_{j}\right)=c_{j}+\frac{F_{j}}{y_{j}}\right)$.

\section{Profit maximization,}

There are two possibilities for the firm to operate in the market. It can use its prise to compete, (Bertrand competition) or it can use its quantity to compete (Cournot competition).

\section{Bertrand competition}

We first start with price competition that is the firm competes on price. For all variety producing firms we have the following profit function 


$$
\pi_{j}=p_{j} y_{j}\left(p_{j}\right)-c_{j} y_{j}\left(p_{j}\right)-F_{j}
$$

Note that the quantity produced by the firms depends on the price the firms charge, see equation (A4.17). I we substitute this equation in the profit function, this results in the following profit function;

$$
\pi_{j}=\alpha I \frac{p_{j}^{1-\sigma}}{\sum_{i=1}^{n} p_{i}^{1-\sigma}}-\alpha I \frac{p_{j}{ }^{-\sigma}}{\sum_{i=1}^{n} p_{i}^{1-\sigma}} c_{j}=\alpha I\left(\frac{p_{j}^{1-\sigma}-p_{j}{ }^{-\sigma} c_{i}}{\sum_{i=1}^{n} p_{i}^{1-\sigma}}\right)
$$

Next to find the optimal price we differentiate the profit function with respect to price and set it equal to 0 to find the extreme value of the profit function.

$$
\frac{\partial \pi_{j}}{\partial p_{j}}=\alpha I\left(\frac{\left\{(1-\sigma) p_{j}^{-\sigma}+\sigma p_{j}^{-\sigma-1} c_{j}\right\}\left\{\sum_{i=1}^{n} p_{i}^{1-\sigma}\right\}-(1-\sigma) p_{j}^{-\sigma}\left\{p_{j}^{1-\sigma}-p_{j}^{-\sigma} c_{j}\right\}}{\left[\sum_{i=1}^{n} p_{i}^{1-\sigma}\right]^{2}}\right)=0
$$

Because the denominator of the above equation is unequal 0 the numerator has to be equal to 0 that is $\left\{(1-\sigma) p_{j}^{-\sigma}+\sigma p_{j}^{-\sigma-1} c_{j}\right\}\left\{\sum_{i=1}^{n} p_{i}^{1-\sigma}\right\}=(1-\sigma) p_{j}^{-2 \sigma}\left\{p_{j}-c_{j}\right\}$ next multiplying by $\frac{p_{j}^{\sigma+1}}{\left\{\sum_{i=1}^{n} p_{i}^{1-\sigma}\right\}}$ and rearranging results in ${ }^{198}$

$$
p_{j}=\frac{\sigma-(\sigma-1) s_{j}}{(\sigma-1)\left(1-s_{j}\right)} c_{j}
$$

As can be seen the price is a fixed markup on the marginal cost. The mark up depends on the price elasticity and the market share and the parameter $\sigma>1$ (elasticity of substitution). We

\footnotetext{
${ }^{198}(1-\sigma)\left(1-s_{j}\right) p_{j}=\left[-\sigma-(1-\sigma) s_{j}\right] c_{j}$ thus $(\sigma-1)\left(1-s_{j}\right) p_{j}=\left[\sigma-(\sigma-1) s_{j}\right] c_{j}$ which results in equation (A4.20).
} 
know that the price is determined by a mark-up depending on the price elasticity, over marginal cost in the following way $p_{j}=\frac{1}{1-\frac{1}{\varepsilon}} c_{j}$. Using this the price elasticity equals:

$$
\varepsilon_{\text {Bertrand }}=\sigma-(\sigma-1) s_{j}{ }^{199} .
$$

As noted before if the market share $\left(s_{j}\right)$ of variety $j$ decreases, the price elasticity increases.

If the output is the same for all varieties and there are $n$ varieties than the market share of variety $j$ becomes; $s_{j}=\frac{p_{j}{ }^{1-\sigma}}{\sum_{i=1}^{n} p_{i}{ }^{1-\sigma}}=\frac{1}{n}$. In case the number of varieties is large that is $\frac{1}{n}$ tends to zero we have a mark-up over marginal costs of $\frac{\sigma}{\sigma-1}>1$ and a price elasticity of $\sigma$.

\section{Cournot competition}

If firms determine the optimal output to maximize their profit and thus use quantity to compete we have Cournot type of competition. Again using equation (A4.19) to express the price in terms of output. Substituting the indirect demand function we find the associated profit function:

$$
\pi_{j}=p_{j}\left(y_{j}\right) y_{j}-c_{j} y_{j}-F_{j} \Rightarrow \pi_{j}=\frac{y_{j}^{1-1 / \sigma}}{\sum_{i=1}^{n} y_{i}^{1-1 / \sigma}} \alpha I-c_{j} y_{j}-F_{j}
$$

To find the optimal output level which generates maximum profit equals we differentiate the profit function with respect to output and set it equal to zero:

$$
\frac{d \pi_{j}}{d y_{j}}=\frac{(1-1 / \sigma) y_{j}{ }^{-1 / \sigma} \sum_{i=1}^{n} y_{i}^{1-1 / \sigma}-(1-1 / \sigma) y_{j}{ }^{-1 / \sigma} y_{j}^{1-1 / \sigma}}{\left(\sum_{i=1}^{n} y_{i}^{1-1 / \sigma}\right)^{2}} \alpha I-c_{i}=0
$$

$$
\begin{aligned}
& 1991-\frac{1}{\varepsilon}=\frac{(\sigma-1)\left(1-s_{j}\right)}{\sigma-(\sigma-1) s_{j}} \text { and } \frac{\sigma-(\sigma-1) s_{j}}{\sigma-(\sigma-1) s_{j}}-\frac{(\sigma-1)\left(1-s_{j}\right)}{\sigma-(\sigma-1) s_{j}}=\frac{1}{\varepsilon} \text { and } \\
& \frac{\sigma-\sigma s_{j}+s_{j}-\sigma+\sigma s_{j}+1-s_{j}}{\sigma-(\sigma-1) s_{j}}=\frac{1}{\varepsilon} \text { which can be rewritten as } \frac{1}{\sigma-(\sigma-1) s_{j}}=\frac{1}{\varepsilon} .
\end{aligned}
$$


This results in the following price equation ${ }^{200}$ :

$$
p_{j}=\frac{\sigma}{(\sigma-1)\left(1-s_{j}\right)} c_{i}
$$

In this case the price elasticity equals:

$$
\varepsilon_{\text {Cournot }}=\frac{\sigma}{1+(\sigma-1) s_{j}}
$$

If the output of the varieties is the same and there are $n$ varieties the market share equals $1 / n$. If the number of varieties is large the market share reduces to zero. The mark up over marginal cost than becomes $\frac{\sigma}{\sigma-1}>1$ (see equation (A4.23) and the price elasticity equals $\sigma$ and see equation (A4.24)).

Thus if the number of varieties is large Bertrand and Cournot competition results in the same fixed price elasticity and the same fixed mark up over marginal costs, independent of the market share of the variety.

\section{Price elasticity of the demand}

Calculating the price elasticity of the direct demand curve and the indirect demand curve. Of course we can directly calculate the price elasticity using equation (4A.19) ${ }^{201}$ :

$200\left\lfloor(1-1 / \sigma) y_{j}^{-1 / \sigma}-(1-1 / \sigma) y_{j}^{-1 / \sigma} \frac{y_{j}^{1-1 / \sigma}}{\sum_{i=1}^{n} y_{i}^{1-1 / \sigma}}\right\rfloor \frac{\alpha I}{\sum_{i=1}^{n} y_{i}^{1-1 / \sigma}}=c_{i}$

$\left\lfloor(1-1 / \sigma)-(1-1 / \sigma) \frac{y_{j}{ }^{1-1 / \sigma}}{\sum_{i=1}^{n} y_{i}{ }^{1-1 / \sigma}}\right\rfloor \frac{y_{j}{ }^{-1 / \sigma} \alpha I}{\sum_{i=1}^{n} y_{i}{ }^{1-1 / \sigma}}=c_{i} \Rightarrow p_{j}\left[(1-1 / \sigma)-(1-1 / \sigma) s_{j}\right]=c_{i}$ note that

$s_{j}=\frac{y_{j}{ }^{1-1 / \sigma}}{\sum_{i=1}^{n} y_{i}{ }^{1-1 / \sigma}}$ and $p_{j}=\alpha I \frac{y_{j}{ }^{-1 / \sigma}}{\sum y_{i}{ }^{1-1 / \sigma}}$. 


$$
\frac{d y_{j}}{d p_{j}} \frac{p_{j}}{y_{j}}=\frac{-\sigma \alpha I p_{j}^{-\sigma-1} \sum_{i=1}^{n} p_{i}^{1-\sigma}-(1-\sigma) p_{j}^{-\sigma} \alpha I p_{j}^{-\sigma}}{\left(\sum_{i=1}^{n} p_{i}^{1-\sigma}\right)^{2}} \times \frac{p_{j}}{\frac{\alpha I p_{j}^{-\sigma}}{\sum_{i=1}^{n} p_{i}^{1-\sigma}}}=-\sigma+(\sigma-1) s_{j}
$$

In the same way the we can use the inverse demand (equation (A4.17)) for calculating the price elasticity.

\section{A.4.7 The Large Number Assumption}

As Martin et al. (2004, pp. 40-46) point out, the large number of varieties assumption of goods have important implications.

\section{Fixed mark-up}

In the case of large number of varieties, the optimal price is a constant markup over marginal costs, and the equilibrium price does not depend on the type of competition. Thus the demand of varieties only depends on their own price but not on the market share of the variety and is the same for all existing varieties.

\section{Fixed firm scale}

This also means that given the constant mark up, free entry and homothetic cost function that the quantity of output and the price of the varieties are the same because they all depend on the same parameter and the profit functions are identical for all varieties. It also implicates that the scale of the firm in equilibrium is fixed. If the price exceeds the marginal costs, because $\left(\frac{\sigma-1}{\sigma}\right)>1$ than firm makes a profit in the short run. Because of free entry new firms

201

$$
\begin{aligned}
& \frac{-\sigma \alpha I p_{j}{ }^{-\sigma-1} \sum_{i=1}^{n} p_{i}^{1-\sigma}-(1-\sigma) p_{j}{ }^{-\sigma} \alpha I p_{j}{ }^{-\sigma}}{\left(\sum_{i=1}^{n} p_{i}^{1-\sigma}\right)^{2}} \times \frac{p_{j}}{\frac{\alpha I p_{j}{ }^{-\sigma}}{\sum_{i=1}^{n} p_{i}{ }^{1-\sigma}}}= \\
& \frac{-\sigma p_{j}{ }^{-\sigma-1} \sum_{i=1}^{n} p_{i}{ }^{1-\sigma}-(1-\sigma) p_{j}{ }^{-\sigma} \alpha p_{j}{ }^{-\sigma}}{\left(\sum_{i=1}^{n} p_{i}{ }^{1-\sigma}\right)} \times p_{j}{ }^{1+\sigma}=-\sigma-(1-\sigma) \frac{p^{1-\sigma}}{\sum_{i=1}^{n} p_{i}{ }^{1-\sigma}} .
\end{aligned}
$$


will enter the market. This reduces the demand for the existing types of goods and thus the firm's profit. This process will continue until the profit reduces to zero, or in other words when the price equals the average cost the market is in equilibrium, no firm will enter nor exit the market. In equilibrium we have:

$$
p_{j}=\frac{\sigma}{\sigma-1} c_{j}=c_{j}+\frac{F_{j}}{y_{j}}
$$

From this equilibrium condition the equilibrium output of the firm can be calculated, that is:

$$
y_{j}=\frac{F_{j}}{c_{j} \frac{1}{\sigma-1}}
$$

This is simply the fixed cost divided by the profit rate or there where the firm breaks even.

The fixed cost just equals net operating profit that is revenue's minus variable costs. Because the costs parameters are the same and the parameter the equilibrium output is fixed.

There are two more important implications that is; in equilibrium there is only one variety per firm and there is only one firm per variety. As Baldwin et al. show these are rather results than assumptions.

\section{One variety per firm}

When a firm produces more varieties than the elasticity exceeds $\sigma$. and the firm will charge a price which is in excess of that of a firm producing just one variety. This will decrease its demand and finally reduce to zero as long as the price is in excess of that of a single producing firm.

\section{One firm per variety}

If a firm decides to produce exact the same variety as an already existing firm than it faces Cournot or Betrand competition. The associated profit is in this case is below the profit that can be earned by producing a unique variety, so the firm will finally decide for production of a new variety.

\section{Elasticity of substitution and price elasticity of demand}

If the price elasticity does not depend on the price of other product if the number of competitors becomes large, and their market share is low it easy to calculate the price 
elasticity, which equals $\varepsilon_{d}=-\sigma^{202}$ In the same way the elasticity of substitution which equals $\varepsilon_{s}=-\sigma^{203}$

As Baldwin et al. note, the above features make the Dixit-Stiglitz model of Monopolistic Competition extremely handy and tractable, but one can question whether this large number assumption is realistic.

${ }^{202}$ Rewriting equation (A4.6) and differentiating results in $\ln y_{i}-\ln y_{j}=-\sigma\left\{\ln p_{i}-\ln p_{j}\right\} \Rightarrow$ $d \ln y_{i}=-\sigma d \ln p_{i} \frac{1}{y_{i}} d y_{i}=-\sigma \frac{1}{p_{i}} d p_{i} \Rightarrow \frac{d y_{i}}{d p_{i}} \frac{p_{i}}{y_{i}}=-\sigma=\varepsilon_{d}$ ${ }^{203}$ Rewriting equation (A4.6) in log's and differentiating results in $\ln \left(\frac{y_{i}}{y_{j}}\right)=-\sigma \ln \left(\frac{p_{i}}{p_{j}}\right)$ and $d \ln \left(\frac{y_{i}}{y_{j}}\right)=\frac{1}{\frac{y_{i}}{y_{j}}} d\left(\frac{y_{i}}{y_{j}}\right)=-\sigma d \ln \left(\frac{p_{i}}{p_{j}}\right)=\frac{1}{\frac{p_{i}}{p_{j}}} d\left(\frac{p_{i}}{p_{j}}\right) \Rightarrow \frac{d\left(\frac{y_{i}}{y_{j}}\right)}{d\left(\frac{p_{i}}{p_{j}}\right) \frac{p_{j}}{y_{i}}}=-\sigma=$ 


\section{Appendix 5}

Romer's Model of Endogenous

Technological Change 


\section{A.5.1 Introduction}

In this appendix we will pay attention to the Romer model of expanding varieties of endogenous growth theory (EGT). The reason for this is that we use part of EGT to describe endogenous technological progress and its externalities. One of the basic insights from EGT is that creation of knowledge is intentionally the result of microeconomic firm behaviour which results in positive externalities for the overall economy. However for knowledge creation investments are needed which have to be financed by firms' profits which is not possible in a perfect competitive environment. Other market forms like monopoly, oligopoly and monopolistic competition do allow firms to make profits. Especially the market of monopolistic competition appears to be suitable for our analysis.

Additional to that, new or endogenous growth theory ${ }^{204}$ incorporates two important points. First it views technological progress as a product of economic activity. Previous theories, such as neo classical growth theory, treated technology as given, or a product of nonmarket forces. new growth theory is often called "endogenous" growth theory because it internalizes technology into a model of how markets function.

Secondly, EGT holds that unlike physical objects, knowledge and technology are characterized by increasing returns, which drive the process of growth. Because ideas (and thus knowledge) can be infinitely shared and reused, knowledge can be accumulated without limits. This contrary to the use of (physical) capital goods which leads to obsolesce and depreciation which results in decreasing returns to scale.

In EGT the market plays a central role in knowledge creation and technical progress. Firms invest in research and development because this can result in profits if they are successful. They can make use of the available stock of knowledge without cost. This leads not only to new products and new and more efficient production processes but also to an increase in the stock of knowledge and technological progress as a kind of unintended byproduct. This process of increasing returns to knowledge drives the process of economic growth.

In a perfectly competitive environment firms make no profit. Therefore there is no opportunity to invest in research and development. Thus perfect competition is not suited to analyse the role of research and development in the economy. As noted before, in the case of monopolistic competition, firms can make a profit. By investing in research and development firms can develop a unique product to become a monopolist which results in profits to finance further research and development. Romer (1990) used the model of monopolistic competition as developed by Dixit and Stiglitz (1977) to analyse the role of research and development and innovation on the economy's growth.

${ }^{204}$ There are a large number of non technical overview for example Cortright (2001). 
Ethier (1982) used the Dixit-Stiglitz model to analyse trade in differentiated intermediate goods. He used the functional form of the Dixit-Stiglitz utility function and interpreted it as a production function. On the one hand there is labour as a production factor, and on the other hand there is a variety of intermediate (capital) goods as a production factor. For the intermediate good a CES structure is applied with constant elasticity of substitution between the intermediate goods. In his approach more variety of intermediate goods leads to an increase in factor productivity. Ethiers' approach of the Dixit-Stiglitz model has been very important for the development of the new growth theory. Romer $(1987,1990)$ used Ethier's specification to model endogenous growth. In Romer's (1990) model, of endogenous growth, increasing returns to scale results from specialisation in the production of intermediate goods. The Dixit and Stiglitz approach is used to model horizontal product differentiation. Because of this product differentiation firms producing intermediates can make a profit. This profit opportunity is used by firms to innovate in new products (i.e. a new variety of intermediate goods) by investing in research and development. Often a special case of the CES structure of intermediate goods in the production function is used.

In this appendix we successively review the basic elements of EGT as introduced by Romer (1990) which is often revered to as the product variety model. We start with describing the production side of the economy, the production of final goods in section A.5.2, A.5.3. In section A.5.4 and A.5.5. we further review the expanding varieties model of Romer (1990) where firms invest in research and development and create new types of different varieties of capital goods. What this means in terms of output and income is resumed in section A.5.6. In the last section (A.5.7) we look at the positive externalities of innovation for the economy leading to endogenous growth.

\section{A.5.2 Production of Final Goods}

First we resume with final output and the profit maximizing behaviour of the final goods sector by looking at a representative firm $j$. Final goods production and output for each finalgoods-producing firm equals:

$$
Y_{j}=L_{j}^{1-\alpha} K_{j}^{\alpha}
$$

Here $K_{j}=\left[\sum_{i=1}^{N} K_{i, j} \frac{\sigma-1}{\sigma}\right]^{\frac{\sigma}{\sigma-1}}$ and $K_{i, j}$ for $i=1, \ldots, N$ are $N$ different varieties (types) of capital goods used for production of final goods by firm $j$. This type of production function exhibits the same properties at the Dixit-Stiglitz utility function in the model of monopolistic 
competition as it was described before. The parameter $\sigma$ is an indicator of substitutability (elasticity of substitution) between the different types of capital goods. In case we set $\frac{\sigma-1}{\sigma}=\alpha$ and inserting in the above expression, this leads to $K_{i}^{\alpha}=\left[\sum_{j=1}^{N} K_{i, j}^{\alpha}\right]^{\frac{1}{\alpha} \times \alpha}=\sum_{j=1}^{N} K_{i, j}^{\alpha}$, that means there is no substitutability between the different types of capital goods. Using this result and substituting this in the production function of equation (A5.1) we have the following adjusted production function:

$$
Y_{j}=L_{j}^{1-\alpha} \sum_{i=1}^{N} K_{i, j}^{\alpha}
$$

Output of final goods by firm $j$ depends on labour and capital. Although labour and aggregate capital can be substituted, this is not the case between the different types of capital used by firm $j$. The production function is additive in the different types of capital goods.

\section{A.5.3 Final-Goods-Producing Firms; Profit Maximization}

Profits of final-goods-producing firms are revenues minus cost. The market for final goods is fully competitive therefore the profit function of one firm represents the profit function of the final goods sector of the economy. If we normalize the price of final goods to one then this results in the firm's profit function below:

$$
\pi_{j}=Y_{j}-w L_{j}-\sum_{i=1}^{N} p_{j} K_{i, j} \text { for } j=1, \ldots, N
$$

If the labour market and the market for final goods are also fully competitive then the wage rate for each firm is the same and equals the economy wide wage rate. Maximizing the profits of the final goods sector results in the first order conditions with respect to labour $(L)$ and all $N$ types of capital goods $\left(K_{j}\right.$ for $\left.j=1, \ldots, N\right)$ :

$$
\begin{aligned}
& \frac{\partial \pi}{\partial L}=\frac{\partial Y}{\partial L}-w=0 \text { and } \frac{\partial Y}{\partial L}=(1-\alpha) L^{-\alpha} \sum_{j=1}^{N} K_{j}^{\alpha} \\
& \frac{\partial \pi}{\partial K_{j}}=\frac{\partial Y}{\partial K_{j}}-p_{j}=0 \text { and } \frac{\partial Y}{\partial K_{j}}=\alpha L^{1-\alpha} K_{j}^{\alpha-1} \text { resulting in: } \alpha L^{1-\alpha} K_{j}^{\alpha-1}=p_{j} \quad j=1, \ldots, N
\end{aligned}
$$


The economy wide wage rate, which equals the marginal product of labour, can be derived from the first order condition above:

$$
w=w_{j}=(1-\alpha) L^{-\alpha} \sum_{j=1}^{N} K_{j}^{\alpha} \text { for } j=1, \ldots, N
$$

The other $N$ first order conditions result in the price of the $N$ different types of capital goods, which equal their marginal product resulting in the inverse and direct demand curves:

$$
p_{j}=\alpha L^{1-\alpha} K_{j}^{\alpha-1} \text { for } j=1, \ldots, N
$$

This relation is used to derive the demand for all $N$ different types of capital goods, which equals:

$$
K_{j}=\frac{\alpha^{1 /(1-\alpha)} L}{p_{j}{ }^{1 /(1-\alpha)}} \text { for } j=1 \ldots, N
$$

Using the two expressions above the price elasticity of demand for capital goods can be calculated. Using equation (A5.5) or (5.6) we find the following price elasticity of demand:

$$
\varepsilon_{d}=\frac{d K_{j}}{d p_{j}} \frac{p_{j}}{K_{j}}=-\frac{1}{(1-\alpha)}
$$

This price elasticity is used by the capital-goods-producing firms to charge a monopolistic price above marginal costs. The mark-up thus depends on the elasticity of the demand for capital goods.

\section{A.5.4 Capital-Goods-Producing Firms; Profit Maximization}

The profit of firm $j$, who has invented a new type of capital good, is revenue minus cost. The revenues are the price multiplied by the quantity of types of capital goods. The firm can produce a new type of capital good by applying the available knowledge, which is represented in the number of types of capital to transfer one unit of final good in a new capital good. The stock of knowledge is non rival and non exclusive, so there are no costs associated with using it. This results in the following production function and cost function of capital goods:

$$
K_{j}=\gamma_{j} Y_{j}
$$


The output of type $K_{j}$ depends on the amount of final goods, where $\gamma_{j}$ is the amount of final goods needed to produce the amount of $K_{j}$ capital goods of type $j$. For simplicity we set $\gamma_{j}=1$. At the same time the costs of producing one unit of capital good are one unit of final good at a price of one. Final goods are thus transferred into the capital good of type $j$. Using R\&D one unit of final good is transferred into one unique new capital good. This actually means that there is a linear production function for producing capital goods. Using the profit function of the capital good firms, $\pi_{j}=p_{j} K_{j}-K_{j}$ and using the price relation (A5.5) we find:

$$
\pi_{j}=\alpha L^{1-\alpha} K_{j}^{\alpha}-K_{j} \quad j=1, \ldots, N
$$

All capital-goods-producing firms are maximizing the profit with respect to output, that is 'Cournot' Competition, this results in:

$$
\frac{\partial \pi_{j}}{\partial K_{j}}=\alpha^{2} L^{1-\alpha} K_{j}^{\alpha-1}-1=0 \quad j=1, \ldots, N
$$

From that the output of capital goods which maximizes the firms profit is derived and this equals:

$$
K_{j}=K=\alpha^{\frac{2}{1-\alpha}} L \quad j=1, \ldots, N
$$

Using the optimal output and inserting this in the second FOC condition, or in the demand function for capital goods, gives us the price the capital good producing firms charge:

$$
p_{j}=p=\alpha L^{1-\alpha}\left[\alpha^{\frac{2}{1-\alpha}} L\right]^{\alpha-1}=\frac{1}{\alpha} \quad j=1, \ldots, N
$$


Note that this result coincides with the fixed mark-up price. The price equals the marginal cost times $\frac{1}{\left(1-\frac{1}{\varepsilon}\right)}=\frac{1}{\alpha}{ }^{205}$. The last equation can be used to calculate the profit of the capital good producing firm. Note that $\pi_{j}=p_{j} K_{j}-K_{j}=\left(p_{j}-1\right) K_{j}$, and $\left(p_{j}-1\right)=\frac{1-\alpha}{\alpha}$ which is the profit rate. The profit of a type $j$ capital good producing firm equals the profit rate multiplied by output:

$$
\pi_{j}=\pi=\frac{1-\alpha}{\alpha} K=(1-\alpha) \alpha^{\frac{1+\alpha}{1-\alpha}} L \text { for } j=1, \ldots, N
$$

We can also use the profit function, $\pi_{j}=\left(p_{j}-1\right) K_{j}$, and maximize this function with respect to the price, that is Bertrand Competition and determine the price which maximizes profit. This results in:

$$
\begin{aligned}
& \frac{\partial \pi_{j}}{\partial p_{j}}=K_{j}+\left(p_{j}-1\right) \frac{d K_{j}}{d p_{j}}=0 \Rightarrow K_{J}=\left(p_{j}-1\right) \frac{1}{(1-\alpha) \alpha L^{1-\alpha} K_{j}{ }^{\alpha-2}} \\
& \frac{K j}{P_{j}}=\frac{1}{\alpha L^{1-\alpha} K_{j}^{\alpha-2}}=\left(1-\frac{1}{p_{j}}\right) \frac{1}{(1-\alpha) \alpha L^{1-\alpha} K_{j}^{\alpha-2}} \quad\left(1-\frac{1}{p_{j}}\right)=(1-\alpha) \Rightarrow \\
& p_{j}=\frac{1}{\alpha} \text { which equals equation (A5.10) }
\end{aligned}
$$

Inserting this price in the demand function also gives us the equilibrium output of capital goods which maximizes the profit of capital good producing firms:

$$
K_{j}=K=\frac{\alpha^{1 / 1-\alpha} L}{\left(\frac{1}{\alpha}\right)^{1 / 1-\alpha}}=\alpha^{2 / 1-\alpha} L \text { for } j=1, \ldots, N(\mathrm{~A} 5.12)
$$

Of course the profit rate and profits are the same as above. Note that the result only depends on labour which is fixed, and therefore the profits of the capital-goods-producing firms are also fixed.

${ }^{205} 1-\frac{1}{\left|\frac{1}{1-\alpha}\right|}=(1-(1-\alpha))=\alpha$. 
Profit maximization is where marginal revenue ${ }^{206}, M R=\alpha^{2} L^{1-\alpha} K_{j}{ }^{\alpha-1}$ meets marginal costs which equals $M C=1^{207}$. This results in equilibrium quantity and price ${ }^{208}$.

\section{Figure 5.1 Demand for and Supply of Capital Goods for all $N$ Capital goods}

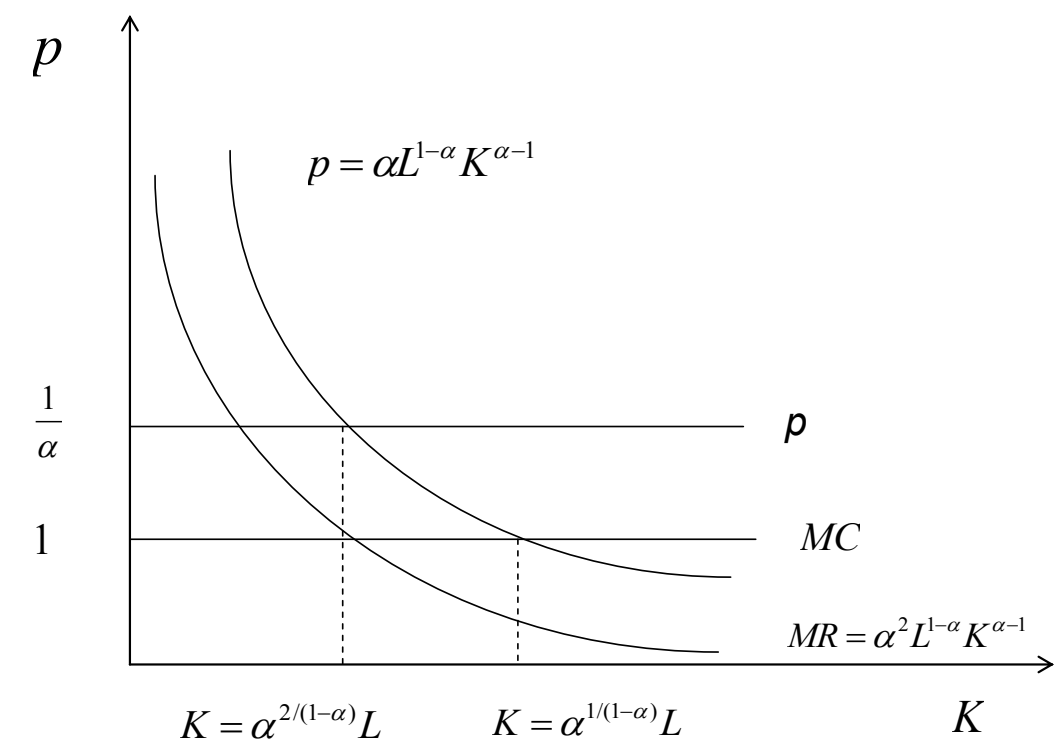

If we look at figure A5.1 we see what the welfare consequences are for the economy if capital-good-producing firms charge a price above marginal costs. Therefore we have to look at the producer's and consumers surpluses. In case of perfect competition the producer's surplus is zero (no profits). The consumer surplus equals the area under the demand curve up to the point where the price equals marginal costs which equals 1 . In case of monopoly, the

${ }^{206}$ Total revenue equals $T R=p_{j} * K_{j}=\alpha L^{1-\alpha} K_{j}^{\alpha-1} * K_{j}=\alpha L^{1-\alpha} K_{j}^{\alpha}$ and $M R=\frac{d T R}{d K_{j}}=\alpha^{2} L^{1-\alpha} K_{j}^{\alpha-1}$ resulting in quantity and price of capital goods.

${ }^{207}$ The social planner maximization problem equals $\operatorname{Max} \sum_{t=0}^{\infty}\left[\frac{1}{1+\rho}\right]^{t} u\left(c_{t}\right)$ subject to the resource constraint $N_{t} L^{1-\alpha} K^{\alpha}{ }_{t}=C_{t}+N_{t} K_{t}+Z_{t}$ resulting in $\alpha N_{t} K^{\alpha-1}{ }_{t}=N_{t}$ and $K_{t}=K=\alpha^{\frac{1}{1-\alpha}}$.

${ }^{208}$ The quantity results from $M R=\alpha^{2} L^{1-\alpha} K_{j}^{\alpha-1}=1=M C$ or $\alpha^{2} L^{1-\alpha}=K_{j}{ }^{1-\alpha}$. Next using $K_{j}^{\alpha-1}=\frac{1}{\alpha^{2} L^{1-\alpha}}$ to substitute in the price equation $p_{j}=\alpha L^{1-\alpha} K_{j}^{\alpha-1}$ results in the equilibrium price $p_{j}=1 / \alpha$. 
producer's surplus equals that of the profit of the firm which equals the rectangular $\left(\frac{1}{\alpha}-1\right) \alpha^{\frac{2}{(1-\alpha)}} L$. This equals the pecuniary externality of innovation. The consumer surplus is the area under the demand curve up to the point where the price equals $p=\frac{1}{\alpha}$. It is easy to see that consumers and producer's surpluses in case of perfect competition exceed those of capital good producing firms where they charge a price above marginal costs. Because all firms charge the same price and produce the same output for the overall economy the pecuniary externalities have to be multiplied by $N_{t}$, that is the number of firms.

If innovation can be patented for example for one period, then the value of such an innovation equals the future profits (next period). Discounting the future profits gives us the value of innovations or the price of a capital good.

$$
\frac{\pi}{R}=\frac{1}{R}(1-\alpha) \alpha^{\frac{1+\alpha}{1-\alpha}} L
$$

As will be shown later, the return on capital is constant. We have assumed that profits are available for the firm next period.

\section{A.5.5 Research and Development}

For capital-goods-producing firms, in order to innovate, they have to invest in research and development to create a unique type of capital good. The firm has to determine how much to investment in research and development to maximize profit. We assume that the cost, measured in final goods, of doing research is:

$$
\Delta N_{t}=\theta Z_{t} \text { or } N_{t+1}=N_{t}+\theta Z_{t}
$$

Here $Z_{t}$ is the expenditure (measured in final goods at a price of 1) on research and development and $\theta$ is a parameter indicating the productivity of research and development. $\Delta N_{t}$ is the output of research which at the same time increases the stock of knowledge. Because existing knowledge $\left(N_{t}\right)$ does not depreciate and is freely available to all firms, this leads to competition between firms producing capital goods. This also why the "production function" of knowledge / new types of capital goods is linear and exhibits constant returns to scale. 
Firms that maximize profit will continue to spend resources on research and development up to the point where marginal revenues equal marginal costs. The revenues are output time the price of capital goods. The price in a competitive environment equals all discounted future profits. The total discounted value of profits equals $\frac{\pi}{R}$ which is the price of capital goods. The output, new capital goods resulting from research and development, equals $\Delta N_{t}$. That means we have:

$$
\Delta N_{t} \frac{\pi}{R}-Z_{t}
$$

Inserting the relation between resources spent and output of research and development (production function of knowledge / new capital goods types) results in:

$$
\pi_{R \& D}=\theta Z_{t} \frac{\pi}{R}-Z_{t}
$$

Here $\pi_{R \& D}$ is the profit investing in research and development. Maximizing profit means differentiating the profit function with respect to used resources for investments in research and development. This results in the equality between marginal revenue and marginal cost, that is:

$$
\theta \frac{\pi}{R}=1
$$

Because of free entry and competition the profits tend to zero. The above results in $R=\theta \pi$, and substituting profit results in return on capital:

$$
R=\left\{\theta(1-\alpha) \alpha^{\frac{1+\alpha}{1-\alpha}} L\right\}
$$

\section{A.5.6 Innovation, Output, Income and Growth}

As in the previous appendix, to see the development of the economy over time we need the distribution of income between labour and capital. Because we use a two period overlapping generation's model, savings accrue out of labour income in the first period. Previous these saving were used for capital formation which resulted in next period's capital stock and 
production capacity. No savings are used for next period's capital stock but also for research and development which increases the number of varieties and the overall economic productivity.

\section{Production and output}

To see what the innovative firm contributes to the regional economy we make use a of a footnote by Barro and Sala-i-Martin (1996) ${ }^{209}$. Below Romer's expanding product variety model of endogenous growth by innovation is summarized.

$$
Y_{t}=L^{1-\alpha} \sum_{j=1}^{N_{t}} K_{j}^{\alpha}=N_{t} L^{(1-\alpha)} K^{\alpha}
$$

This equation can also be written as $Y_{t}=\bar{A} N_{t}$ where $\bar{A}=L \alpha^{\frac{2 \alpha}{1-\alpha} 210}$. This production function is similar to the production function which is used in neo classical growth theory. In both cases the firm's capital stock is in equilibrium. In neo classical growth theory this equals aggregate capital stock. In the Romer's model this is not the case. Aggregate capital stock is determined by the number of types, and this is endogenously determined.

It follows that the development of income depends on the existing stock of technology which depends on the effort in R\&D. It is easy to see that production growth equals the growth of the number of different capital goods, or the variety of capital goods, that is $\frac{Y_{t+1}}{Y_{t}}=\frac{N_{t+1}}{N_{t}}=1+g$.

\section{Income}

Next we want to find out how these externalities influence the income distribution. To analyse the development of income resulting from innovation we make use of the following equation of income distribution:

$$
Y_{t}-N_{t} K=w_{t} L+R N_{t} \pi
$$

\footnotetext{
${ }^{209}$ See Barro and Sala-i-Martin (1994, footnote 9 on page 219): 'Since the factor prices equal the respective marginal product, the households aggregate income, $w L+r \pi N$, can be shown to equal the economy's net product, $Y-N K$, ${ }^{210}$ Inserting the optimal; capital stock equation (A5.12) $K_{j}=K=\alpha^{\frac{2}{1-\alpha}} L$ results in $Y_{t}=N_{t} L^{(1-\alpha)}\left(\alpha^{\frac{2}{1-\alpha}} L\right)^{\alpha}$.
} 
Net income $\left(Y_{t}-N_{t} K\right)$, gross production minus the used inputs for producing capital goods, is paid as remuneration for labour $\left(w_{t} L\right)$ and capital $\left(R N_{t} \pi\right)$ according to the marginal product of those factors.

We can see that the production function has a Cobb-Douglas structure (equation (A5.1) and (A5.2)). One of the properties of the Cobb-Douglas is that factor incomes are fixed proportions of total income. Using this property we can find the share of wage and capital income. The wage rate which equals the marginal product of labour is derived by multiplying equation (A5.4) by labour force. Next we can insert the equilibrium level of capital. The income share of labour amounts to the wage rate multiplied by the amount of labour:

$$
L w_{t}=(1-\alpha) N_{t} L^{1-\alpha} K^{\alpha} \text { implying that } L w_{t}=(1-\alpha) N_{t} L \alpha^{\frac{2 \alpha}{1-\alpha}}=(1-\alpha) \bar{A} N_{t}
$$

Labour income increases because the wage rate increases (we assume that there is no population growth thus the labour force is fixed). The wage rate increases because labour productivity increases ${ }^{211}$.

Additional to labour income we have capital income which consists of income from assets holdings. We assume that total assets are evenly distributed among the old generation of the population that invests in innovative firms when they are young. The total assets consist of all discounted profits of all capital-good-producing firms each producing a unique capital good's. This amounts to:

$$
T A=\frac{\pi}{R} N_{t}
$$

Here $T A$ is the total amount of assets in the economy. Next we can easily determine income from asset holdings. This is of course the return on capital times the amount of assets in the economy. Therefore the capital income in the economy equals:

$$
\text { Capital income }=R\left(\frac{\pi}{R} * N_{t}\right)=N_{t} \pi=N_{t} \frac{1-\alpha}{\alpha} K=(1-\alpha) \alpha \bar{A} N_{t}{ }^{212}
$$

\footnotetext{
${ }^{211}$ Dividing total output by the labour force result in the production per unit labour. This equals $\frac{Y_{t}}{L}=y_{t}=N_{t} k^{\alpha}$ where $k=\frac{K}{L}$ Capital labour ratio is constant in equilibrium.
} 
Capital income increases because of new varieties of capital goods. Profits however remain the same for all different types of capital goods.

Wage income plus capital income equals net income. If we substitute the above result in $Y_{t}-N_{t} K=w_{t} L+N_{t} \pi$ we find $N_{t} L^{1-\alpha} K^{\alpha}-N_{t} K=(1-\alpha) N_{t} L^{1-\alpha} K^{\alpha}+\frac{1-\alpha}{\alpha} N_{t} K$, which can be written as:

$$
\bar{A} N_{t}-\alpha^{2} \bar{A} N_{t}=(1-\alpha) \bar{A} N_{t}+(1-\alpha) \alpha \bar{A} N_{t}
$$

where $\bar{A}=L \alpha^{\frac{2 \alpha}{1-\alpha}}$. Dividing both side by $N_{t}$ and rearranging leads to: ${ }^{213}$

$$
K=\alpha^{2 /(1-\alpha)} L \text { or } K=\alpha^{2} \bar{A}
$$

This is of course the optimal value of different capital goods for profit-maximizing innovative firms. We will use the above result to determine the contribution of an innovative firm to regional activity.

\section{A.5.7 Economic Development; The Equation of Motion}

After having determined capital income and labour income, we can formulate the equation of motion which captures the development of the economy over time. The economy's total resources can be used for consumption, research and development and for next period capital formation. We know that the next period's capital stock equals the number of different types of capital good multiplied by the level of each capital good, which is fixed in equilibrium. Therefore we have the following resource constraint of the economy:

$$
Y_{t}-N_{t} K=C_{t}+N_{t+1} K+Z_{t} \text { or } Y_{t}-N_{t} K-C_{t}=N_{t+1} K+Z_{t}=S_{t}
$$

$$
\begin{aligned}
& { }^{212} K=\alpha^{2 /(1-\alpha)} L=\alpha^{2} A \text { and because } \alpha^{2} \alpha^{\frac{2 \alpha}{1-\alpha}}=\alpha^{\frac{2(1-\alpha)+2 \alpha}{1-\alpha}}=\alpha^{\frac{2-2 \alpha+2 \alpha}{1-\alpha}}=\alpha^{\frac{2}{1-\alpha}} \text { and } \\
& N_{t} \frac{1-\alpha}{\alpha} K=(1-\alpha) \alpha A N_{t} . \\
& { }^{213} L^{1-\alpha} K^{\alpha}-K=(1-\alpha) L^{1-\alpha} K^{\alpha}+\frac{1-\alpha}{\alpha} K \text { which implies that } \alpha L^{1-\alpha} K^{\alpha}=K+\frac{1-\alpha}{\alpha} K \text { and } \\
& \alpha L^{1-\alpha} K^{\alpha}=\frac{1}{\alpha} K \text { which results in } \alpha^{2} L^{1-\alpha}=K^{1-\alpha} .
\end{aligned}
$$


Reformulating this equation results and substituting equation (A5.14) for $Z_{t}$ results in $^{214}$ :

$$
S_{t}=N_{t+1} K+Z_{t}=\left(\alpha^{2} A+\frac{1}{\theta}\right) N_{t+1}-\frac{1}{\theta} N_{t}
$$

Savings are used for next period's capital formation but also for resources devoted to research. From the consumption side we already know that savings equals:

$$
S_{t}=\hat{s} w_{t} L=\hat{s}(1-\alpha) \bar{A} N_{t}
$$

Here $w_{t} L$ is given by equation (A5.20). Equating the two above equations gives us the equation of motion in terms of varieties of good, that is: ${ }^{215}$ :

$$
N_{t+1}=\frac{(\theta \hat{s}(1-\alpha) \bar{A}+1)}{\left(\theta \alpha^{2} \bar{A}+1\right)} N_{t}
$$

From this equation the following growth rate results:

$$
\frac{N_{t+1}}{N_{t}}=\frac{\theta \hat{s}(1-\alpha) \bar{A}+1}{\theta \alpha^{2} \bar{A}+1}=(1+g)
$$

A positive growth rate requires that $\frac{N_{t+1}}{N_{t}}>1$. That means that $\hat{s}(1-\alpha)>\alpha^{2} \mathrm{We}$ assume that this will hold ${ }^{216}$.

${ }^{214} N_{t+1} K+Z_{t}=N_{t+1} K+\frac{\Delta N_{t}}{\theta}=\left(K+\frac{1}{\theta}\right) N_{t+1}-\frac{1}{\theta} N_{t} \cdot$ Next substituting the equilibrium value of $K=\alpha^{2} \bar{A}$ (equation (A5.24)) we find $N_{t+1} K+Z_{t}=\left(\alpha^{2} A+\frac{1}{\theta}\right) N_{t+1}-\frac{1}{\theta} N_{t}$.

${ }^{215}\left(\alpha^{2} A+\frac{1}{\theta}\right) N_{t+1}-\frac{1}{\theta} N_{t}=\hat{s}(1-\alpha) \bar{A} N_{t}$ and this equals $\left(\alpha^{2} A+\frac{1}{\theta}\right) N_{t+1}=\left\lfloor\hat{s}(1-\alpha) \bar{A}+\frac{1}{\theta}\right\rfloor N_{t}$.

Multiplying both sides by $\theta$ and rearranging results in equation (A5.27).

${ }^{216} \theta \delta(1-\alpha) \bar{A}>\theta \alpha^{2} \bar{A}$ which means that $\hat{S}(1-\alpha)>\alpha^{2}$ If the labour share is about $75 \%$ and the capital share $25 \%$ this would mean that $\hat{S} 0,75>0,0625$ or $\hat{s}>0,0833$ remember that $\hat{s}=\frac{1}{2+\rho}$ and $\rho>1$ where $\rho$ is an indicator for the subjective rate of time preference. 


\section{References}


Aalders, R.,2007. Convergentie en Divergentie tussen Europese Regio's (Convergion and Diversion between European Regions), Economisch Statistische Berichten, Jaargang 92 no 4524 pp. 747-750.

Acemoglu, D.,S. Johnson \& J.A.Robinson., 2005. Institutions as a Fundamental Cause of Long-Run Growth, In: P. Aghion, \& S. Durlauf, ed. 2005. Handbook of Economic Growth 1(A). Amsterdam: Elsevier, pp. 385-472.

Acemoglu, D.,2009. Introduction to Modern Economic Growth. Princeton: University Press. Acemoglu, D., 2007. Introduction to Modern Economic Growth. [e-book] Cambridge: MA: MIT. Available at: www.econ-www.mit.edu/faculty/acemoglu /books lacemoglu ec growth 1.pdf \& acemoglu ec growth 2.pdf. [Accessed December 12-09-2007].

Anderson, L.R. \& C.A. Holt. 1996. Classroom Games: Information Cascades. Journal of Economic Perspectives, 10(4), pp. 187-193.

Anderson, L.R. \& C.H. Holt. 2008. Information Cascades Experiments, In: C. Plott \& V. Smith, eds 2008. Handbook of Experimental Economic Results 1. Amsterdam: NorthHolland Publishing, pp. 335-343.

Aghion, P \& P. Howitt., 2009. The Economics of Growth. Cambridge/London: The MIT Press.

Antonelli, C., 2009. Localized Technological Knowledge: Pecuniary Knowledge Externalities and Appropability. Papers on Economic \& Evolution 0709. Jena, Germany: Evolutionary Economics Group, Max Planck Institute of Economic.

Arrow, K.J.,1962. The Economic Implications of Learning by Doing. Review of Economic Studies 29, pp. 155-173.

Arrow, K.J. \& M. Kurz., 1970. Public Investments, the Rate of Return, and Optimal Fiscal Policy. Baltimore: John Hopkins Press.

Aschauer, D.A., 1989a. Does Capital Crowd out Private Capital?. Journal of Monetary Economics 24, pp. 171-188.

Aschauer, D.A., 1989b. Is Public Expenditure Productive?. Journal of Monetary Economics 23, pp. 177-200.

Aschauer, D.A., 1990. Is Government Spending Stimulative?. Contemporary Policy Issues 8, pp. 30-46.

Baldwin, R. R. Forslid, P. Martin, G. Ottoviano, \& F. Robert-Nicoud., 2003.,Economic Geography and Public Policy. Princeton: University Press.

Bannerjee, A.V.,1992. A simple Model of Herd Behavior. Quarterly Journal of Economics 107, pp.797-818.

Barro, R.J., 1990. Government Spending in a Simple Model of Economic Growth. Journal of Political Economy, 98, pp. 103-125.

Barro, R.J. \& X. Sala-I-Martin.,1992. Public Finances in Models of Economic Growth, Review of Economic Studies 59, pp. 645-661. 
Barro, R.J. \& X. Sala-I-Martin.,1995. Economic Growth. New York/London/Montreal: McGraw-Hill.

Bartik, T.J., 1994. What Should the Federal Government Be Doing about Urban Economic Development?, Upjohn Institute Staff Working Paper, No. 94-25.

Bartik, T.J., 2003. Local Economic Development Policies, Upjohn Institute Staff Working Paper, No. 03-91.

Basu, D., 2008. A simple Test of the Neoclassical View of Production, Technical Change and Distribution, Working Paper, Colorado State University.

Bernard, A.B. \& S.N. Durlauf., 1991. Convergence of International Output Movements. National Bureau of Economic Research Working Paper, No. 3717.

Bikhchandani, D., D. Hirshleifer \& I. Welch., 1998. Learning from the Behavior of Others: Conformity, Fads, and Informational Cascades. Journal of Economic Perspectives 12, pp. 151-170.

Bikhchandani, S. \& S. Sharma.,2001. Herd Behavior in Financial Markets. IMF Staff Papers, pp. 279-310.

Birenda, K.R. \& S. Rajiv., 2009. Generalized Cost Success Functions. Economic Theory 40, pp. 139-149.

Birenda, K.R. \& S. Rajiv., 2007. Generalized Cost Success Functions. Jena Economic Research Papers 2007-082, Jena, Germany: Friedrich Schiller University and Max Plank Institute of Economics.

Bond, E.W. \& L. Samuelson., 1986. Tax Holidays as Signals. American Economic Review 76, pp. 820-826.

Bowles, S., 2004. Microeconomics: Behavior, Institutions, and Evolution. Priceton: Russell Sage Foundation and Princeton University Press.

Brakman, S. \& H. Garretsen, ed., 2003. Locatie en concurrentie, Preadviezen van de Vereniging voor de Staathuishoudkunde. Amsterdam: Koninklijke Vereniging voor de Staatshuishoudkunde.

Brakman, S., H. Garretsen \& C. van Marrewijk., 2001. An Introduction to Geographical Economics. Cambridge: University Press.

Brakman, S. \& B.J. Heijdra, eds.,.2004. The Monopolistic Revolution in Retrospect. Cambridge: University Press.

Brander, J.A., 1992. Comparative Economic Growth: Evidence and Interpretation. Canadian Journal of Economics 25, pp.792-818.

Brooks, M.A. \& B.J. Heijdra., 1988. An exploration on Rent-Seeking, Discussion Paper 8807, Department of Economics, University of Tasmania.

Brousseau, E. \& M'hand Fares., 2000. Incomplete Contracts and governance structures: are incomplete contract theory and new-institutional economics substitutes or complements? In: C. Menard ed. 2000. Institutions, Contracts and Organizations. 
Perspectives from New Institutional Economics. Cheltenham: Edward Elgar, pp.399 421.

Buiter, W.H., 1981. Time Preference, and International Lending in Borrowing in an Overlapping Generations Model. Journal of Political Economy 89, pp. 769-797.

Capello, R., 2007. Regional Economics. London/New York: Routledge.

Chorgon, L.C., 2007. The Theory of Contest: A Survey, Working paper 07-51, Department of Economics, Universidad Carlos III, Madrid, Spain.

Church, J.R. \& R. Ware (1999) Industrial Organization; A Strategic Approach. Boston: Irwin/McGraw-Hill.

Coase, R.H., 1960. The problem of Social Cost, Journal of Law and Economics 3, pp.1-44.

Cortright, J., 2001. New Growth Theory, Technology and Learning: A Practitioners Guide,

Reviews of Economic Development Literature and Practice: No. 4, U.S. Economic Development Administration. Portland: Impresa, Inc.

Chorgon, L.C., 2007. The Theory of Contest: A Survey, Working paper 07-51, Department of Economics, Universidad Carlos III, Madrid, Spain.

Croix, D. de la \& P. Michel., 2002. A Theory of Economic Growth: Dynamics and Policy in Overlapping Generations. Cambridge: University Press.

Dasgupta, P., 2007. Economics: A Very Short Introduction. Oxford: University Press.

DeLong, J.B., 1991. Machinery Accumulation and Productivity Growth in the Very LongRun: A Five-Nation Look, Harvard Institute of Economic Research, Discussion Paper, No. 1551, Cambridge, MA.

Diamond, P., 1995. National Debt in a Neoclassical Growth Model. American Economic Review 55, pp. 1126-1150.

Dixit, A.K.,1987. Strategic Behavior in Contest. American Economic Review 5, pp. 891-898.

Dixit, A.K., 1990. Optimization in Economic Theory. $2^{\text {nd }}$ ed. Oxford: Oxford University Press.

Dixit, A.K., 1996. The Making of Economic Policy: A Transaction-Cost Politics Perspective, Cambridge: the MIT Press.

Dixit, A.K. \& S. Skeath., 1999. Games of Strategy. New York/London: W.W. Norton \& Co.

Dixit, A.K. \& J. Stiglitz., 1977. Monopolistic Competition and Optimum Product Diversity. American Economic Review 67(3), pp. 297-308.

Dowrick, S., 1992. Technological Catch-up and Diverging Incomes: Patterns of Economic Growth 1960-88. Economic Journal 102, pp. 600-610.

Easterly, W., \& S. Rebelo., 1993. Fiscal Policy and Economic Growth: An Empirical Investigation. Journal of Monetary Economics 32, pp. 417-458.

Eggertsson, T.,1990. Economic Behavior and Institutions. Cambridge: University Press.

El-Agraa, A.M., 2004. The European Union, Economics \& Policies. Essex: Prentice Hall Financial Times, Pearson Education Limited. 
Ethier, W.J.,1982. National and International Returns to Scale in the modern Theory of International Trade. The American Economic Review 72(3), pp. 389-405.

European Union., 2000, Lisbon European Council, 23 and 24 March 2000, Presidency Conclusions. Available at: http://www.europarl.europa.eu/summits/lis1_en.htm.

[Accessed November 2006]

European Union., Regional Policy / Why do we need Regional Policy.

Available at: http://ec.europa.eu/regional_policy/policy/why/index_en.htm. [Accessed 08-May-2007.]

European Union., Regional Policy. Available at:

http://ec.europa.eu/regional_policy/intro/working1_en.htm. [Accessed15-Sepember2007]

European Union., 2008; Fifth interim report on economic and social cohesion. Available at: http:/ec.europa.eu/regional_policy/sources/docoffic/official/reports/_interim5/ com_2008_371_nl.pdf. [Accessed june-2009]

European Union., 2009, Press Release, Informal meeting with EU ministers on the situation of GM on 23 November 2009 reconfirms need for European coordination, Brussels, 23 rd November, 2009, Availeble at; http://europa.eu/rapid/pressReleasesAction.do? reference=MEMO/09/515. [Accessed 23 November 2009].

Farrel, J.P., 1987. Information and the Coase Theorem. Journal of Economic Perspectives 1, pp. 113-129.

Findlay, R., 1987/2008. Comparative Advantage, in: S.N. Durlauf \& L.E. Blume eds. The New Palgrave: A Dictionary of Economics, $2^{\text {nd }}$ ed. Houndsmills, Basinstoke: PalgraveMacmillan, pp. 514-17.

Fingleton, B. et al., 2007. Editorial, Spatial Economic Analysis 2(3), pp. 215-218.

Fox, W.F. \& M.N. Murray., 1998. Incentives, Firm Location Decisions, and Regional Economic Performance. In: H.F. Ladd ed. Local Government Tax on Land Use Policies in the United States. Cheltenham: Edward Elgar, pp.168-181.

Furubotn, E. \& R. Richter., 2000. Institutions and Economic Theory; The Contributions of the New Institutional Economics. Michigan: University of Michigan Press.

Garcia-Mila, T. \& T.J. McGuire., 2002. Tax incentives and the City, in: W.G. Gale \& J. Rothenberg Peck ed. 2002. Brookings-Wharton Papers on Urban Affairs, pp. 95-132.

Garfinkel, M.R. \& S. Skaperdas., 2007. Economics of Conflict: An Overview. In: T. Sandler \& K. Hartley ed 2007. Handbook of Defence Economics Volume 2, Chapter 22. Amsterdam: North Holland, pp. 649-709.

Geerdink, G.C., P.J. Stauvermann \& A.E. Steenge.,2010. Innovation, Herd Behavior and Regional Development. In: Aarentsen, A.J.,W. van Rossum \& A.E. Steenge eds. Governance of Innovation, Firms, Clusters and Institutions in a Changing World. Edward Elgar Publ.pp.93-106 
Geerdink, G.C. \& P.J. Stauvermann. 2009., Is Competition Between Region Welfare Increasing? In: C. Karlsson, B. Johansson \& R.S. Stough ed. 2009. Innovation, Agglomeration and Regional Competition. Cheltenham: Edward Elgar, pp. 403-421.

Geerdink, G.C. \& P.J. Stauvermann.,2007. Coase, externalities, property rights and the legal system in: A. Prinz, A.E. Steenge, \& J. Schmidt, (eds.), The Rules of the Game: Institutions Law and Economic, Lit Verlag, Muenster, pp. 103-130.

Geerdink, G.C. \& P.J. Stauvermann., 2006. The influence of Different Institutional Settings on Welfare in an Open Economy Forthcoming in: The Role of Intangibles on Endogenous Growth: Human Capital, R\&D and Informational Flows" Publisher unknown yet

Geerdink, G.C. \& P.J. Stauvermann., 2006. A New Theory of Income Distribution and a New Microeconomic Foundation of Factor Income, Paper presented at the 10th Conference on Macroeconomic Analysis and International Finance, Rethymno, Crete, May 25-27, 2006.

Gertler, M. \& K. Rogoff., 1990. North-South lending and endogenous capital-market inefficiencies. Journal of Money, Credit and Banking 20, pp. 559-588.

Gibbons, R., 1992., Game Theory for Applied Economists. Princeton: University Press.

Glaeser, E.L., 1999. Help Poor People, Not Poor Places. The Wall Street Journal (August 22), A22.

Glaeser, E.L., 2001. The Economics of Location-Based tax Incentives. Discussion Paper Harvard University 10.29.

Gonzalez, F.M., 2004. Insecure Property and Technological Backwardness. The Economic Journal 115, pp. 703-721.

Gonzalez, F.M., 2007. Effective Property Rights, Conflict and Growth. Journal of Economic Theory 137, pp. 127-139.

Gonzalez, F.M \& H.M. Neary,. 2004. Optimal Growth Policy under Private Enforced Property Rights, Discussion Paper No.; 04-15. Vancouver, Canada: Department of Economics, The University of British Columbia.

Grandville, de LA O. \& R. Solow., 2009. Economic Growth, A Unified Approach, New York/Cambridge: University Press.

Greenstone, M. \& E. Moretti., 2003. Bidding for Industrial Plants: Does Winning a 'Million Dollar Plant' Increase Welfare? Mimeo, MIT, UCLA and NBER.

Grossman, H.I. \& Kim, M.J., 1995. Swords or Ploughshares? A Theory of the Security of Claims to Property, Journal of Political Economy 103, pp.1275-88.

Gylfalson, T., 1999. Principles of Economic Growth. Oxford, USA: University Press.

Gylfalson, T.,1993. Optimal Saving, Interest Rates, and Endogenous Growth. In: T.M. Anderson \& K.O. Moene ed. Endogenous Growth. Chichester: Wiley-Blackwell, pp. 127-145. 
Haaparanta, P., 1989. The Intertemporal Effects of International Transfers. Journal of International Economics 26, pp. 373-382.

Hall, R.E. \&C.I. Jones., 1999. Why do some countries produce so much more Output per Worker than Others?. Quarterly Journal of Economics 114(1), pp. 83-116.

Hart, O., 1995. Firms Contract and Financial Structure. Clarendon Lectures in Economics. Oxford: Clarendon Press.

Hendrikse, G., 2003. Economics, management of Organizations; Co-ordination, motivation and Strategy. London: McGraw-Hill.

Hirshleifer, J., 1987a. Conflict and Settlement. In: J. Eatwell, P. Milgate \& P. Newman ed. 1987. The New Palgrave: A Dictionary of Economics. London.

Hirshleifer, J., 1987b. The Economic Approach to Conflict. In: G. Radnitzky, \& P. Bernholz ed. 1987. Economic Imperialism. New York: pp. 335-363.

Hirshleifer, J., 1988. The Analytics of Continuing Conflict. Synthese 76, pp. 201-233.

Hirshleifer, J., 1989. Conflict and Rent-Seeking Success Functions: Ratio vs. Difference Models of relative Success. Public Choice 63, pp. 101-112.

Hirshleifer, J., 1994. The Dark Side of the Force, Western Economic Association International 1993 Presidential Address. Economic Inquiry 33, pp. 1-10.

Hirshleifer, J., The Macrotechnology of Conflict. Journal of Conflict Resolution 44, pp. 773792.

Hospers, G.J., \& G.C. Geerdink, 2010. Wij zijn Twente, no. 3, pp. 29-31.

Hospers, G.J., 2006. Silicon Somewhere?, Assessing the Usefulness of best Practices in Regional Policy. Policy Studies 27(1), Routledge.

Hussein, K. and A.P. Thirlwall, 2000, The AK model of "new" growth theory is the HarrodDomar growth equation: investment and growth revisited. Journal of Post Keynesian Economics, Voll. 22, no. 3, pp. 427-435.

Innovatieplatform, 2010. Available at: http://www.innovatieplatform.nl/.[Accessed 05 April 2010].

Iwamoto, Y., 1990. An Evaluation of Public Investment Policy in Postwar Japan. Economic Review 41, pp. 250-261.

Janeba, E. \& G. Schjelderup, 2003. Tax Competition: A Review of the Theory. Discussion Paper, University of Colorado at Boulder.

Kelly, T.M., J.W. Henderson \& S.L. Seaman., 1997. The Efficiency of Tax Abatement in the Markets for Jobs. Journal of Economics 23, pp. 73-88.

Kemp, M.C., 1962. Foreign Investment and the National Advantage. Economic Record 38, pp. 56-62.

Koning, E. de., 2005. Understanding the Significace of the Closure of Ericsson Enschede for the Twente Economy. Master Thesis University Twente. Enschede, The Netherlands. 
Konrad, K.A., 2007. Strategy in Contests- an introduction. [e-book] Berlin Germany: WZBBerlin. Available at: http://bibliothek.wzb.eu/pdf/2007/ii07-01.pdf. [Accessed 06-062008].

Klundert, Th. van de, 1997. Groei en instituties; Over de oorzaken van economische ontwikkeling. Tilburg: University Press.

Krugman, P., 1991. Myth and Reality of US Competitiveness. Science, pp. 811-815

Krugman, P., 1991. Increasing Returns and Economic geography. The Journal of Political Economy 99(3), pp. 483-499.

Krugman, P., 1994. Competitiveness a Dangerous Concept. Foreign Affairs, pp.22-44. Avaialable at: www.economist.com/research/Economics/alphabetic.cfm? letter=C\# competitiveness. [Accessed 05 October 2006].

Laffont, J.\& D. Martimort., 2002. The Theory of Incentives, The principal Agent Model. Princeton, New Jersey: University Press.

Labini, P.S., 1995. Why the Interpretation of the Cobb-Douglas Production Function must be radically changed. Structural Change and Economic Dynamics 6, pp. 485-405.

Lucas, R.E., 1988. On the Mechanics of Economic Development. Journal of Monetary Economics 21, pp. 3-32.

Lynde, C. \& J. Richmond., 1993. Public Capital and Total Factor Productivity. International Economic Review 34, pp. 401-413.

Marrewijk, C. van, 2007. International Economics, Theory, Applications, and Policy. New York/Oxford: University Press.

Macdougall, G.D.A., 1960. The Benefits and Costs of Private Investment from Abroad: A Theoretical Approach. Economic Record 36, pp. 13-35.

Macho-Stadler, I. \&, J.D. Perez-Castrillo., 2001. An Introduction to the Economics of Information, Incentives and Contracts. New York/Oxford: University Press.

Makowski, L. \& J.M. Ostroy., 2001. Perfect Competition and the Creativity of the Market. Journal of Economic Literature, pp. 479-535.

Marrewijk, C. van., 2007. International Economics. New York/Oxford: University Press.

Martin, R.L., 2004. A study on the Factors of Regional Competitiveness. Cambridge Econometrics, Cambridge and ECORYS-NEI Rotterdam available at: http://ec.europa.eu/regional_policy/sources/docgener/studies/study_en.htm [Accessed 14-09-06].

McCandless, G.T.\& N. Wallace., 1991. Introduction to Dynamic Macro Economic Theory, An Overlapping Generation Approach. Cambridge, Masachusetts and London England:: Havard University Press.

Milgrom, \& Roberts., 1992. Economics, Organization and Management. Englewood Cliffs, New Jersey: Prentice Hall. 
Ministerie van Economische Zaken, 2007. Pieken in de Delta. Available at: http://www.ez.n1/ Onderwerpen/Meer_innovatie/Pieken_in_de_Delta. [Accessed December 2008]

Myles, G.D., 1995. Public Economics. New York/Cambridge: University Press.

Neary, P.J., 2004. Monopolistic Competition and International Trade Theory in: Brakman, S. \& B.J. Heijdra, eds.,.2004. The Monopolistic Revolution in Retrospect. Cambridge: University Press, pp 159-185.

Neary, P.J., 2000a. Of Hype and Hyperbolas: Introducing the new Economic Geography, Woking Paper WP0019.pdf, Available at: www.ucd.ie/economics/research /papers/2000/wp0019.pdf [Accessed 7-12-2008]

Neary, P.J., 2000b. Monopolistic Competition and International Trade Theory, Woking Paper

WP0025.pdf, Available at: www.ucd.ie/economics/research/papers/2000/wp0025.pdf [Accessed 7-12-2008]

North, D.C., 1991. Institutions. Journal of Economic Perspectives 5(1), pp. 97-112.

North, D.C., 1990. Institutions, Institutional Change and Economic Performance. New York/Cambridge: University Press.

Nti, K.O., 1997. Comparative Statistics of Contests and Rent-Seeking Games. International Economic Review 38, pp 43-59.

Oates, W.E., 2003. Fiscal Competition or Harmonization? Some Reflections. National Tax Journal, LIV, pp. 507-215.

Obstfeld, M. \& K.S. Rogoff.,1994. Foundations of International Macro Economics. Cambridge, Massachusetts, London, England: The MIT Press.

Otto, G. \& G.M. Voss., 1994. Public Capital and Private Sector Productivity, Economic Record 70, pp. 121-132.

Pasinetti, L.L., 1977. On Non-Substitution in Production Models, Cambridge Journal of Economics 1, pp. 389-394.

Perez-Castrillo, L.D. \& T. Verdier., 1992. A General Analyzes of Rent Seeking Games, Public Choice 73, pp. 335-350.

Pelkmans, J., 2006. European Integration, Methods and Economic Analyses, Prentice Hall Financial Times, Pearson Education Limited, Essex

Persson, T., 1985. Deficits and Intergenerational Welfare In Open Economies, Journal of International Economics 19, pp. 67-84.

Porter, M.E., 2000. Location, Competition, and Economic Development: Local Clusters in a Global Economy, Economic Development Quarterly 14(1), 15-34.

Provincie Overijsel., 2005. InnovatiePlatform Twente, Available at: http://www.twentseinnovatieroute.nl/ [Accessed December 2008].

Quah, D.. 1993. Galton's Fallacy and Tests of the Convergence Hypothesis, in: T.M. Andersen \& K.O. Moene, Endogenous Growth, Oxford. 
Ratner, J.B., 1983. Government Capital and the Production Function for U.S. Private Output, Economic Letters 13, pp. 213-217.

Rebelo, S., 1991. Long-Run Policy Analysis and Long-Run Growth, Journal of Political Economy 99, pp. 500-521.

Ribeiro, M.J., 2008. Endogenous Growth: Analytical Review of its Generating Mechanisms, NIPE WP 4 / 2003, University off Minho, Portugal. Available at: http://repositorium. sdum.uminho.pt/bitstream/1822/6968/1/NIPE_WP_4_2003.pdf

[Accessed December 2008]

Robinson, J., 1934. Euler's Theorem and the Problem of Distribution, Economic Journal 44, pp. 398-414.

Robinson, J., 1954. The Production Function and the Theory of Capital, Review of Economic Studies 55, pp. 81-106.

Robson, A.R.W. \& S. Skaperdas., 2005. Costly Enforcement of Property Rights and the Coase Theorem, Working Paper, robsonskaperdas0605. Available at: www.socsci.uci.edu/ sskaperd robsonskaperdas0605/.pdf. [Accessed December 2005].

Romer, D.,2006. Advanced Macroeconomics, $3^{\text {rd }}$ ed. New York/London/Montreal: McGrawHill.

Romer, P.M.,1986., Increasing Returns and Long-run Growth, Journal of Political Economy 94, pp. 1002-37.

Romer, P.M.,1989. Capital Accumulation in the Theory of Long-Run Growth, in: R.J. Barro (ed.), Modern Business Cycle Theory, pp. 51-127.

Romer, P.M.,1990. Endogenous Technological Change, Journal of Political Economy 98, pp. 71-102.

Romer, P.M., 1994. The Origins of Endogenous Growth, Journal of Economic Perspectives, pp. 3-22.

Salanie, B., 1997. The Economics of Contract; A Primer. Cambridge/London: The MIT Press. Sachs, J.D. \& G. McGord., 2008. Geography of Regional Development, in: S.N. Durlauf \& L.E. Blume (eds.) The New Palgrave Dictionary of Economics, $2^{\text {nd }}$ ed., Palgrave Macmillan.

Schweizer, U., 1988. Externalities and the Coase Theorem: Hypothesis or Result, Journal of Institutional and Theoretical Economics (JITE) 144, pp. 245-266.

Skaperdas, S. \& L. Gan., 1995. Risk Aversion in Contests, Economic Journal 105, pp. 951962.

Skaperdas, S., 1992. Cooperation, Conflict, and Power in the Absence of Property Rights, American Economic Review 82, pp. 720-739.

Skaperdas, S., 1996. Contest Success Functions, Economic Theory 7, pp. 283-290.

Stauvermann, P. J.,1991. National Debt in an Open Economy, University of Dortmund. 
Stauvermann, P. J., 1992. Endogenous Growth, Land and Dynamic Efficiency, History of Economic Ideas 10, pp. 1-17.

Stauvermann, P. J.,1997. Endogenous Growth in OLG-models; Normative and Positive Aspects of the New Growth theory (written in German). Wiesbaden: Deutscher Universitaetsverlag.

Stauvermann, P. J.,2002. Why is there so much Peace? Defence and Peace Economics 13, pp. 61-75.

Stauvermann, P. J.,2005. A Revised Harrod-Domar Model, mimeo.

Stauvermann, P. J.,2007. Economic Theory of Conflicts, mimeo.

Steenge, A.E.,2004. The Coase Theorem, Economic Lineage, and the Small Numbers Problem, in: A. Prinz, A.E. Steenge. \& J. Schmidt (eds.) Institutions in Legal and Economic Analysis. Münster: Lit Verlag, pp. 47-84.

Steenge, A.E., \& R.van den Berg., 2007. Transcribing the Tableau Econonmique: InputOutput Analusis a la Qeusnay, A Journal of The History of Economic Thought, pp 331358.

Stigler, G.J., 1957. Perfect Competition, Historically Contemplated, Journal of Political Economy 65, pp. 1-17.

Stigler, G.J.,1987. Competition, The New Palgrave of Economics, Eds. John Eatwell, Murray Milgate and Peter Newman. pp. 531-536. Palgrave Macmillan

Stiglitz, J., 2006 Global Public Goods and Global Finance: does global governance ensure that the global public interest is served, in: Touffut, (ed.) Advancing Public Goods. Cheltenham: Edward Elgar, pp. 149-164.

Suranovic, S.M., 2006, International Trade Theory and Policy. [e-book]. Available at: http://internationalecon.com/Trade/Tch110/T110-2.php. [Accessed 24 August 2009].

Takayama, A., 1994. Analytical Methods in Economics, Harvester Wheatsheaf

Takayame,A., 1990. Mathematical Economics. $2^{\text {nd }}$ ed. Cambridge, New York, Port Chester Melbourne, Sydny: Cabridge University Press;

Thisse, J.F., 2007. Editorial, Spatial Economic Analysis, Vol. 2 No 3 2007, Routledge, pp 215-218

Thisse, J.F. \& K.Behrens.,2007. Regional Economics, a new Economic Geography Perspective, Regional Science and Urban Economics, Science Direct 37, pp. 457-465.

Tullock, G., 1980. Efficient Rent Seeking. In: J.M. Buchanan, R.D. Tollison \& G. Tullock,.ed. (1980), Toward a Theory of the Rent-Seeking Society, A \& M University Press.

Viscusi, W.K., J.M. Vernon \& J.E. Harrington, Jr., 2000. Economics of regulation and Antitrust, $3^{\text {rd }}$ ed., MIT Press. 
Visscher, K. \& P.C. de Weerd-Nederhof., 2006. Rise and Fall of an Innovative Organisation: The Innovation Journey of Ericsson Enschede, International Journal of Innovation Management, pp. 217-235.

Vogel, R.M., 2000. Relocation Subsidies: Regional Growth or Corporate Welfare?, Review of Radical Political Economics 32, pp. 437-447.

Washington Post, 24-11-2009, GM asks Europe for Restructuring Help, Available at: www.washingtonpost.com/wp-dyn/content/article/2009/11/23/AR2009112303929.html [Accessed 24 November 2009].

Waelde, K., 2007. Applied Intertemporal Optimization,[e-book] Availalble at www.waelde.com/aio. [Accessed May 2007].

Williamson, O.E., 2000. The New Institutional Economics: Taking Stock, Looking Ahead, Journal of Economic Literature 38(3), pp. 595-613.

Williamson, O.E., 1998. Transaction Cost Economics: How it Works; Where it is Headed, De Economist 146(1), pp 23-58.

Williamson, O.E., 1997. Transaction Cost Economics and Public Administration, in: P.B. Boorsma, K. Aarst and A.E. Steenge. (eds), Public Priority Setting: Rules and Costs, Dortrecht: Kluwer Academic Publishers.

Williamson, O.E. \& S.G. Winter, ed., 1993. The Nature of the Firm: Origins, Evolution, and Development, New York/Oxford: University Press.

Wilson, J.D. (1986) A Theory of Interregional Tax Competition, Journal of Urban Economics 19, pp. 296-315.

World Economic Forum., 2009. The Global Competitiveness Report 2009-2010. Available at: http:/www.weforum.org/en/initiatives/gcp/Global\%20Competitiveness\%20Report/inde x.htm. [Accessed 27 September 2009].

Wyplosz, C. and R.Baldwin, 2003, The economics of European Integration, Mc Graw-Hill

Zhang, W., 2006. Discrete dynamical systems, bifurcations and chaos in economics. Elsevier The Netherlands. 
Nederlandse samenvatting 


\section{Inleiding}

Zoals de titel al aangeeft gaat dit onderzoek over 'regionale economische ontwikkeling.' In de inleiding gaan we in op het onderwerp van onderzoek, hoe het is opgezet en de relevantie er van. In dit onderzoek besteden we in het bijzonder aandacht aan het feit dat regio's zelf een actieve rol hebben in het proces van economische ontwikkeling. De activiteiten van de regio's hebben we onderverdeeld in concurrentie en samenwerking tussen regio's. Dat betekent dat er allerlei interacties tussen regio's plaatsvinden. Daarom luidt de ondertitel 'spelen van concurrentie en samenwerking.' We kijken naar de rol van concurrentie en samenwerking, dat wil zeggen, economische integratie, bij de regionaal economische ontwikkeling.

Aanleiding voor dit onderzoek zijn meer of minder recente ontwikkelingen. Ten eerste de observatie dat regio's vaak dezelfde doelen en belangen nastreven en daarvoor ook vaak dezelfde middelen gebruiken. Dit leidt er toe dat er concurrentie tussen regio's ontstaat. Ten tweede dat regio's steeds meer samenwerkingsverbanden met elkaar zoeken. Daarnaast vormt regionale ontwikkeling een belangrijk specifiek beleidsterrein van de EU.

Er wordt vanuit gegaan dat regionale economische ontwikkeling versterkt kan worden door de concurrentiekracht van de regio te verbeteren. De verantwoordelijkheid hiervoor ligt bij de regio's zelf. Innovatie wordt als een van de belangrijkste instrumenten gezien om de concurrentiekracht te verbeteren en om zodoende meer bedrijven aan te trekken en meer werkgelegenheid en inkomen te realiseren.

Een ander belangrijk aspect om de regionale economische ontwikkeling te verbeteren is meer samenwerking tussen regio's. Er kan daardoor meer gebruik worden gemaakt van allerlei externaliteiten hetgeen de efficiency verbetert en leidt tot een versterking van regionale concurrentiekracht. Deze regionale samenwerking, coördinatie van economische activiteiten, kan dus een stimulans voor de economische ontwikkeling vormen. Door economische integratie krijgen we een betere mobiliteit van productiefactoren wat tot een meer efficiënt gebruik kan leiden en daardoor een stimulans voor de economische ontwikkeling kan vormen.

Het onderzoek richt zich op interacties tussen verschillende regio's, waarbij de nadruk ligt op institutionele verschillen tussen regio's. Binnen de regionale en ruimtelijke economische wetenschap wordt hier ook aandacht voor gevraagd. We citeren (vrij vertaald) Capello (2007): Wat we nog nodig hebben zijn modellen die micro-economisch territoriaal gedrag en verdere immateriële elementen van het economisch ontwikkelingsproces bevatten. Tevens geeft zij aan wat we hierbij onder een regio moeten verstaan. Het concept regio (vrij vertaald) betreft 'een gebied in economische termen, dat kan worden gezien als een systeem van locale (technologische) externaliteiten; een verzameling van materiële en immateriële factoren die vanwege hun aanwezigheid een positieve (beperkende) invloed hebben op transactiekosten en daardoor op de productiviteit en innovatiekracht van bedrijven.' 
Tevens is de recente aandacht binnen de economie van institutionele verschillen als verklaring voor verschil in economische ontwikkeling van landen en regio's (Acemoglu e.a., 2005) een motivatie. Daarnaast zijn regio's feitelijk natuurlijk altijd verschillend. De centrale probleemstelling van dit onderzoek kan dan ook als volgt worden geformuleerd;

Het analyseren van de consequenties van regionale concurrentie en samenwerking, in de context van economische integratie, op efficiency, met speciale aandacht voor interacties tussen regio's met verschillen in institutionele structuur.

Globaal valt het onderzoek in drie delen uiteen. Allereerst de analyse van concurrentie op efficiëntie en economische ontwikkeling. Ten tweede de analyse van samenwerking en economische integratie en het effect daarvan op efficiëntie en economische ontwikkeling van regio's. Als laatste de coördinatieproblemen die uit concurrentie en samenwerking tussen regio's voortvloeien.

In hoofdstuk twee beginnen we met een overzicht van de belangrijkste theoretische elementen die in het onderzoek worden gebruikt. In de appendices wordt daar uitgebreider bij stil gestaan.

\section{Concurrentie tussen regio's, verbetert het de efficiëntie?}

In het derde en vierde hoofdstuk analyseren we regionale concurrentie en de effecten hiervan op de regionale economische ontwikkeling. Als uitgangspunt voor het begrip regionale concurrentie gebruiken we de definitie van Stigler (1987). Deze luidt als volgt: 'Concurrentie is de rivaliteit tussen individuen (of groepen, landen of regio's) welke voortkomt uit het feit dat twee partijen iets willen bereiken wat ze niet allebei kunnen bereiken'. We gaan er vanuit dat regio's en hun beleidsmakers bepaalde doelstellingen voor ogen hebben. Dit kan bijvoorbeeld zijn regionale productie, werkgelegenheid of inkomen. Bedrijven zijn over het algemeen verantwoordelijk voor de regionale productie en voor een groot deel ook voor de werkgelegenheid. Om deze doelstellingen te realiseren is het van groot belang dat bedrijven zich vestigen in de regio. Omdat er meerdere regio's zijn die belangstelling voor die bedrijven hebben zal er concurrentie ontstaan tussen regio's. Om het gedrag van de regio's (in casu, de regionale beleidsmakers) te modelleren hanteren we de economische conflicttheorie. Regio's investeren om bedrijven aan te trekken. Deze investeringen moeten worden afgezet tegen de verwachte opbrengsten in termen van werkgelegenheid en andere zaken. Naarmate een regio meer investeert zal de kans dat een bedrijf zich vestigt toenemen. Andere regio's onderkennen dit en zullen hier op reageren door ook te investeren. Dit is de interactie tussen de concurrerende regio's. Op een geven moment zullen die het hoogst bereikbare niveau van 
investeringen bereikt hebben. Dit wordt het Nash evenwicht genoemd. Geen van de partijen zal zijn gedrag (investeringen) meer veranderen. De relatie tussen investeringen en de kans dat een bedrijf zich vestigt, geven we weer met de 'contest succes function' (CSF). Deze CSF is een belangrijk onderdeel van de economische conflicttheorie. Een dergelijke functie kent meerdere soorten, maar in ons onderzoek beperken we ons tot de meest eenvoudige vorm.

Investeringen van regio's om bedrijven aan te trekken kunnen verschillende vormen aannemen zoals allerlei subsidies, investeringen in goede infrastructuur, faciliteiten voor research en development, fiscale tegemoetkomingen, e.d. Dit zijn over het algemeen bedrijfspecifieke investeringen. Zoals hierboven is aangegeven, wordt het niveau van investeringen bepaald door het verwachte voordeel.

Als regio's verschillen zal een bedrijf een voorkeur hebben voor de regio waar het een maximale winst kan behalen. De betreffende regio heeft als het ware een comparatief voordeel ten opzichte van andere regio's Deze andere regio's kunnen hun 'comparatief nadeel' compenseren door extra te investeren of subsidies te verstrekken aan het bedrijf om het aan te trekken. Daardoor wordt de kans vergroot dat het bedrijf zich in de regio vestigt. Dit leidt to een 'second best solution' en tot een bepaalde mate van inefficiëntie. Ten eerste is er een kans dat het bedrijf zich vestigt in een regio wat economisch gezien niet leidt tot een 'least cost combination', de laagst mogelijke kosten. Ten tweede vestigt het bedrijf zich slechts in één regio. De investeringen van alle andere (verliezende) regio's om het bedrijf aan te trekken zijn dan als het ware weggegooid. Het is daarom duidelijk dat dit soort concurrentie niet leidt tot meer efficiëntie en ook geen bijdrage levert aan de economische ontwikkeling van regio's.

In hoofdstuk drie worden verschillende varianten van regionale concurrentie ('spelen') bekeken. Hierbij maken we gebruik van de economische conflicttheorie. Allereerst wordt er een onderscheid gemaakt tussen de 'volledige aansprakelijkheid' variant en de 'beperkte aansprakelijkheid' variant. Bij de eerste variant wordt de investering door de regio's gedaan voordat de onderneming besluit waar zij zich vestigt. In het tweede geval wordt afgesproken welke investering het bedrijf ontvangt als zij zich in de regio vestigt. Het zal duidelijk zijn dat de laatste variant minder schadelijk zal zijn m.b.t. verloren investeringen dan de eerste variant. Verder wordt concurrentie tussen twee en meerdere regio's geanalyseerd. Naarmate het aantal concurrerende regio's toeneemt, zullen de investeringen per regio afnemen. De oorzaak hiervan ligt in het feit dat de kans dat een bedrijf zich vestigt afneemt naarmate er meer regio's concurreren. Het totaal van verlorengaande investeringen neemt echter toe, omdat meer regio's meedoen aan het concurrentiespel.

Op basis van bovenstaande analyse komen we tot twee belangrijke conclusies. Ten eerste leidt dit soort concurrentie niet tot een verbetering in efficiëntie maar tot meer inefficiënties. Als gevolg daarvan levert het geen bijdrage aan de economische ontwikkeling van regio's. 
Ten tweede, het is moeilijk om dit soort concurrentie te voorkomen. Als een regio 'begint' dan moeten de andere regio's volgen anders maken ze geen kans op vestiging van nieuwe bedrijven in hun regio.

In het vierde hoofdstuk gaan we specifieker in op de rol van innovatie en innovatieve bedrijven op de economische ontwikkeling van een regio. We beginnen met een vrij uitgebreide beschrijving van de rol van innovatie op de regionale economische ontwikkeling. Hiervoor maken we gebruik van de endogene groei theorie, meer specifiek Romer's (1990) model van 'endogene technologische veranderingen'. Hiervoor hebben we gekozen omdat in Romer's (1990) model het ondernemersgedrag met betrekking tot investeringen in research \& development is gemodelleerd. Daarnaast laat het model zien dat dit ondernemersgedrag leidt tot positieve externaliteiten voor de economie. Marktprikkels, d.w.z. 'winst', zijn de belangrijkste reden voor ondernemers om te investeren in innovatie. Daarnaast leidt innovatie tot positieve externaliteiten voor de economie in zijn geheel. Dit kan zich uiten in een verhoging van de productiviteit of een verlagen van de kosten per eenheid product voor de regio. Op basis daarvan kan de concurrentiekracht van de regio's verbeteren. Dit stimuleert de economische ontwikkeling en leidt tot 'endogene' economische groei.

Door beleidsmakers wordt innovatie als een belangrijk instrument voor het verbeteren van de regionale concurrentiekracht en regionale economische ontwikkeling gezien. Daardoor wordt echter ook de concurrentie tussen regio's om de gunst van innovatieve bedrijven gestimuleerd. We zouden hieruit kunnen afleiden dat beleidsmakers een voorkeur voor innovatieve bedrijven hebben. Hierdoor kunnen problemen ontstaan rond de concurrentie tussen regio's om de innovatieve bedrijven en rond de vraag hoe innovatieve bedrijven te onderkennen. Om deze concurrentie vorm te geven hanteren we net als in het vorige hoofdstuk de economische conflicttheorie. We beperken ons echter tot twee regio's en de 'volledige aansprakelijkheid' variant. Na enige analyse komen we tot soortgelijke conclusies als in het vorige hoofdstuk. Het verschil met dat hoofdstuk is echter dat er nu sprake is van positieve externaliteiten. Waar het innovatieve bedrijf zich ook vestigt, beide regio's hebben er voordeel bij. De productiviteit van beide regio's wordt vergroot en productie en inkomen (looninkomen) stijgen. Deze positieve externaliteiten beperken zich niet tot de regio waar het bedrijf zich uiteindelijk vestigt. Dit wordt echter niet door de regio's als zodanig onderkend. Zou dit wel het geval zijn dan zou samenwerking tot een groter voordeel leiden voor de twee regio's. Er ontstaat hiermee echter wel een coördinatieprobleem tussen de twee regio's. Op voorhand zijn de regio's niet bereid samen te werken door af te zien van concurrentie.

Het laatste aspect waar we in dit hoofdstuk naar kijken is het effect van stimulering van innovatieve bedrijven door de regionale overheid met, bijv., financiële ondersteuning voor 'research en development'. Zoals in het begin is gezegd, leidt marktwerking in geval van positieve externaliteiten ( die het gevolg zijn van innovatie) niet tot een optimaal resultaat. Investeringen door bedrijven in innovatie zijn te laag omdat geen rekening is gehouden met 
positieve externaliteiten. In dit geval zou de overheid kunnen ingrijpen door innovatieve bedrijven te subsidiëren zodat het optimale niveau van investeringen in innovatie wordt gerealiseerd. Zo gauw echter de overheid subsidie aan de bedrijven verstrekt kan zij niet goed nagaan of het bedrijf ook daadwerkelijk de subsidie voor innovatie gebruikt. Wat zich hier voordoet is het probleem van informatie-asymmetrie. Als gevolg hiervan zal het bedrijf de subsidie gebruiken voor investeringen die het meest winstgevend zijn. Zij zal investeren tot het punt waar innovatie hetzelfde rendement oplevert als de alternatieve investering. Als we er van uitgegaan dat naarmate meer geïnvesteerd wordt in innovatie het rendement afneemt, zal er niet meer in innovatie worden geïnvesteerd. De winst van het bedrijf zal stijgen, maar de investeringen in innovatie blijven onveranderd, en zodoende kunnen de externaliteiten onvoldoende geïnternaliseerd worden.

\section{Economische integratie van regio's met verschil in instituties}

In de hoofdstukken vijf en zes staat de economische ontwikkeling van regio's eveneens centraal. $\mathrm{Nu}$ echter wordt gekeken naar de bijdrage van economische samenwerking en integratie op de economische ontwikkeling van regio's. Met economische samenwerking bedoelen we: Elk type overeenkomst tussen landen c.q. regio's waarin afspraken geregeld zijn om economische activiteiten te coördineren.

Bij economische integratie staat vaak vrij verkeer van personen, goederen en diensten en kapitaal centraal. Als gevolg hiervan vindt een efficiëntere allocatie plaats, wat een positief effect heeft op de concurrentiekracht en economische ontwikkeling. Waar echter weinig rekening mee wordt gehouden is het feit dat institutionele verschillen ook van invloed kunnen zijn op die mobiliteit. In de economische wetenschap hebben instituties voor lange tijd een relatief beperkte aandacht gekregen. Recentelijk zien we echter dat steeds meer gekeken wordt naar de betekenis van instituties voor het functioneren van de economie. Gekeken wordt bijvoorbeeld of verschillen in instituties een verklaring kunnen vormen voor het verschil in regionaal economische ontwikkeling.

Over het algemeen wordt er van uit gegaan dat instituties slecht geleidelijk veranderen. Dat betekent dat op korte termijn aanpassingen vrij gering zullen zijn. In hoofdstuk vijf kijken we naar de gevolgen van economische integratie op korte termijn. We kijken dan naar de effecten van integratie indien regio's verschillen in institutionele structuur. We vergelijken twee regio's in een situatie van autarkie met de situatie van economische integratie van die twee regio's.

Om te komen tot een inkomensverdeling hebben we gebruik gemaakt van een onderhandelingsmodel. Voor de aanbodkant gebruiken we de Leontief productiefunctie. 
Inkomen wordt verdeeld op basis van onderhandeling tussen eigenaren van productiefactoren. De uitkomst van het onderhandelingsproces hangt onder andere af van de onderhandelingspositie van de betrokken partijen. Op die positie zijn twee aspecten van invloed, namelijk de institutionele structuur en de investeringen die de partijen zich getroosten om een zo groot mogelijk aandeel van het totale inkomen te bemachtigen. De institutionele structuur wordt in dit geval gevormd door, bijv., de juridische regelgeving en de overlegstructuur tussen werkgevers, werknemers en overheid. Deze structuur beïnvloedt de onderhandelingspositie van de partijen. Ook investeringen die partijen zich getroosten om een zo groot mogelijk aandeel te bemachtigen zijn daarop van invloed. Om dit proces te modeleren maken we wederom gebruik van de economische conflicttheorie. Naarmate partijen minder hoeven te investeren om hun onderhandelingspositie te versterken kunnen meer middelen gebruikt worden voor productieve activiteiten. Afhankelijk van de institutionele structuur zullen partijen meer of minder investeren in het versterken van hun onderhandelingsposities. We zouden kunnen zeggen dat de institutionele setting efficiënt is als partijen niet hoeven te investeren in die positie. In deze context kunnen we ook stellen dat een bepaalde institutionele structuur efficiënter is dan een andere. We bedoelen dan dat een institutionele structuur waar door partijen minder in wordt geïnvesteerd om de onderhandelingspositie te verbeteren, de efficiëntere is.

Voor de aanbodkant gebruiken we dan een Leontief productiefunctie met vaste technische coëfficiënten. $\mathrm{Er}$ is gekozen voor vaste technische coëfficiënten omdat de inkomensverdeling voor een belangrijk deel institutioneel bepaald wordt en slechts langzaam verandert. (Merk hierbij op dat bij de Leontief productiefunctie er geen micro-economische onderbouwing is voor de inkomensverdeling. In de neoklassieke theorie, daarentegen, vindt inkomensverdeling plaats op basis van de marginale productiviteit van de productiefactoren).

Vervolgens analyseren we wat het effect is van economische integratie van twee regio's met een verschillende institutionele structuur. Beide regio's kennen een efficiënte institutionele structuur maar verschil in institutionele structuur leidt tot verschil in inkomensverdeling (looninkomen en kapitaalinkomen). We kijken daarbij naar de economische ontwikkeling in autarkie en integratie met volledige kapitaalmobiliteit. Voor het modeleren van consumentengedrag gebruiken we een twee-perioden 'overlapping generations' model (OLG). Dit heeft onze voorkeur omdat we willen analyseren wat het effect is van economische integratie. We hebben dus een periode voor integratie, de autarkie situatie, en een periode na integratie. Dit sluit goed aan op de 'twee perioden' zoals deze worden gebruikt in OLG modellen.

Allereerst wordt gekeken naar de autarkie-situatie van de twee regio's. Als we uitgaan van twee regio's waar alleen de institutionele structuur verschilt dan heeft dit tot gevolg dat gegeven de Leontief productiefunctie het inkomen en de totale productie in beide regio's gelijk is. Dit komt omdat in evenwicht arbeid de beperkende factor is en deze is gelijk voor 
beide regio's. Wat natuurlijk verschilt, is de inkomensverdeling want deze is afhankelijk van de institutionele structuur. Kapitaalinkomen en looninkomen verschillen per regio. Als gevolg hiervan zullen de consumptieve bestedingen en de besparingen ook verschillen. De oorzaak is dat bij een gelijke consumptiequote maar bij verschillend looninkomen de totale consumptieve bestedingen en besparingen ook verschillen. Vanzelfsprekend is daardoor de kapitaalgoederenvoorraad in de evenwichtssituatie ook verschillend. De vraag rijst dan waarom het inkomen en productie voor beide regio's hetzelfde kan zijn. Dit komt doordat het evenwicht van de twee regionale economieën wordt gekenmerkt door over-accumulatie van kapitaal. Arbeid (die voor beide regio's hetzelfde is) is de beperkende factor is en bepaalt de totale productie. Wat van belang is dat ook het rendement op kapitaal, en de reële lonen, verschillen per regio. Zoals al gezegd, is dit het gevolg van verschillen in institutionele structuur. We merken op dat dit vooral van belang is voor integratie omdat we dan van kapitaalmobiliteit uitgaan.

Als integratie plaatsvindt, zal er één geïntegreerde markt voor besparingen ontstaan. Door het verschil in rendement op kapitaal zullen de besparingen naar die regio vloeien waar deze het hoogst is. Dat betekent dat de kapitaalgoederenvoorraad in de twee regio's zal veranderen als gevolg van kapitaalmobiliteit. Voor de regio met het hoogste rendement op kapitaal zal deze stijgen terwijl de andere regio een daling van de kapitaalgoederenvoorraad te zien zal geven. Het effect van deze verschuiving hangt af van de autarkie-situaties van de twee regio's, namelijk de mate en het niveau van over-accumulatie van de kapitaalgoederenvoorraad. Er zijn in principe twee situaties denkbaar. Na integratie zijn de twee economieën opnieuw in evenwicht. In deze situatie is arbeid voor de twee economieën nog steeds de beperkende factor. Verschillen in rendement op kapitaal hebben tot verschuiving van de kapitaalgoederenvoorraad geleid, maar voor beide regio's geldt dat er nog steeds sprake is van evenwicht en over-accumulatie van kapitaal. We merken op dat de over-accumulatie van de regio met een hoger rendement op kapitaal toeneemt en dat de overaccumulatie van de andere regio afneemt. Daarnaast kan er, voor de regio met een lager rendement op kapitaal, een situatie ontstaan waarbij de kapitaalgoederenvoorraad de beperkende factor is (en niet arbeid) waardoor de economie op een (negatief) groeipad komt. De regio met het hogere rendement is vanzelfsprekend nog steeds in evenwicht. Door het verschil in rendement gaan alle besparingen naar de regio met het hoogste rendement. Dit leidt er toe dat de kapitaalgoederenvoorraad in de andere regio de volgende periode reduceert en tot nul tendeert. Daarmee 'verdwijnt' deze regio - althans economisch gezien.

Economische integratie van de hierboven beschreven regionale economieën kan dus leiden tot een desastreuze economische ontwikkeling. In het meest gunstige geval blijven het regionale product en inkomen na integratie gelijk aan die van de autarkie-situatie. In het meest ongunstige geval verdwijnt één van de economieën. Wel moeten we in ogenschouw nemen 
dat de institutionele structuur zich op lange termijn zal aanpassen, en zodoende de inkomensverdeling ook.

Er is al op gewezen dat instituties een hogere efficiency kunnen bewerkstelligen. Omdat de institutionele structuur karakteristieken heeft van een verzameling publiek goederen, wordt deze niet via de markt tot stand gebracht. De overheid heeft dan een functie om dit type voorziening beschikbaar te stellen. Dit levert positieve effecten op en komt de efficiency van de economie als geheel ten goede. We citeren Dasgupta (2007), vrij vertaald: 'De accumulatie van productief kapitaal is slechts een indirecte oorzaak van welvaart. De echte oorzaak is de aanwezigheid van progressieve instituties [....], en deze instituties zijn publieke goederen'.

In hoofdstuk zes besteden we hier specifiek aandacht aan. Uitgangspunt is dat de overheid investeert in instituties van de economie. Dit leidt tot een bepaald type publiek kapitaal. Dit resulteert weer in positieve externe effecten die de economische ontwikkeling van regio's ten goede kan komen. Waar vooral onze interesse naar uit gaat is, net als in het vorige hoofdstuk, wat het effect is van verschillen in economische structuur op economische integratie van regio's. Om dit te analyseren kiezen we voor eenzelfde aanpak als in het vorige hoofdstuk. We vergelijken de situatie van twee regio's, de autarkie-situatie met de situatie van integratie. Om de verschillen in institutionele structuur mee te nemen gaan we er van uit dat deze in de ene regio efficiënter is dan in de andere regio. Dit doen we door te veronderstellen dat publiek kapitaal in de ene regio productiever is dan in de andere regio.

Voor het modelleren van de aanbodkant gebruiken we een neoklassieke productiefunctie met kapitaal en arbeid maar ook publiek kapitaal als argument. Verder gaan we er van uit dat de factoren arbeid en kapitaal afnemende meeropbrengsten kennen. Ook gaan we er van uit dat de arbeidsproductiviteit stijgt als de regionale kapitaalintensiteit (de ratio kapitaal-arbeid) stijgt. Des te meer kapitaal, des te beter werkt 'leren door te doen'.

Aan de andere kant gaan we er ook van uit dat naarmate de private kapitaalgoederenvoorraad stijgt de productiviteit van het publiek kapitaal daalt. Des te geavanceerder de werking van de economie (hoge ratio kapitaal-arbeid) des te meer investeringen in institutionele structuur nodig zijn. Om dit aspect mee te nemen is de ratio van publiek-privaat kapitaal opgenomen in de productiefunctie. Hierdoor krijgen we een soort tegengesteld effect. Als de kapitaalgoederenvoorraad toeneemt, zal de arbeidsproductiviteit ook toenemen vanwege het genoemde 'leren door te doen' effect. Aan de andere kant zal de productiviteit van het publiek kapitaal afnemen doordat het private kapitaal stijgt waarbij dus de ratio publiek-privaat daalt. Er worden meer en hogere eisen gesteld in een zich sterk ontwikkelende economie.

Ondernemers produceren zogeheten eindgoederen en opereren op een markt van volledige concurrentie, en streven naar maximale winst. Arbeid en privaat kapitaal zijn de endogene variabelen terwijl publiek kapitaal en de kapitaalratio exogene variabelen voor 
ondernemers zijn. Externaliteiten worden gegenereerd door 'leren door te doen' wat zich uit in de ratio kapitaal-arbeid. De overheid investeert in instituties door middel van investeringen in publiek kapitaal. Deze worden gefinancierd door belastingheffing. Uitgangspunt daarbij is dat de begroting in evenwicht is en dat belastingheffing door middel van 'een bedrag ineens' plaatsvindt zodat dit niet leidt tot verstoring van de relatieve prijzen. De vraagkant wordt gemodelleerd met het twee perioden OLG model zoals dat ook in het vorige hoofdstuk is gedaan.

Om de effecten van integratie te analyseren vergelijken we twee regio's in een autarkie-situatie en dezelfde twee regio's na integratie Het verschil tussen de autarkie-situatie en economische integratie is dat er bij economische integratie sprake is van factormobiliteit. We nemen aan dat werknemers wel in een andere regio kunnen gaan werken maar in dezelfde regio blijven wonen; ze gaan 'forensen'. Verder gaan we er vanuit dat er verschillen zijn in de productiviteit van publiek kapitaal. Als gevolg van deze productiviteitsverschillen verschillen de twee regio's ook in autarkie. De regio met een hogere productiviteit heeft ook een hoger inkomensniveau en dat geldt eveneens voor het rendement op kapitaal en de reële lonen. De private kapitaalgoederenvoorraad en de publieke kapitaalgoederenvoorraad verschillen eveneens, d.w.z. zijn hoger voor de regio met een hogere productiviteit van publiek kapitaal. Omdat er verschillen in rendement op kapitaal zijn tussen de twee regio's zal dat consequenties hebben als de regio's integreren. Na integratie zal er een gezamenlijke kapitaalmarkt ontstaan. Besparingen zullen geïnvesteerd worden in de regio met het hoogste rendement op kapitaal. Daardoor ontstaat er een verschuiving in de kapitaalgoederenvoorraad. Deze zal stijgen in de regio met een hoger rendement op kapitaal, terwijl in de regio met een lager rendement deze zal dalen. Dit heeft twee effecten voor de regio's. Allereerst zal de ratio kapitaal-arbeid veranderen, maar ook de ratio publiek-privaat kapitaal en daarmee de productiviteit van publiek kapitaal. Door de opening van de kapitaalmarkt zal er voor beide regio's één rendement op kapitaal ontstaan als gevolg van het arbitrage proces. Het bijzondere is echter dat de verschillen tussen de twee regio's, de productie van eindgoederen en inkomen, groter worden. Dit komt doordat het effect van 'leren door te doen' externaliteiten dat van het publiek kapitaal (ratio publiek / privaat kapitaal) overtreft. Voor de regio met een hoger rendement in autarkie betekent dit dat het positief effect van externaliteiten, doordat de ratio kapitaal-arbeid stijgt, het negatief effect overtreft (doordat de ratio van publiek-privaat kapitaal daalt). Het omgekeerde geldt natuurlijk voor de regio met het lagere rendement op kapitaal in autarkie.

De volgende vraag die dan gesteld kan worden is of integratie wel zin heeft. Om die te beantwoorden kijken we naar het totaaleffect van integratie en vergelijken dat met de autarkie-situaties van de regio's. Als we de geaggregeerde regio's vergelijken dan blijkt dat integratie van regio's tot een hoger inkomen en productieniveau leidt. Dit is het gevolg van de werking van de externaliteiten. De effecten van veranderingen van de ratio kapitaal-arbeid 
overtreffen de effecten van verandering van de ratio publiek-privaat kapitaal. Het extra inkomen en productie van de ene regio als gevolg van factormobiliteit overtreft dan dat van de daling van inkomen en productie van de andere regio.

De bovenstaande situatie stelt ons voor een dilemma ingeval een regio wil integreren en de andere niet (als zij integreren levert dat voordeel op voor de gezamenlijke regio's). Hoe kan dan alsnog de ene regio overtuigd worden om te integreren? Er kan een surplus gerealiseerd worden door samen te werken. Daarnaast is er een belangenconflict, één regio wil integreren omdat dit een voordeel oplevert terwijl de andere regio dit juist niet wil omdat dit economische schade veroorzaakt. Dit zou opgelost kunnen worden door de benadeelde regio te compenseren voor de geleden schade. De regio die het meeste voordeel heeft spreekt af de andere regio te compenseren. Dit is mogelijk doordat er externaliteiten door de samenwerking geïnternaliseerd kunnen worden. Voorwaarde is wel dat de afspraken c.q. contracten geloofwaardig zijn en dat beide partijen zich eraan houden. Dit laatste wordt voor een belangrijk deel mede bepaald door de institutionele omgeving.

\section{Analyse van de coördinatieproblemen, een toepassing van het 'Coase' theorema}

In het laatste hoofdstuk gaan we explicieter kijken naar de rol van de institutionele structuur bij het tot stand komen en het handhaven van (bindende) afspraken. Deze afspraken hebben tot doel om concurrentie tussen regio's te voorkomen en om regio's te stimuleren om economische activiteiten te coördineren en/of over te gaan tot economische integratie om zodoende gebruik te kunnen maken van optredende externaliteiten.

We beginnen het hoofdstuk met een beschrijving van het Coase theorema. Het Coase theorema stelt dat het probleem van externaliteiten via onderhandelingen tussen partijen kan worden opgelost. Daardoor is er geen noodzaak tot overheidsingrijpen. De redenering is als volgt. Als de eigendomsrechten zijn toegedeeld, dan zullen betrokken partijen via onderhandelingen het probleem van externaliteiten oplossen. Dit onderhandelingsproces leidt tot compensatie voor de veroorzaakte externe effecten. Daardoor wordt uiteindelijk dezelfde efficiënte oplossing bereikt als wanneer de overheid c.q. de centrale planner, corrigeert voor, of rekening houdt met, externe effecten. Belangrijke voorwaarde is dat de transactiekosten (van het onderhandelingsproces) verwaarloosbaar zijn. Verder is van belang dat inkomen geen beperkende factor vormt. Dat betekent dat afhankelijk van de eigendomsverdeling diegene die de compensatie van de externe effecten voor zijn rekening neemt daartoe ook in staat is, gegeven zijn inkomen.

Dit gegeven sluit goed aan bij de problemen van samenwerking zoals die in de vorige hoofdstukken zijn beschreven. Er is sprake van externe effecten en partijen kunnen met elkaar 
onderhandelen om tot een oplossing te komen die contractueel kan worden vastgelegd. Een belangrijk aspect daarbij is de 'credibility' (geloofwaardigheid) van de contracten, i.h.b. de mate waarin ze afdwingbaar zijn. Uitgangspunt is dat contracten incompleet zijn. Niet alles kan contractueel worden opgenomen i.v.m. de daarmee gemoeide transactiekosten. Door incompleetheid van contracten kunnen achteraf meningsverschillen over de inhoud ontstaan, en/of worden de contracten ex post niet nageleefd. De benadeelde partij kan dan een en ander juridisch proberen af te dwingen.

Natuurlijk speelt hier de juridische context, als onderdeel van de institutionele structuur, een belangrijke rol. Als een van de partijen het contract verbreekt kan dit juridisch worden aangevochten door de andere partij. De uitkomsten van juridische processen zijn niet op voorhand zeker en bekend. Daarnaast zullen partijen, als het zover komt, moeten investeren om het proces voor de rechtbank te winnen. Dit zou men transactiekosten kunnen noemen en dit betekent dan dat partijen hiermee rekening houden bij de besluitvorming. Als gevolg hiervan zullen, afhankelijk van het juridische systeem, in sommige situaties externaliteiten wel c.q. niet via onderhandelingen kunnen worden opgelost.

Bij de analyse maken we onderscheid tussen de veroorzaker van externe effecten en de partij die de gevolgen er van ondervindt. Als de eigendomsrechten bij de veroorzaker liggen zal de andere partij (die de gevolgen ondervindt) de veroorzaker compenseren voor externe effecten. Hierover wordt dan onderhandeld en worden afspraken gemaakt die eventueel contractueel vast worden gelegd. Als echter de partij de afgesproken compensatie niet betaalt, zal de veroorzaker zich ook niet aan de afspraken houden. Externaliteiten worden dan niet geïnternaliseerd en de partij die de gevolgen van de externaliteiten ondervindt, zal dit onderkennen. Om dit te voorkomen zal deze partij de gemaakte afspraken, de te betalen compensatie, nakomen. In dit geval is er geen 'credibility' probleem, want beide partijen zullen zich aan de afspraak houden.

In het tweede geval wordt er onderhandeld en worden afspraken gemaakt m.b.t. compensatie van de partij die de gevolgen van de externaliteiten ondervindt. De veroorzaker kan achteraf besluiten zich niet aan de afspraken te houden. In dat geval moet de andere partij proberen dit af te dwingen. Daarvoor kan deze naar de rechtbank gaan. De uitspraak van de rechtbank is echter omgeven met onzekerheid en gaat gepaard met kosten. Daarbij komt nog dat beide partijen moeten investeren als het een rechtszaak wordt. We gaan er daarbij vanuit dat als een partij meer investeert, de kans om de zaak te winnen toeneemt. Als beide partijen ongeveer hetzelfde investeren zal de kans om de zaak te winnen niet veranderen. Hier gebruiken we weer de economische conflicttheorie. De afweging (van de partij die de gevolgen van de externe effecten ondervindt en tevens de eigendomsrechten bezit) om een rechtszaak te beginnen bestaat uit het vergelijken van de verwachte opbrengst met de kosten. Als dit positief uitvalt, zal een rechtszaak worden aangespannen. Als dit echter negatief uitvalt, zal de partij niet overgaan tot het afdwingen van afspraken via een rechtszaak. In dit 
geval is er wederom sprake van een 'credibilty' probleem. Dit wetende zal de betreffende partij op voorhand geen afspraken maken m.b.t. compensatie voor externaliteiten omdat deze ex-post niet worden nagekomen en niet kunnen worden afgedwongen. Er is een 'hold-up' situatie ontstaan en externaliteiten worden niet geïnternaliseerd, wat tot een potentieel welvaartsverlies leidt.

Vervolgens kijken we in hoeverre twee verschillende juridische systemen een oplossing bieden voor het 'credibility' probleem. Daarbij maken we een onderscheid tussen het Romeinse rechtssysteem en het Angelsaksische. Bij het Angelsaksische systeem moeten beide partijen de eigen kosten van de rechtszaak betalen terwijl in geval van het Romeinse rechtssysteem de verliezende partij alle kosten moet betalen. Ingeval van externaliteiten leidt, zoals we gezien hebben, samenwerking tot een surplus. Er is een prikkel om samen te werken, ex ante. De partij die de afgesproken compensatie moet betalen zal altijd geneigd zijn om zich hieraan, ex post, te ontrekken. Dit leidt tot contractbreuk, en kan door de andere partij voor de rechtbank worden aangevochten. Zowel de partij die het contract breekt en niet nakomt als de partij die besluit om het contract af te dwingen voor de rechtbank, zal de verwachte opbrengsten afzetten tegen de kosten. De verwachte opbrengst bij contractbreuk is gelijk aan de kans dat de rechtszaak in het voordeel uitvalt vermenigvuldigd met de compensatie die betaald had moeten worden. Voor de partij die besluit naar de rechter te gaan ligt dit precies omgekeerd. Hier gaat het om de kans dat de rechtszaak wordt gewonnen maal de te ontvangen compensatie zoals vastgelegd in het contract. Als we naar de kosten kijken dan verschilt dat per systeem. In geval van het Romeinse rechtssysteem zijn de verwachte kosten, de totale kosten dus, ook de kosten van de tegenpartij maal de kans dat de zaak wordt verloren. In het geval van het Angelsaksische systeem zijn de kosten hetzelfde in geval van een gewonnen en een verloren zaak. De kans op een succesvolle afloop van de rechtzaak wordt door twee elementen bepaald. Ten eerste de eigendomsrechten en ten tweede de middelen die geïnvesteerd worden, bijv. de kosten voor het inhuren van goede advocaten, e.d. Als gevolg hiervan is de verwachte 'pay-off' van contractbreuk in het Romeinse systeem aanzienlijk lager zijn dan in het geval van het Angelsaksische systeem. De prikkel om het contract ex post niet na te leven ontbreekt daardoor. Het 'credibilty' probleem doet zich dus niet voor in deze institutionele setting. Daardoor kunnen externaliteiten wel geïnternaliseerd worden via onderhandelingen.

\section{Conclusie}

In de inleiding hebben we aangegeven dat dit onderzoek zich bezighoudt met de invloed van concurrentie en samenwerking tussen regio's op de regionale economische ontwikkeling. Daarbij spelen regionale beleidsmakers en politici een steeds belangrijkere rol. Dit resulteert 
in op elkaar anticiperende regio's in hun streven de concurrentiekracht te verbeteren om daardoor de regionaal economische ontwikkeling te stimuleren. We concluderen dat dit enerzijds kan leiden tot concurrentie en anderzijds tot samenwerking tussen regio's.

Als we concurrentie tussen regio's als spel modelleren, dan komen we tot de conclusie dat de uitkomst negatief is als we het totaaleffect bekijken. De concurrentie tussen regio's kan leiden tot verspilling van investeringen en subsidies van locale overheden. De oorzaak hiervan ligt in het feit dat concurrentie plaatsvindt door middel van het faciliteren van bedrijven om zich in de regio te vestigen. Een ander aspect is dat door deze concurrentie bedrijven zich vestigen op een economisch gezien minder gunstige vestigingsplaats. Als we wat nader ingaan op de externe effecten die het resultaat zijn van innovatie, dan komen we tot dezelfde conclusie. Een ander aspect is dat om gebruik te maken van externaliteiten de regionale overheden bedrijven financieel zouden kunnen ondersteunen. Op die manier kan volledig gebruik gemaakt worden van de aanwezigheid van externaliteiten. Deze financiële ondersteuning leidt echter tot opportunistisch gedrag van bedrijven. Zij zullen de extra financiële middelen voor andere, meer productieve doeleinden aanwenden. Dit dilemma kan in de regel niet worden opgelost vanwege bestaande informatie-asymmetrie.

Hoewel concurrentie tussen regio's geen bijdrage levert aan de economische ontwikkeling is het de vraag of dit voorkomen kan worden. Hier rijst een probleem omdat concurrerende regio's in een bepaald type prisoner's dilemma verzeild raken. Als een van de regio's begint te concurreren, dan moeten andere regio's volgen - anders verliezen ze het spel.

Economische samenwerking en integratie kan de regionale concurrentiekracht en de regionale economische ontwikkeling versterken. De belangrijkste oorzaak is dat als gevolg van factormobiliteit meer efficiëntie wordt bereikt. Wat daar bij vaak over het hoofd wordt gezien is dat factormobiliteit ook wordt beïnvloed door de institutionele structuur. Economische integratie en samenwerking tussen regio's met een sterk verschillende institutionele structuur kan dan niet de gewenste economische ontwikkeling tot gevolg hebben. Als alleen kapitaal mobiel is, leidt economische integratie niet tot de gewenste economische ontwikkeling. De mogelijkheid tot efficiency verbetering blijft achterwege doordat de institutionele structuur niet of slechts langzaam verandert waardoor re-allocatie plaatsvindt die niet leidt tot stijging van productiviteit.

Naast het feit dat instituties beperkingen kunnen opleggen aan de economische integratie, kunnen instituties ook een positieve invloed hebben op efficiency problemen. Ook hier geldt dat door verschil in instituties (d.w.z. verschil in efficiency), economische samenwerking en integratie tot een onevenwichtige economische ontwikkeling kunnen leiden. De positieve externaliteiten van integratie kunnen dan niet over de regio's evenwichtig worden verdeeld. Dat betekent dat er terughoudendheid m.b.t. integratie zal zijn. Dit kan echter worden opgelost door afspraken te maken tussen de betrokken regio's over een meer evenwichtige verdeling. Zodoende zal er voor alle betrokken regio's een prikkel bestaan tot 
economische samenwerking. Dit komt de economische ontwikkeling van alle betrokken regio's ten goede. Willen de afspraken stand houden, dan moet er wel een institutionele structuur voorhanden zijn om opportunistisch gedrag te voorkomen. Is dit niet het geval, dan kunnen de regio's verzanden in een hold-up situatie.

Als laatste wordt gekeken naar bepaalde problemen die zich kunnen voordoen ingeval de betrokken partijen via onderhandelingen externaliteiten willen internaliseren. Het blijkt dat er in het geval van het 'de veroorzaker betaalt' principe een contractueel probleem ontstaat; er is een prikkel om ex post afspraken, die contractueel zijn vastgelegd, niet na te komen. Om te kijken welke rol (juridische ) instituties spelen concluderen we dat het Romeins juridisch systeem een oplossing kan bieden voor opportunistisch gedrag.

Samenvattend kunnen we stellen dat concurrentie tussen regio's om regionaal economische ontwikkeling te stimuleren nogal wat haken en ogen met zich brengt. De uitkomst is inefficiënt en de concurrerende regio's komen in een bepaald type 'prisoner's dilemma. Economische samenwerking en integratie kunnen een positieve bijdrage leveren aan regionale economische ontwikkeling. Echter, indien er grote institutionele verschillen zijn doemen er coördinatieproblemen op. Daardoor kan van de mogelijke voordelen van integratie geen gebruik worden gemaakt. Onderhandelingen, naar analogie van het Coase theorema, tussen regio's kunnen daarbij een oplossing zijn. Echter moet er wel een geëigende institutionele structuur voorhanden zijn wil dit succesvol zijn. Het Romeinse juridische systeem is daar, als gezegd, beter geschikt voor dan het Angelsaksische systeem. 


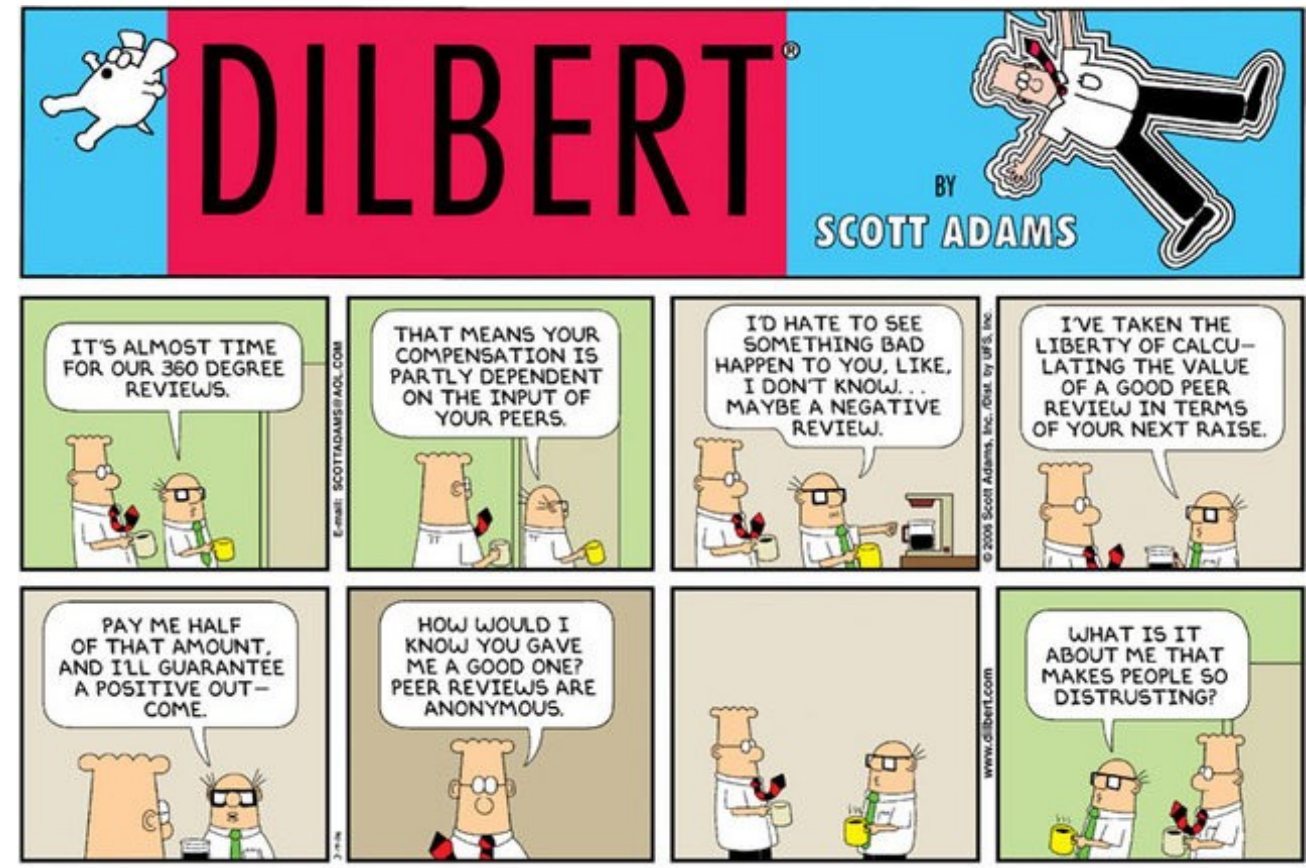

- Scott Adams, Inc./Dist. by UFS, Inc.

(source: http//www.marginalrevolution.com/photos/uncategonized/dilbert20060319.jpg) 